\title{
A Snapshot of
}

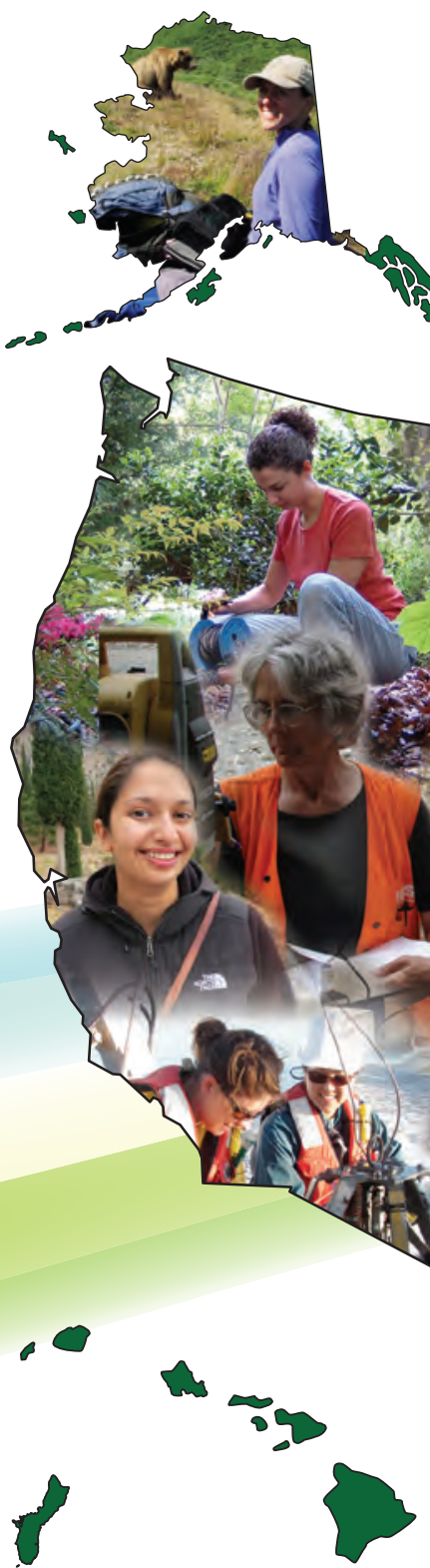

\section{of the U.S. Geological Survey in STEM and Related Careers}

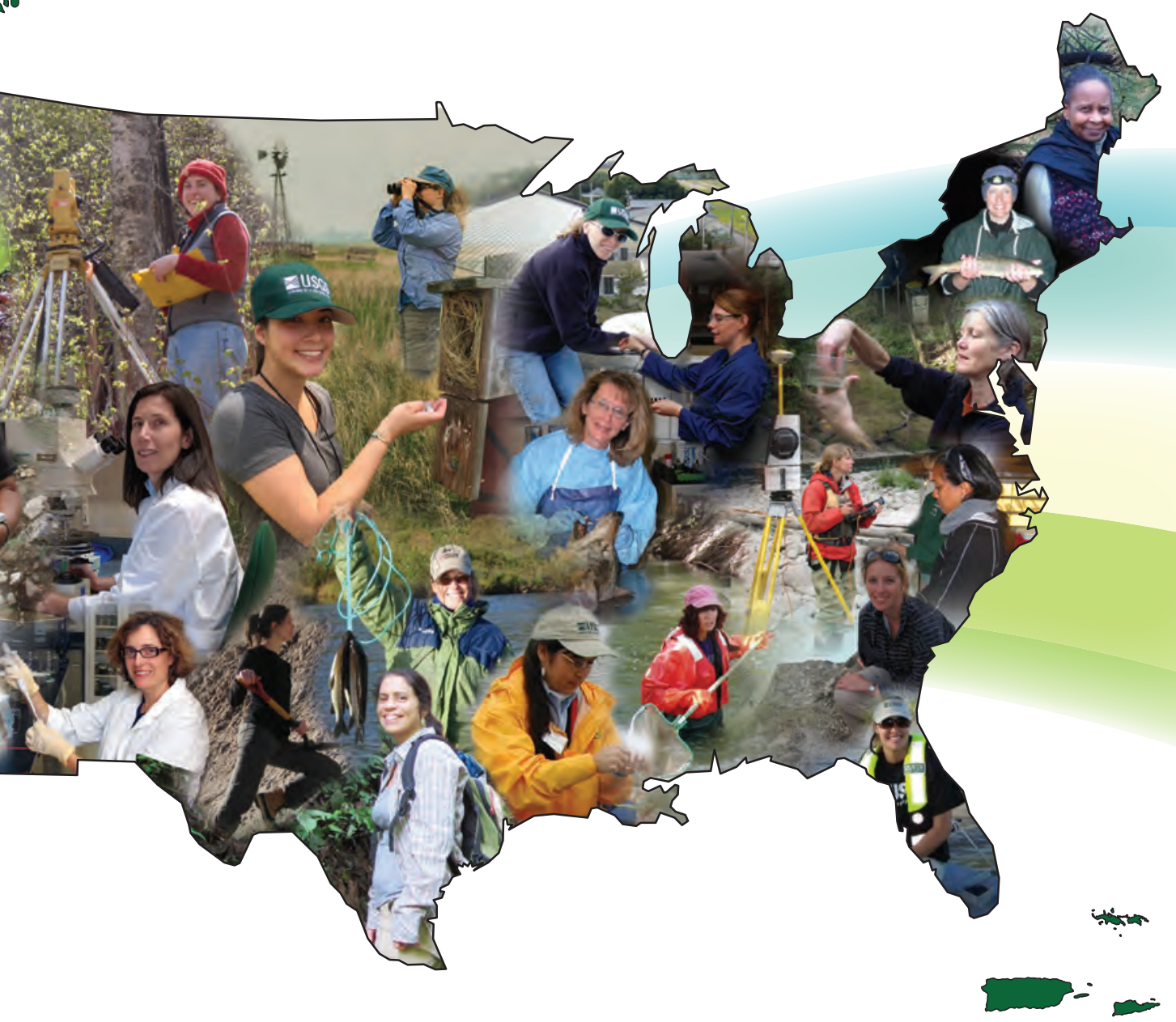

Science

Circular 1443

Technology

Engineering

Mathematics

U.S. Department of the Interior

U.S. Geological Survey 
Title page (facing): U.S. Geological Survey (USGS) hydrologist Tia-Marie Scott collects a water sample from the West Branch Delaware River at South Kortright, New York, downstream of a wastewater treatment plant for water-quality analysis. The samples collected were used to determine concentrations of emerging contaminants, including hormones, pharmaceuticals, and wastewater indicator compounds, to assess the contribution of these compounds to the environment from wastewater treatment plants. Photograph by the USGS. 


\section{A Snapshot of}

\section{Women \\ of the U.S. Geological Survey in STEM and Related Careers}

By Susan C. Aragon-Long, Virginia R. Burkett, Holly S. Weyers, Susan M. Haig, Marjorie S. Davenport, and Kelly L. Warner

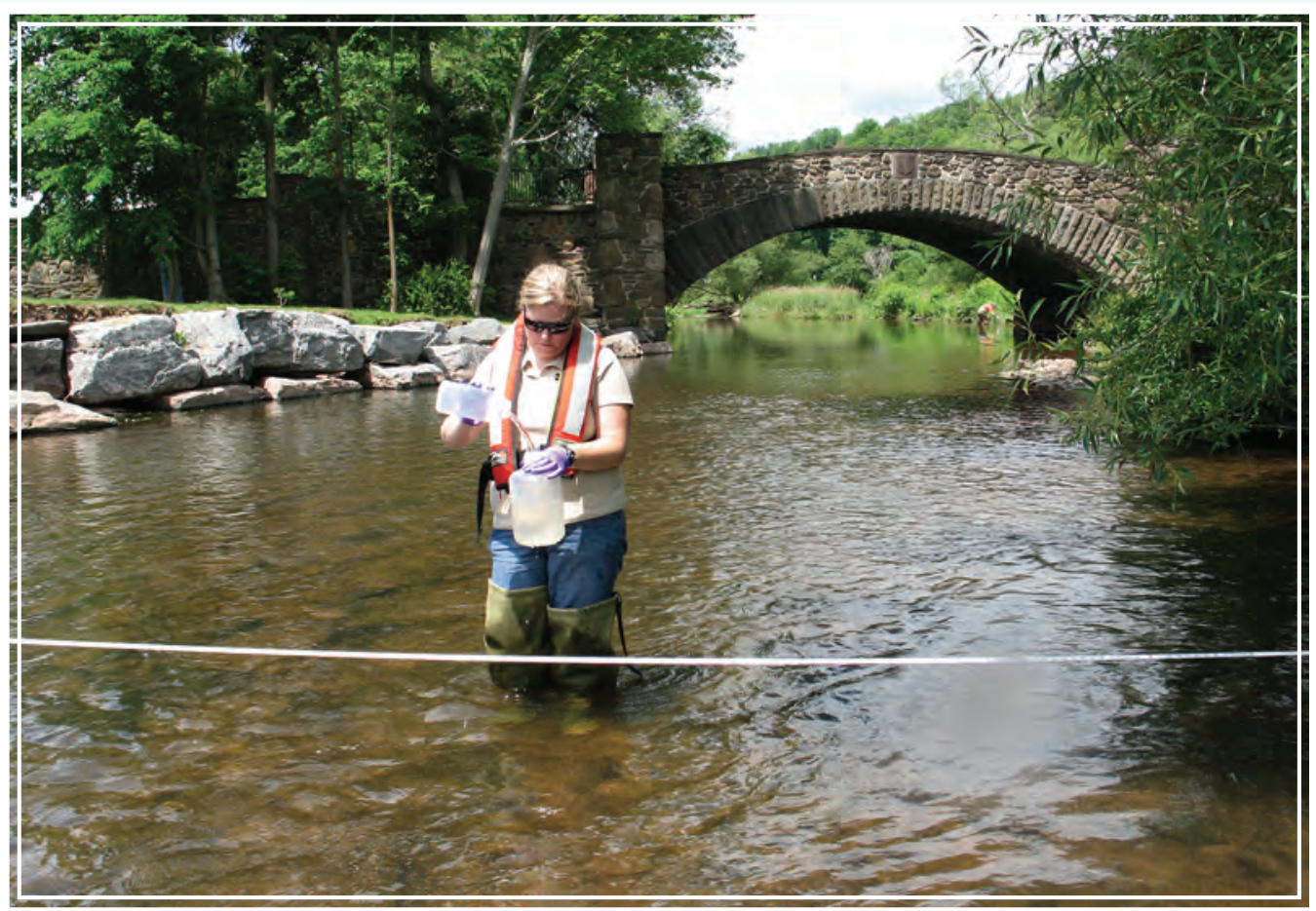

Circular 1443 


\section{U.S. Department of the Interior RYAN K. ZINKE, Secretary}

\section{U.S. Geological Survey James F. Reilly II, Director}

\section{U.S. Geological Survey, Reston, Virginia: 2018}

For more information on the USGS - the Federal source for science about the Earth, its natural and living resources, natural hazards, and the environment-visit https://www.usgs.gov or call 1-888-ASK-USGS.

For an overview of USGS information products, including maps, imagery, and publications, visit https://store.usgs.gov.

Any use of trade, firm, or product names is for descriptive purposes only and does not imply endorsement by the U.S. Government.

Although this information product, for the most part, is in the public domain, it also may contain copyrighted materials as noted in the text. Permission to reproduce copyrighted items must be secured from the copyright owner.

All photographs are provided by the individuals being portrayed in this circular. Although most of the photographs in this report are by the U.S. Geological Survey and are in the public domain, photographs in individual biographical entries may be copyrighted. Please contact the individual on the biographical entry to obtain permission to use photographs.

Suggested citation: Aragon-Long, S.C., Burkett, V.R., Weyers, H.S., Haig, S.M., Davenport, M.S., and Warner, K.L., 2018, A snapshot of women of the U.S. Geological Survey in STEM and related careers: U.S. Geological Survey Circular 1443, 100 p., https://doi.org/10.3133/cir1443.

\section{Library of Congress Cataloging-in-Publication Data}

Names: Aragon-Long, Susan C., author. | Geological Survey (U.S.), issuing body.

Title: A snapshot of women of the U.S. Geological Survey in STEM and related careers / by Susan C. Aragon-Long, Virginia R. Burkett, Holly S. Weyers, Susan M. Haig, Marjorie S. Davenport, and Kelly L. Warner. Other titles: U.S. Geological Survey circular ; 1443. 1067-084X

Description: Reston, Virginia : U.S. Geological Survey, 2018. | Series: Circular, ISSN 1067-084X; 1443 | Includes bibliographical references and index.

Identifiers: LCCN 2018024567| ISBN 9781411342323 | ISBN 1411342321

Subjects: LCSH: Geological Survey (U.S.)--Officials and employees--Biography. | Women scientists--United States--Biography. | Geological Survey (U.S.)--History. | Geological Survey (U.S.)--Vocational guidance. | Women in science--United States.

Classification: LCC QE76 .A73 2018 | DDC 509.2/520973--dc23 | SUDOC |

19.4/2:1443

LC record available at https://lccn.loc.gov/2018024567

ISSN 1067-084X (print)

ISSN 2330-5703 (online)

ISBN 978-1-4113-4232-3 


\section{Contents}

Introduction .1

Women Pioneers at the USGS. 2

Past and Current Women Senior Scientists in the USGS 3

USGS Recipients of the Presidential Early Career Award for Scientists and Engineers (PECASE) 4

Opportunities With the USGS . .5

What If I Am Not a Scientist? .5

What Opportunities Are Available for Students? …………..................................................

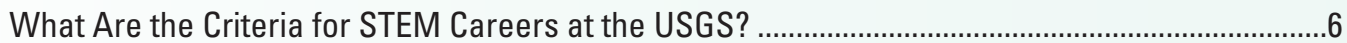

Profiles of USGS Women. .. .7

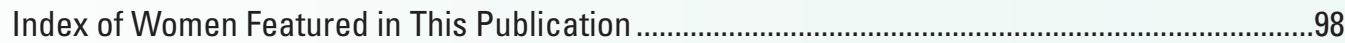

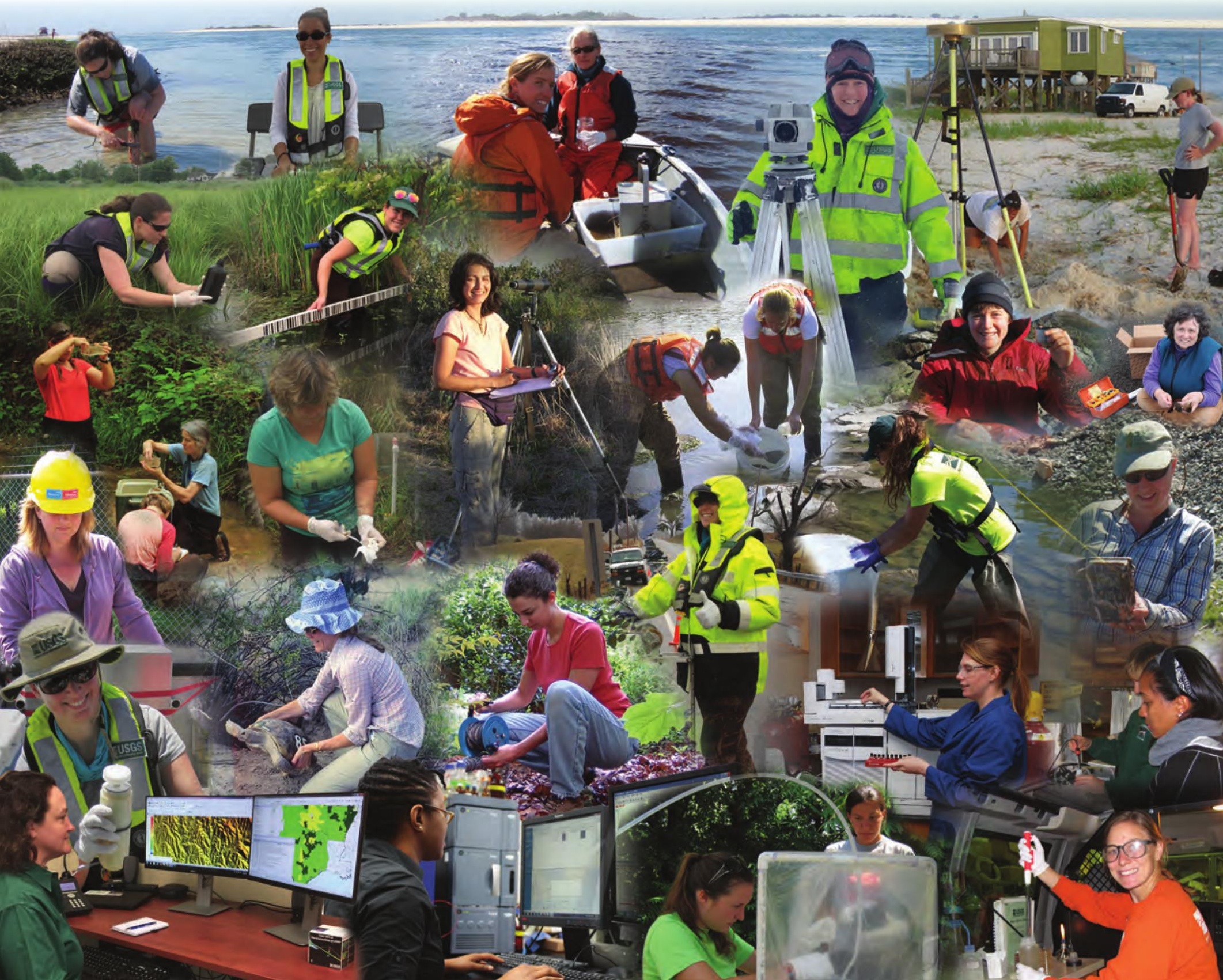


"Reading the profiles of the remarkable women in this book, I was reminded of how the simple joy of curiosity, exploration, and discovery drive all of us from our earliest days to a life of scientific examination of the world around us. Although I have seen a profound change of inclusiveness in the culture of the STEM community, we have a long way to go to build a culture where women feel totally supported in their desire to explore. By highlighting the roles and experiences of the women scientists who have been pathfinders, we hope to reinforce the aspirations of young women seeking to be part of our STEM future. We are proud to highlight the contributions of the more than 3,000 women who help make the USGS a world leader in revolutionary science and a vanguard in developing the next generation of worldclass scientists."

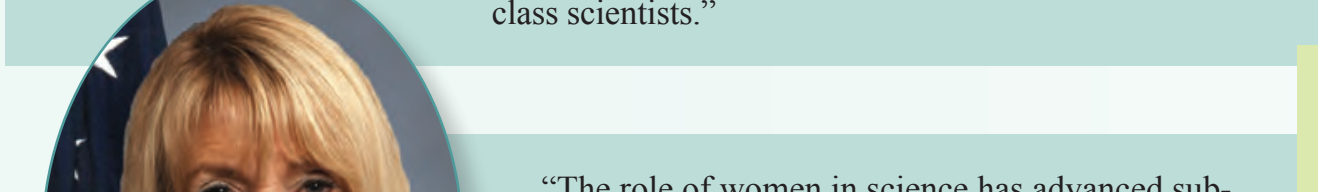

"The role of women in science has advanced substantially over the past two decades, and there is

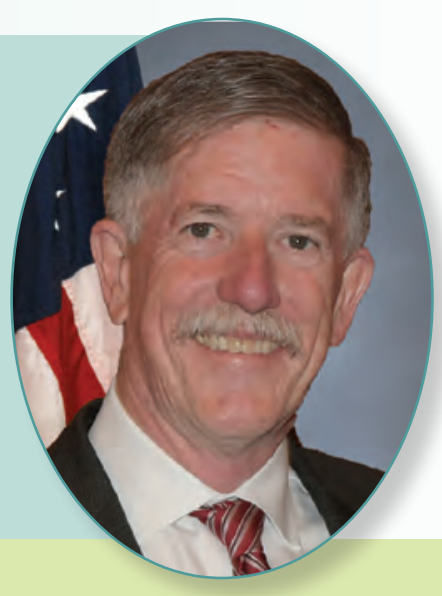

James F. Reilly II

Director, U.S. Geological Survey 2018-present no place in government where the contributions of women scientists shine brighter than in the USGS. When I arrived at the USGS, I was struck by the number of capable women in science leadership roles, many working in international circles as experts in frontiers ranging from astrogeology to mineral exploration, paleoclimatology, and land remote sensing. At a time when many women question whether they will have opportunities to advance in their scientific careers, take pride in what they are contributing to society, and also find time for their families, the women of the USGS prove every day

Marcia McNutt that it is possible."

Director, U.S. Geological Survey 2009-2013

"The USGS is committed to a diverse workforce, as unique perspectives are assets to our science and allow for creativity and innovation. It is wonderful to see that more women are pursuing scientific careers than in the past. Highlighting the accomplishments of women scientists is important for their own recognition as well as for inspiring young women now and into the future. To that end, the USGS is actively engaged in many programs to encourage all youth to appreciate the wonders of science and to pursue careers in this field. In particular, USGS engagement with youth and the wide range of research and learning experiences offered to students directly support the STEM Education Coalition. These USGS activities focus on increasing scientific literacy in the general public and attracting and preparing the future STEM workforce."

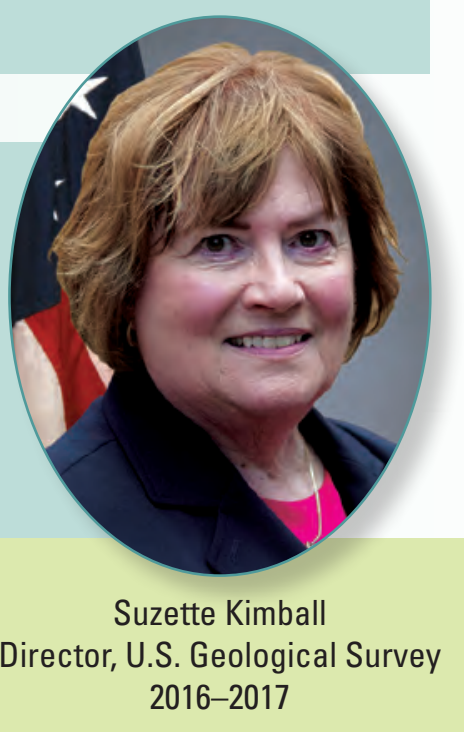

2016-2017

"For more than a century, women have played an integral role in science at the USGS. In the 1970s and early 1980s, about half of the women in the USGS workforce were part-time or intermittent employees. The face of our workforce started to change dramatically in the 1990s as the proportion of women with degrees in the geosciences started to rise. Today, women are employed full-time at virtually all levels in our organizational structure, from field positions to senior scientists and associate directors. The women in this book represent just a sample of the extensive talent and significant achievements of women across the USGS, and as a bureau, we continue to give high priority to recruitment and support of women in STEM."

Deputy Director, U.S. Geological Survey 2015-present 


\title{
A Snapshot of
}

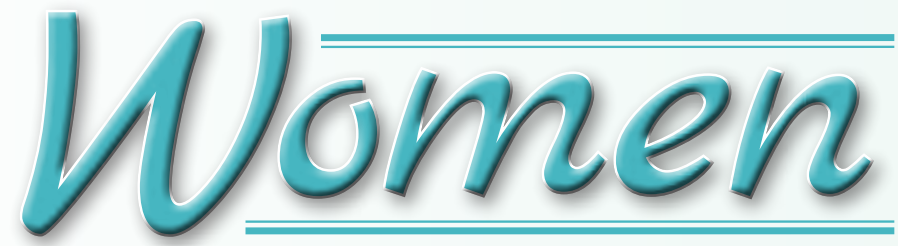

\section{of the U.S. Geological Survey in STEM and Related Careers}

\author{
By Susan C. Aragon-Long, Virginia R. Burkett, Holly S. Weyers, Susan M. Haig, \\ Marjorie S. Davenport, and Kelly L. Warner
}

\section{Introduction}

The term "STEM" has been used to group together the fields of science, technology, engineering, and mathematics and to describe education and professions related to these fields. The professional fields connected to STEM education are thought of as engineering, medicine, and computer technology. Yet these professional fields are merely the tip of the iceberg. Numerous opportunities in STEM fields encompass environmental research. The possibilities range from predicting the next earthquake to saving polar bears from extinction to developing a vaccine for salmon measles.

The science of natural systems is complex and often requires people from a variety of fields of expertise to make headway with a solution. To that end, the U.S. Geological Survey (USGS) has long recognized the need for a diversity of STEM expertise to address the Nation's environmental research needs and the vision to facilitate integration of these fields. We are team builders!

In this book, we point out the many facets of research carried out by USGS STEM scientists in an effort to show career options and pathways not typically pursued. The women portrayed were selected by USGS associate and regional directors as representative of particular fields and to inspire future generations.

The seeds for this book were planted by former USGS Directors Marcia McNutt and Suzette Kimball. From the inspiration they provided, former USGS Associate Director and current Chief Scientist for Climate and Land Use Change, Virginia Burkett, coordinated this project. The team of Virginia Burkett, Susan Aragon-Long, Marjorie Davenport, Susan Haig, Kelly Warner, and Holly Weyers carefully sought to develop a book that showcased the variety of science and science support fields so important to accomplishing the mission of the USGS. The book was produced by the publishing team of Anna Glover, Suzanne Roberts, Alan Jones, Kimberly Waltenbaugh, Debra Foster, and Katharine Schindler.

We thank the thousands of women in the USGS who have dedicated their careers to the advancement of science and an improved understanding of our changing world. Each of you has blazed a trail for others to follow. We also thank the friends, family, and colleagues of the individuals portrayed in this circular who contributed many of the photographs in this publication. 


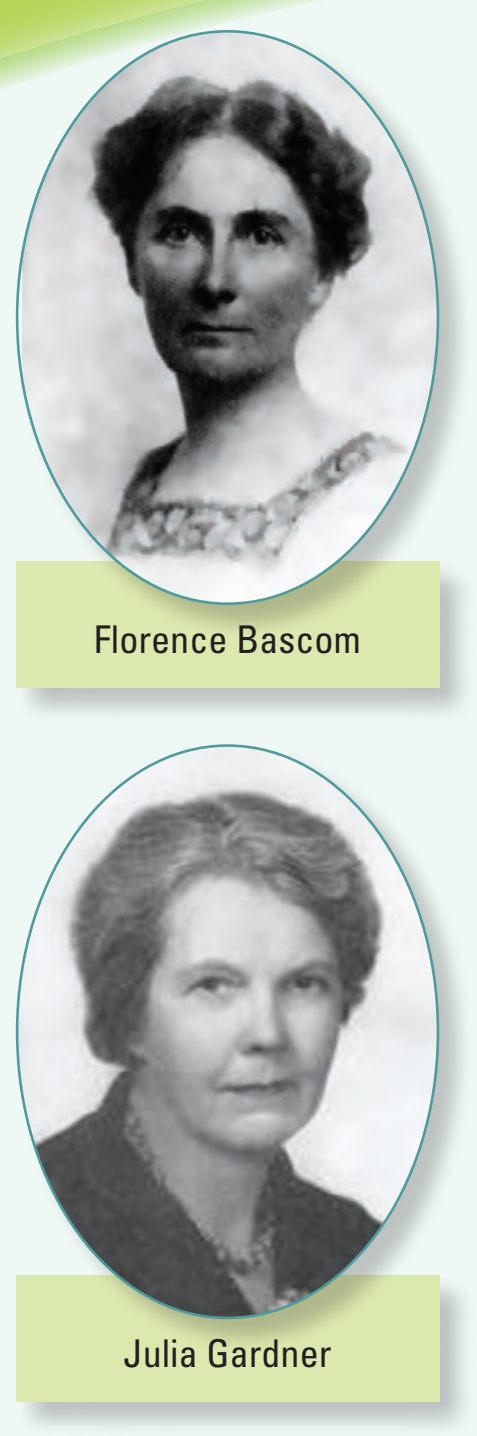

\section{USGS Mission} Statement

"The USGS serves the Nation by providing reliable scientific information to describe and understand the Earth; minimize loss of life and property from natural disasters; manage water, biological, energy, and mineral resources; and enhance and protect our quality of life."

\section{Women Pioneers at the USGS}

Florence Bascom was the first woman hired by the U.S. Geological Survey (USGS) in 1896, and she remained a pioneering geologist for 40 years. Julia Gardner soon followed Bascom's lead and, using her experience as a paleontologist, helped pinpoint the Japanese military's launch sites for balloonborne incendiary bomb attacks against the Pacific Northwest by analyzing seashells in the sand ballast of balloons. After World War II, she was assigned to the Allied Forces supreme commander in Tokyo where she worked with Japanese geologists to map the western Pacific islands. Since then, many women have followed in her footsteps but with an ever-increasing diversity of backgrounds, education, and interests. Today, women scientists, engineers, and mathematicians work for the USGS not only in geology but also in wildlife ecology, mapping, water resources, marine biology, and more in the United States and around the world. Recently, these women were led by female Secretaries of the Interior (Gale Norton and Sally Jewell) and Directors of the USGS (Marcia McNutt and Suzette Kimball). Thus, the USGS has evolved into an all-inclusive, world-renowned center for Earth science excellence where women of all backgrounds and science training can find a rewarding career.

In this volume, we highlight some of our best and brightest scientists and sciencesupport professionals in an effort to showcase the diversity of science, technology, engineering, and mathematics (STEM) careers open to young people and to celebrate the accomplishments of these USGS leaders in their respective fields. Here you will learn that Jayne Belnap's job takes her around the world looking at soil crusts to study their effects on the viability of incredibly complex desert ecosystems, Susan Haig is concerned with monitoring endangered species on six continents, and Jill Baron works on climate change in mountain ecosystems. Together, these and all women of the USGS contribute to perhaps the most diverse science agency in the world and to the mission of the USGS. Their hope is for the continued growth of young people's interest in STEM fields as a means of ensuring our prosperous, safe, and healthy future on the planet Earth.

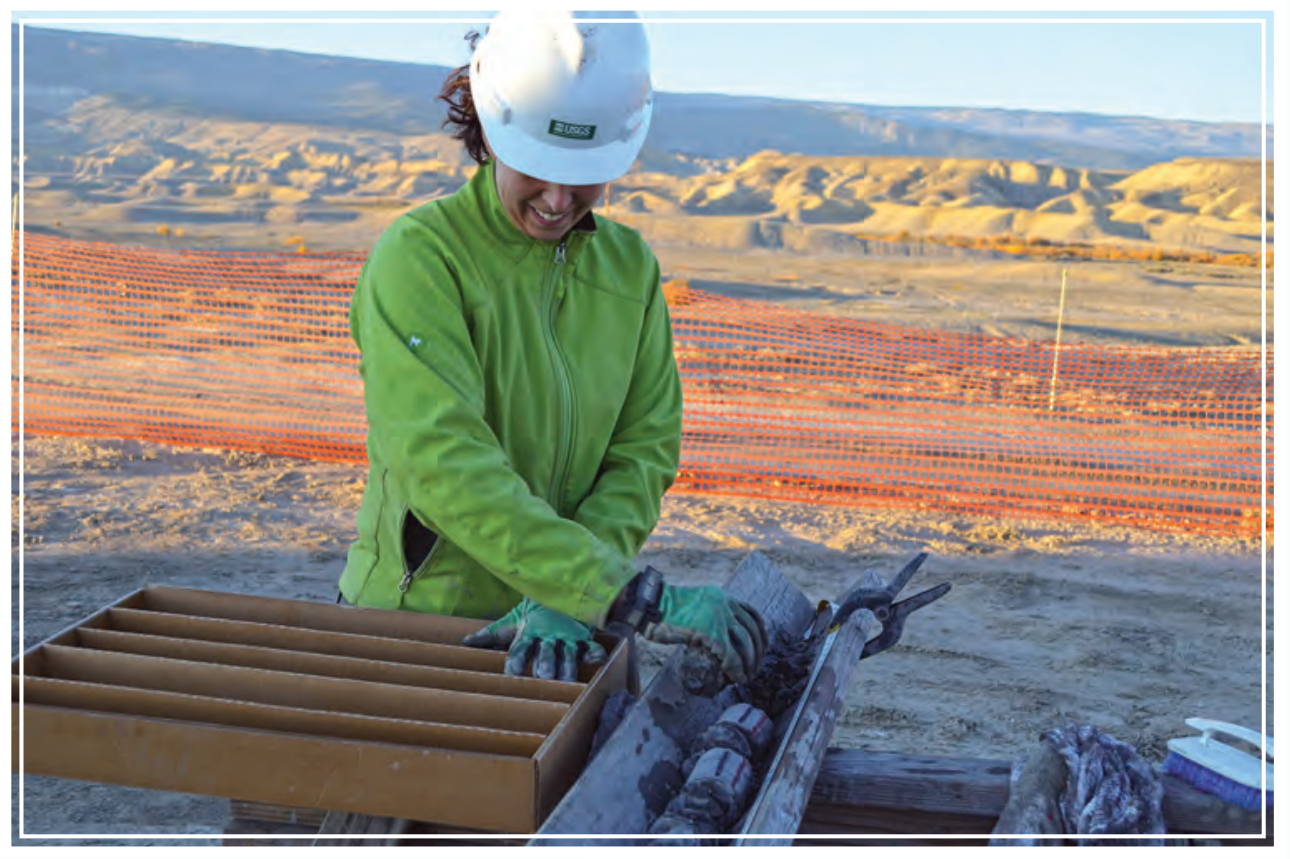

USGS geologist Sarah Hawkins, lead scientist for the Mancos Shale assessment, examining a core drilled by the USGS Core Research Center. This core provided valuable data for the assessment. Photograph by the USGS. 


\section{Past and Current Women Senior Scientists in the USGS}

The six former and current senior (ST) scientists shown below are the only women in the USGS whose exceptional achievements have led to their promotion to senior scientist. Fewer than 50 scientists among the almost 9,000 current employees currently hold this designation in the USGS.

USGS ST scientists are recognized for their contributions to the agency and are internationally known for their efforts on behalf of natural science.

The ST scientists, like many students, started as high school or university students trying to sort out future careers and lives. From the biographies in this book, you can deduce that many of the women decided that they wanted to pursue their love of nature or science and dedicated a great deal of time and effort to becoming the scientists they are today. Some of the other women whose choices took them down different career paths found a way to work in an environment where their skills could promote science and foster nature.

Whichever paths these women chose, they received the full support of the USGS, which has been an organization that strives to support all staff throughout their life decisions and transitions, allowing them to raise a family, take care of elderly relatives, or pursue further education. The many worklife balance opportunities, such as family leave, teleworking, onsite day care in some places, and a good health care plan, have been key elements in this support. The variety of educational and cultural backgrounds of the hundreds of women in STEM and science support careers at the USGS ensure that there will always be a kindred spirit nearby who is willing to share her experiences and advice.
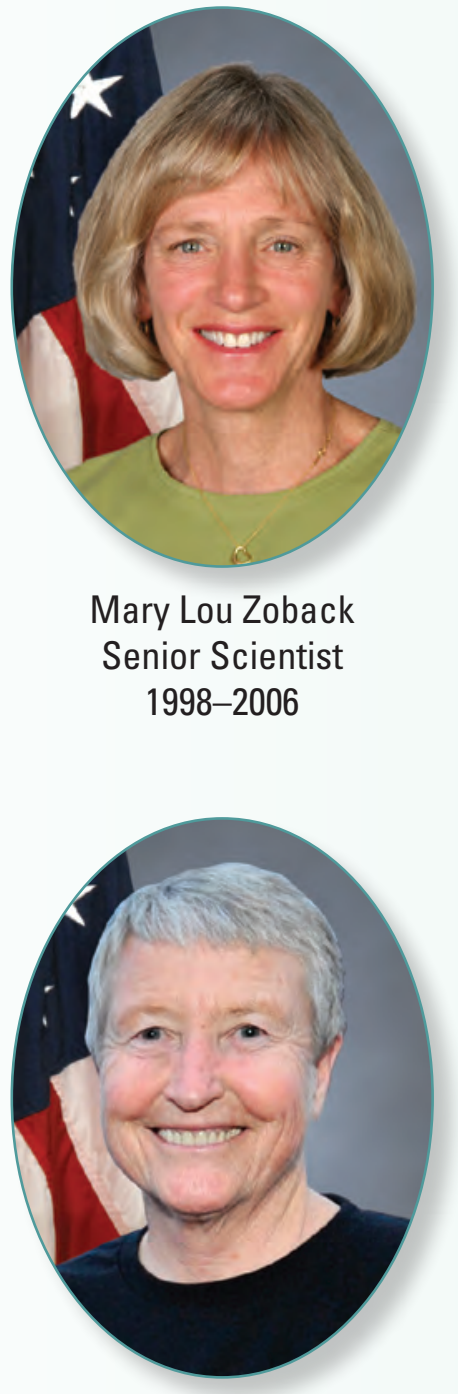

Jayne Belnap Senior Scientist 2010-present
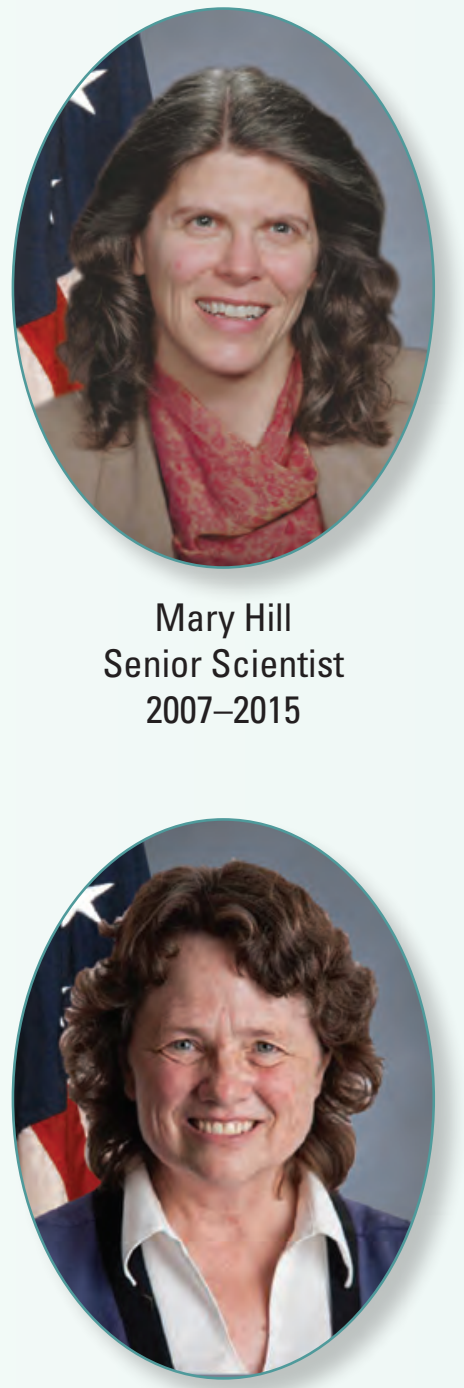

Susan Haig Senior Scientist 2015-present

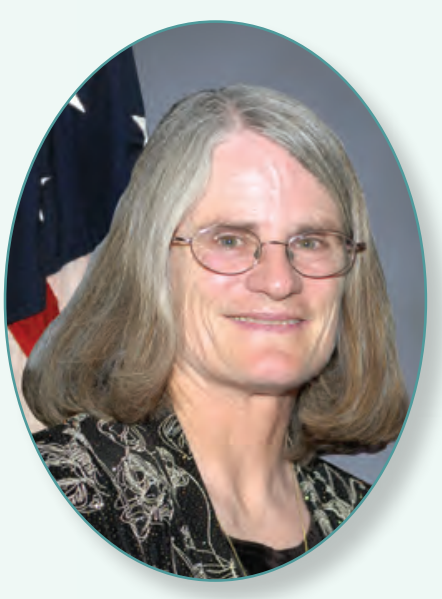

Marith Reheis

Senior Scientist

2011-2013

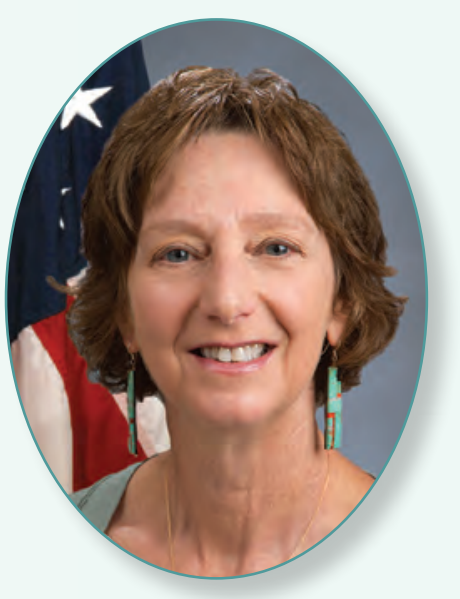

Jill Baron

Senior Scientist

2015-present 


\section{USGS Recipients of the Presidential Early Career Award for Scientists and Engineers (PECASE)}

The Presidential Early Career Award for Scientists and Engineers (PECASE) is the highest recognition granted by the U.S. Government to scientists and engineers in the early stages of their research careers. Each year, 10 departments and agencies of the U.S. Government join together to nominate outstanding scientists and engineers whose discoveries and advancements expand the horizons of science and technology, contribute to their agencies' missions, and benefit America's economy and the health and safety of the Nation's people.
The awards were established by President Clinton in 1996 and are coordinated by the Office of Science and Technology Policy within the Executive Office of the President. Awardees are selected for their pursuit of innovative research at the frontiers of science and technology and their commitment to community service as demonstrated through scientific leadership, public education, or community outreach. These nine women from the USGS have received PECASE awards for their work.

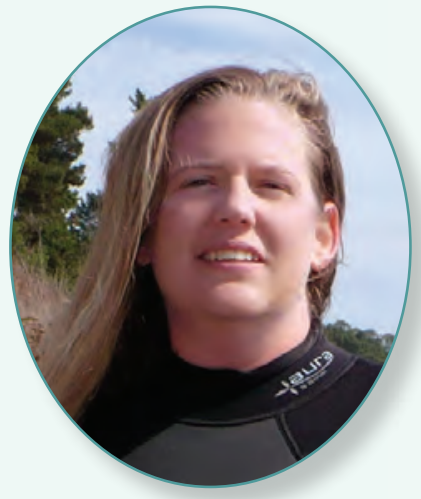

Jeanne Hardebeck 2009

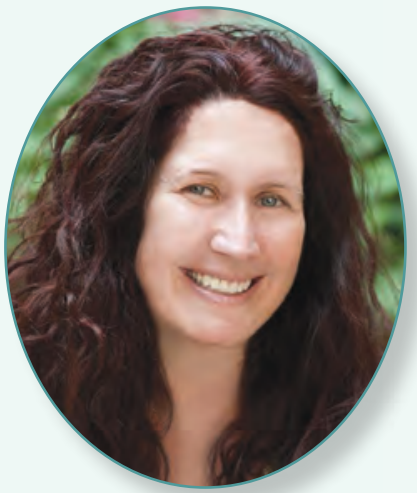

Pamela Nagler

2009

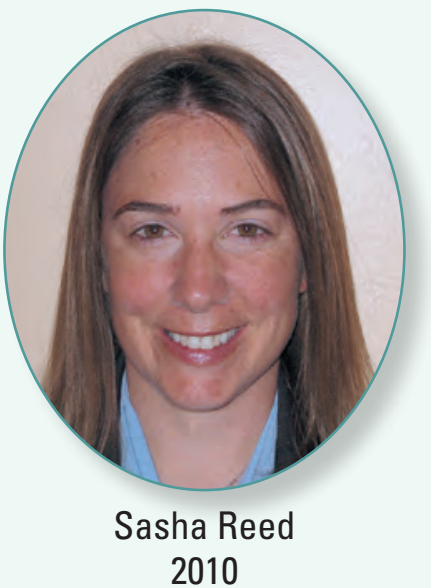

2010

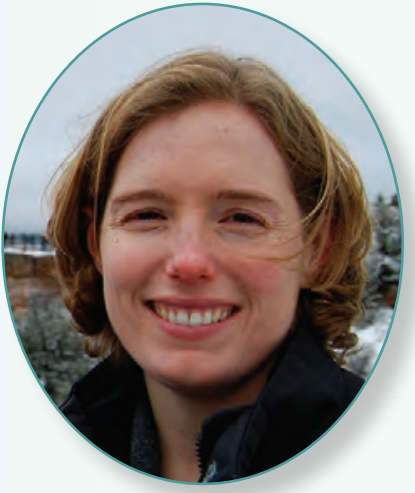

Elizabeth Cochran 2010

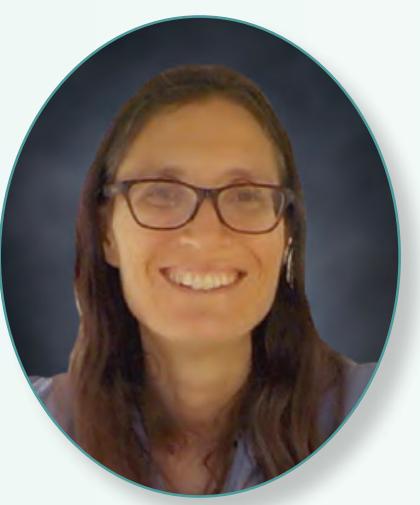

Karen Felzer 2011

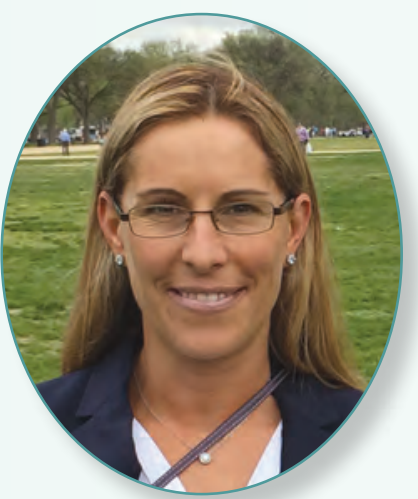

Anna Chalfoun 2012

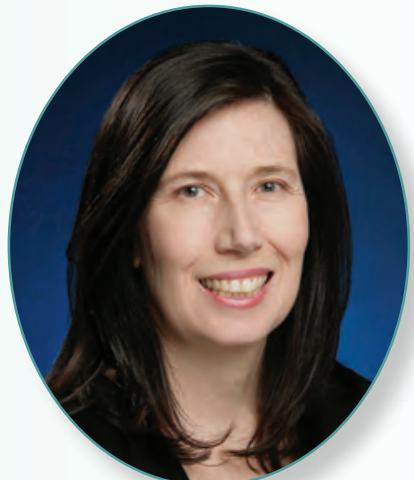

Maureen Purcell 2013

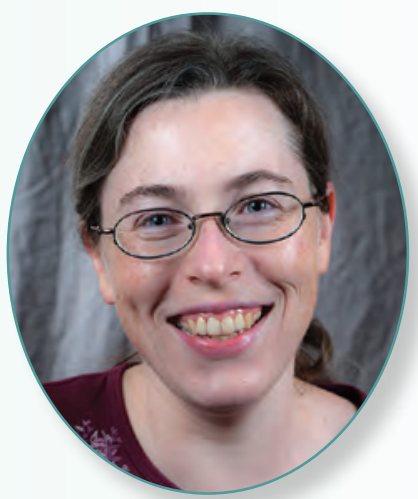

Sarah Minson 2014

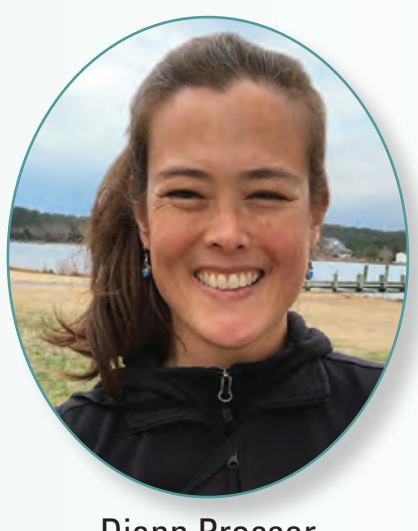

Diann Prosser

2017 


\section{Opportunities With the USGS}

The USGS (usgs.gov) is among the largest natural science organizations in the world, with thousands of scientists, technicians, support staff, and administrators working across all 50 States and U.S. territories and around the world. As part of the U.S. Department of the Interior, the USGS helps its sister agencies by addressing their research needs: Bureau of Indian Affairs (bia.gov), Bureau of Land Management (blm. gov), Bureau of Ocean Energy Management (boem.gov), Bureau of Reclamation (usbr.gov), Fish and Wildlife Service (fws.gov), and National Park Service (nps.gov).

Countless types of scientists are required to fulfill the needs of the seven USGS mission areas: Climate and LandUse Change, Core Science Systems, Ecosystems, Energy and Minerals, Environmental Health, Natural Hazards, and Water Resources. Entry-level science, technical, support, and administrative positions generally require an undergraduate (B.A. or B.S.) degree in the appropriate field. Managerial positions often require master's level (M.S.) degrees, whereas more senior-level science positions are generally hired at the Ph.D. level and beyond. All USGS jobs that are open to the public are posted on USAJobs.gov.

\section{What If I Am Not a Scientist?}

The work of scientists depends on administrators, budget and finance analysts, communicators, artists, safety managers, facilities specialists, and other support professionals to get the science to those who have an interest or a need for the science. The people in these positions also are essential for the day-to-day operations of the USGS.

\section{What Opportunities Are Available for Students?}

The USGS also offers Federal internship and employment opportunities for current students, recent graduates, and those with an advanced degree through the Pathways Programs:

- The Internship Program is for students who are in high school, college, trade school, or other qualifying educational institution. This program offers paid opportunities to work in Federal agencies and explore Federal careers while completing your education.

- The Recent Graduates Program is for those who have graduated within the past 2 years from a qualifying educational institution or certificate program. The Recent Graduate program offers career development with training and mentorship.

- The Presidential Management Fellows Program is for those who have completed an advanced degree from a qualifying educational institution. The program is also open to current graduate students who will complete all degree requirements (including dissertations) by the application deadline.

More information about the USGS Pathways Programs is available from the Human Capital Services and Support office at https://www2.usgs.gov/humancapital/sw/ studentandrecentgrads.html.

The USGS Cooperative Fish and Wildlife Research Unit Program trains graduate students for careers in fisheries and wildlife. The program is staffed by USGS scientists who serve as faculty members in 40 universities across the country. More information is available at https://www.usgs.gov/science/mission-areas/ ecosystems/cooperative-research-units.
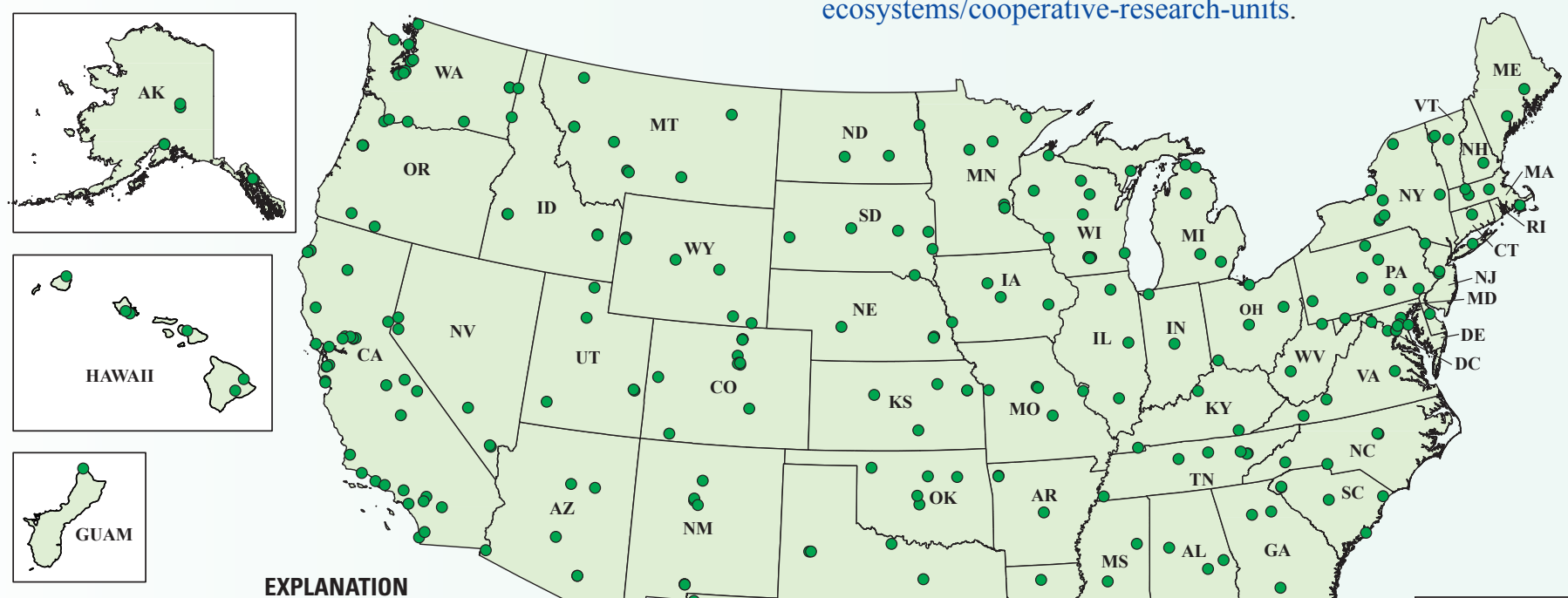

- U.S. Geological Survey office or field station

Map scales and projections vary

Women work for the U.S. Geological Survey in every State and territory of the United States.

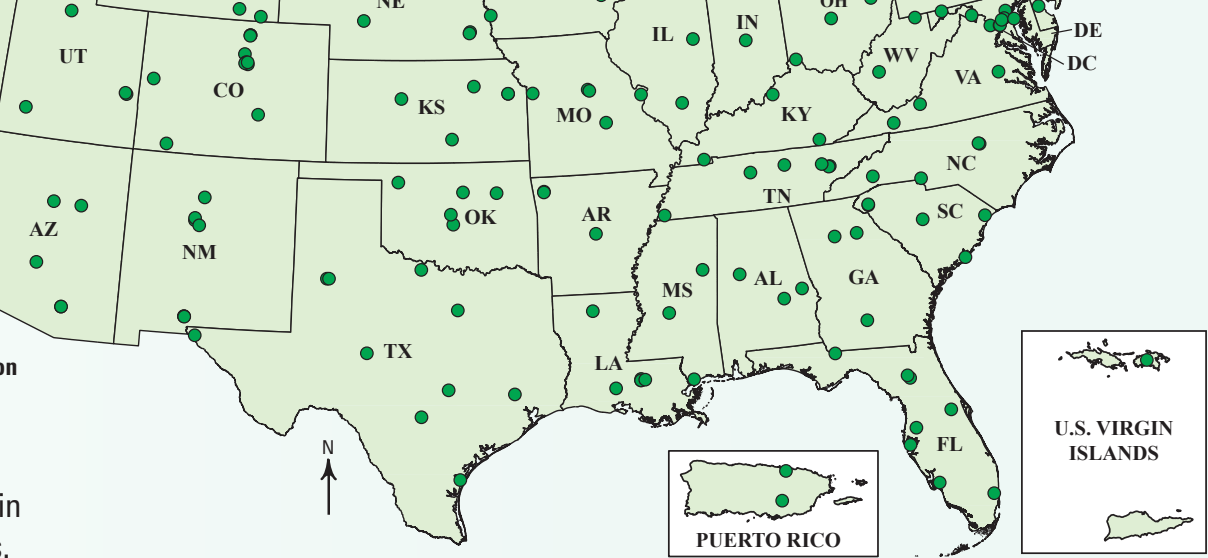




\section{What Are the Criteria for STEM Careers at the USGS?}

Criteria for hiring in various STEM fields vary widely; hence, it is helpful to look at the requirements as you choose a field so you know what to expect. The Human Capital Services and Support office has information about the requirements that are used for most of the science-related careers at the USGS. You can access the information at https://www2.usgs.gov/ humancapital/sw/careercards.html.

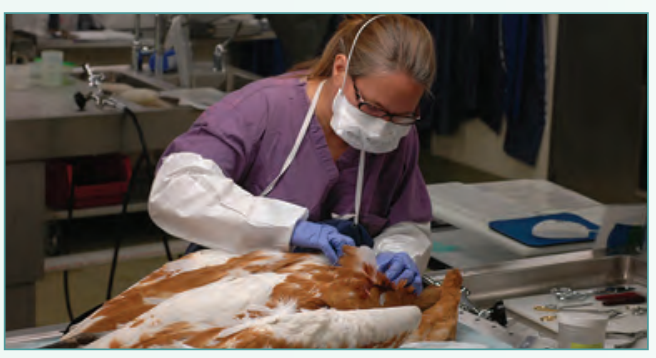

Biologist

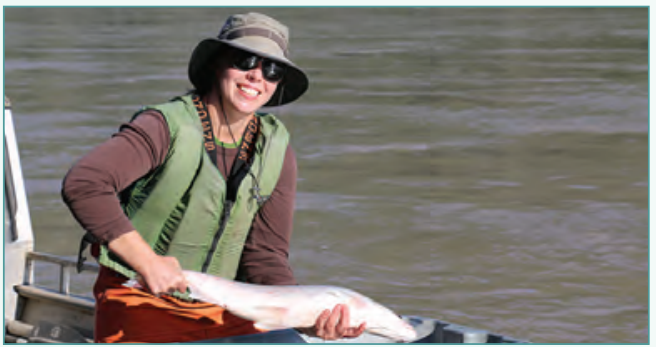

Biological science technician

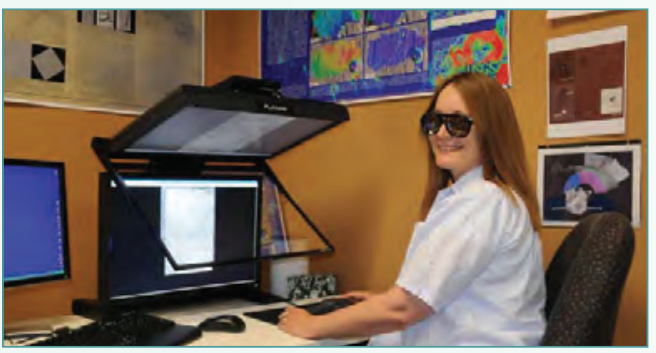

Cartographer

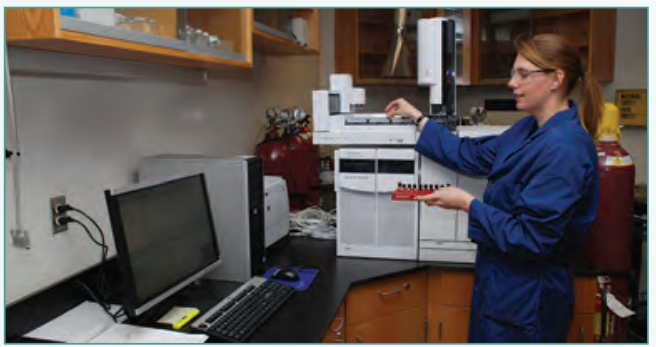

Chemist

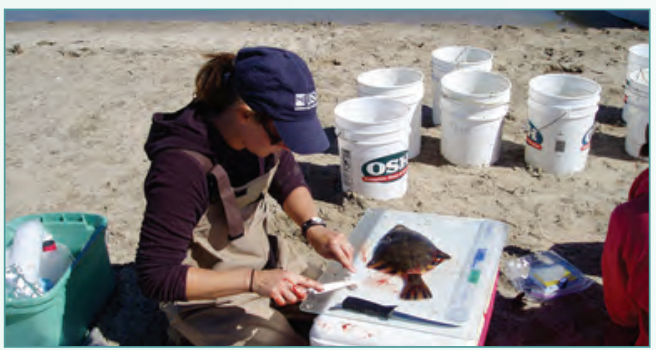

Ecologist

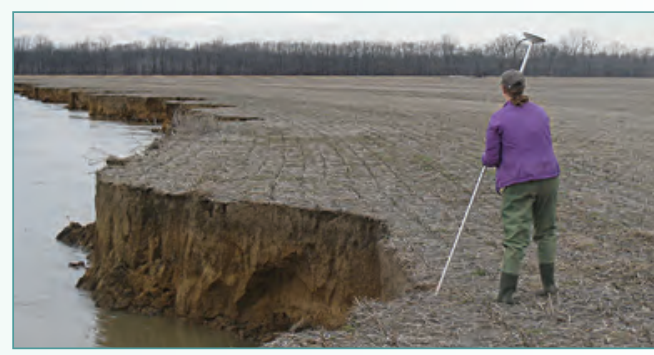

Geographer

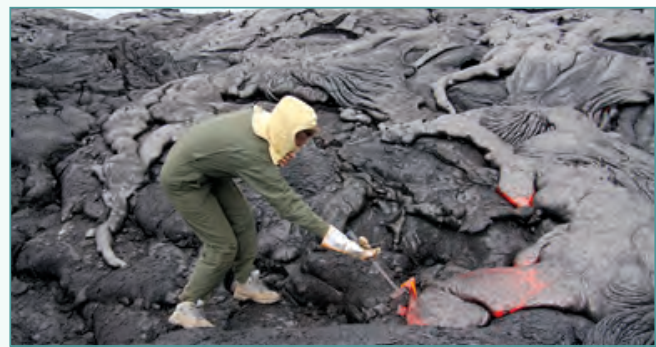

Geologist

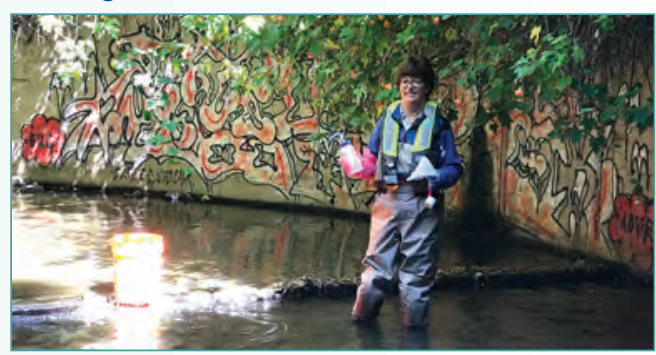

Hydrologist

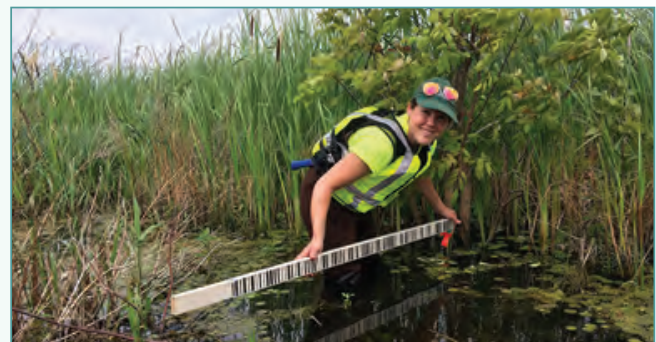

Hydrologic technician

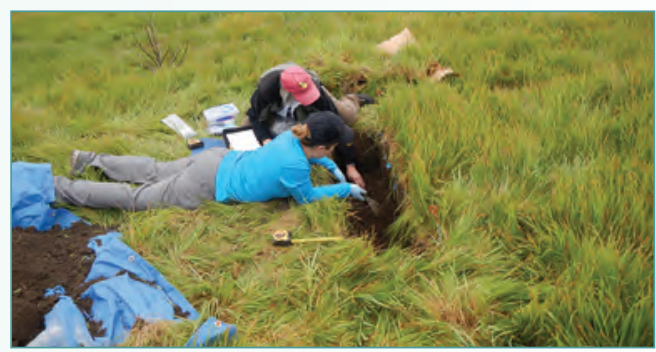

Physical scientist 


\section{Gill Baron}

\section{Co-Director of the John Wesley Powell Center for Analysis and Synthesis and Senior Scientist with the Fort Collins Science Center, in Fort Collins, Colorado}

"Science is more than a body of knowledge; it is a way of thinking." - Carl Sagan

I had the most remarkable public high-school biology teacher, soft-spoken Mr. Lee, who got his class thinking, doing, and teaching younger students through an organization called the Biology Honor Society. Importantly, he would never answer a question; "go find out" was his answer each time. We conducted field research in teams on field trips he organized. These were not just any field trips; he would load us on a bus from Wisconsin each spring break and drive to the Chiricahua Mountains of Arizona to do ecological transects from the desert floor up to the subalpine forest. In coastal Georgia, we ran similar transects to look at ecological change from the water line through dunes to pines. He inspired a sense of awe about the natural world and a sense of responsibility and capability in us that persists to this day. Because of him, more than 50 of us have gone on to careers in science, natural resource management, or education. We have honored him over the years with reunions of this amazing group and plan to do so again in 2020.

I am a senior scientist for the USGS and, at the same time, a senior research ecologist at the Natural Resource Ecology Laboratory at Colorado State University. My work involves applying what we know about ecosystems to managing human-dominated regions and understanding how climate change and atmospheric nitrogen deposition to mountain ecosystems affect biogeochemistry and ecology. I helped found the John Wesley Powell Center for Analysis and Synthesis where we bring together scientists to collaborate in earth sciences.

I love living in Colorado where my husband and children and I can ski, bicycle, hike, backpack, or simply car camp with our dogs.
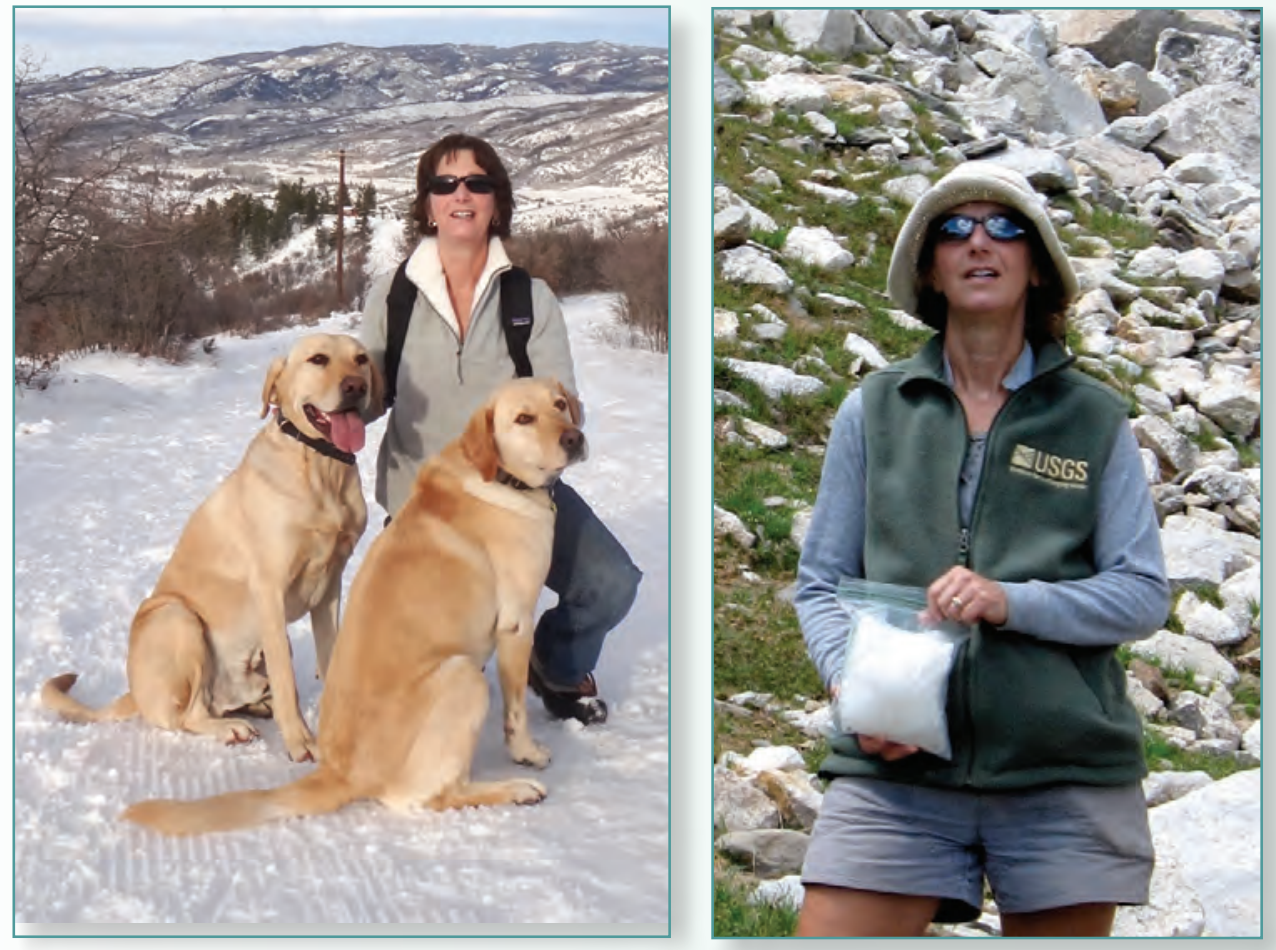

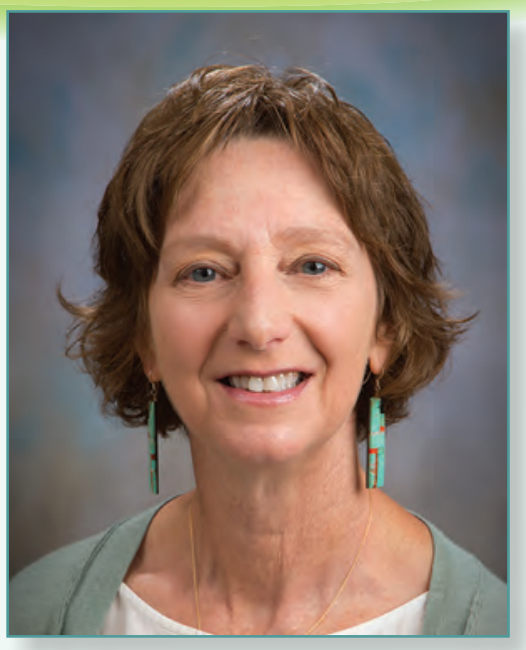

My Ph.D. dissertation described the first 10 years of research at the Loch Vale watershed; my research inspired graduate students, and I received a U.S. Department of the Interior Meritorious Service Award for this long-term ecosystem study that encompassed complex ecological questions with regional and national implications.

Jill Baron has a bachelor's degree in plant sciences (with a minor in geology) from Cornell University, a master's in land resources from the University of Wisconsin, Madison, and a doctorate in rangeland ecosystems ecology from Colorado State University. She was named a Woman of Vision in 2015 by Colorado Women of Influence for her work advancing women's role in science.

https://www.usgs.gov/staff-profiles/ jill-baron 


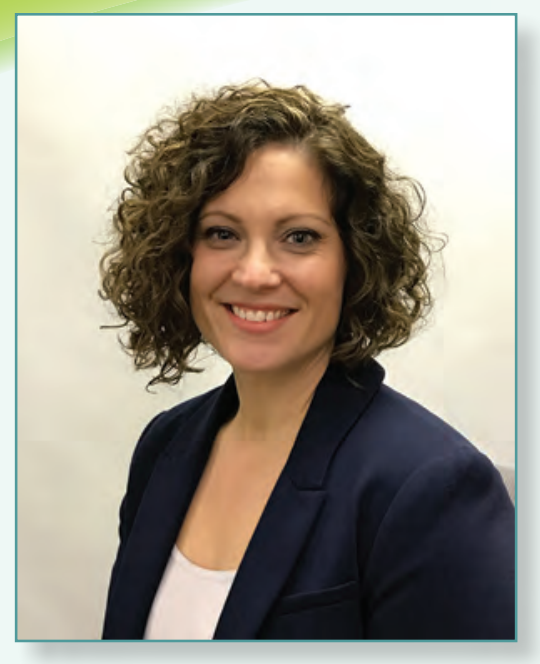

My passion for science and understanding the "big picture" motivates me to find answers to environmental issues using innovative technologies and collaborative efforts.

Miya Barr has a bachelor's degree in geology and geophysics from the University of Missouri in Rolla. https://www.usgs.gov/staff-profiles/ miya-n-barr

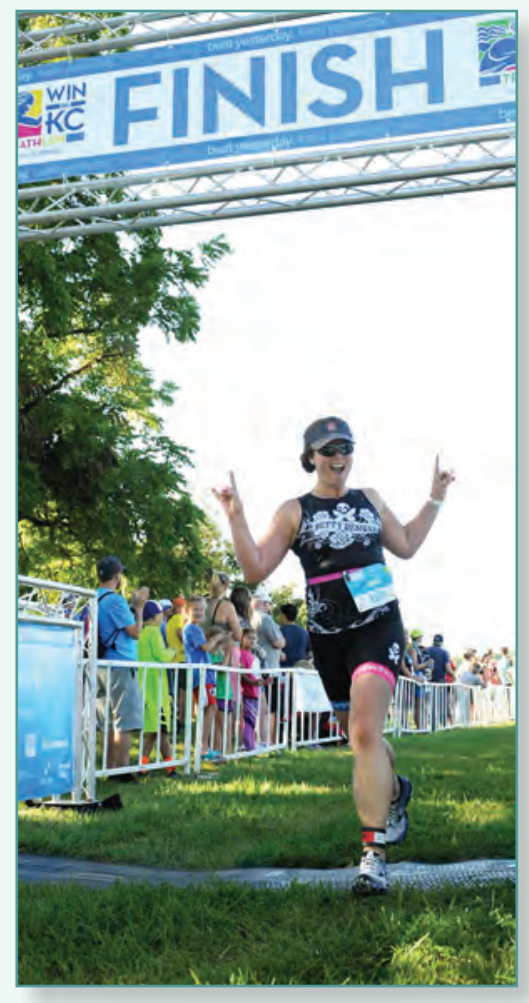

Miya Barr

\section{Hydrologist at the Central Midwest Water Science Center in Lee's Summit, Missouri}

"Far and away the best prize that life has to offer is the chance to work hard at work worth doing." - Theodore Roosevelt

I remember being in kindergarten and getting a Weekly Reader with the Mount St. Helens eruption on the cover. I was fascinated and wanted to learn as much as I could about volcanoes. That Christmas, my grandmother got me a subscription to National Geographic. I cherished every issue and would dive in and study the pictures and read as much as I could comprehend from cover to cover. While working as a student for the USGS during college, through a chance encounter with a visiting hydrologist, I participated in three volunteer science studies at the Cascades Volcano Observatory. Because of that work, I got to see Mount St. Helens, the volcano I first fell in love with back in kindergarten!

My work is to collect and look at sediment samples in the laboratory, measure water levels and flow of streams, and study the effects of storms and floods on the levels of bacteria, nutrients, and sediment in streams. One of my most challenging projects was studying changes in the water quality after a breach in a reservoir, which sent almost 1.5 billion gallons of water into a State park. I also lead teams investigating these issues and mentor young scientists.

I was born in the Loveland, Colorado, area, and that is where my camping and hiking habits began. I love going back and visiting places I went to as a child. Now when I go back, I find myself studying the landscape and looking at the geomorphology and being able to explain to friends and family how a stream or valley was formed or what type of rocks they are looking at. I usually put one in my pocket for my collection just like when I was a kid.

In my spare time, I compete in races all year round, including triathlons, halfmarathons, obstacle course races, and local $5 \mathrm{~K}$ and $10 \mathrm{~K}$ races for charities. Triathlons are my favorite because of all the different elements involved. I love to compete and train and see how much I can improve for each race. I also keep up with my childhood loves of camping, floating, hiking, and backpacking around the Missouri Ozarks. I also spend a lot of time at Lake of the Ozarks fishing and boating with my friends. My bucket list includes visiting all 58 national parks; I'm halfway there!
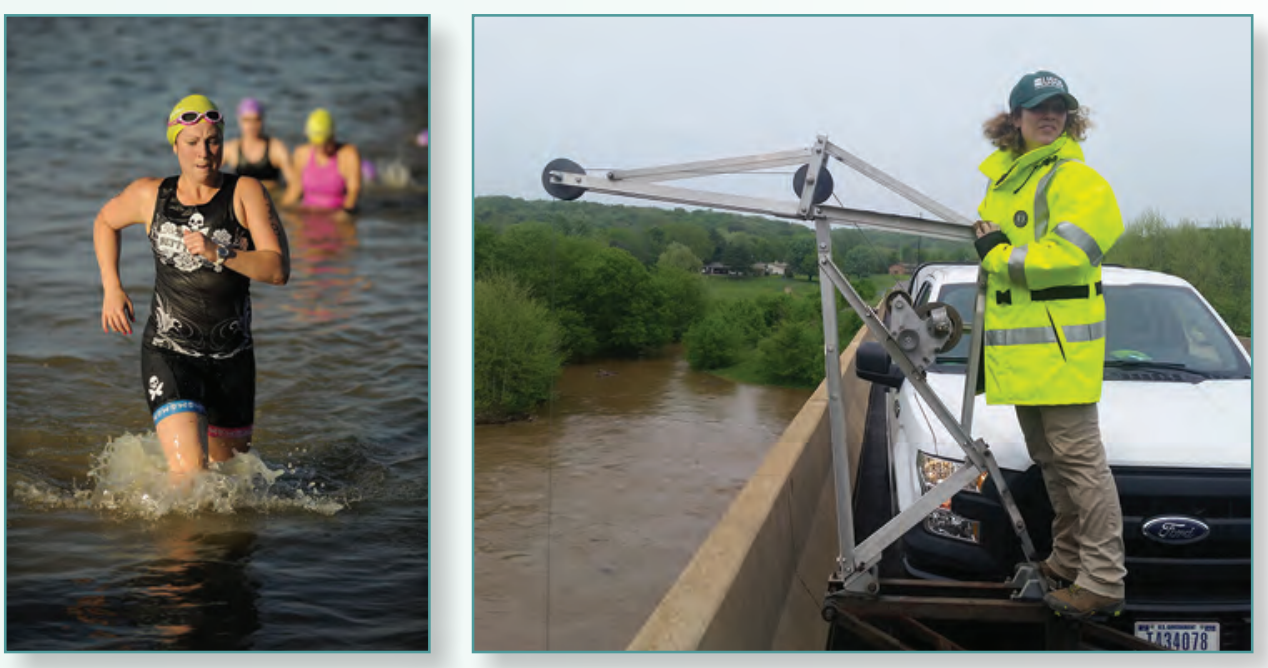


\section{Adrienne Bartlewitz}

\section{Chief of Staff of the Water Mission Area in Reston, Virginia}

"If you can't fly then run, if you can't run then walk, if you can't walk then crawl, but whatever you do you have to keep moving forward." - Martin Luther King, Jr.

I really enjoyed the civics class I took in high school, and because of that class, I only applied to colleges in the Washington, D.C., area with the hope that I could work for the Federal Government. I was fortunate enough to get an internship in college with the Office of Management and Budget through a recommendation from a childhood friend, which in turn led me to being hired with the USGS after college.

In my job, I manage the day-to-day workings of the USGS Water Mission Area. I approach my work always with the taxpayer in mind and make sure the way we are spending our funding really has value that will benefit the public. Doing this makes it easy to promote the work of the USGS to stakeholders, partners, Congress, and the general public.

I enjoy traveling and seeing the world. Traveling provides an education of different cultures and acceptance of and love toward people who are different from me. Some of my favorite travel memories are having a four-course meal in a small cafe in Paris, hiking the Na Pali coast in Kauai, running down the active Cerro Negro volcano in Nicaragua, taking pictures with fake vampire teeth in Dracula's castle in Romania, and snorkeling in the Great Barrier Reef in Australia.
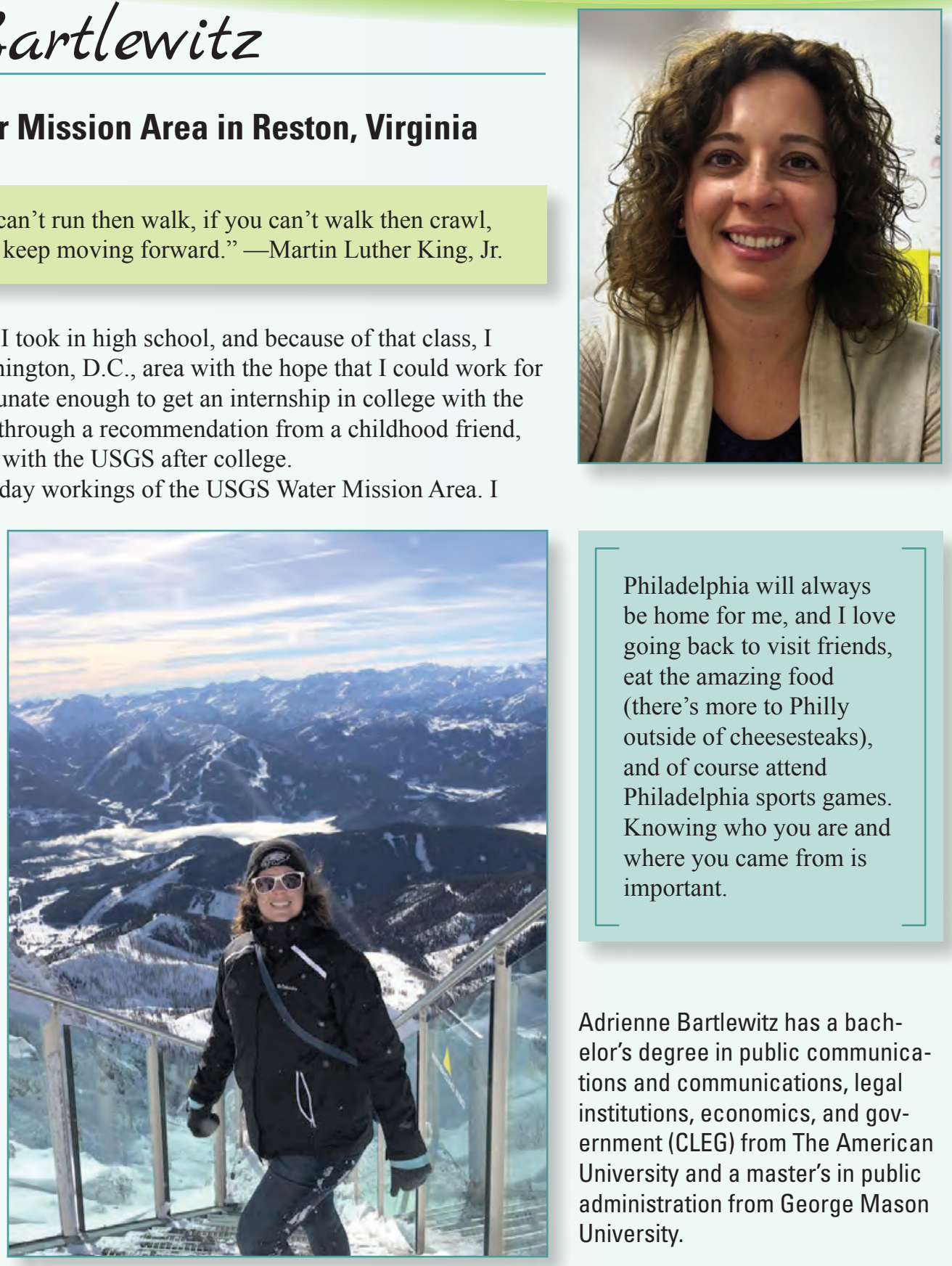

Philadelphia will always be home for me, and I love going back to visit friends, eat the amazing food (there's more to Philly outside of cheesesteaks), and of course attend Philadelphia sports games. Knowing who you are and where you came from is important.
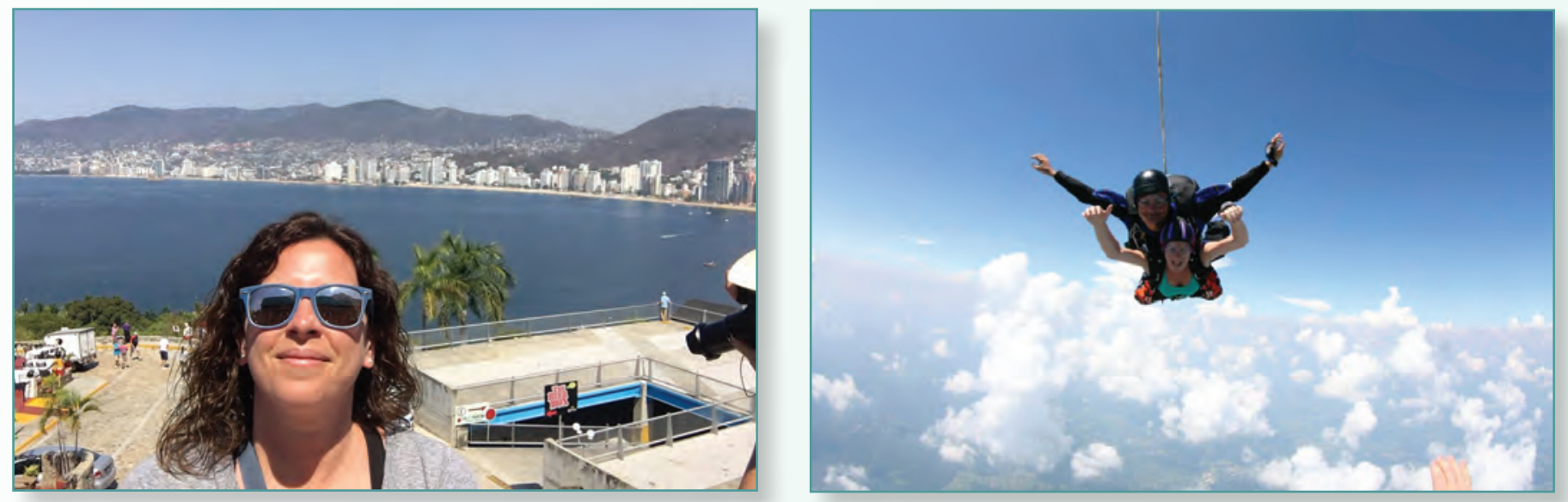


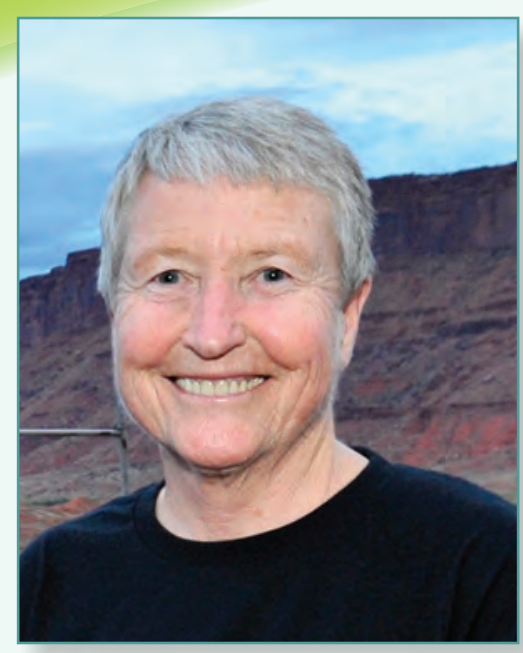

Science is only a part of the discussion; there are cultural voices, economic voices, and they need to be listened to. Science can tell you about the true bottom line, but other factors have to be considered as well.

\section{Jayne Belnap}

\section{Research Ecologist with the Southwest Biological Science Center in Moab, Utah}

When I was a child, I would smash crusts, similar to my dad, a prospector, whose job was to drive around and find minerals. Growing up in Utah, I spent my youth exploring the deserts of the Colorado Plateau and the Great Basin. At first, I studied marine biology, but then gravitated toward ecology because I discovered that I preferred working with entire ecosystems rather than individual species.

I was working as a seasonal botanist in Canyonlands National Park when I discovered the appeal of soil crusts; Dr. Kimball Harper, a professor at Brigham Young University, showed me plots of soils he was studying to evaluate the role of soil crusts on their ecosystems. I became increasingly absorbed in understanding soils and their roles in ecosystem function.

My work has focused on helping land and resource managers find a balance between land use and sustainability. I have been studying how climate change can affect drylands ecosystems, for example, how dust can change the times and amounts of snowmelt in the mountains near the desert or how human activities can affect dust and elements in it. I have been applying science to develop adaptation options for people who manage these lands as well as those who enjoy their use. I have been part of creative, successful, and cost-effective efforts to reduce soil erosion and restore plant productivity by using local materials and labor. My work has taken me around the world, from the western United States to Iceland, Kenya, Tanzania, Ethiopia, Zimbabwe, South Africa, Mongolia, China, Australia, and even Antarctica.
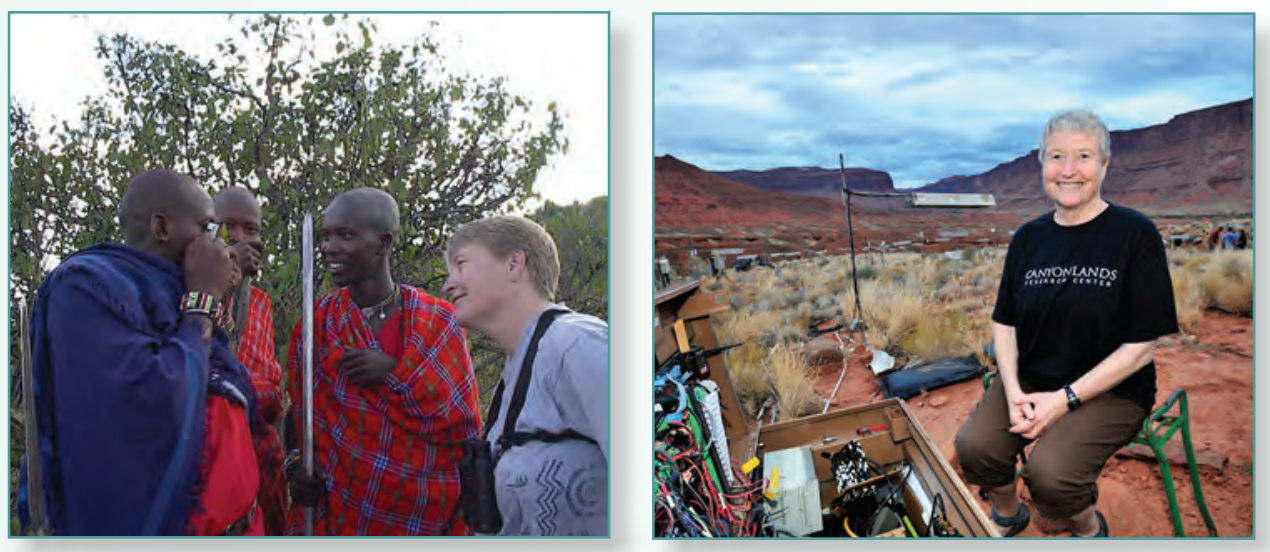
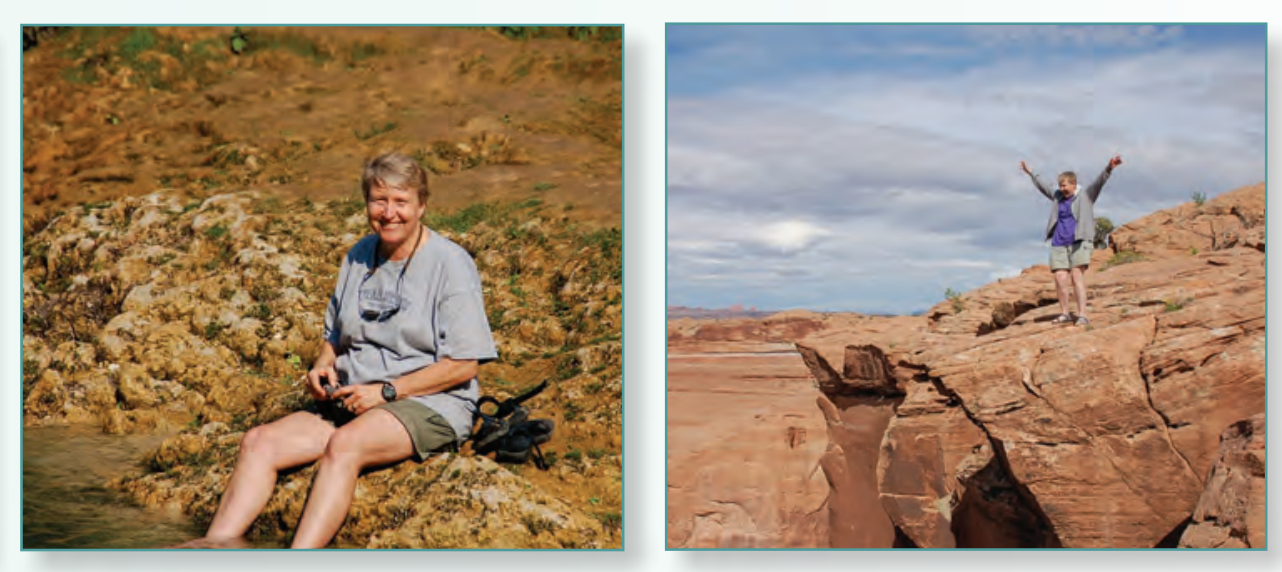

Jayne Belnap has bachelor's degrees in natural history and biology from the University of California, Santa Cruz, a master's in ecology from Stanford University, and a doctorate in botany and range science from Brigham Young University. She has been recognized by the Ecological Society of America as one of the most outstanding ecologists in the United States.

https://www.usgs.gov/staff-profiles/ jayne-belnap

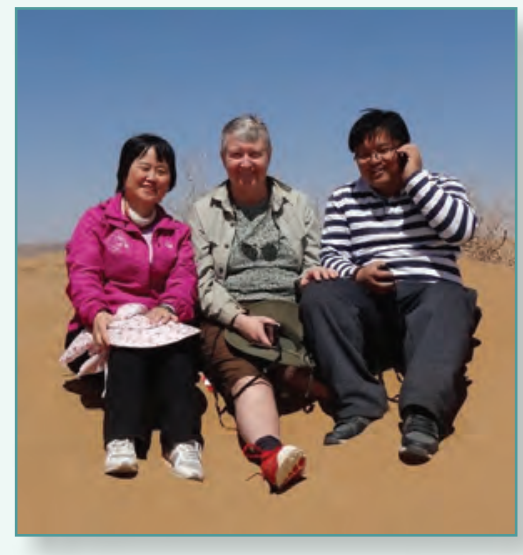




\section{Kristin Berry}

\section{Supervisory Research Wildlife Biologist at the Western Ecological Research Center in Riverside, California}

"Look deep into nature, and then you will understand everything better." -Albert Einstein

I grew up in the Mojave Desert and lived the first three decades of my life on the edge of the desert at a naval weapons testing center. As a child, I played in the desert, chasing and catching lizards. In high school, I took advanced science and math classes. The students had opportunities to work with scientists at the research station after school, and I was fortunate to work on a research project in a chemistry lab, creating new organic compounds and identifying their structures, and even coauthoring a paper. All my early experiences combined to help me realize that my preference in science was in the population biology of desert vertebrates and desert vegetation rather than organic chemistry.

At my job with the USGS, I research the health, diseases, behavior, demography, ecology, and genetics of Agassiz's desert tortoise, a threatened species with rapidly declining populations in the Mojave and western Sonoran Deserts. As part of my research projects, I analyze effects of human activities on tortoises and their habitats from the proximity of desert cities, towns, and settlements; roads; livestock grazing; recreational vehicle use; shooting; and mining. Other research interests include the natural recovery of desert vegetation after disturbance.

I have published more than 100 articles, including a book chapter. Several of my articles have been on new and emerging diseases, and one recent publication named a new species of desert tortoise in the Sonoran Desert! I have also mentored several students for graduate degrees and teach workshops every year.

I find the wide-open spaces of the Mojave, Great

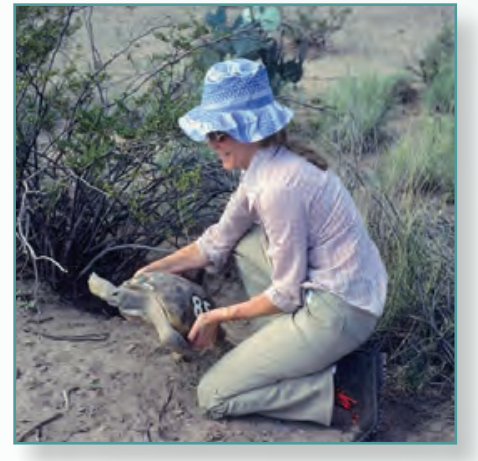
Basin, and Sonoran Deserts to be beautiful and inspiring places for research projects and private time. To me, the silence and solitude are important for creative thinking and renewal of the spirit.
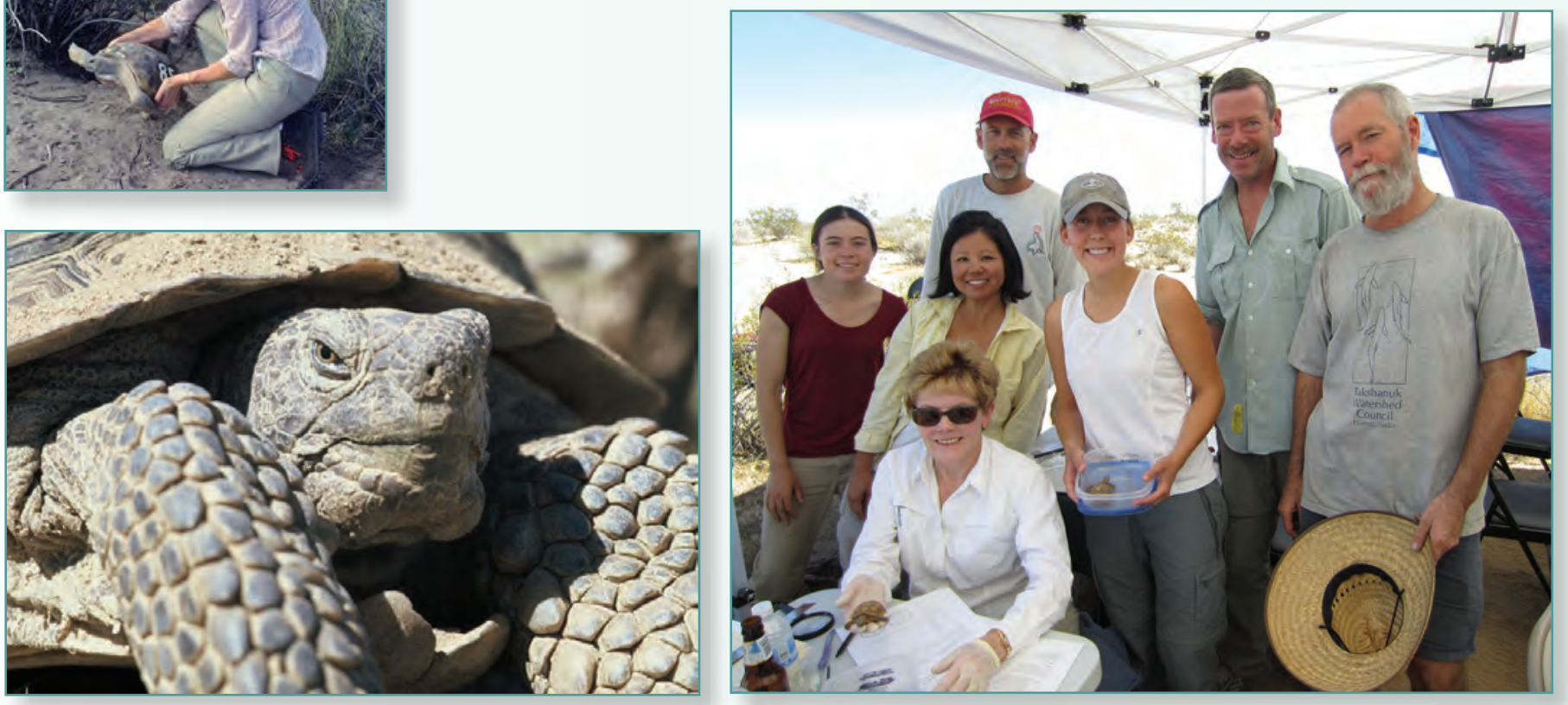


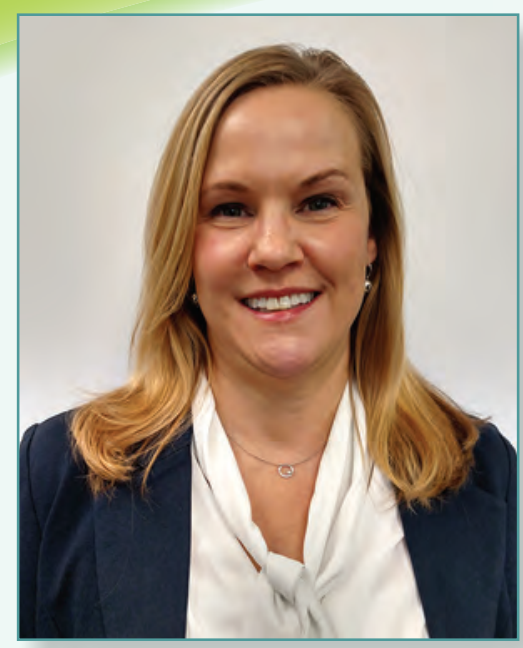

In contemplating how best to apply my degrees in biology and geoscience to make the world a better place, I remember thinking that a career related to water resources would be useful and interesting because of the many ways water is essential to most areas of life.

Amy Beussink has a bachelor's degree in geosciences and biology from Southeast Missouri State University and a master's in watershed management from the University of Arizona.

https://www.usgs.gov/staff-profiles/ amy-m-beussink

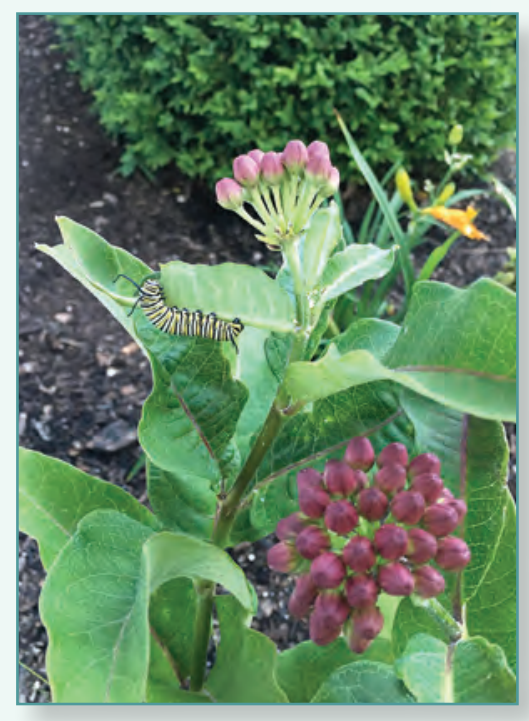

Amy Beussink

\section{Director of the Central Midwest Water Science Center in Rolla, Missouri}

"Traveler, there is no path; The path is made by walking." —-Antonio Machado

I grew up in an outdoors-loving family; my father enjoyed fishing and hunting, and both of my parents were gardeners. As a child, I spent a lot of time outdoors scouting out places for my dad to hunt, along with boating and fishing in the lakes, streams, and ponds of the Midwest. My appreciation of nature and science developed from those early experiences. Throughout school, I was most interested in physical, biological, earth, and other sciences and enjoyed the challenges of problem solving in classes like geometry and trigonometry. In college, I took a 6-week geology field trip to Utah and was awed by the western landscapes I encountered that were so different from those in my native Missouri. During my grad school search, I was drawn to finding my way back out west to learn what made the region so different from where I had grown up.

Finishing grad school, I wanted to put my degrees in biology and geoscience to the best use possible to serve the common good. Seeing the issues the West experiences regarding water, I decided to tie my degrees to managing that most essential resource to all life. During my career, I have used my water-quality research and expertise in forest hydrology and watershed restoration to help with issues in Arizona, Montana, and Texas. I'm now back in my home State of Missouri where I am guiding colleagues and giving them opportunities to develop new knowledge, skills, and abilities to advance their careers and bring solutions to the communities they serve and am encouraging female colleagues in science to consider leadership roles.

In my personal time, I enjoy landscaping with native plants that attract pollinators. I spend lots of time outdoors with my dog, a rescued Rhodesian ridgeback; I also provide a foster home to a ridgeback rescue organization. Another great love for me is baseball, particularly rooting for the St. Louis Cardinals. I love traveling and appreciate the time I spent living in different parts of the country, but I am grateful for the chance to be living back home close to friends and family.
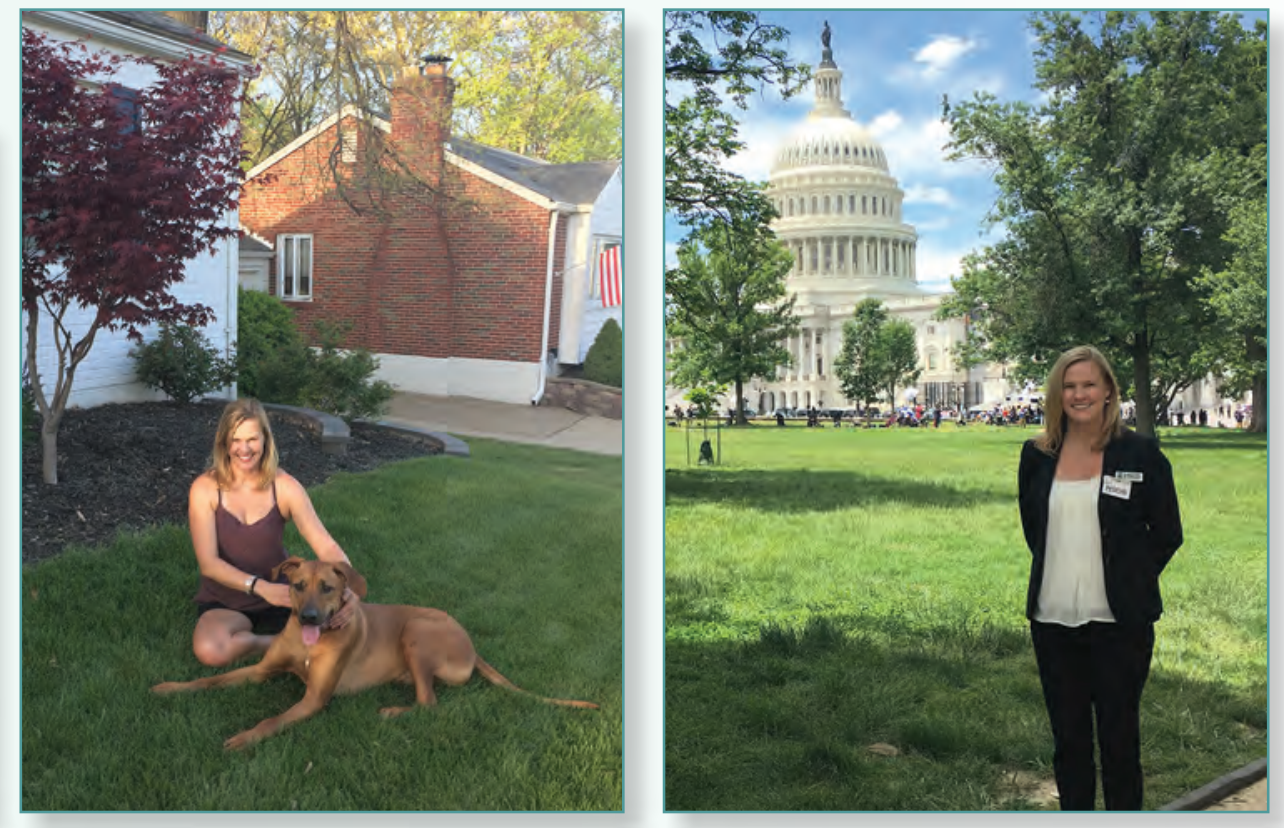


\section{Gesslyn Brown}

\section{Research Geographer with the Earth Resources Observation and Science Center in Sioux Falls, South Dakota}

"Education is thinking, and thinking is looking for yourself and seeing what's there, not what you got told was there." —-William Least Heat-Moon, "Blue Highways: A Journey into America"

I credit the fascinating and beautiful landscapes I saw out of airplane windows with sparking my interest in geography. As a child, I lived in Venezuela, England, and Australia. All this exposure to such a large variety of landscapes, climates, and cultures gave me a great appreciation for geography and its immense and vital variability. My mother had a special folder where she kept all the maps that came with the issues of National Geographic and we would pore over them together, discussing how many parts of the world are very different. When I was a teenager and took road trips with my mom, my job was to be the map reader and navigator and prevent us from getting lost, which further developed my concepts of space, distance, and geography.

I have worked on mapping and assessing land cover and land use, tracking the seasonal or periodic life cycles of plants and animals, and monitoring the effects of drought. The common thread for all my research has been the application of remote-sensing technologies to help analyze vegetation cycles, environmental hazards, and vulnerability to natural hazards in real time or near real time. My research has resulted in the development of two weekly indices that quantify the effects of droughts on vegetation nationwide.

As a geographer, I am challenged each day to help answer questions like "What are the interconnections among climate, land cover, land use, and water resources?" and "How does the relative strength of different influences on vegetation condition and water resources vary across time and space?" These questions are important because our land and water supply us with critical resources necessary for human health and survival and we need to understand why, how, where, and when they are changing. I hope my research has helped build knowledge about how vegetation behaves and what affects it.
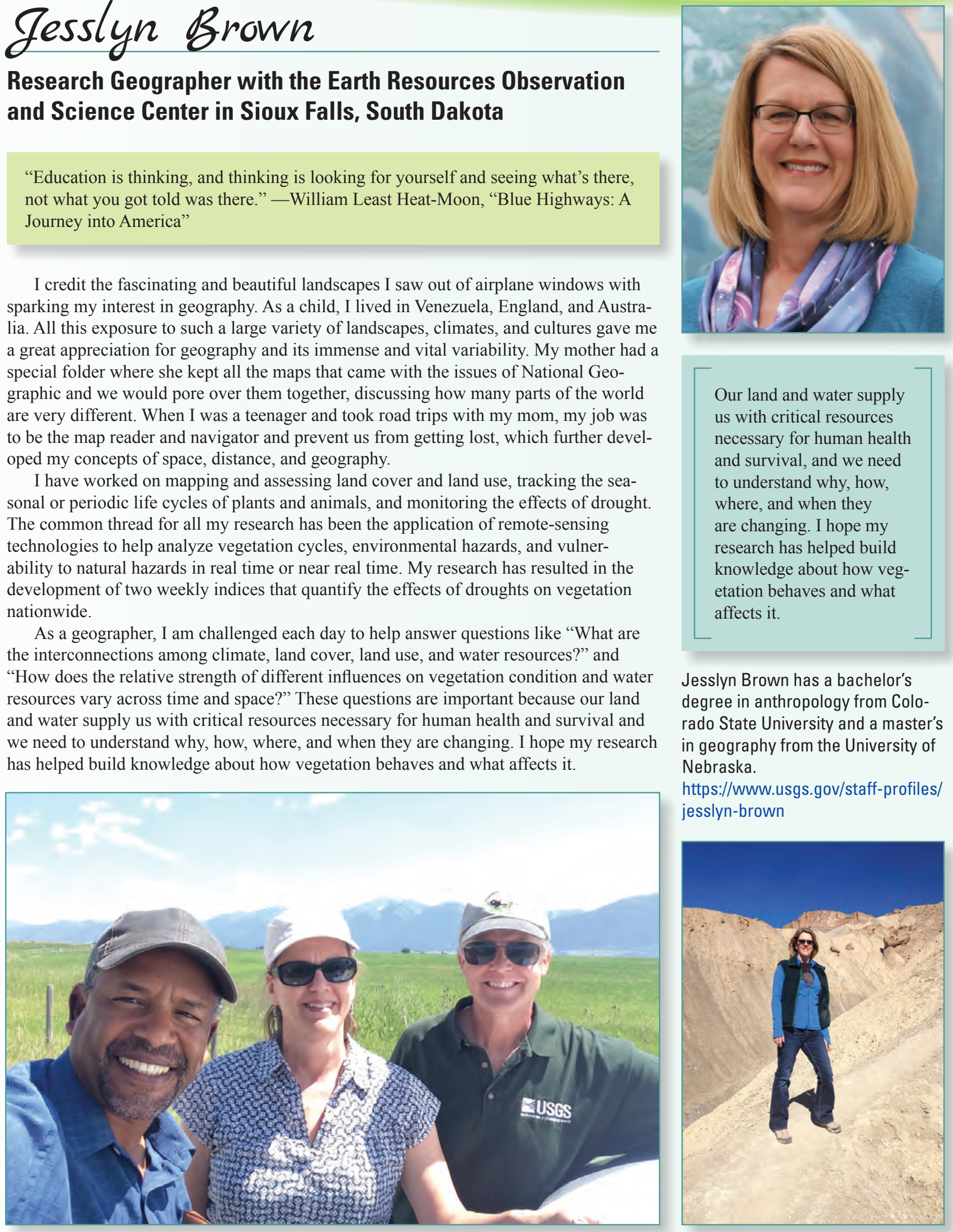

Our land and water supply us with critical resources necessary for human health and survival, and we need to understand why, how, where, and when they are changing. I hope my research has helped build knowledge about how vegetation behaves and what affects it.

Jesslyn Brown has a bachelor's degree in anthropology from Colorado State University and a master's in geography from the University of Nebraska.

https://www.usgs.gov/staff-profiles/ jesslyn-brown

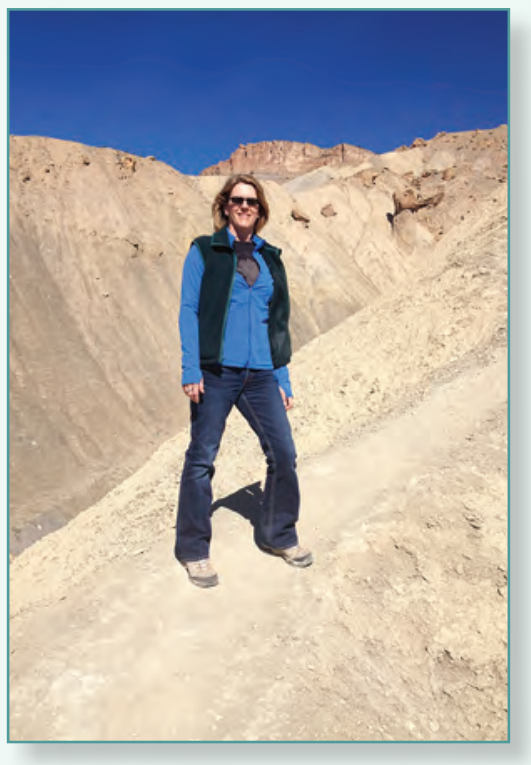




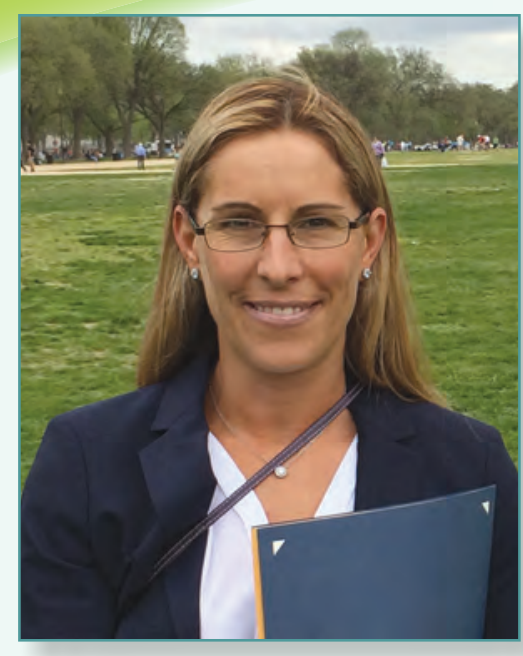

Because of the cooperative programs we undertake with the Wyoming Game and Fish Department and other agencies to address critical research needs of nongame wildlife species within the State, all graduate student projects in my lab have both applied and conceptual components that are well-suited for students interested in learning how to apply the scientific method to their work as well as address real-world wildlife conservation issues.

Anna Chalfoun has a bachelor's degree in biological sciences from Smith College, a master's in wildlife science from the University of Missouri-Columbia, and a doctorate in wildlife biology from the University of Montana.

https://www.usgs.gov/staff-profiles/ anna-chalfoun

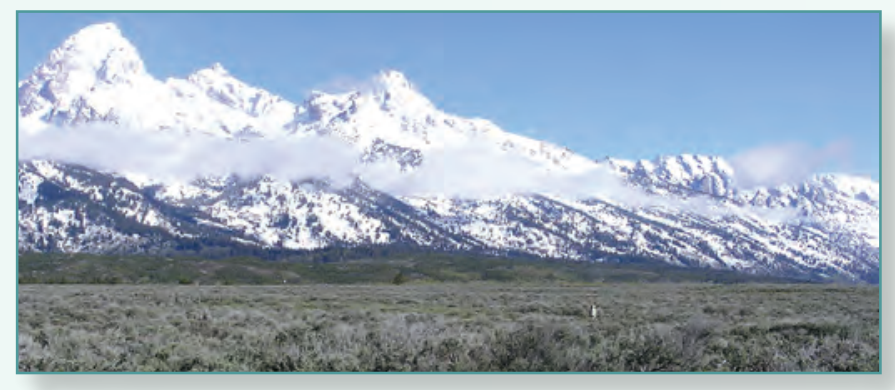

\section{Anna ehalfoun}

\section{Wildlife Ecologist at the Wyoming Cooperative Fish and Wildlife Research Unit in Laramie, Wyoming}

In my role at the USGS, I focus on examining relationships between wildlife and their habitats and how human activities affect these relationships. I aim to understand why wild animals, particularly songbirds, small mammals, the American pika, reptiles, and amphibians, select particular habitats and whether such choices are optimal or counterproductive, and why. Some of my research has focused on habitat changes caused by energy development, climatic variability, and invasive species encroachment.

In addition to working with the USGS, I am also an associate professor within the Department of Zoology and Physiology at the University of Wyoming. I have published works on wildlife habitat selection, the effects of human-induced habitat change on wildlife, predation on bird nests, how birds live and care for their young, and ecological traps.

I was selected for a Presidential Early Career Award for Scientists and Engineers and honored by President Obama. I served first as a board member and then as the presidentelect of the Cooper Ornithological Society, the second largest ornithological society in North America before it merged with the American Ornithologists' Union to form the American Ornithological Society (AOS). I am currently serving on the Council and Conservation Committee of the AOS.
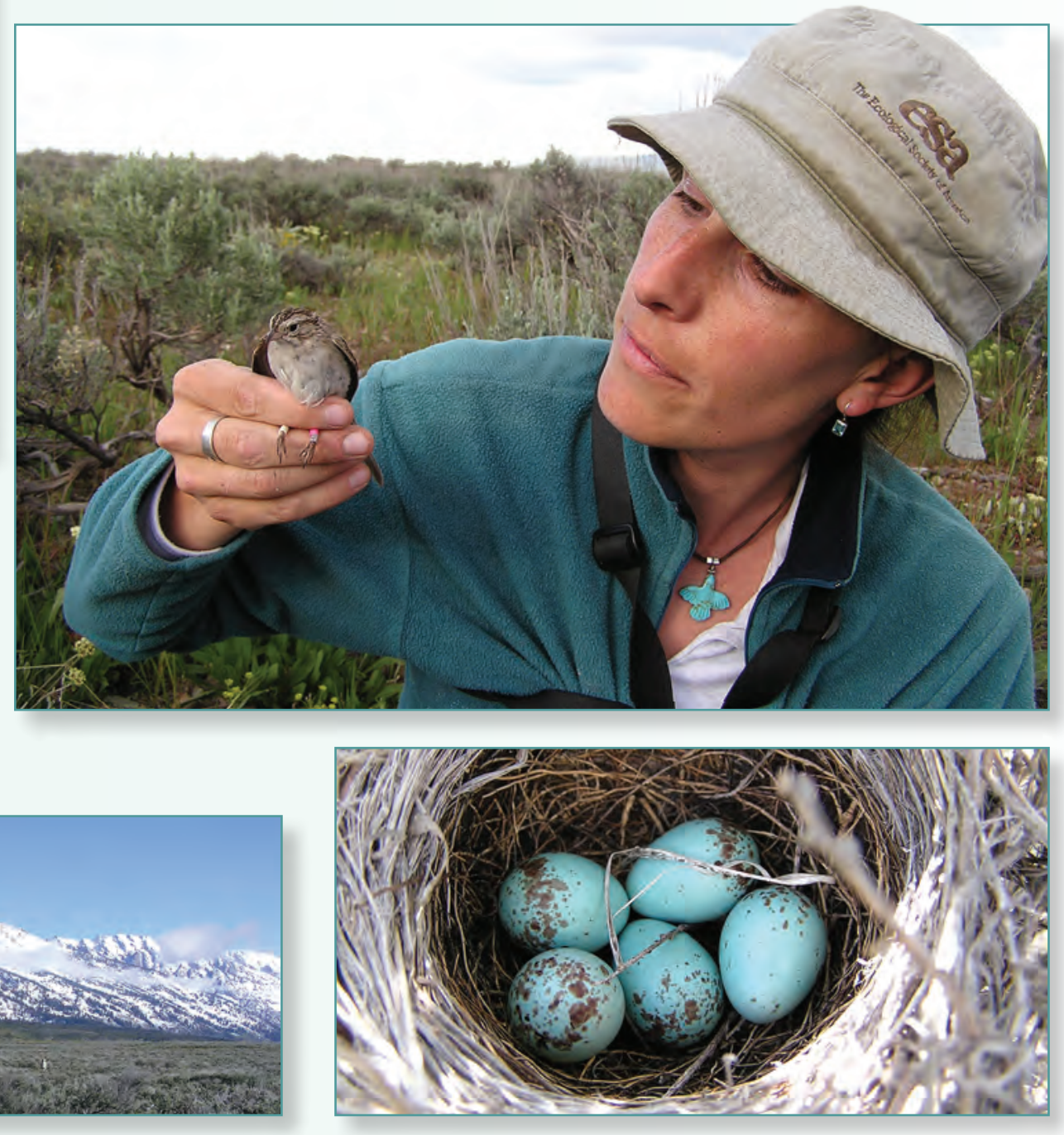


\section{Victoria ehristensen}

\section{Research Hydrologist at the Upper Midwest Water Science Center in Mounds View, Minnesota}

\begin{abstract}
"If your actions inspire others to dream more, learn more, do more, and become more, you are a leader." — John Quincy Adams
\end{abstract}

In elementary school, my teacher, Mrs. Hiller, told us to draw a picture of what we wanted to be when we grew up. I had never thought about it. I expected I'd be a mom, just like all the other grown-up women in my life. I knew some women were nurses and secretaries and, of course, I could be a teacher. All the kids scribbled away: police officers, firemen, ballerinas. I didn't want to be a ballerina - too impractical. I didn't want to be a teacher - too many kids. I didn't want to be a nurse - too much blood. So my future was decided by default: I drew a picture of a secretary behind a desk. Mrs. Hiller collected the pictures, but then surprised us with another blank sheet of paper and told us to draw a picture of what we would want to be if we were the opposite sex. That was the turning point. I didn't have to be a nurse or a teacher or a secretary-I could be anything! I quickly drew myself as President of the United States. Of course, we all know I did not become President, but that was when I realized I could become anything, even a scientist.

I did not start my career like most scientists. I worked in management, marketing, and finance for environmental consulting firms. During these jobs I found that I really enjoyed working with scientists on environmental issues, so I started on a new path and new career in science, bringing along a unique skill set that I use to help manage projects and communicate about science.

My current work takes me into the national parks and farming communities across the Midwest to study water-quality and nutrient cycling issues related to land and waterlevel management. My previous career gave me the skills to manage the financial and communication side of projects, but many scientists do not have that experience. Therefore, I helped develop a USGS project management course specifically for scientists. I also help other scientists communicate their messages to a broad audience through my current role as an editor for the USGS GeoHEALTH newsletter.
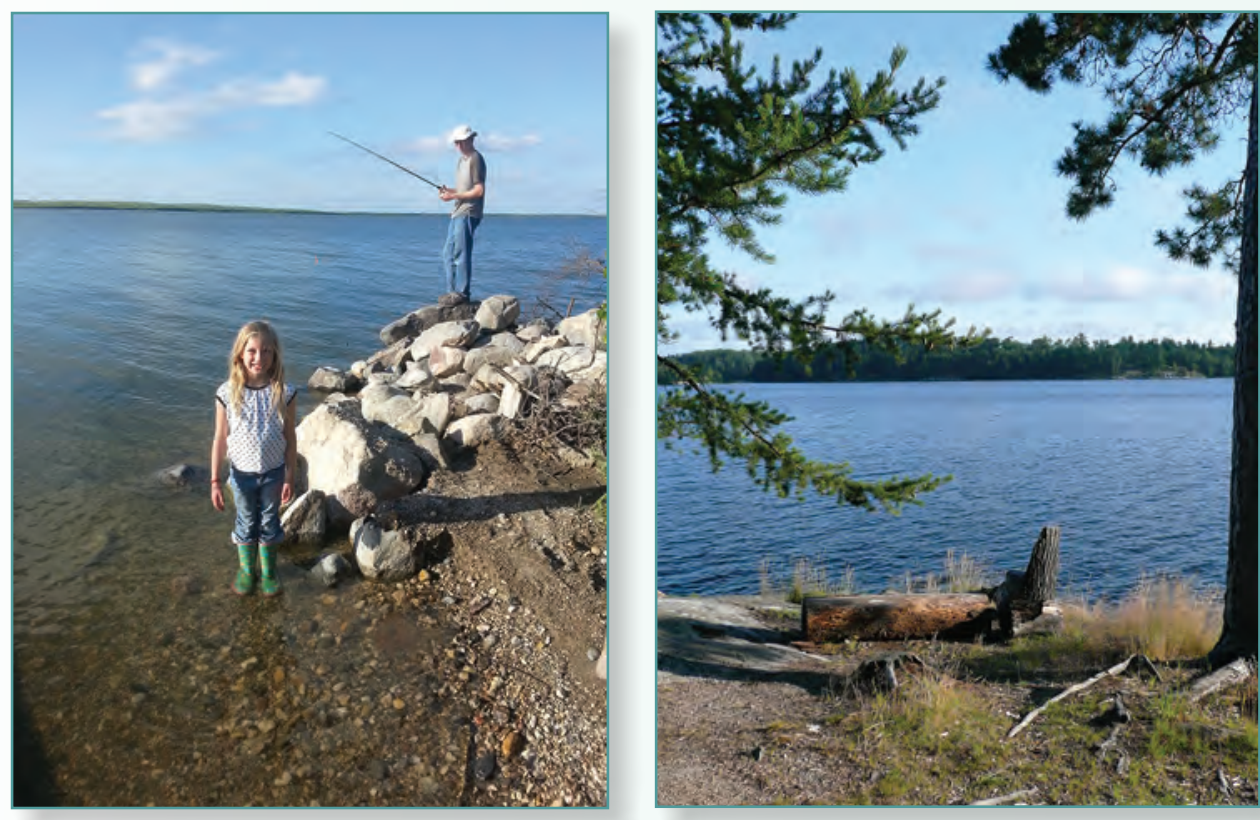

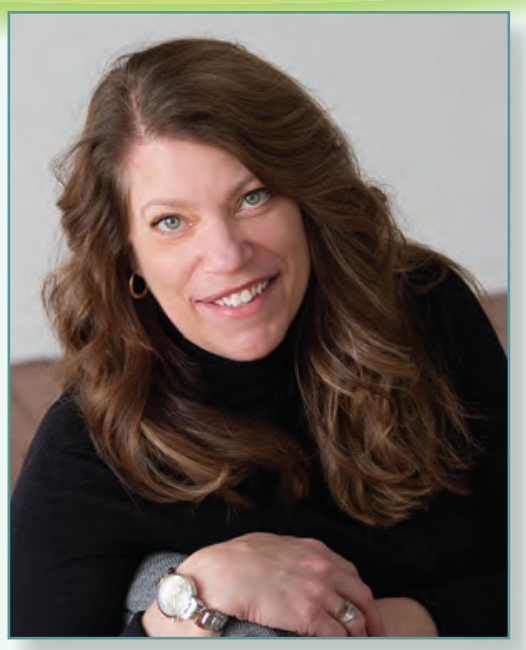

I love to write and communicate about science at the USGS. But, some evenings, when my work day is through, I like to change course and do some creative writing for kids. I can't believe I get to do such cool work, then share and inspire others.

Victoria Christensen has a bachelor's degree in international management from Hamline University and a bachelor's degree in geology and a master's in water resources from the University of Kansas; she is currently studying for her doctorate in environmental and conservation science and communication at North Dakota State University. She is also a published author, having written nonfiction books on science topics for children as well as a fictional series around the adventures of a fourth-grade scientist. https://www.usgs.gov/staff-profiles/ victoria-glenn-christensen

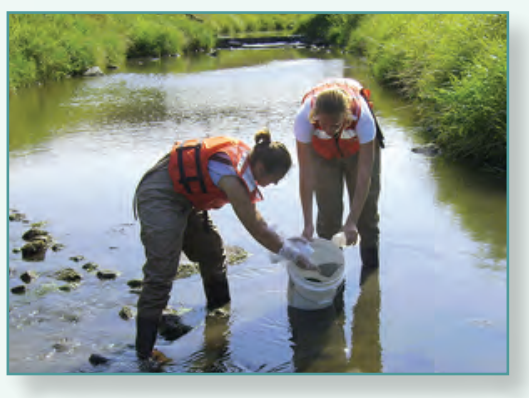




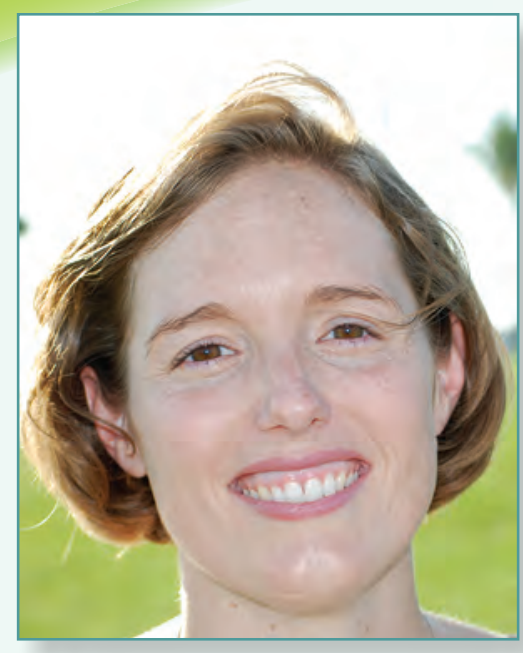

My work on the effects of Earth tides on the timing of earthquakes suggested that earthquakes may be triggered by very small stress changes.

Elizabeth Cochran has a bachelor's degree in geophysics from the University of California, Santa Barbara, and a doctorate in geophysics and space physics from the University of California, Los Angeles. She was an assistant professor with the Earth Science Department at the University of California, Riverside, and is a visiting associate with the Division of Geological and Planetary Sciences at the California Institute of Technology.

https://www.usgs.gov/staff-profiles/ elizabeth-cochran

\section{Elizabeth eochran}

\section{Research Geophysicist at the Earthquake Science Center in Pasadena, California}

"We look at science as something very elite, which only a few people can learn.

That's just not true." - Mae Jemison

My seismology career began in high school when, as part of the Young Scholars Program of the National Science Foundation, I installed a seismometer at my parents' house and one in the local mountains. Needless to say, my parents weren't too happy when at the end of the project I told them that the ground motions at their house were amplified by a factor of four compared with the nearby site in the mountains!

I research activities that can trigger earthquakes, processes that can cause faults to rupture, and how waves from earthquakes travel and may potentially cause damage. My team and I deploy seismic stations to study earthquakes, including the magnitude 7.2 earthquake in El Mayor Cucapah in Baja California in Mexico in 2010 and the magnitude 5.7 earthquake in Prague, Oklahoma, in 2011. I have also explored how disposal of waste byproducts into deep wells from energy production can sometimes induce earthquakes. I was the chief scientist for the USGS earthquake early warning system for the west coast of the United States and ShakeAlert, and I am now the project chief for the Induced Seismicity Project.

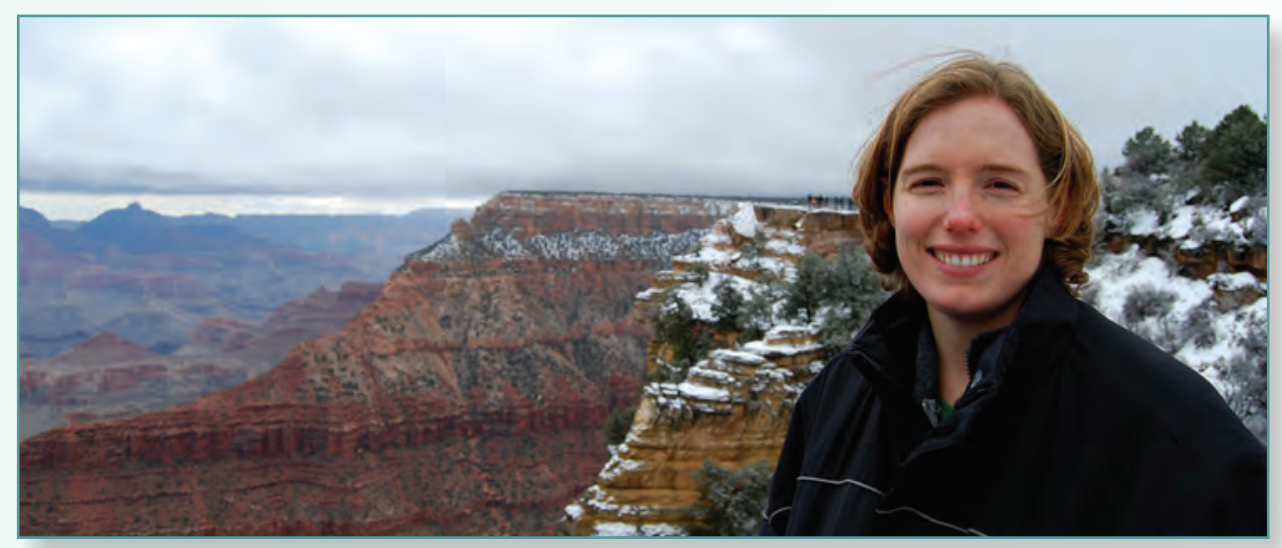

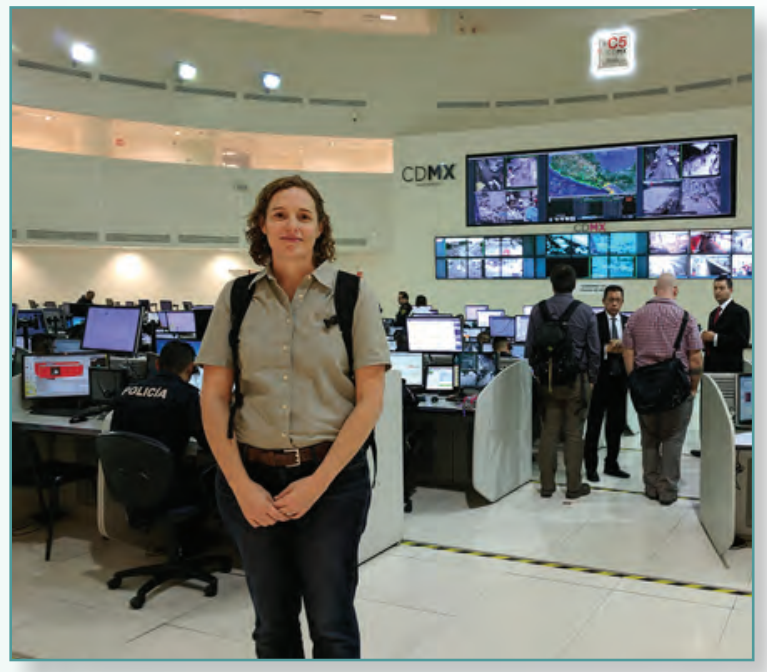




\section{Alissa eoes}

\section{Supervisory Hydrologist and Water-Quality Specialist at the Arizona Water Science Center in Tucson, Arizona}

"The worst walls are never the ones you find in your way. The worst walls are the ones you put there-you build yourself. Those are the high ones, the thick ones, the ones with no doors in." - Ursula K. Le Guin, "The Language of the Night"

I grew up in rural upstate New York and spent my childhood building forts in the woods, catching frogs in ponds, and sneaking into orchards to climb trees and eat apples. This freedom to roam the outdoors led to my love of nature. I didn't understand this fondness for the natural environment until college, when I took Geology 101 on the suggestion of a friend who knew that I was unhappy with my pre-med classes. That geology class, and later other environmental science classes, fascinated me, and changed my academic trajectory. I am extremely fortunate to have found the path that led me to a career in a field that I love!

I started working with the USGS when I was a graduate student. I work with the water found underground, in the soil or in pores and crevices in rock. This groundwater is one of the primary water supplies in the Nation. I have investigated the water chemistry of aquifers in the Southwest, recharge in the coastal plain aquifers of North and South Carolina and in short-lived stream channels in Arizona, flow of groundwater in the aquifer system of the mid-Atlantic Coastal Plain, and contamination of streams and rivers by organic compounds.

My favorite part of my work is the opportunity to apply science to real-world environmental issues. There is nothing more satisfying than working with a partner agency to understand their water-resource questions, design and implement an investigative study, and then provide them with the information their water-resource decision makers need to ultimately answer those questions.

When not working, I enjoy hiking, camping, and, yes, even skiing in the mountains of Arizona.
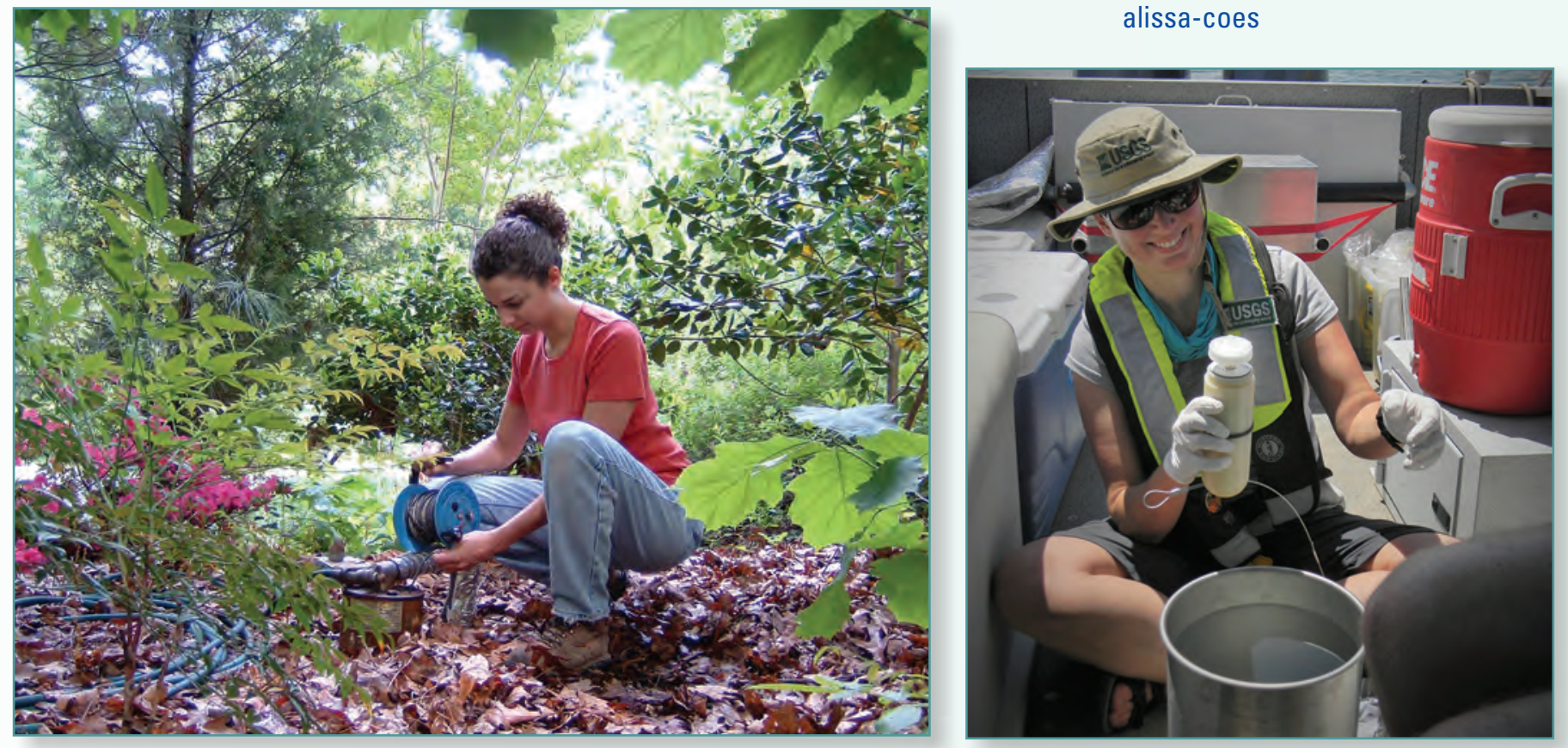


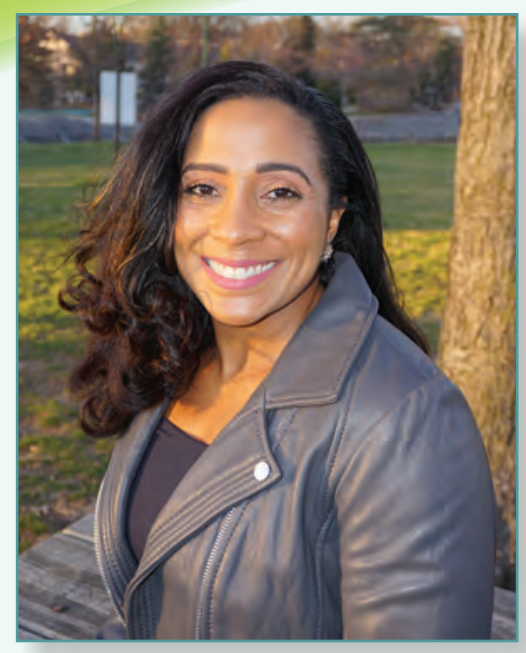

Motivation is what keeps you going, but perseverance, integrity, passion, and inspiration are the keys to the success of any great leader.

Margo Corum has a bachelor's degree in biology from George Mason University and a master's in environmental policy and management from the University of Maryland.

https://www.usgs.gov/staff-profiles/ margo-d-corum
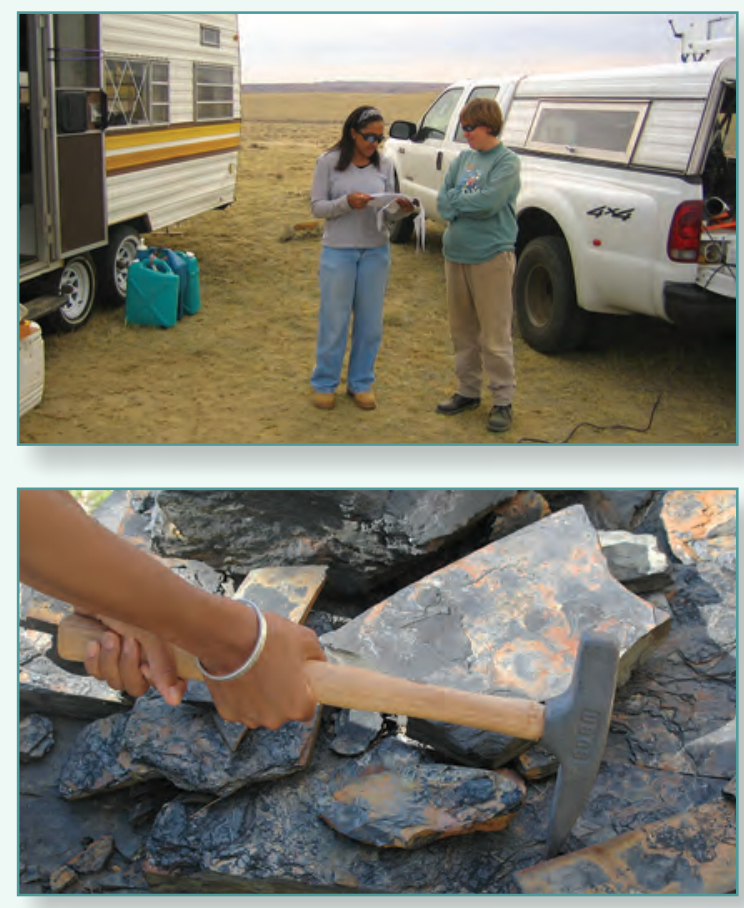

\section{Margo eorum}

\section{Associate Coordinator for the Energy Resources Program in Reston, Virginia}

"If you're always trying to be normal, you will never know how amazing you can be." - Maya Angelou

I have always been drawn to the outdoors and ocean. As a small child, I loved playing in the mud and creeks with insects and salamanders. In second grade, I asked Santa for a microscope, and from that point knew I wanted to be a scientist. The question was, "What field?" In the third grade, my brother and I joined the Young Astronaut Club because we were fascinated with space and the Earth. In the ninth grade, my biology teacher proved to be a true inspiration. For the first time in school I was being challenged in the sciences and had to work hard for my grades, but even more than that, my teacher made me want to learn more about biology.

I started with the USGS in a biogeochemistry laboratory while I was still in college, and I decided I should take geology courses as electives because I was working for the USGS. As a student appointment at the USGS, I studied the cycle of sulfur as it moves from the ground to the air and then into plants and through the food chain in the Florida Everglades. I have also studied the chemistry of water that is produced as a byproduct from the production of oil and gas and created a method to study how wind-energy production affects wildlife. I also lead a team that evaluates links between geology, energy resources, and human health.

My great loves are scuba diving and hiking. Being in the ocean in complete silence and observing creatures in their habitat is such a surreal feeling; it's like being in a giant aquarium that never ends. Hiking, on the other hand, is the beauty above sea level. As you hike, you see the geology and biology of a particular location. Both hiking and diving provide me with an endless connection to the natural world. My own inspiration for scuba diving and hiking stem from a fascination with the ecosystems of oceans and mountains. Diving and hiking inspire me to keep learning, and they show me why science is so important to all aspects of life.

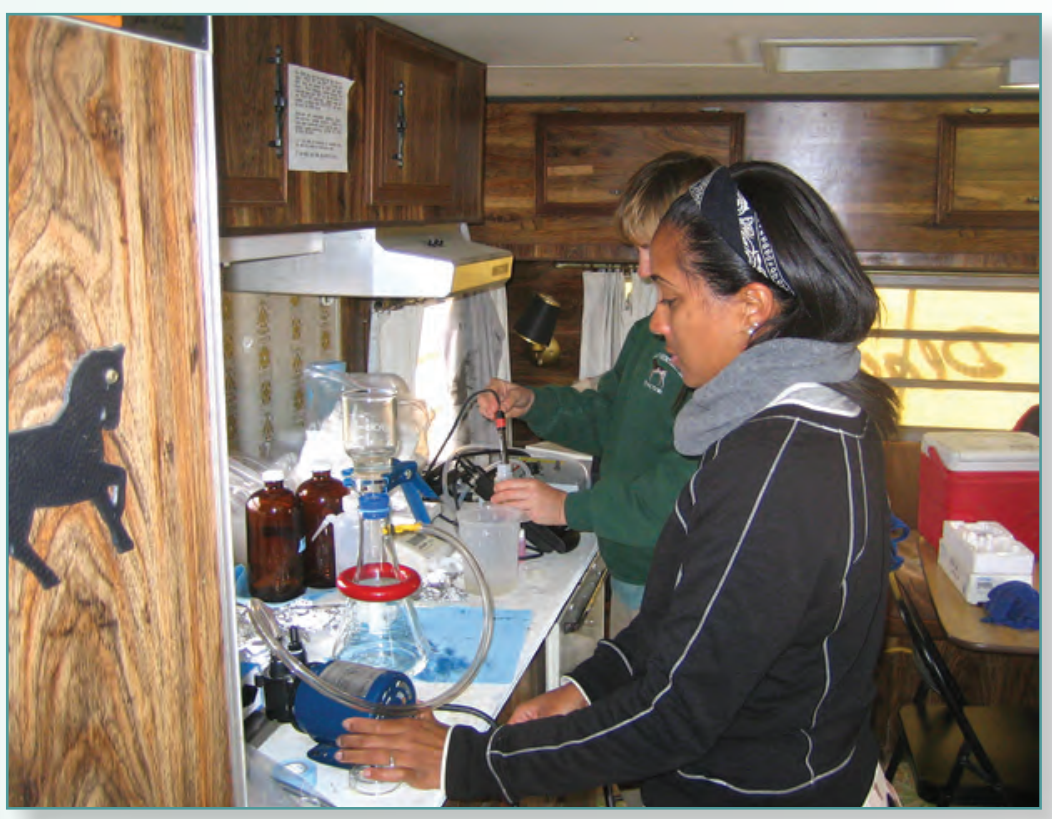




\section{Isabelle eozzarelli}

\section{Research Hydrologist with the Water Cycle Branch of the Water Mission Area in Reston, Virginia}

When I was young, my father, an engineering professor, took me, my five siblings, and our mom with him when he went on year-long sabbaticals to Holland and Italy. My parents decided that their children would attend the local public schools and be completely immersed in the foreign language and culture. My parents' attitude was that we would be fine and figure things out on our own, and even though I did not know Dutch or Italian, it turned out that they were right. My parents' steadfast confidence that I could handle any challenge and be successful gave me perseverance and courage throughout my life, even when my path challenged societal norms, like earning a degree in geomechanical engineering as a woman in the early 1980s. Those same trips provided many formative experiences that influenced my career choices. For example, I vividly remember visiting Pompeii and seeing the effects of the eruption of Mount Vesuvius. I was fascinated and disturbed by seeing how humans and the natural world can collide in such a catastrophic way.

In my career at the USGS, I continue trying to understand the interaction of humans and the natural world. I have used my knowledge of chemistry to help protect natural resources. I lead a team that is researching the fate and effect of oil and gas development to understand how they might affect drinking water quality and ecosystem health. Each time I publish a scientific paper, I feel pride in the fact that I am forever contributing to the knowledge base we need to protect our resources. I am especially gratified if those papers are coauthored with students or junior scientists I have mentored in the field or in my laboratory.

Because mentoring has been so important to my life, I have taken an active role in mentoring in the USGS and the broader geoscience community by supporting the professional development of junior researchers and graduate and postgraduate students. Because of my own experiences and career path, I particularly enjoy the opportunity to share my experiences with early-career female scientists. I have seen these women become accomplished scientists and role models themselves, and I find that inspiring.

Aside from enjoying time with my family, a favorite way to spend my free time is gardening. I love flowers, and if I could work in my flower garden with my hands in the earth all day, I'd be really happy. I find working in the garden very peaceful and relaxing.
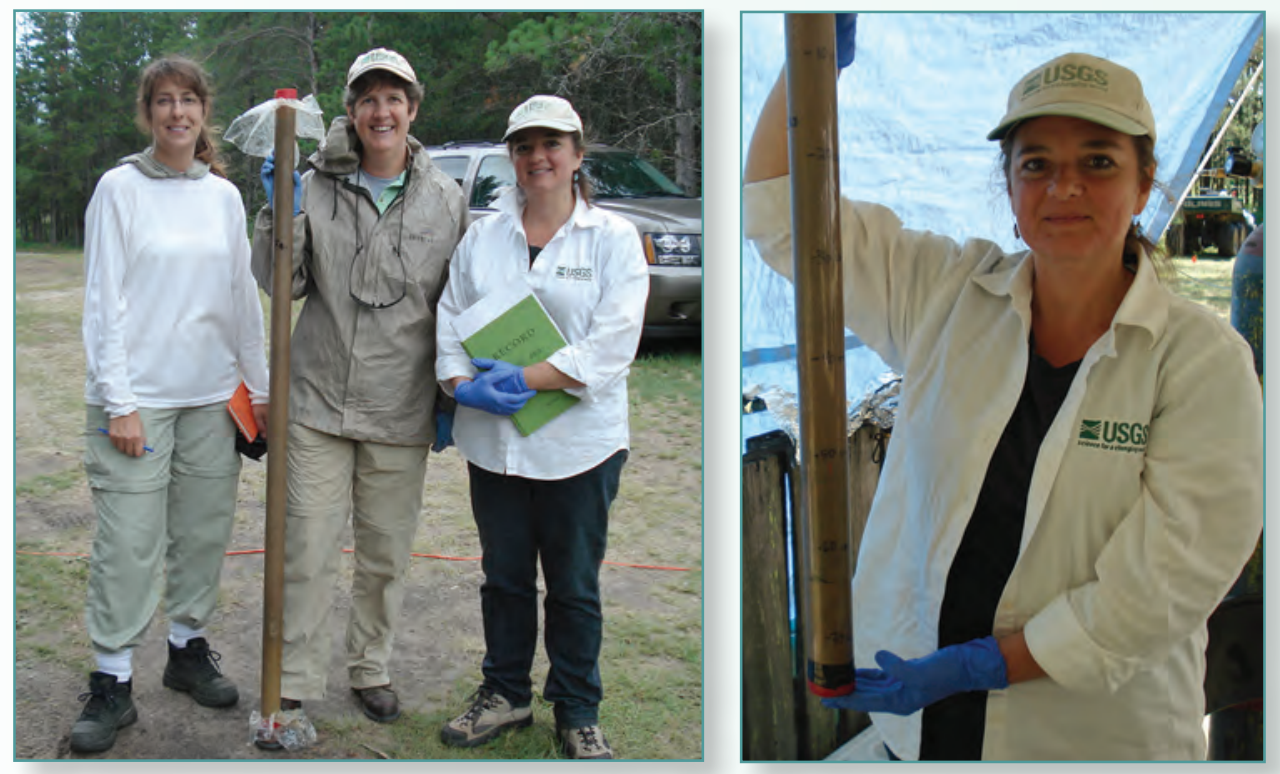

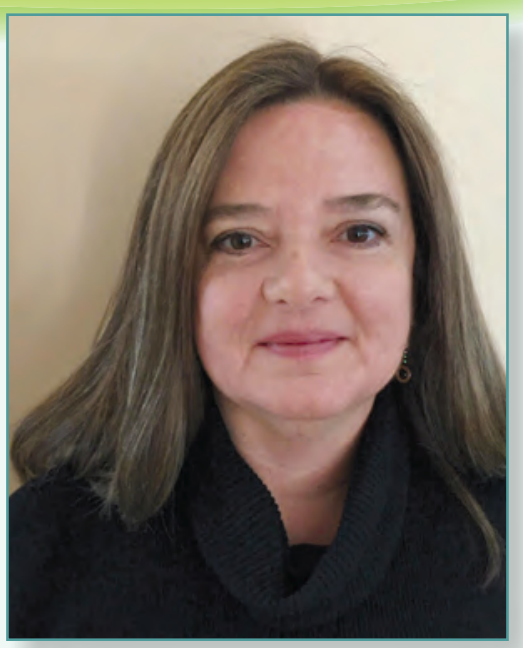

One of the most satisfying parts of my career at the USGS is the mentoring I do at all levels, through formal mentoring programs, informal networking, and science advising. Mentoring is so valuable to me because I can help others advance their careers and the science necessary to protect our environment.

Isabelle Cozzarelli has a bachelor's degree in geomechanics from the University of Rochester and a master's and a doctorate in environmental sciences from the University of Virginia.

https://www.usgs.gov/staff-profiles/ isabelle-m-cozzarelli

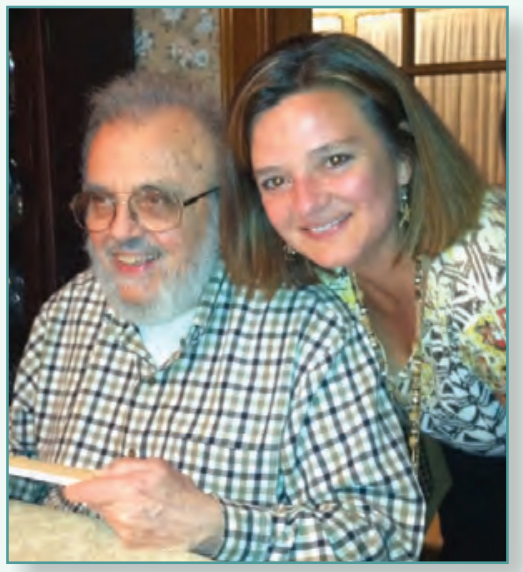




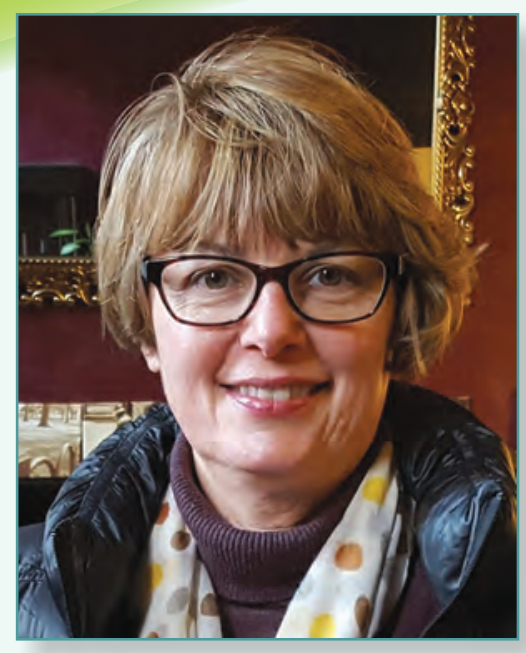

People who are passionate about their work have always inspired me and continue to inspire me to this day.

Kari Craun has a bachelor's degree in geology from the University of Missouri-Kansas City, a master's in photogrammetry from Purdue University, and a second master's in geospatial information science from Northwest Missouri State University.

https://www.usgs.gov/staff-profiles/ kari-craun

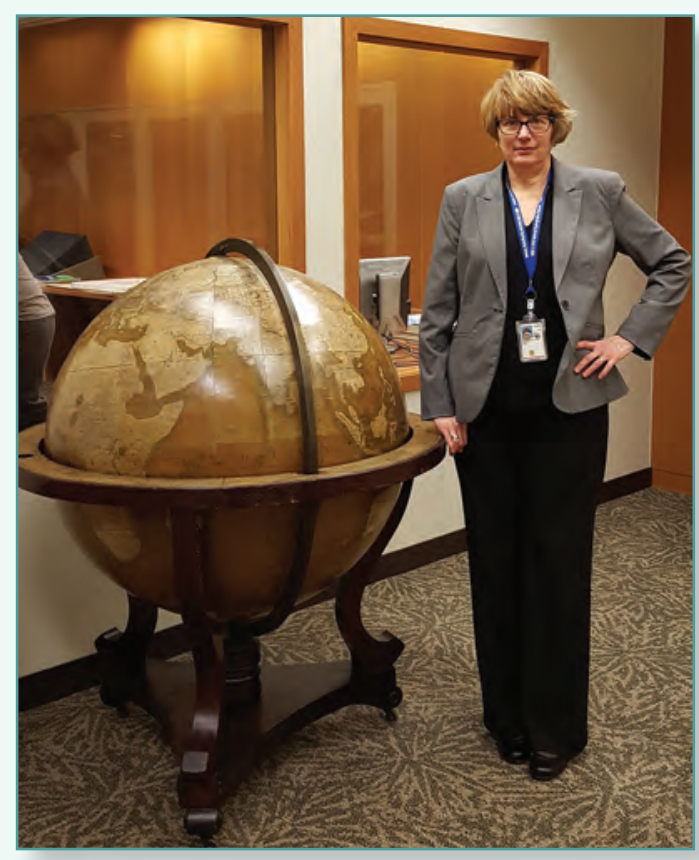

\section{Kari eraun}

\section{Director of the National Geospatial Technical Operations Center in Rolla, Missouri}

"A leader is best when people barely know he exists; when his work is done, his aim fulfilled, they will say, "We did it ourselves." - Lao Tzu, "Tao Te Ching"

Growing up I was a voracious reader, but at the same time, I loved spending time outdoors and traveling with my family. The time I spent traveling and being outdoors heavily influenced my passion for hiking and being in the mountains as well as my decision to get a degree in geology in college. I was also involved in team sports during my school years. I played softball, basketball, volleyball, and tennis. In some cases, I was on the first girls' teams for a particular sport formed at my school. Participating in these sports teams fostered my confidence and taught me leadership, cooperation, and responsibility. Many of the opportunities I have had throughout my life and career are because of the influence of pioneering women in scientific fields who came before me, and I feel lucky to never have felt limited in the things I could or couldn't do because I am female.

Having great mentors along the way has also been a huge influence on me. I remember taking a test for an advanced biology class in high school. After the test, as I sat in a different class, my advanced biology class instructor came in and pulled me aside just to express his genuine excitement over how well I had done. This same instructor let his class perform some fairly advanced laboratory research at a local university; I even was able to use their centrifuge and microscopes. In college, I probably learned more about my field from teaching assistants than anyone else in my college career. These people took time out of their busy schedules to help me understand very complex subjects. Having supportive people who are passionate about their work to help and encourage me gave me confidence in my skills and abilities in science, and they continue to inspire me to this day.

I had several jobs when I was in high school. I worked as a phlebotomist (taking blood samples) in a hospital. I distinctly remember working with patients who had sustained serious injuries or were very ill and were either in the emergency room or in the intensive care unit. This level of responsibility at such a young age affected my maturity level and increased my confidence in working under stressful conditions. In college, I also worked at a car wash that employed primarily former convicts living in a halfway house nearby. These kinds of experiences all influenced my ability to work with a variety of people under a diverse set of conditions and to realize there are good people everywhere and it is really important not to be too quick to judge

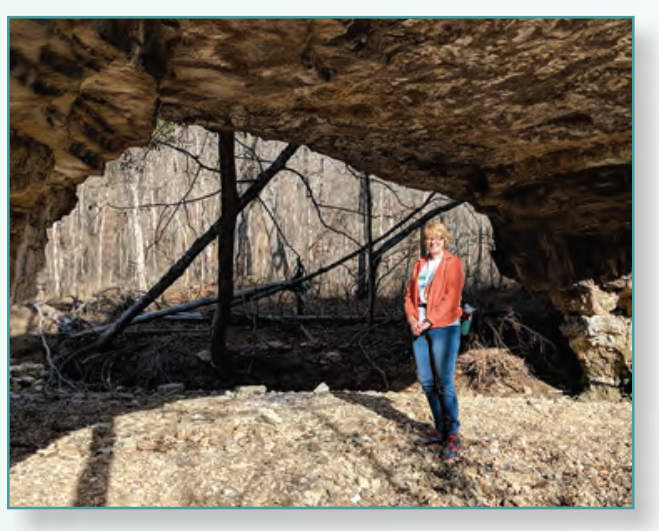
based on a person's current circumstances.

As the director of the National Geospatial Technical Operations Center, I oversee operations to support and maintain seamless and current coverage of geospatial data for the United States. These data are used to produce topographic maps and other digital and graphic products. 


\section{Soupy Dalyander}

\section{Research Oceanographer at the St. Petersburg Coastal and Marine Science Center in St. Petersburg, Florida}

"I am among those who think that science has great beauty." - Marie Curie

I was lucky to have many people who inspired, supported, and encouraged me to go into science. My seventh grade science teacher, Mrs. Douglas, had a real knack for making us question what we were assuming we could and couldn't do, and why. For instance, I used to joke that I was going to be the starting first base(wo)man for the Chicago Cubs (don’t worry Rizzo, your job's safe from me). She wouldn't let me get away with thinking I couldn't do something I wanted, even in jest. She asked me, in all seriousness, "Why not?" Later on, in high school, my physics teacher, Mr. McLay, had a gift for making science fun and interesting. It made me feel I could do the same, which has made me enjoy research for all these years.

At the USGS, I study how the nearshore and continental shelf change over time, looking at how water and sand move and change the beach and the seafloor near the shore. I study how barrier islands evolve and how ecosystem restoration decisions may affect coastal communities and habitats. My work has also included studying the movement of sand and oil clusters that formed in the northern Gulf of Mexico during the Deepwater Horizon oil spill and providing information to help their cleanup.

Away from work, I like to spend time with my family, enjoying the outdoors. My husband and I have taken up sailing in the past few years since moving to Florida, though I wish I could get back to the mountains more to hike and camp. I have a tendency to pick up location-specific hobbies, which is perhaps unfortunate given my propensity to move around a lot (shocker, I've had to give up snowboarding and hiking in the mountains since moving to Florida). I'm also a Girl Scout troop leader and I enjoy spending time getting youth involved in science, technology, engineering, and mathematics through the troop and through elementary school outreach.
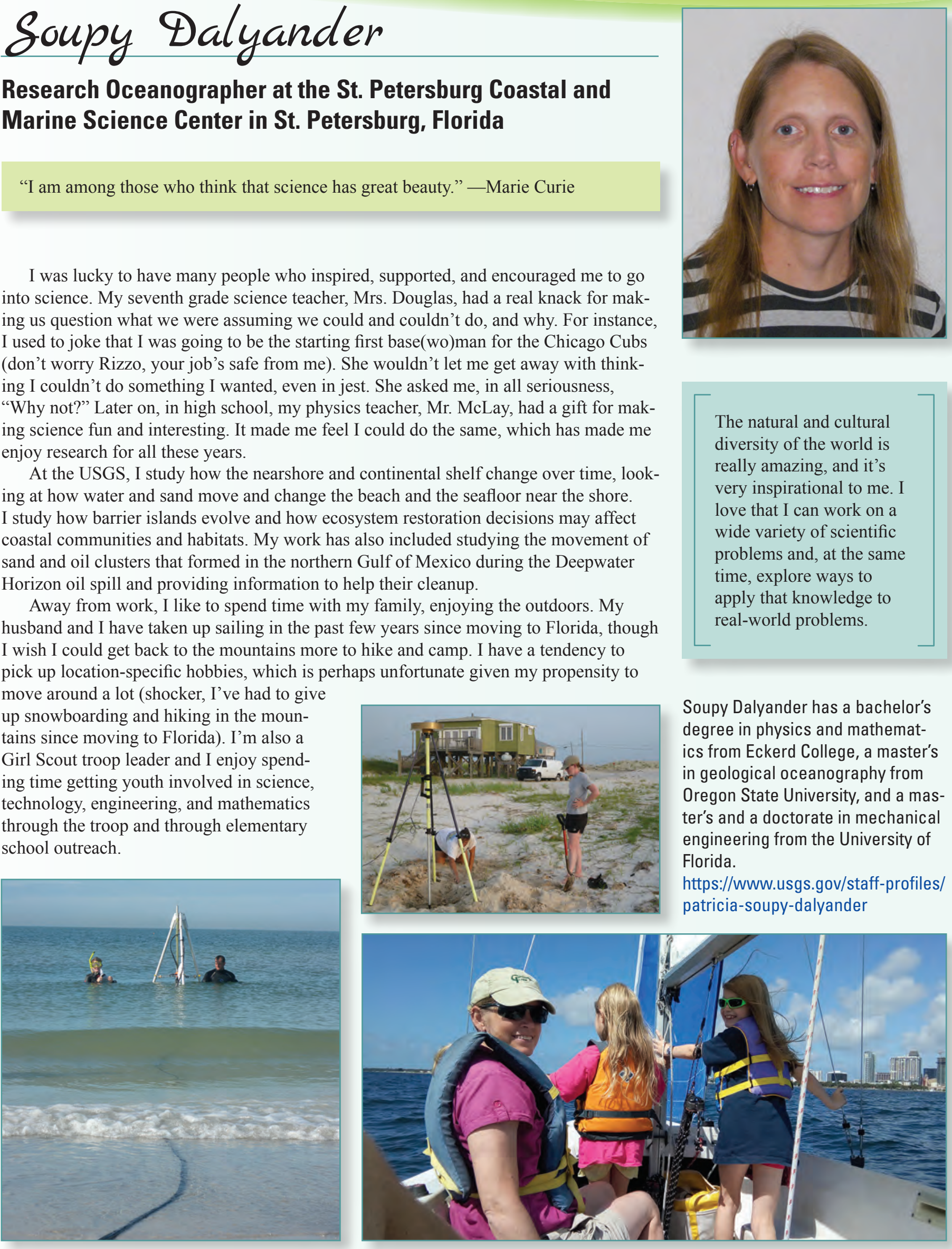

The natural and cultural diversity of the world is really amazing, and it's very inspirational to me. I love that I can work on a wide variety of scientific problems and, at the same time, explore ways to apply that knowledge to real-world problems.

Soupy Dalyander has a bachelor's degree in physics and mathematics from Eckerd College, a master's in geological oceanography from Oregon State University, and a master's and a doctorate in mechanical engineering from the University of Florida.

https://www.usgs.gov/staff-profiles/ patricia-soupy-dalyander

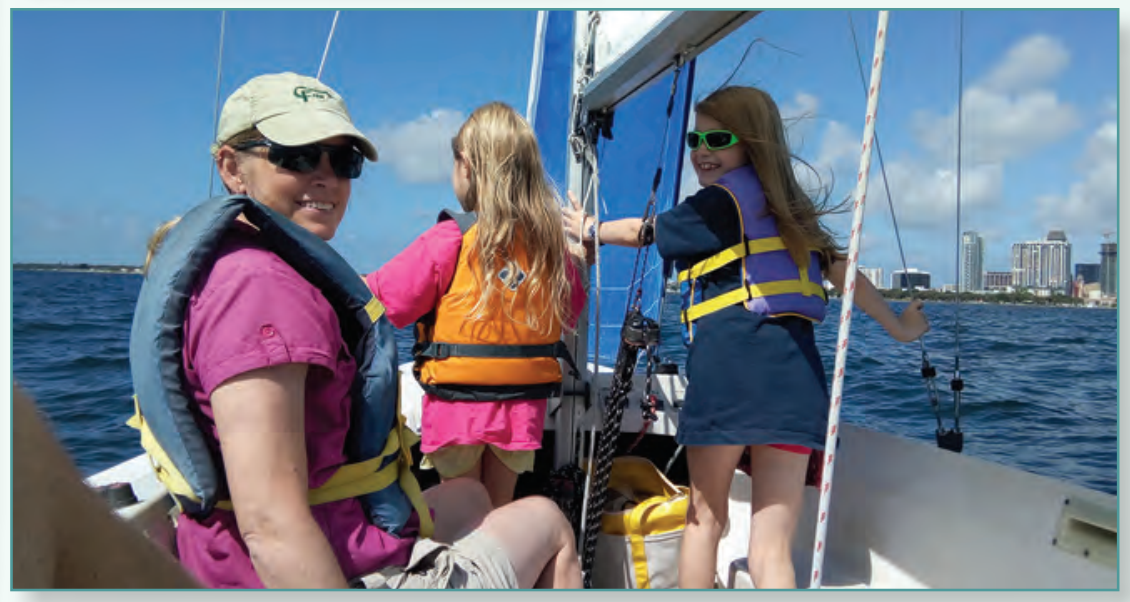




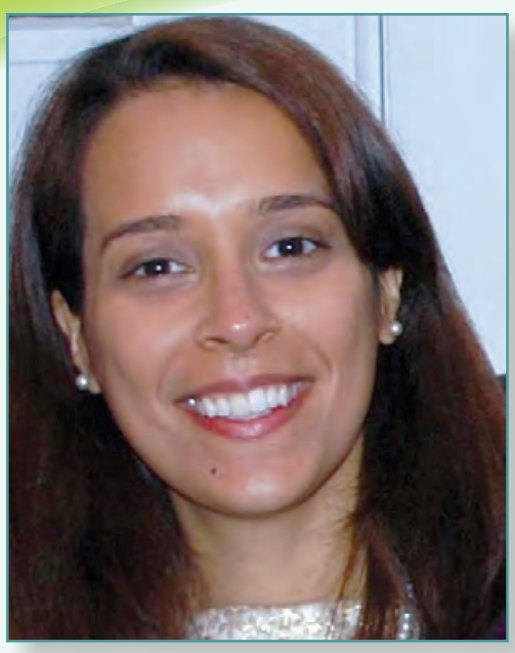

Thanks to supportive leadership, I was given the opportunity to delve into programs such as capital planning where I was responsible for managing the bureau's \$145 million IT portfolio; I was also a lead on the financial analyses, making sure that the USGS met our targets on initiatives like sequestration and the campaign to cut waste.

Shari DeLung has a bachelor's degree in sociology and crime deviance from the Virginia Polytechnic Institute and State University (Virginia Tech).

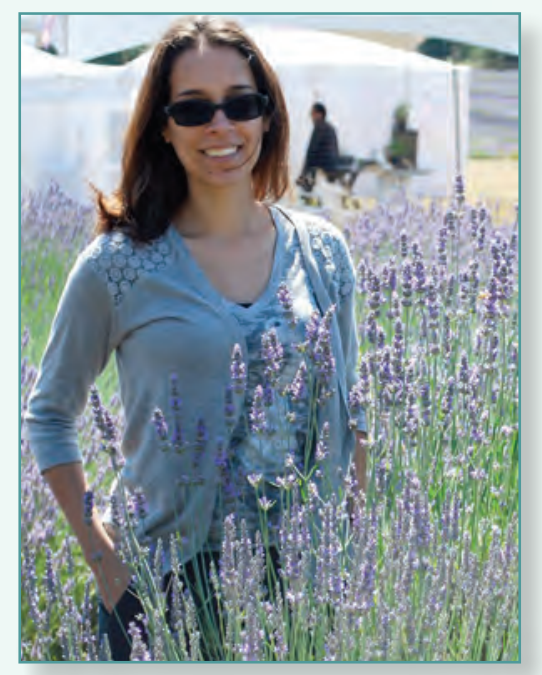

\section{Shari Delung}

\section{Management Analyst in the Office of Administration in Reston, Virginia}

The USGS runs in my family. My mom recently completed a 27-year career with the bureau. She spent a majority of those years working in accounting and finance, and I spent many evenings and weekends in her office throughout my childhood "helping" her. At the time, she would have 3-foot-high dot-matrix printer reports all over her office, inscribed with what looked to me like a secret numerical language. Mom would take a few minutes to explain the reports to me and I would follow up with a thousand repetitions of, "Why?" Her team members would come in and out of her office during those times, bouncing questions and ideas off of each other. I was in awe over their dialogue and knew I wanted to be involved in something that important when I grew up. The best part of those days, aside from spinning in her guest chair, was when she finished with a report and would let me rip the holey sides off the dot-matrix paper and "decorate" her office with the ribbons. I look back on those days with fondness. Without a doubt, my mom has been the guiding force in my life, and I always keep her in mind whenever I'm contemplating a career decision.

One of my first jobs as a student for the USGS was to inventory dozens of boxes that contained glass plates used to produce photographs of early USGS leaders. Since then, I've worked on many information management programs and have led financial analyses to help ensure the USGS was on track to meet its goals relating to various Presidential initiatives. As the USGS conference coordinator, I help employees navigate various conference policies to help them share USGS science at scientific and professional meetings. I also lead teams of leaders and managers to create a line of communication between science and administrative programs. My favorite part of my job is getting to work with employees across the country and throughout all mission areas and regions. I'm passionate about helping USGS employees navigate administrative policies to ensure their scientific endeavors are successful.

Outside of work, I love reading, cooking, and spending time with my family and friends. Living in the D.C. suburbs, there is no shortage of fun activities; my family and I get to experience everything the city has to offer, from the culture to the food, shows, sports, and museums. When we need a break from the fast-paced life of the area, the mountains and the beach are not too far away. I'm also an avid follower of Virginia Tech football. Go Hokies!
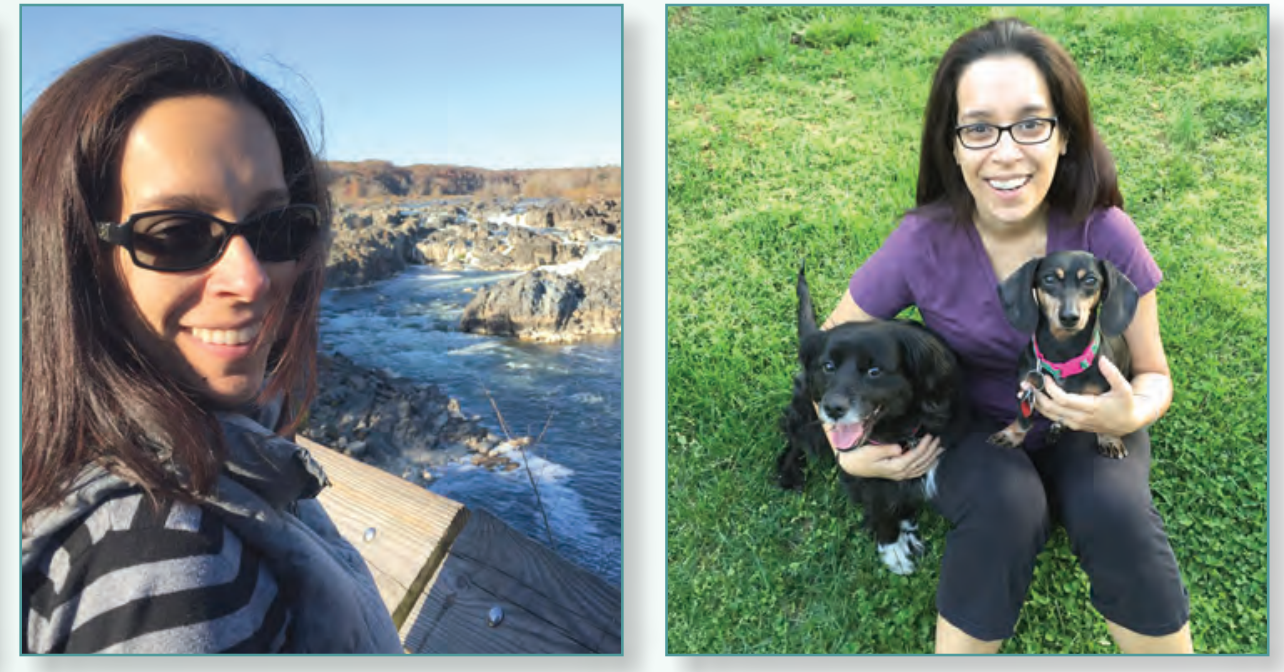


\section{Aimee Devaris}

\section{Regional Director for the Alaska Region in Anchorage, Alaska}

"You must do the thing you think you cannot do." - Eleanor Roosevelt

I was born in Warren, Ohio, but my family moved to El Paso, Texas, when I was in elementary school. The following spring, a very large, long-track tornado tore through northeastern Ohio and northwestern Pennsylvania near our former home. A friend sent me the local newspaper covering the storm damage, and I could not believe the pictures of the destruction and the stories about that day. The mall where we shopped, the pancake house where we occasionally ate, and the roller skating rink where my sister and I skated were destroyed. Eighteen people lost their lives. This event sparked my interest in atmospheric science. More specifically, it triggered my fascination with natural disasters, and I wanted to understand how to make them more predictable and avoidable.

As a meteorologist in the National Weather Service (NWS), I was part of a public awareness program to educate people and reduce death, injury, and property damage or loss caused by severe weather and other hazards like tsunamis in Alaska, and I worked to provide better information and services to the public and scientific community. I then gained national-scale management experience at the NWS headquarters back east and later returned to Alaska to become the regional director before moving into the same role in the USGS. My science background has been important to my understanding of the mission areas of the USGS and our capacity and potential for future work, but equally important has been my leadership and management experience. This experience has helped me bring a fresh perspective to the USGS for planning, organizing, and implementing our science strategies and programs.

In my spare time, I love hiking the Chugach Mountains and fishing, kayaking, and scuba diving in the ocean. I got my dive certification 20 years ago in Juneau, Alaska, in 38-degree water in a dry suit! These days, I prefer diving in Hawaii. Living in Alaska, I have the wonderful opportunity to enjoy both sunrise and sunset within a short 5- to 6-hour span at the beginning of winter, and I am completely captivated by the aurora borealis.

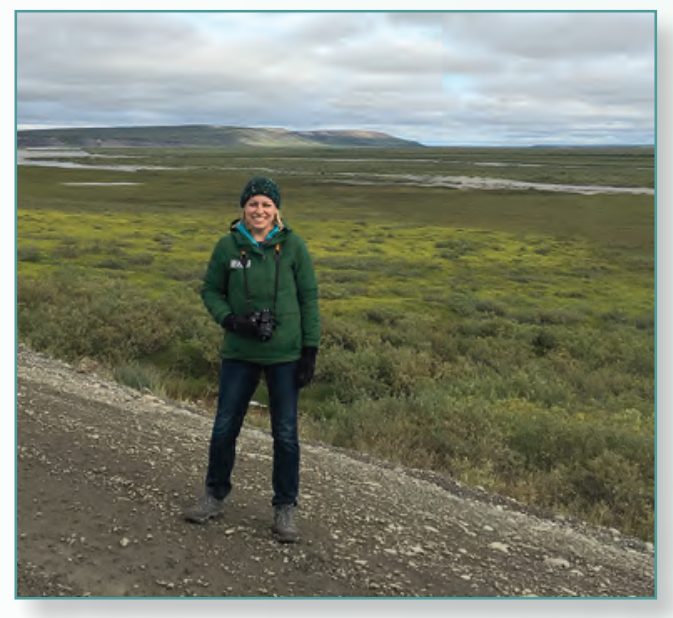

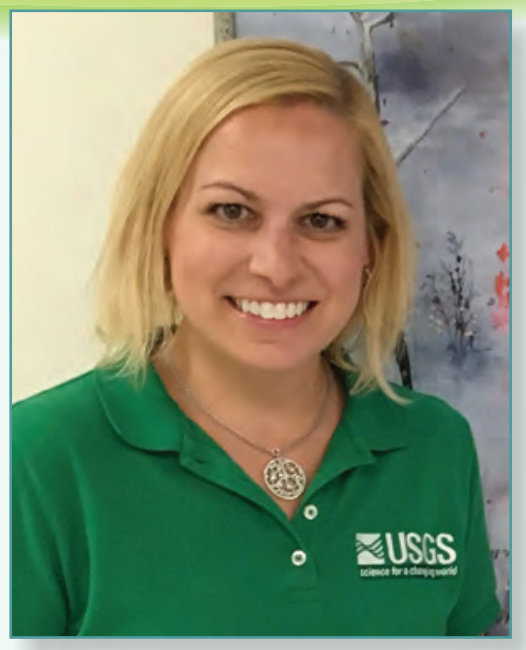

I'm always looking up in the sky for one reason or another, and now I find my son doing the same thing. He says he wants to be a scientist, too, which makes me very happy.

Aimee Devaris has a bachelor's degree in atmospheric sciences and meteorology from Texas A\&M University and a master's in engineering and science management from the University of Alaska, Anchorage. https://www.usgs.gov/staff-profiles/ aimee-devaris

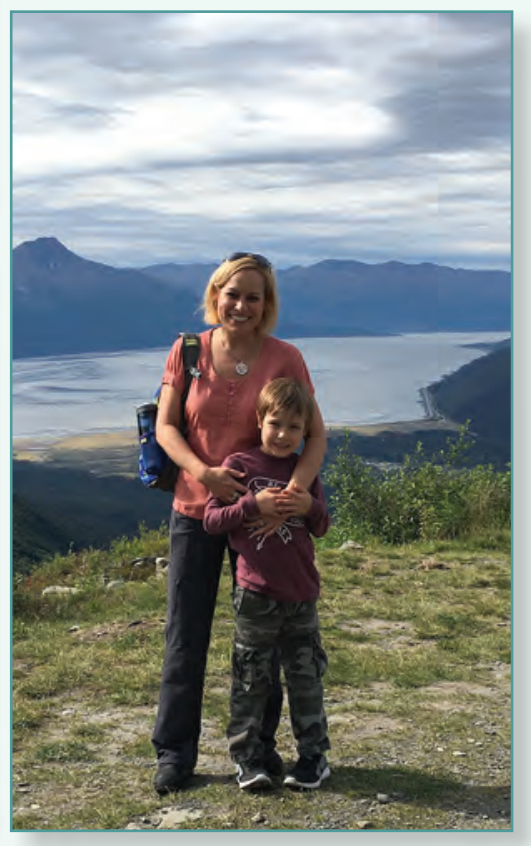




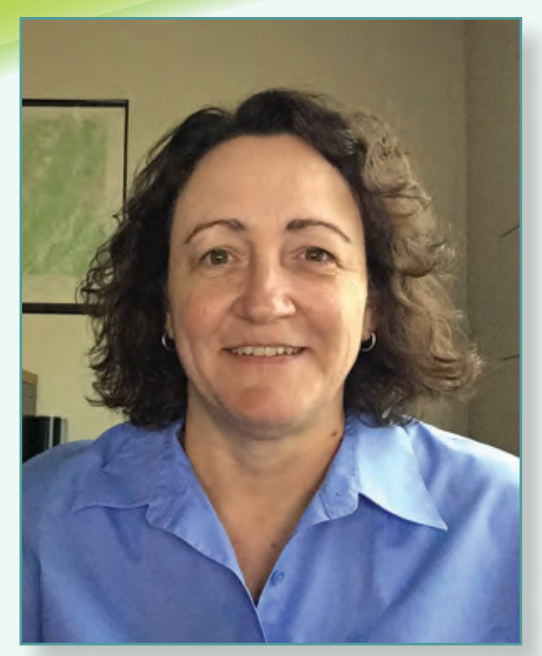

Take advantage of opportunities to gain new skills and abilities; they can lead you to places you hadn't previously considered. Explore nature and the world around you.

Claire DeVaughan has a bachelor's degree in geography from Frostburg State University.

https://www.usgs.gov/staff-profiles/ claire-devaughan

\section{elaire DeVaughan}

National Map Liaison for the National Geospatial Program in Austin, Texas

My parents were avid hikers and travelers, and they had an easily accessible collection of maps, so I was exposed to maps and navigation at an early age. Studying maps was a big part of every family trip. I was introduced to USGS topographic maps by my mother, as she had some maps of favorite areas in Virginia where she had hiked, or places she wanted to visit, such as the Grand Canyon and Yosemite. My mother and I took a month-long cross-country drive when I was 16, which allowed me the opportunity to find interesting and scenic routes for us through the western states and to navigate while she drove through cities like Chicago, Las Vegas, and St. Louis.

As a child I drew maps of my neighborhood and places we went on vacation. I took a world geography class in ninth grade, which was the most fascinating class in my high school experience. As an undecided major at college orientation, I decided to take a physical geography course my first semester, which was even more interesting than the class in high school. I declared a major in geography soon after. Living near the USGS headquarters at the time, I was lucky enough to be able to get an internship while still in school and living at home.

I am a cartographer in the National Geospatial Program, working with partners and users of The National Map to improve its data, products, and services. I have worked in support of the 3D Elevation Program, creating video lessons that are hosted on the USGS YouTube channel, researching names for the U.S. Board on Geographic Names, maintaining geographic databases, producing thematic maps, designing websites, and collecting and editing data for digital mapping services.

I'm an avid motorcyclist, having recently done a 12-day tour around South Island of New Zealand, as well as several long-distance trips to the east coast of the United States and through the southern Rockies and frequent trips throughout Texas.
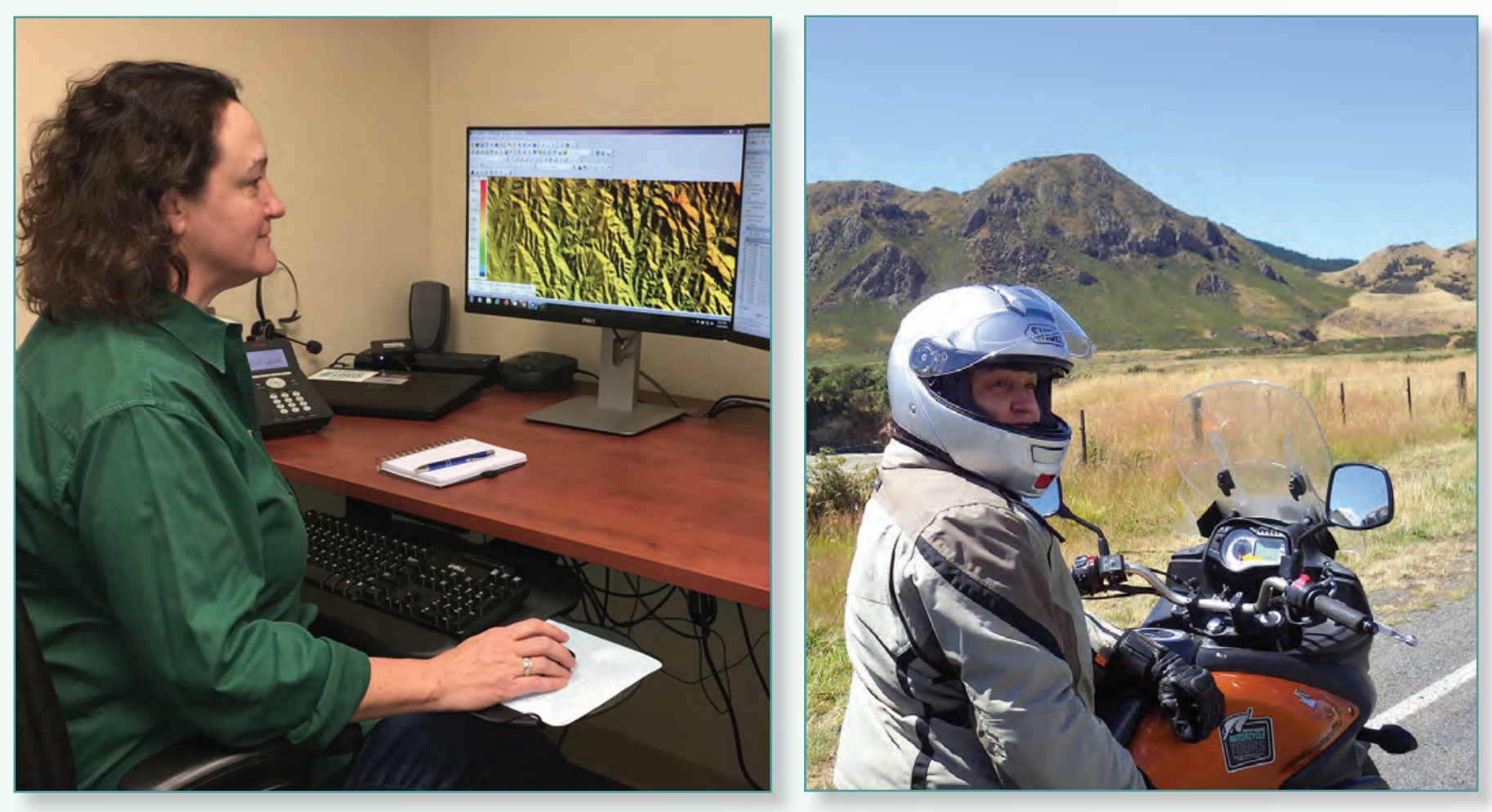


\section{Kim Dibble}

\section{Fish Biologist with the Grand Canyon Monitoring and Research Center in Flagstaff, Arizona}

"Do not let anyone tell you that these people made work of play. They simply realized that the most fun lies in seeing and studying the unknown." - Aldo Leopold

It's hard for me to remember when I first decided to become a scientist; science was in everything I did. Being the daughter of both a researcher and an avid gardener, the majority of my youth was spent in my father's research lab or picking and shucking dreadful quantities of peas from the garden for my mother. Although not opposed to video games, my parents encouraged me and my sister to play outside and instilled a strongly independent streak in us. This was not always a good thing because we frequently got into trouble for swimming in forbidden water holes, running through fish raceways, and feeding marshmallows to alligators, which was probably illegal.

In college, I spent my summers studying mussels, bugs, and fish in rivers; I loved the freedom of being able to explore a variety of environments but also began to recognize that we humans affect our world. As a sophomore, I was stationed at a remote research lab north of the Arctic Circle, studying the influence of climate change and warming permafrost on river food webs. Ironically, my team was using oil pipeline roads that crisscrossed the landscape for our study, and it was not lost on me that the burning of the contents of those pipelines accelerated the warming I was in Alaska to study.

I am now studying the influence of dam operations on fish populations in rivers across the western United States. My job allows me to contribute applied science to an adaptive management program, effectively combining my interests in science and public policy to promote ecosystem function in one of the most altered river systems in the world. In an interesting twist to my career, I have picked up some modeling skills that I'm using to predict how river temperatures and fish will respond to a warmer and drier climate in the future.

My passion for science has not subsided but has been emboldened by the recent birth of my two children. I have a feisty son who likes to roar like a dinosaur and a daughter who has already mastered her "fishy" face and is ready to take on the world. Neither could truly understand how much they mean to me and how much they've changed the focus of my life. My science is now for my children and all the kids of their generation so that we can give them the chance to explore nature as my sister and I did when we were kids.
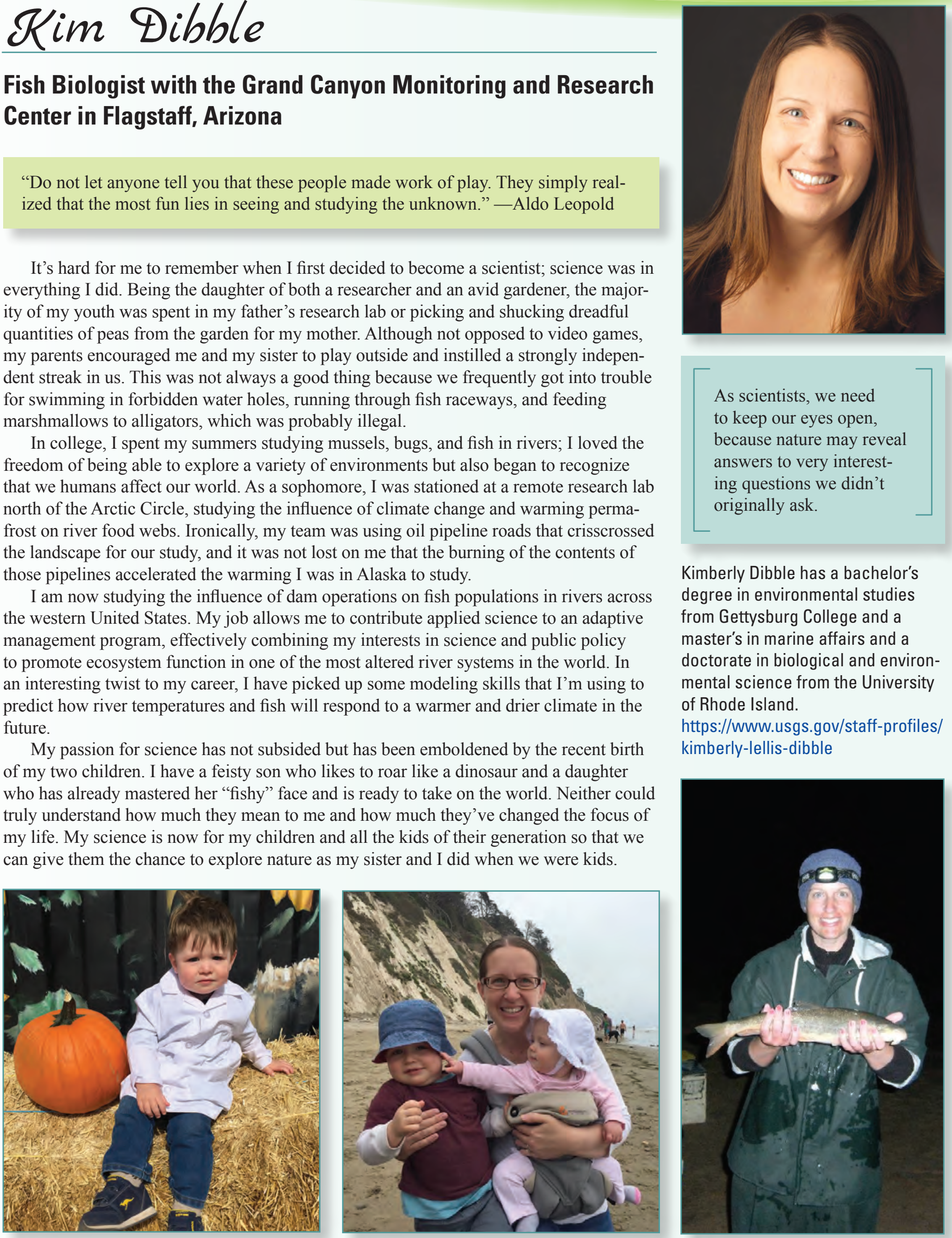

As scientists, we need to keep our eyes open, because nature may reveal answers to very interesting questions we didn't originally ask

Kimberly Dibble has a bachelor's degree in environmental studies from Gettysburg College and a master's in marine affairs and a doctorate in biological and environmental science from the University of Rhode Island.

https://www.usgs.gov/staff-profiles/ kimberly-lellis-dibble

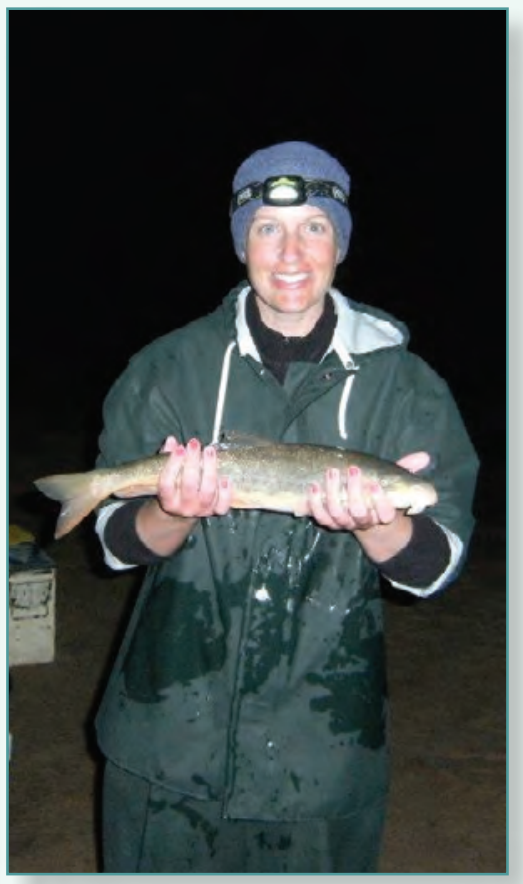




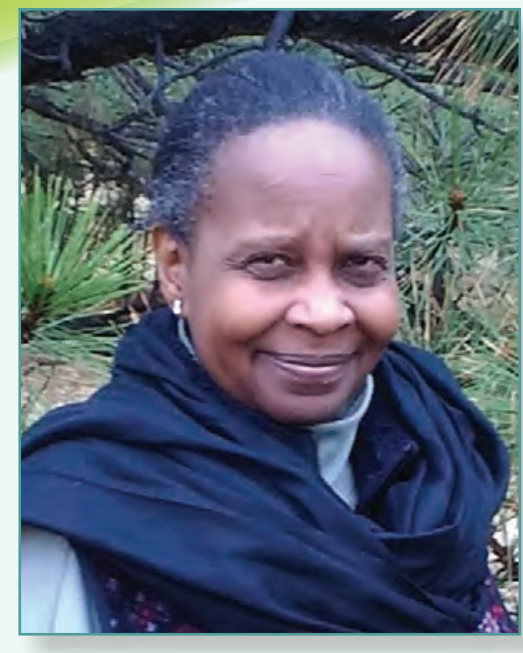

In my career, I've been fortunate to witness the effect of USGS science and mapping on planning efforts and educational opportunities for entities in the United States and their international partners. The most enjoyable part of my job has been building relationships and supporting those who build relationships.

\section{Sherry Durst has a bachelor's} degree in geography from the University of Colorado at Denver. https://www.usgs.gov/staff-profiles/ sherry-durst

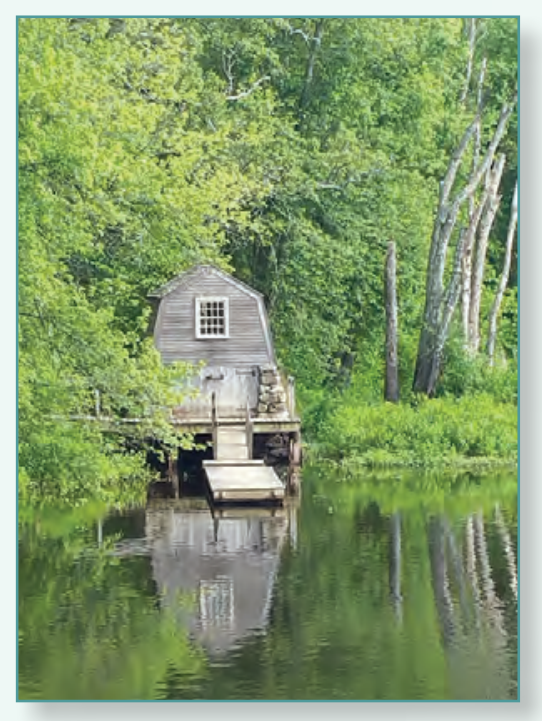

Sherry Đurst

\section{Project Manager with the National Geospatial Program in Denver, Colorado}

\begin{abstract}
"Let yourself be silently drawn by the strange pull of what you really love. It will not lead you astray." - Rumi
\end{abstract}

I've always been an avid reader. Even as a child, whenever a location was mentioned in a storybook, I wanted to discover where it was on a map. Of course in those early days, many of the book locations were entirely fictional and couldn't be found on any map, but that didn't dampen my interest in knowing where things happened in relation to me and my world. My parents supported this fascination with maps and globes. For example, when we prepared for family vacations, I loved helping my parents work out our travel route using a road atlas. Even when we weren't planning a trip, I'd sometimes pick up the atlas, choose a random State and follow the roads with my fingers, stopping only for large cities and big rivers. When mountain roads became squiggles, I felt like my fingers were making invisible works of art. Names of locations were no longer fictional. Truth or Consequences, N.M., was one of my favorites.

In my early days with the USGS, I took the geology mapped in the field by geologists and transferred it onto greenline mylar quadrangles, at the same time learning basic drafting techniques and picking up some geology in the process! I went on to create topographic maps and have been helping others learn about mapping at the USGS and how mapping services can help with earthquakes, landslides, flooding, humanitarian assistance, and international cooperation.

Reading continues to be a hobby, but I also enjoy going to museums, learning anything about trains, and getting "lost" on country roads and finding my way home. One of my great loves is trains; whenever I stand on railroad tracks, I wonder where they lead and what the terrain is like that supports the tracks and think of those wonderful trains from the past and present. Maps give me the bird'seye view to follow those tracks and let my imagination roam along them.
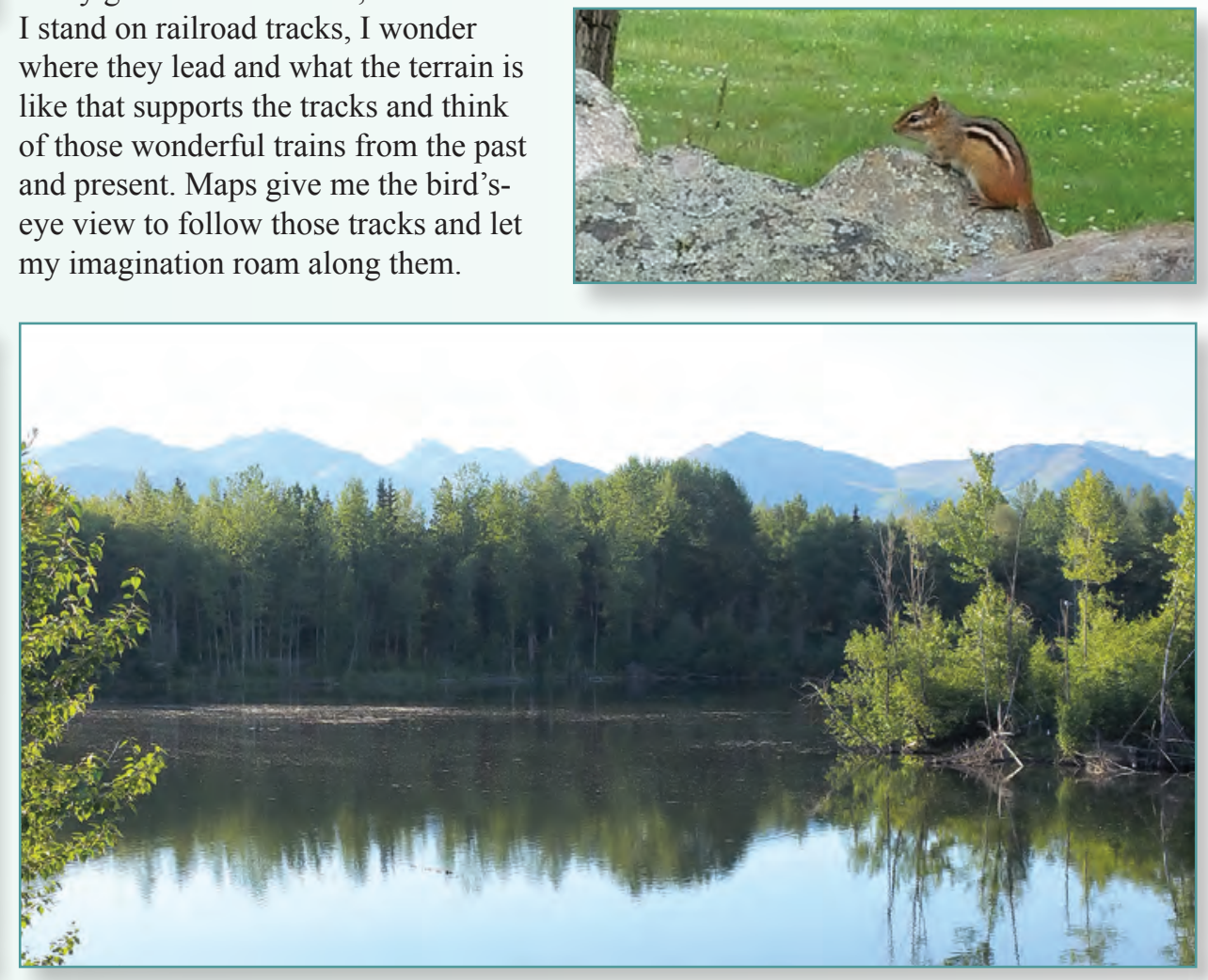


\section{Amy East}

\section{Research Geologist at the Pacific Coastal and Marine Science Center in Santa Cruz, California}

While I was growing up, my Dad, a science enthusiast who had majored in geology, made sure to talk about science often with me and gave me plenty of fuel for the imagination. When I was about seven, he gave me his copy of Tharp and Heezen's map of the floor of the world's ocean and his globe of the Moon; I kept both in my room and loved studying them. He still gives me rocks and fossils most years for Christmas.

My family moved around a lot when I was young; we lived in four countries while I was growing up. This instilled a love of travel in me, and I've now been to more than 40 countries. Seeing many different kinds of landscapes helped develop my perspective on how different kinds of earth-surface systems and processes work. From my first geology class in college, I was hooked on the earth sciences and knew I wanted to make my career in the field. I love looking at how different parts of a landscape are connected, especially rivers and high-elevation mountain ranges.

With the USGS, I've focused on landscapes in the western United States, studying the effects of dams and dam removals on rivers, and effects of dam operations on landscapes and archaeological sites of the Colorado River corridor. My work has taken me from the arid landscapes of the Navajo Nation to study the effects of drought there, to Olympic National Park in Washington to study how changes in climate and ecology may affect the course of river channels, to Hawaii to study the effects of river flooding on the health of coral reefs, and to Alaska, Taiwan, and Ireland to study modern and ancient continentalcrust formation.

My work and personal interests definitely overlap: I'm a whitewater kayaker, and much of my work involves studying rivers. My husband and I also enjoy camping, hiking, and backpacking. We have started bringing our son, who hopes to become a volcanologist, on more and more of our outdoor adventures.
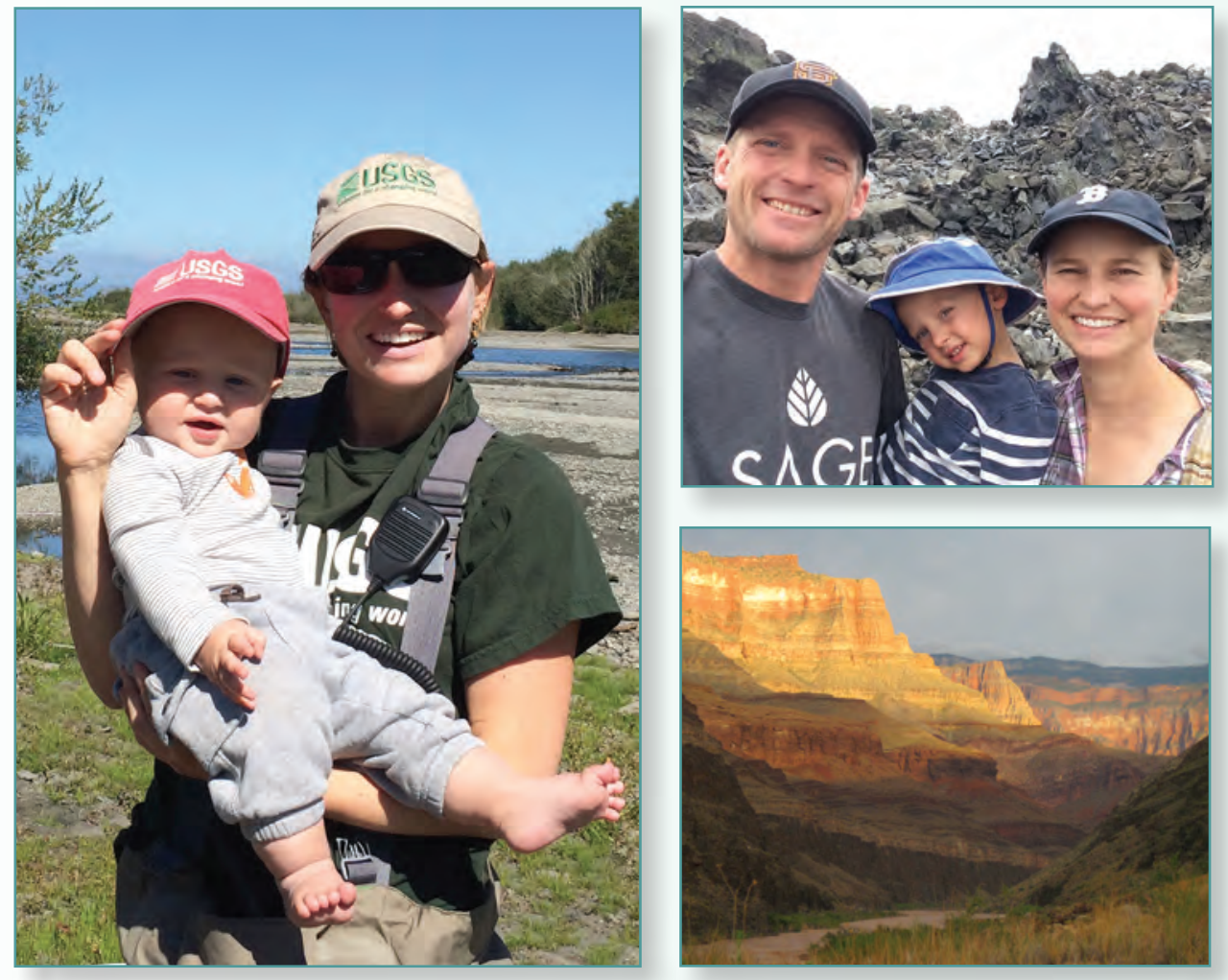

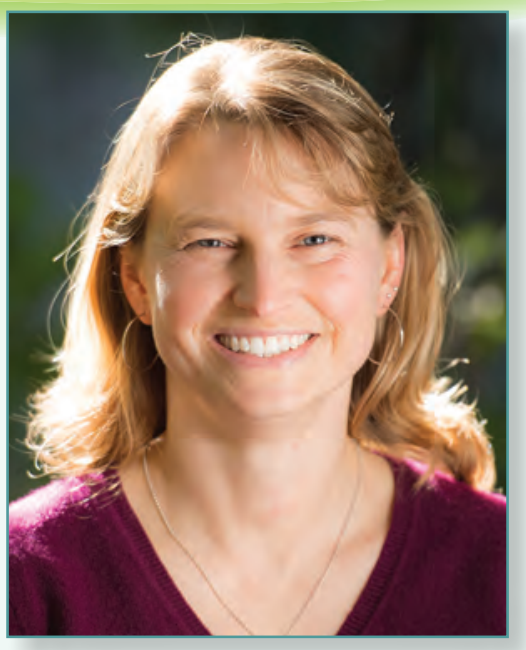

Earth science is fascinating in itself and also in the ways it connects to so many other fields - ecology, atmospheric science, anthropology, and more. The range of scientific topics we can contribute to as earth scientists is essentially limitless.

Amy East has a bachelor's degree in geological sciences from Tufts University and a doctorate in geology and geophysics from the Massachusetts Institute of Technology-Woods Hole Oceanographic Institution joint program. https://www.usgs.gov/staff-profiles/ amy-east

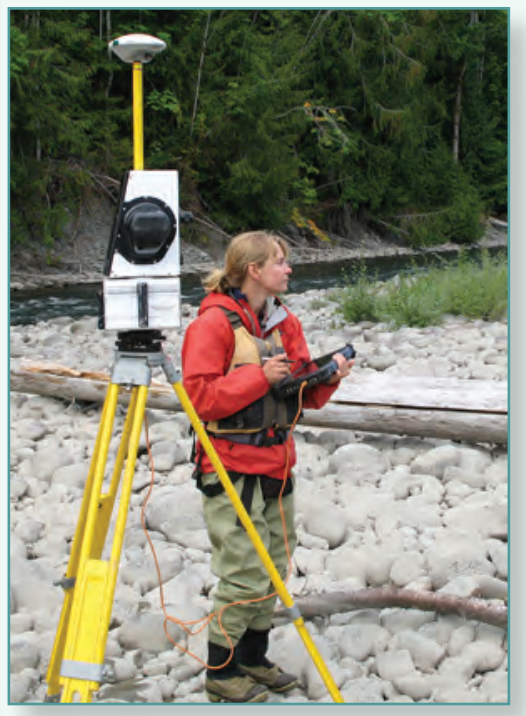




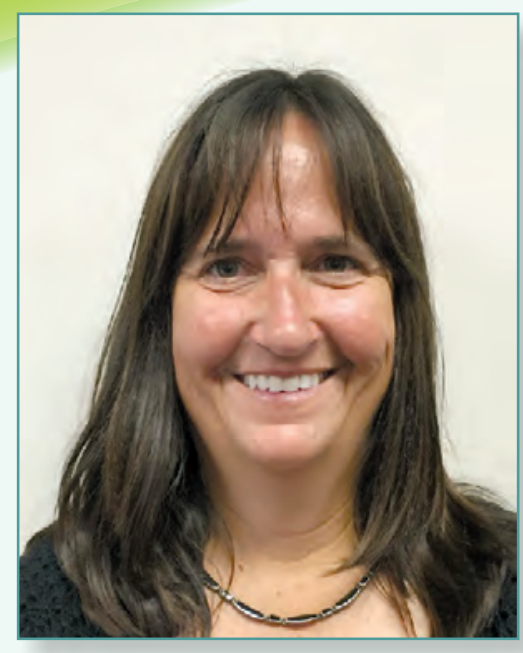

Growing up in a coastal tropical location instilled in me a passion for the water and the creatures that inhabit it. Many of my exotic vacations are centered around exploring nature in, on, or around the water. I've taken two extended adventure trips to the Arctic and Antarctic regions, where I kayaked in both polar localities. In fact, although a different focus, my career is centered around the study of water.

Claudia Faunt has a bachelor's degree in geological engineering, a master's in engineering, and a doctorate in geological engineering from the Colorado School of Mines.

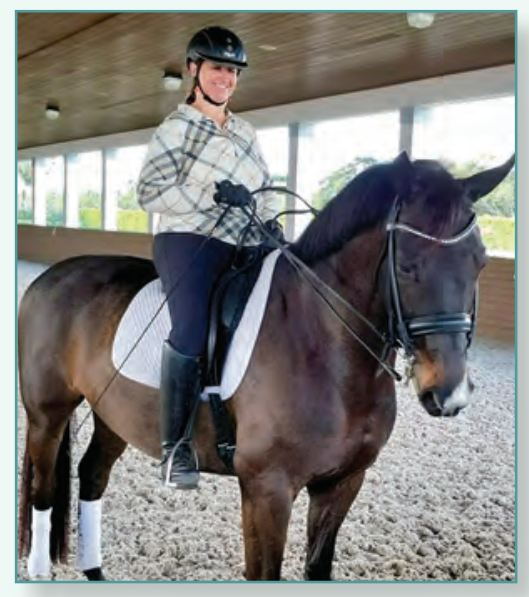

\section{Elaudia Faunt}

\section{Supervisory Hydrologist for the California Water Science Center in San Diego, California}

During my childhood, I explored Florida's countryside and coastal waters and canoed and snorkeled in Florida springs and waterways. I spent my summers at a residential camp nestled in the Blue Ridge Mountains of western North Carolina. At this second home, I had the opportunity to connect with nature and was inspired by hiking in the mountains and putting a paddle in the whitewater of picturesque creeks. These experiences instilled in me an awe of the beauty of nature.

I have wonderful memories of snorkeling among manatees. I grew to share the concern that these passive but comical creatures were becoming endangered from collisions with watercraft. These experiences built on my interest in nature and wildlife and led to my awareness of habitat conservation.

Even though I've always been interested in math and science, reading Rachel Carson's "Silent Spring" at a young age made a lasting impression and further fostered my interest in science and its relevance in stewarding the environment. Building on my childhood experiences in the outdoors, the book made me notice for the first time the farreaching effects humans could have on nature and the environment.

Throughout my career, my interests have been tied to the principles that humans are stewards of the Earth and part of the Earth system, and that they can coexist with nature. The main goal in my studies is to maintain the necessary level of complexity in my work while ensuring that it is still useful to those who rely on it. One highlight of my career was appearing on the news program "60 Minutes" to discuss groundwater and shed light on this largely unseen resource.

After completing my graduate studies, I traveled to the Galapagos Islands and was enthralled with the abundant and diverse wildlife, variations in the landscape, and the excitement of exotic travel. I became an ardent photographer on this trip, and my sense of wonder about nature and insatiable curiosity has led me to travel and photograph nature on all seven continents. Other activities I enjoy are horseback riding, kayaking, snorkeling, swimming, and spending time outdoors. I also enjoy spending time with my rescue boxer, Tyson. He and I take pleasure in our southern California coastal garden, with all its wonderful fruit trees and flowers.
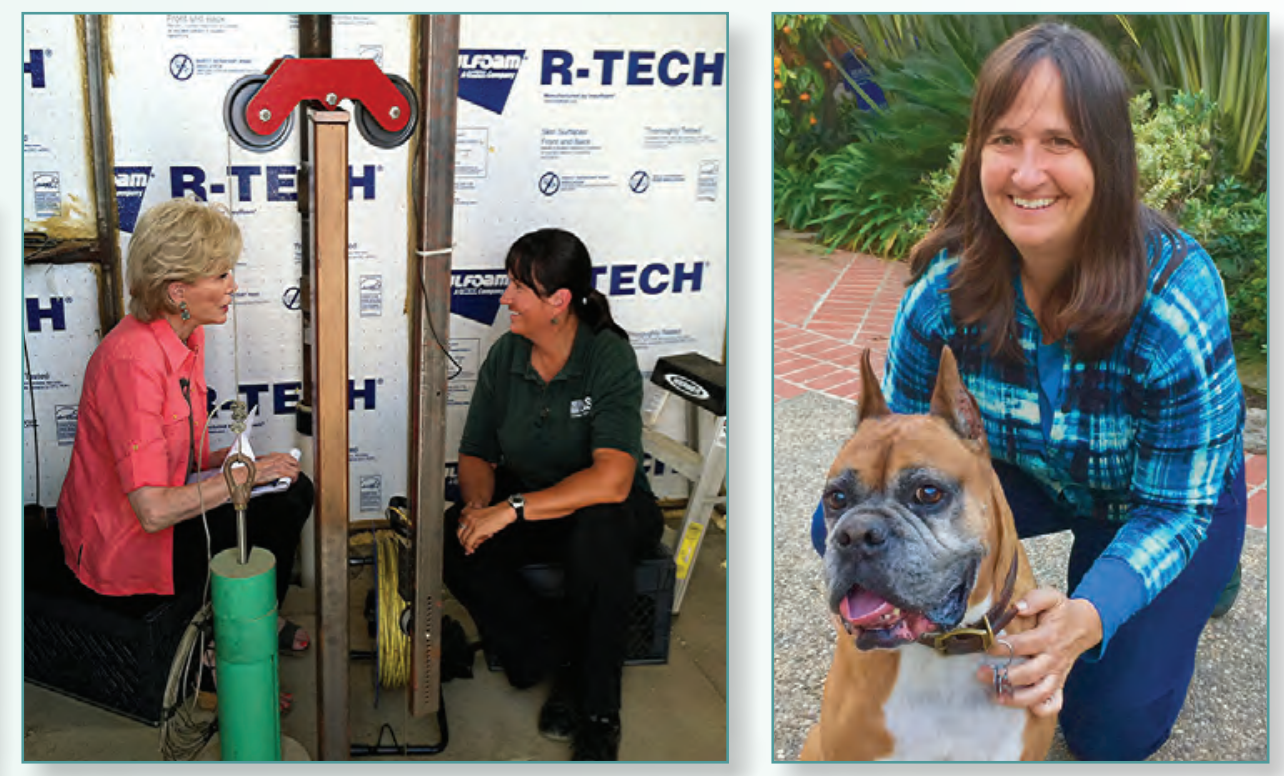


\section{Laura $\mathcal{F l i g h t ~}$}

\section{Hydrologic Technician with the New England Water Science Center in Augusta, Maine}

\begin{abstract}
"When we try to pick out anything by itself, we find it hitched to everything else in the Universe." - John Muir
\end{abstract}

There was never really a question of whether I would go into science or not. Science and math were always my favorite classes starting in the first grade. Growing up, family activities that included fishing, skiing, canoeing, hiking, and generally being outside instilled in me a curiosity and celebration of the out-of-doors and a corresponding impulse to safeguard those places for everyone. To me, the USGS perfectly blended math and science with serving the public and being a steward of the natural environment, so I joined the USGS to serve my home State of Maine.

After my second summer as a student intern, I went on a 3-week field trip to Washington State as part of my college course work. Having only worked in the Maine office of the USGS before, I had not realized the full size of the agency, nor the variety of fields. My colleagues and I met with a volcanologist at the Cascades Volcano Observatory on Mount St. Helens, a hydrologist on the Columbia River, and a bedrock geologist in the channeled scablands in western Washington. That trip made me realize I was part of a much larger and more diverse agency than I'd previously thought, an agency with the goal to collect data that were relevant to the public and that were used to make informed decisions and protect the public.

In my career, I have gone into the field to work on monitoring stations, collected data in streams and on ice, and processed data on groundwater levels, water quality, and rainfall. I've worked on gages that measure the flow of water in streams and rivers in the mountains of Rocky Mountain National Park in northern Colorado, surveyed eelgrass beds on Cape Cod in Massachusetts, measured high-water marks in Connecticut after Hurricane Sandy, and deployed storm-surge sensors at Thunder Hold in Acadia National Park in Maine in anticipation of hurricanes. I also represented the USGS in New England, taking a reporter in a boat to make measurements for a 100-year flood (the type of flood that has a 1-percent chance of happening in a given year).

I am a strong believer in on-the-job training and peer-to-peer mentoring. Over the course of my career, I have become proficient in data, and I'm now testing and leading development of features for the National Water Information System.

When not working, I enjoy mountain biking, hiking, biking, fishing, cross-country skiing, vegetable gardening, and brewing beer. I also enjoy giving back as an active volunteer involved in the maintenance of Appalachian Trail in Maine.
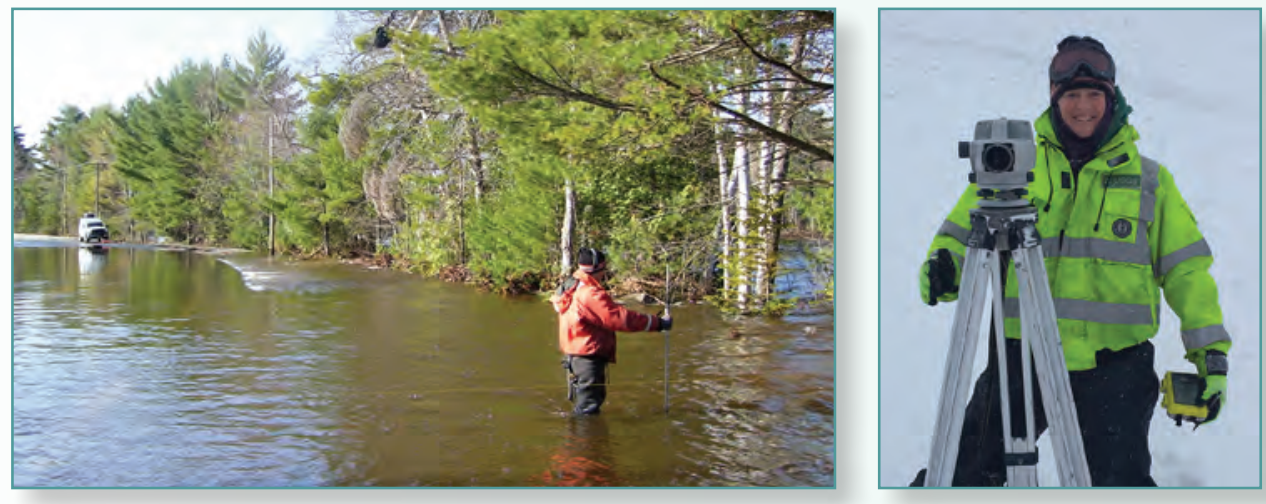

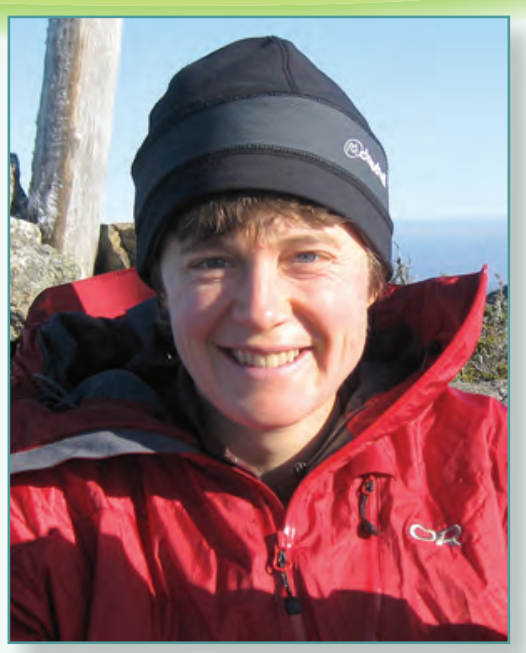

Maine is my home; I enjoy exploring the mountains, waterways, and everything in between in all seasons as well as being close to my family. I love the thriftiness, independence, and wit of Maine people. I'm proud to work in the State I am from and to serve its people.

Laura Flight has a bachelor's degree in environmental studies, with a minor in geology, from the University of Vermont.

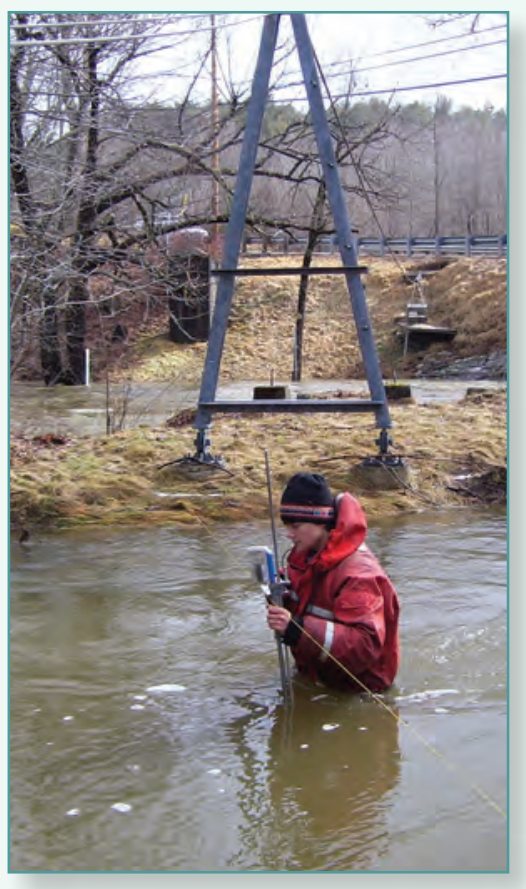




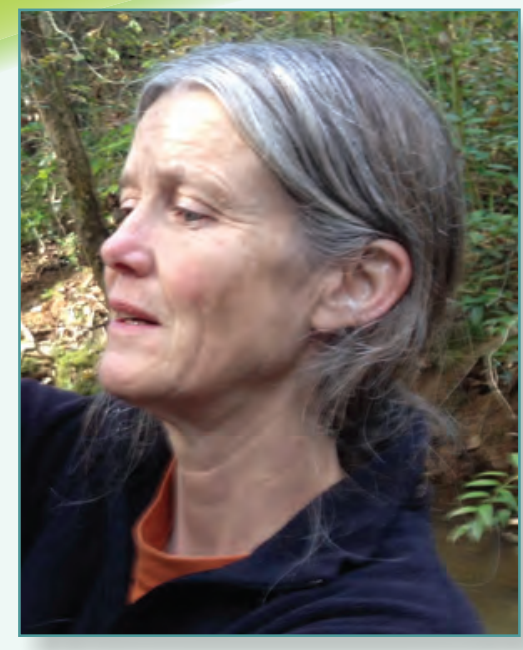

Our continual challenge involves developing the best possible information that can help conserve this rich biological heritage for future generations.

Mary Freeman has a bachelor's degree in biology, a master's in entomology, and a doctorate in forest resources from the University of Georgia.

https://www.usgs.gov/staff-profiles/ mary-freeman

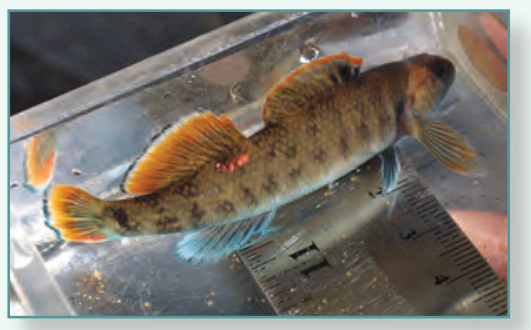

Mary Freeman

\section{Research Ecologist at the Patuxent Wildlife Research Center in Athens, Georgia}

"A pristine stream in a politically unstable setting or with no supporters is not a healthy stream because it is not sustainable." - Judy L. Meyer

From the earliest age I can remember, until my junior year in college, I knew that I would become a veterinarian. But then I started learning the names of dragonflies. The diversity of animals swimming, burrowing, and crawling around in streams and rivers is, to me, endlessly interesting. I was inspired in college by my ecology professors who enjoyed exploring how natural systems work and who, more importantly, encouraged and celebrated that curiosity in others.

Shortly after I completed graduate school, I was surveying fishes in a rocky shoal in a river in southern Georgia, when a fish came up in my fishing net that I knew was something new, an unnamed species! Discovering a new species in a region where fish zoologists had been working for more than a century and where all fish species were thought to have been discovered taught me to entertain even those less probable explanations when interpreting data. I tell students to anticipate making new discoveries and findings beyond anything expected with every study.

I began my Federal career with the USGS at the Fort Collins Science Center field station in Auburn, Alabama, studying the downstream effects of hydropower dams on fishes in the biologically diverse rivers of the southeastern United States. I later joined the Patuxent Wildlife Research Center at the field station in Athens, where I work on issues related to management and conservation in freshwater ecosystems. Working with the USGS has given me the opportunity to explore the ecological processes that support biological diversity and the ability to work with USGS biologists, university scientists and students, resource managers, and nongovernmental organizations. I have documented surprising biological resilience as well as species declines. My goal is to provide managers and stakeholders the information they need to identify options for conserving freshwater biological diversity even as competing demands for water intensify and land use and climate are changing.

In my free time I enjoy canoeing and hiking, donning mask and snorkel to watch fishes in clear mountain rivers, botanizing, and photographing birds and, of course, dragonflies.
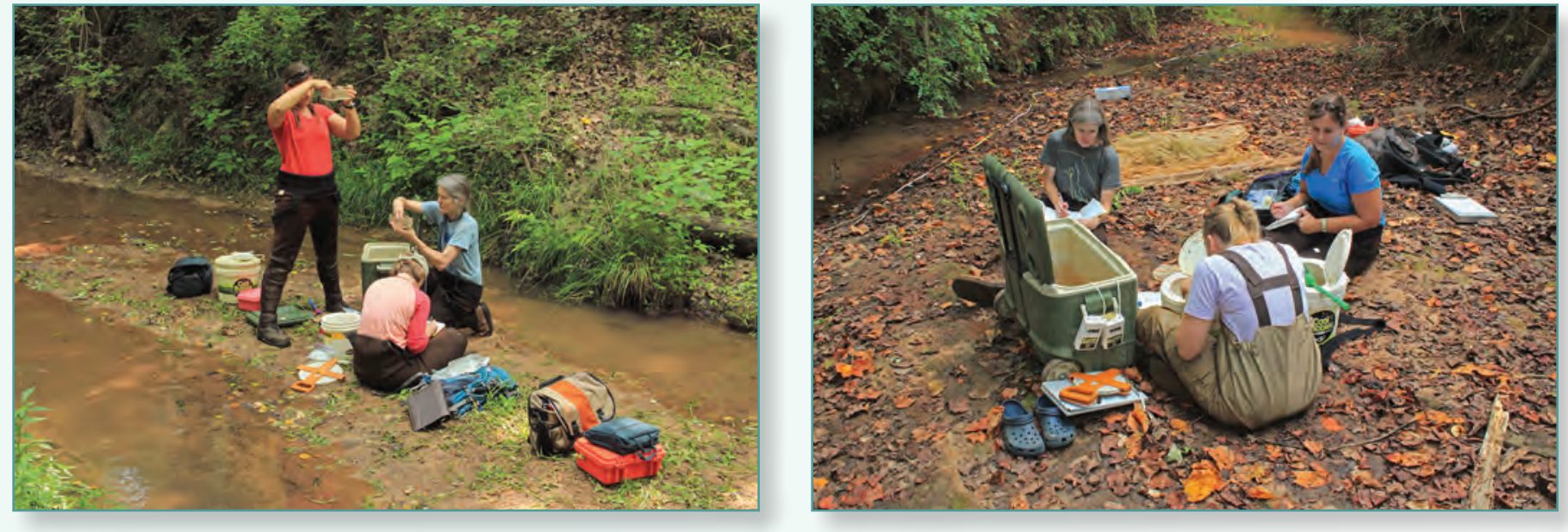


\section{earol (Fritz) Fritzinger}

\section{Logistics Operations Specialist with the Grand Canyon Monitoring and Research Center in Flagstaff, Arizona}

"We must begin thinking like a river if we are to leave a legacy of beauty and life for future generations." - David Brower

As far back as I can remember, I was always drawn to nature and being in the outdoors. I was one of those tomboy kids always playing in the dirt and chasing butterflies. My interest in nature was definitely fostered by my father, who read to me not just children's books but books about science, nature, and all kinds of beautiful natural places around the world. I remember being laughed at by my third grade class, including the teacher, when trying to explain that wildfires could actually benefit forest ecosystems, an idea which was quite forward thinking for the 1960s. The information had come from my father reading to me about recent studies of forest ecosystems. Having a father who encouraged me to learn and understand instead of just accepting "common knowledge" was instrumental to my development as a scientist.

During my senior year in high school, I was chosen to participate in a 3-week Student Conservation Association program in Canyonlands National Park in Utah, which opened my eyes to the magic of the desert in the Southwest and later in life lured me there to the wild and open spaces. In my high school yearbook for my senior year, I was named the "environmentalist" with a full-page picture of me wearing my trusty backpack!

While in college, I went on backpacking and river-running excursions in the Grand Canyon, and the river took my heart. I have spent most of my adult life working on the river, first as a commercial river guide and now working for the USGS as the Grand Canyon Monitoring and Research Center logistics manager. I organize as many as 20 to 30 research trips each year to the Grand Canyon and helicopter activities in the Little Colorado River and work with scientists from many disciplines, including geomorphologists, hydrologists, fishery biologists, aquatic ecologists, plant ecologists, and social scientists. I have a love of working with young people and engaging them in outdoor experiences, and I founded the Grand Canyon Youth, Inc., a nonprofit organization whose mission is to provide youth an experiential education along the rivers and canyons of the Colorado Plateau in an effort to promote environmental awareness.

I love playing in the outdoors every chance I get; I love to walk, cross-country ski, bike, and kayak. I am also an avid gardener and volunteer at two community gardens in addition to nurturing a huge vegetable and flower garden of my own at home. Working with USGS scientists has allowed me to foster my interests in learning about the Grand Canyon ecosystem. Having recently developed an interest in bats, I started a citizen science project to study the role of bats in the river environment.
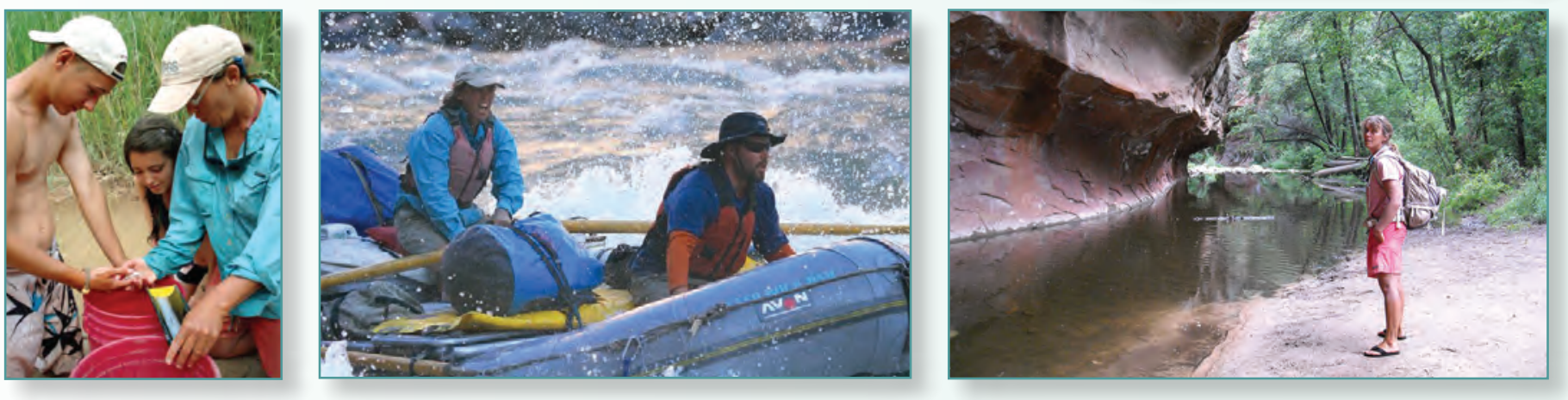

Curiosity for the natural world drives my passion for learning, teaching, and enjoying life.

Carol Fritzinger has a bachelor's degree in natural history and outdoor program leadership from Prescott College.

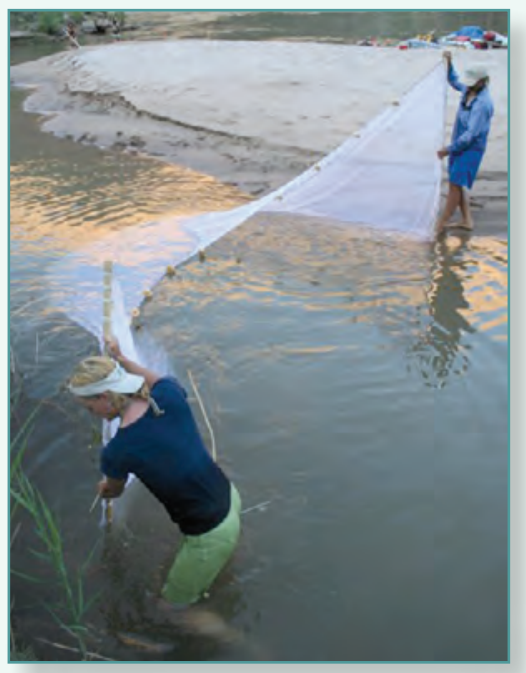




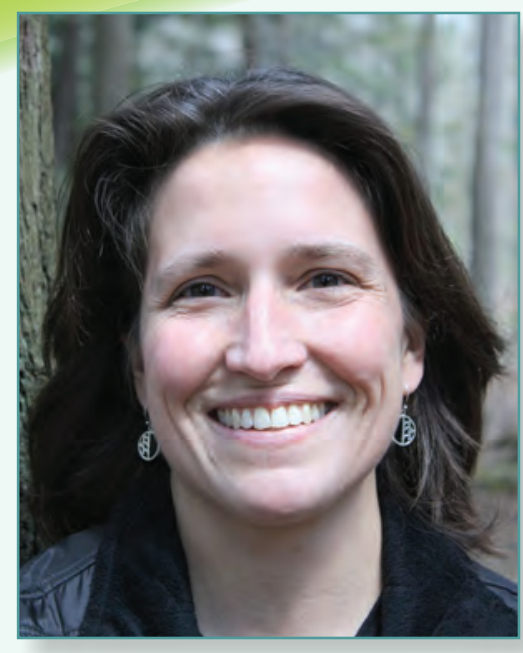

I get to work with an incredible group of graduate students, colleagues, resource managers, biologists, and local communities with the rewarding outcome of informing decisions that help manage wildlife species and conserve some of the most biodiverse places in the world.

Angela Fuller has a bachelor's degree in environmental studies from the University of Maine at Machias and a master's and a doctorate in wildlife ecology from the University of Maine.

https://www.usgs.gov/staff-profiles/ angela-fuller

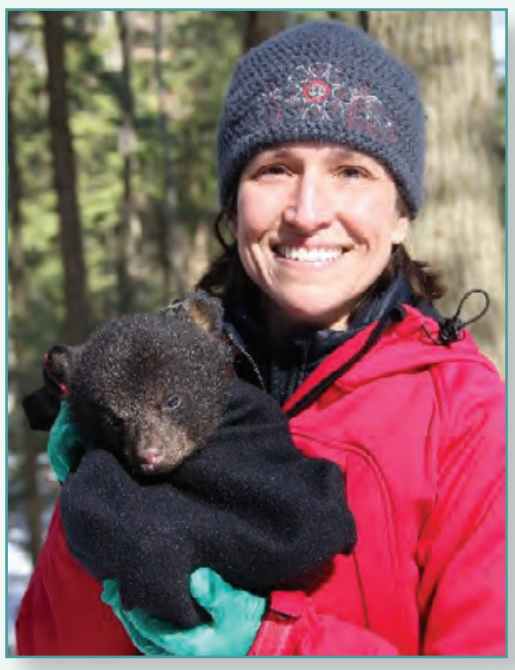

Angela Fuller

\section{Wildlife Ecologist at the New York Cooperative Fish and Wildlife Research Unit in Ithaca, New York}

In high school I really enjoyed science and math classes, and for some reason I thought that the only reasonable career option that used both was to become an engineer. It was not until I switched majors three times as an undergraduate that I discovered an amazing career, that of the wildlife ecologist, and knew I had found my calling.

The field work in my job can be particularly exciting; I capture and fit black bears with radio collars that allow us to monitor their movements, or use scat-detection dogs that sniff out moose scats, allowing us to use genetics to determine which individual left the scat, which we use to estimate the population size.

My research has one unifying theme: to provide information that helps in the conservation and management of wildlife species and has an effect on how wildlife are managed. My research has revolved around how land use and land cover influence the abundance or movements of mammals as well as predicting how different resource management strategies might help natural resource managers and decision makers achieve their conservation or management objectives. My recent work has focused on decision making for managed species, such as white-tailed deer, wild turkeys, and fishers; balancing human activities with conservation of endangered Andean bears in Ecuador; and developing new methods for sampling and monitoring wildlife populations, such as black bear, moose, mink, and fisher. I also teach graduate-level classes in ecology-related topics and mentor graduate students.
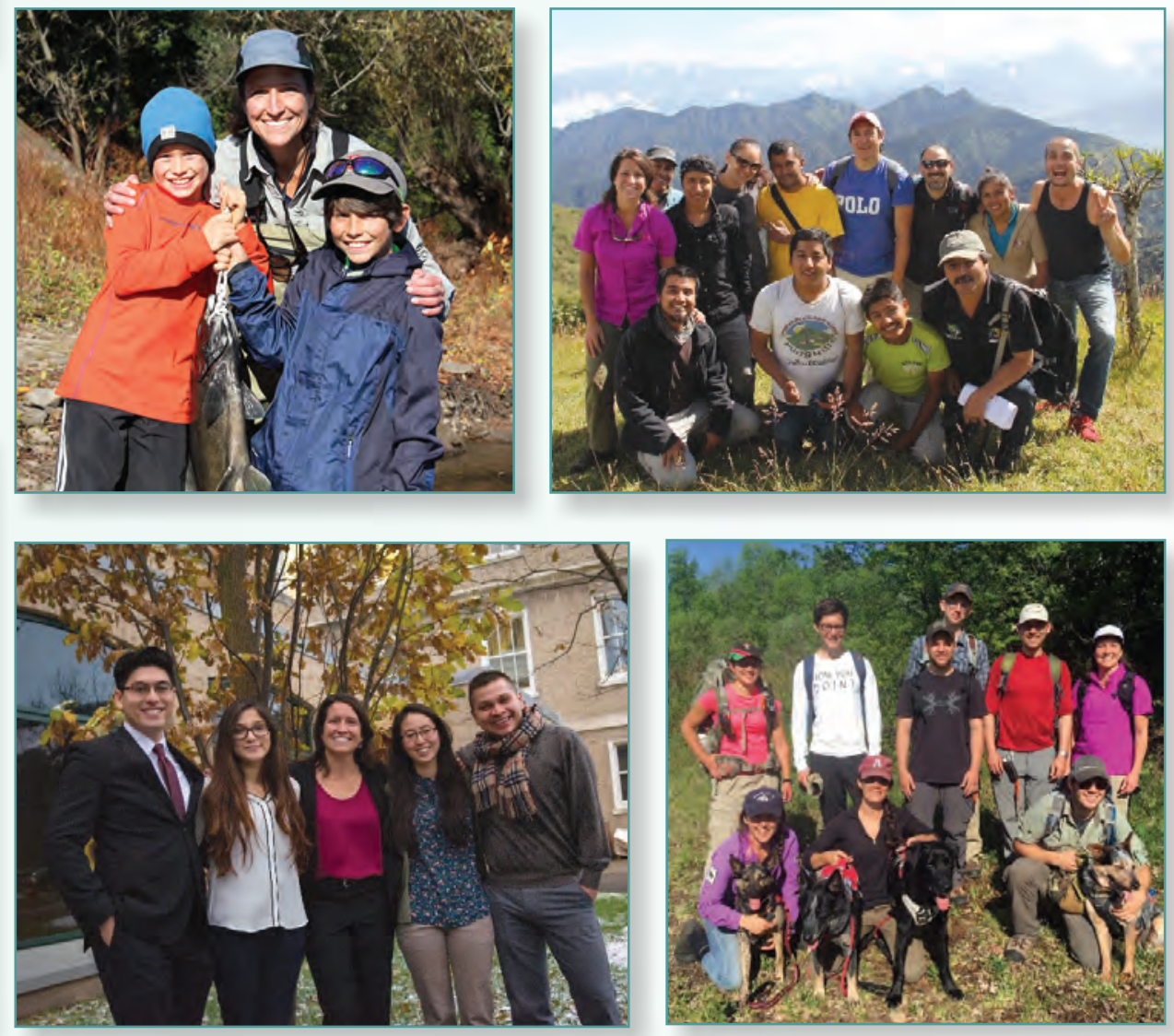


\section{Lisa Gaddis}

\section{Astrogeologist at the Astrogeology Science Center in Flagstaff, Arizona}

"We have a hunger of the mind which asks for knowledge of all around us, and the more we gain, the more is our desire; the more we see, the more we are capable of seeing." -Maria Mitchell

I grew up in New Orleans, Louisiana, a beautiful, historic place with not much in the way of geology, topography, or night sky viewing. So how did I end up focusing on those things for a career? After high school I attended college in New York, and it was there that I learned to appreciate the stars that I had not really seen through the warm haze of the New Orleans sky. The stars and night sky are reminders that we all see the same Moon and we all live on the same planet as we move through space and time.

I am a child of the space race era, when America and Russia were trying to beat each other in "conquering" space. I remember watching the first steps on the Moon and instrument landings on Mars and Venus, and later seeing robots driving on and observing Mars. As the Nation's interest in space has waxed and waned, I have been irretrievably caught up in the space race.

In college, while studying geology, I took an astronomy class and I was hooked: there lay the intersection of the study of rocks and planetary bodies. Some of my teachers in graduate school were among those who designed astronaut sorties on the surface of the Moon, studied the first lunar samples, and helped to select a landing site for the Mars Viking Lander. I sometimes marvel that I helped to define what is involved in being an astrogeologist.

Carl Sagan's TV show "Cosmos" was new during my college days, and it helped to firmly cement my interest in spending my life among the planets. There were no textbooks for a curriculum in planetary science, so as a graduate student, I read many published papers and reports on Moon landings and sample returns, the early Mars missions, and other topics. We learned to use the data returned from numerous missions to study other planets, to use computers to process and analyze those data, and to examine features like volcanoes, sand dunes, craters, rivers, and canyons on Earth to help us understand extraterrestrial landforms.

My first involvement in a National Aeronautics and Space Administration mission was the Magellan mission to Venus, and I used radar data to study unusual volcanoes and other features on that very hot planet. Since then, I've been involved with many more missions and planetary research projects at the USGS, and each one is as exciting as the first. Most recently, I've enjoyed watching my former students as they take their place among the worldwide community of planetary scientists with important places to go and things to do in the Solar System.

I am an avid hiker and skier, and I love to blend my love of geology with my hobbies by traveling to mineral shows and making jewelry using natural gemstones. But my favorite pastime of all is reading: I will always love a good book!
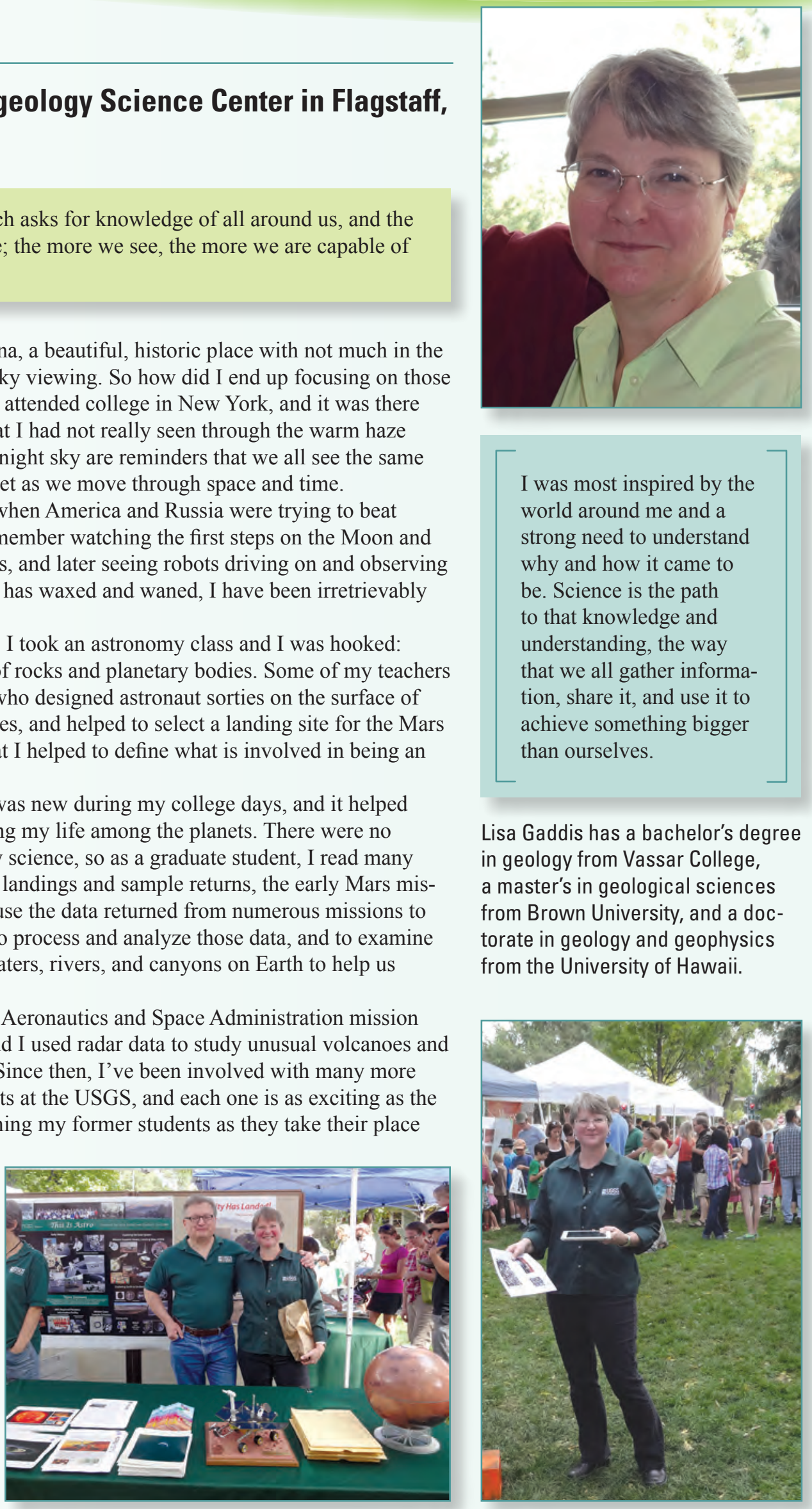

I was most inspired by the world around me and a strong need to understand why and how it came to be. Science is the path to that knowledge and understanding, the way that we all gather information, share it, and use it to achieve something bigger than ourselves.

Lisa Gaddis has a bachelor's degree in geology from Vassar College, a master's in geological sciences from Brown University, and a doctorate in geology and geophysics from the University of Hawaii.

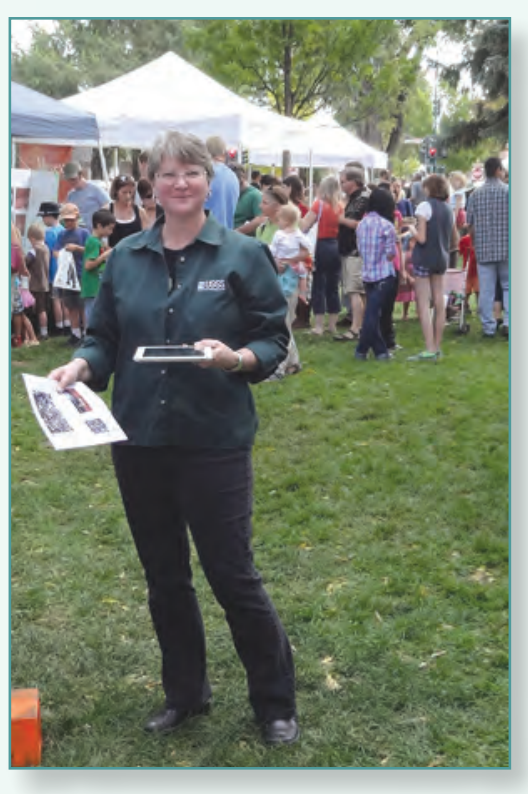




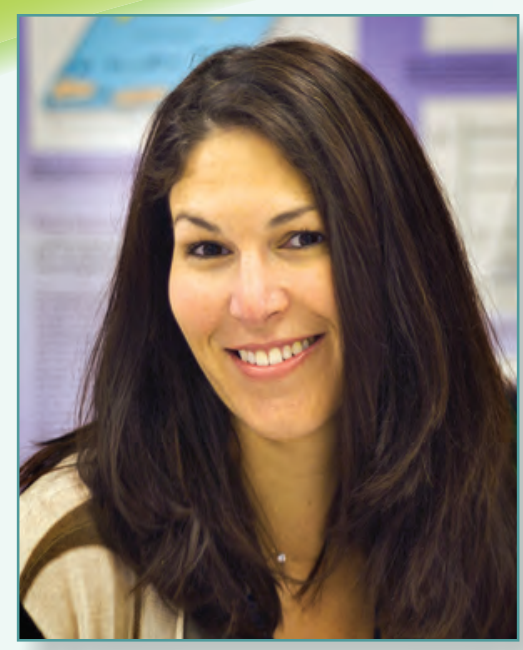

I have been lucky to have many mentors through the years that have kept me motivated and excited about the work I do.

Stephanie Gaswirth has a bachelor's degree in geoscience from Franklin and Marshall College, a master's in geological sciences from Rutgers University, and a doctorate in geological sciences from the University of Colorado, Boulder. https://www.usgs.gov/staff-profiles/ stephanie-gaswirth

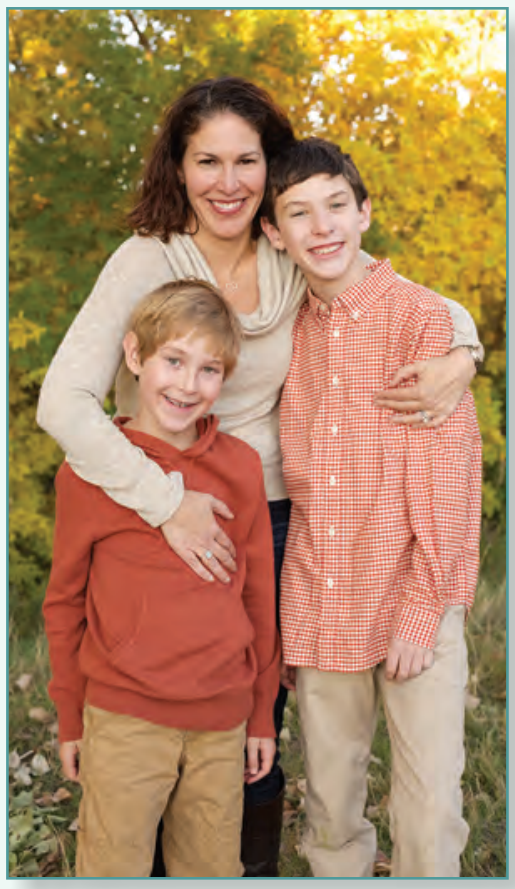

Stephanie Gaswirth

\section{Research Geologist with the Central Energy Resources Science Center in Denver, Colorado}

I grew up enjoying the beaches and the ocean in New Jersey, and these environments fostered an early love of nature and earth sciences. I was inspired to pursue a geology major in college by my intro to geology professor at Franklin and Marshall College, Dr. Bob Wiebe. He was full of energy and passion, and his love of geology was contagious. I have been lucky to have many mentors through the years that have kept me motivated and excited about the work I do. I am a big proponent of mentorship programs.

Although I've been involved in some work that one would imagine is traditional for a research geologist, my work with the USGS defies easy labeling. I have been involved in assessments of petroleum resources in several areas in the United States, including the high-profile Williston and Permian basins. I was even involved in the retrieval and analysis of samples from the Deepwater Horizon well after the spill in 2010. Because my assessments are widely used by policy makers, resource managers, conservationists, and the general public, I have been called upon to give briefings, interviews, and national and international presentations.

In Colorado, I enjoy biking, hiking, camping, snowboarding, and traveling in my beautiful State with my husband and sons.
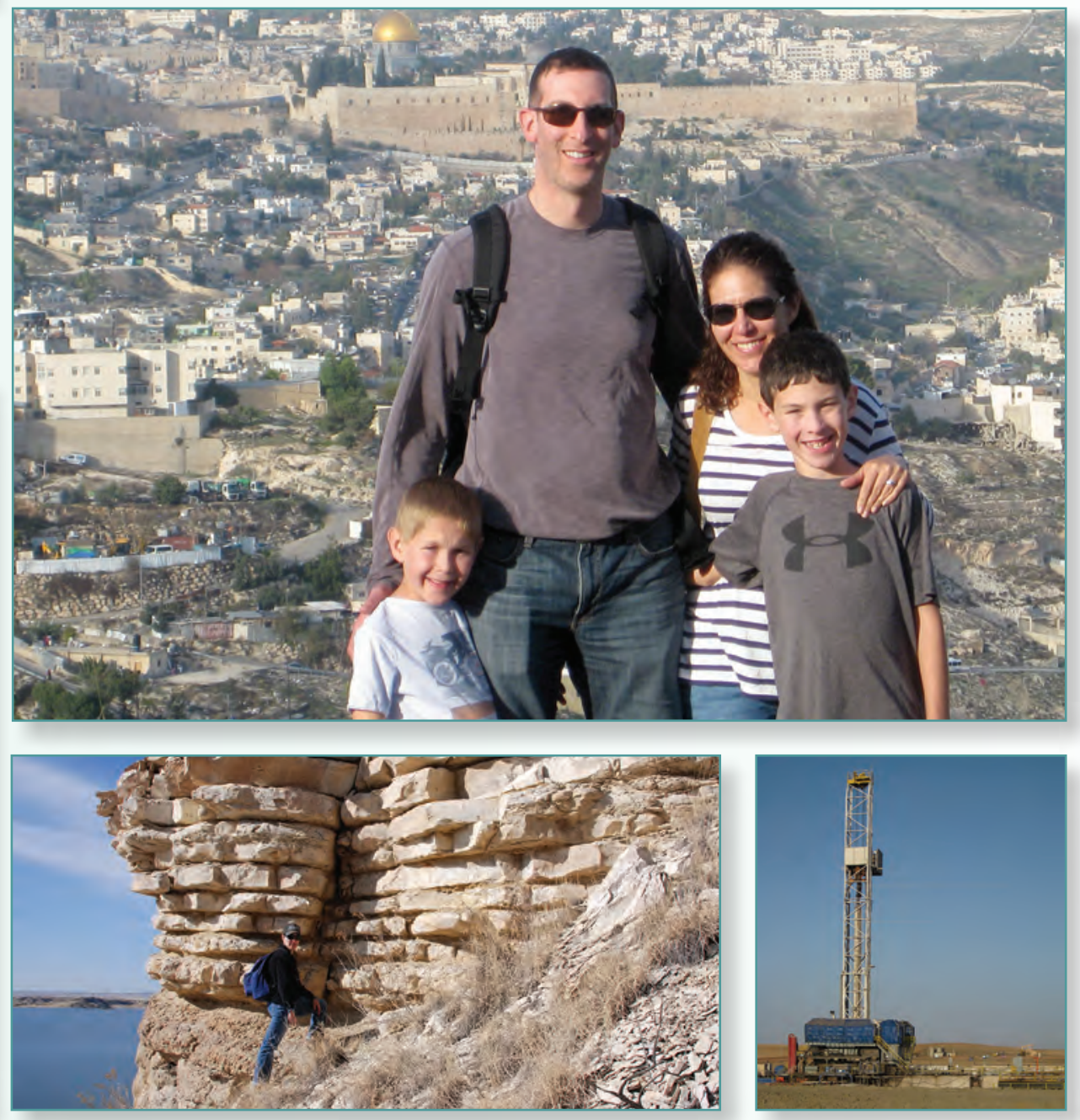


\section{Đurga Ghosh \\ Quality Assurance Coordinator for the Chesapeake Bay Program in Annapolis, Maryland}

"Poor is the pupil who does not surpass his master." — Leonardo da Vinci

I grew up in Bombay, a large metropolis on the western coast of India. As a child, I did not give much thought to science; all I cared about was reading. One of my high school teachers, Sister Ursula, noticed my passion for books and took me under her wing. We would spend hours talking about everything under the sun, including Sister Ursula's experience growing up in Ireland during the civil war. Her favorite topic was women in science. She described these women as visionaries and regaled me with stories about their lives and their research. It was during these sessions that a deep-rooted love for science was born in me. As a young girl, I identified with these women and wanted to grow up to be as famous a scientist as they were.

At university, I followed in the footsteps of my graduate mentor and started teaching, doing research in my spare time. I soon realized that, although satisfactory, teaching can be brought to life when more entrenched in research. I combined my love for teaching impressionable students eager to soak up knowledge and the opportunity to be a scientist working with peers advancing the frontiers of knowledge by becoming a researcher at Pennsylvania State University.

A large part of my research was centered around the relation between one of the building blocks of genetics, RNA, and several forms of cancer. This research led me to join the USGS to study the environmental effects of pollution in the Chesapeake Bay. In addition to analyzing groundwater and soil for signs of pollution, I also help review monitoring efforts to restore and protect the bay. I hope that good science programs across the USGS and elsewhere will provide information to increase public awareness. Science cannot be done in isolation, and a prerequisite for citizen participation in any program requires clearly communicating the science to professionals and the public.

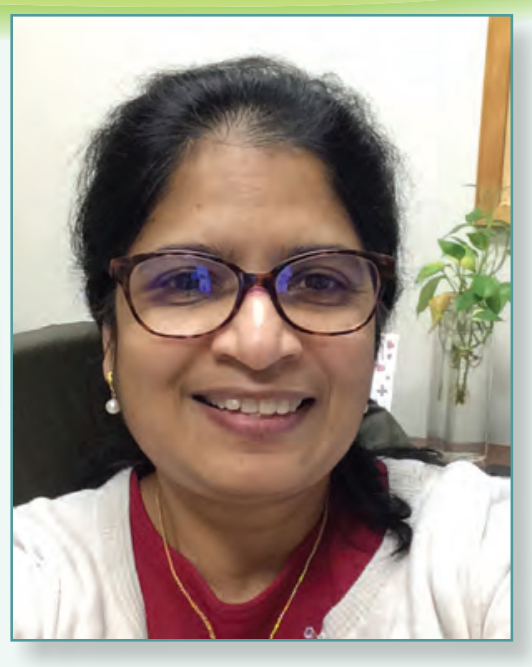

To make a difference, we have to think big, and for that we need to be better informed, so let's learn from science, our greatest teacher of all.

Durga Ghosh has a bachelor's degree in microbiology, a master's in biotechnical sciences, and a doctorate in biochemistry from the University of Mumbai.

https://www.usgs.gov/staff-profiles/ durga-ghosh

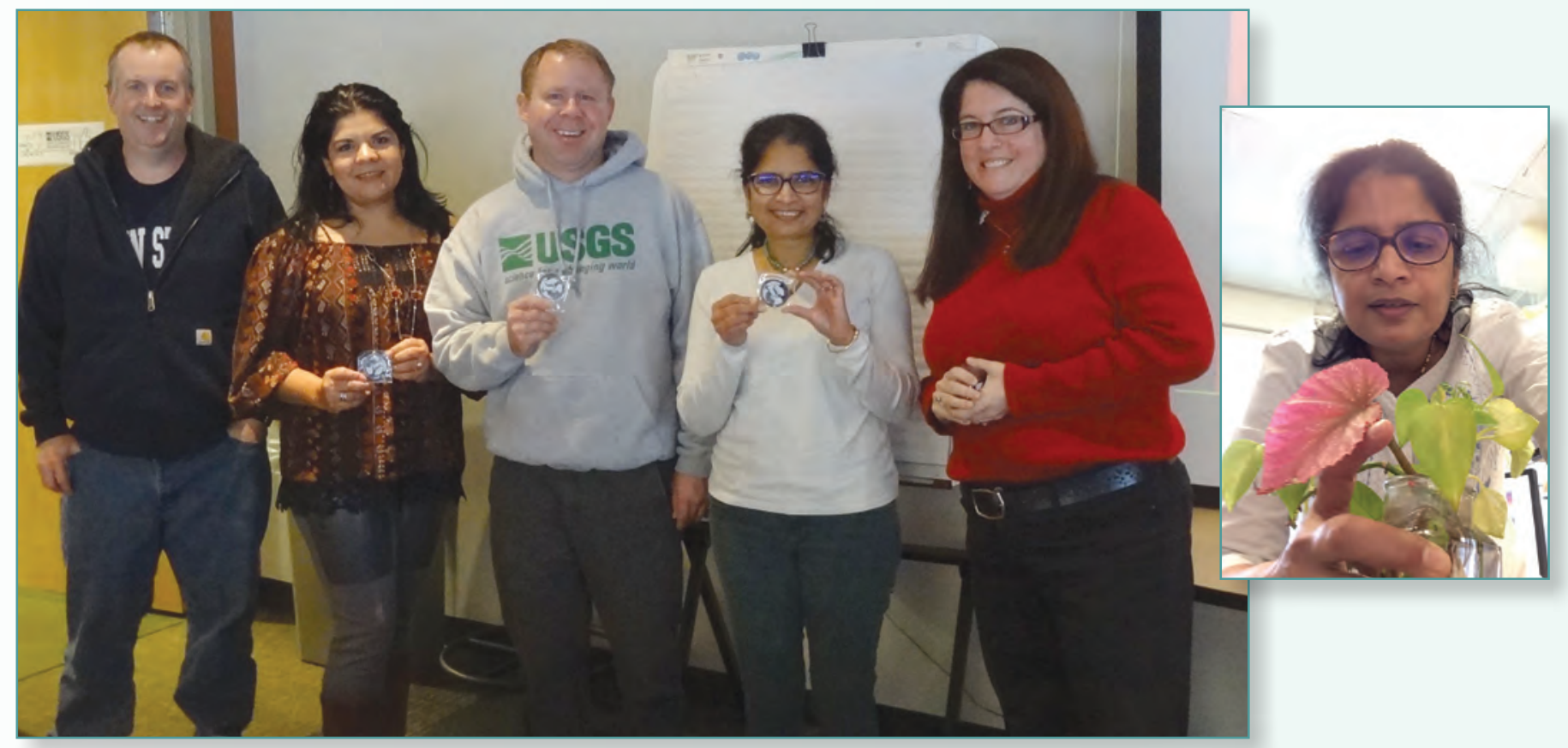




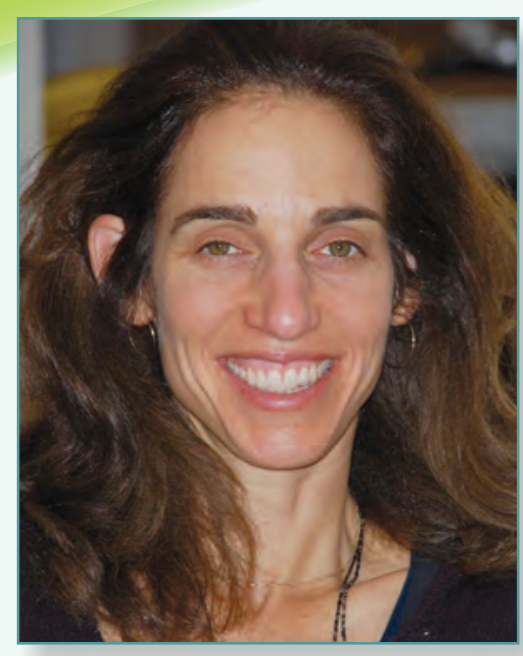

I've had lots of lives, but I'm particularly happy that they eventually brought me to the USGS. I can't imagine many things that are more fascinating than what we're doing here.

Nadine Golden has a bachelor's degree in social science from the University of California, Berkeley, and a master's in geography from San Francisco State University. https://www.usgs.gov/staff-profiles/nadine-golden-0

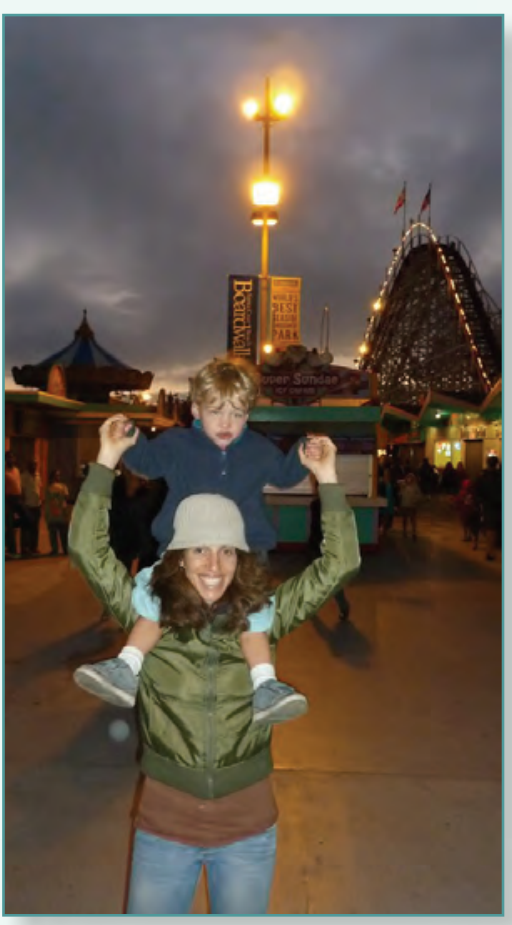

\section{Nadine Golden}

\section{Acting Deputy Director of the Pacific Coastal and Marine Science Center in Santa Cruz, California}

I took a winding path to my current focus on sea floor and coastal geography. It wasn't until grad school that I discovered an affinity for mapmaking, although it was a totally natural fit because it's right at the intersection of my parents' careers as an artist and a scientist. After grad school, I applied my mapmaking skills in widely varied work, from organic farms and bakery cooperatives, to technology companies in Silicon Valley and to submarine volcanoes.

At the USGS, I work on maps, models, and 3D visualizations of the sea floor and the rocky reefs that provide habitat for fish and other organisms in the Pacific Ocean. I also collect and curate photographs and videos of the sea floor originally off the coast of California and ultimately for the entire USGS Coastal and Marine Geology Program. I'm enthusiastic about developing technology to gather and manage data that can be used to detect, analyze, understand, and expand information about the Nation's coast and sea floor. One of my goals is to make USGS maps easy for partners and the public to find and use.
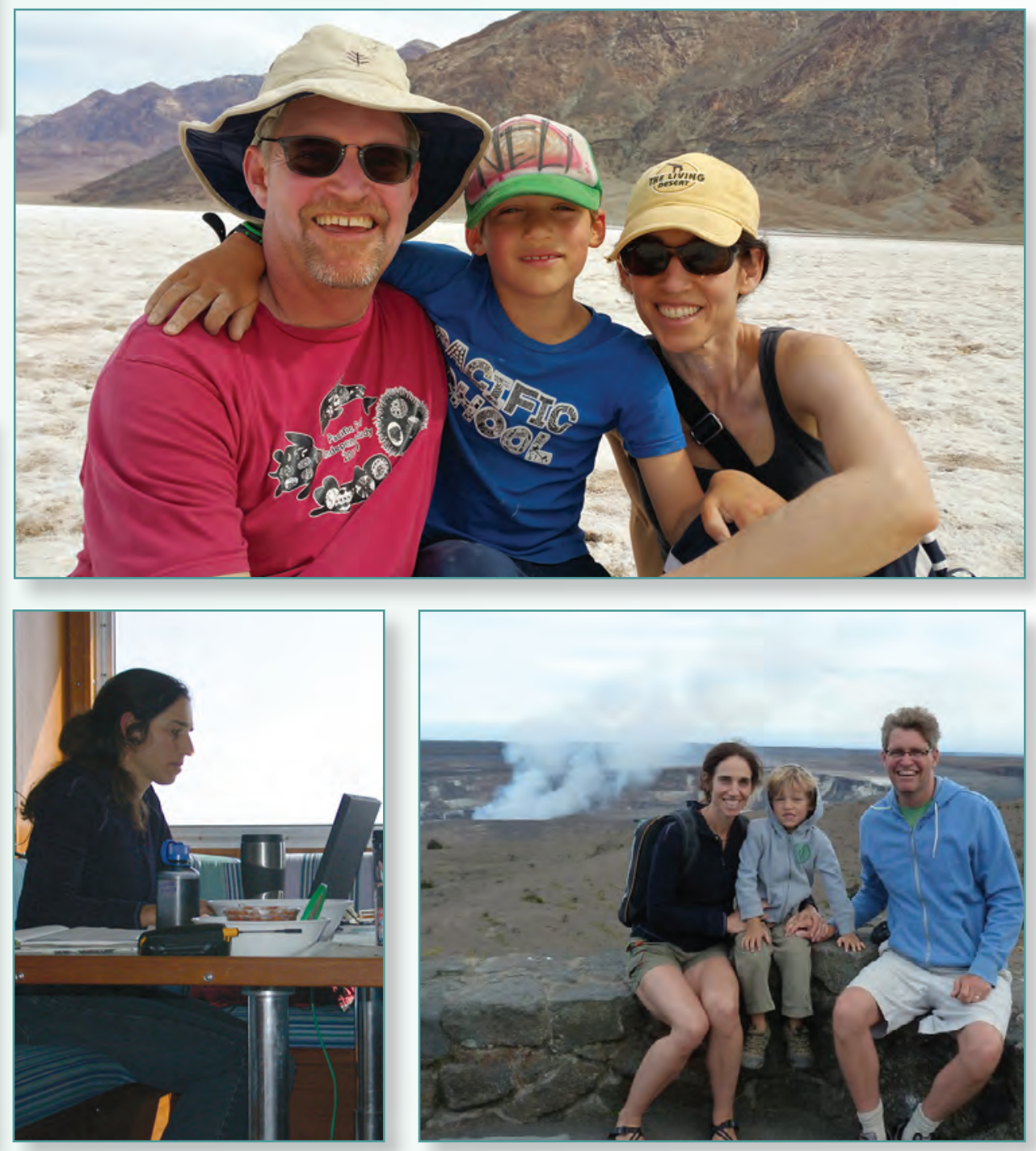


\section{Joan Gomberg}

\section{Research Geophysicist and Seismologist with the Earthquake Science Center in Seattle, Washington}

My father always encouraged me to pursue a career as a scientist. He took me to planetarium shows, plied me with scientific books and magazines, played chess with me, and in general never made me feel like I could not be a scientist because of my gender. This was significant because during this time there was a lot of pressure on young women to make finding a husband and raising a family a top priority. My parents also taught me to be civically and socially engaged; this instilled in me a curiosity about the world that I suspect led to my professional choices later in life.

My first hands-on work as a scientist involved being part of a team that installed and operated seismographs on the Moon; the best part of this was watching instruments being placed on the Moon before the news was broadcast to the rest of the world! We were watching history in the making. As a student I also worked as part of an international team monitoring earthquakes in a region of Greece that has experienced devastating earthquakes in modern times. The field team was international-we collected data from remote places, interacted with locals with very different cultural backgrounds, saw beautiful scenery, and ate simple but fabulous food. I was hooked!

One of my favorite parts of my job is that my work has the practical benefit of helping make the world less vulnerable to natural hazards. After moving to the Pacific Northwest, I discovered the many mysteries of subduction zones, and since then I have developed a new passion for learning about the many ways in which faults move, and have studied the connections between earthquake and volcanic activity, and how landslides move. Most recently my work has turned to the offshore, where the connection between earthquake shaking, submarine slope failure, and sediment transport has captured my attention.

I love traveling with my family, and I am active in professional societies. Having a husband who is a seismologist is tremendous. I cannot imagine not being able to discuss what I do with my partner and to share the same professional passions with him. He also serves as a sounding board for ideas, frustrations, and my go-to person for advice.
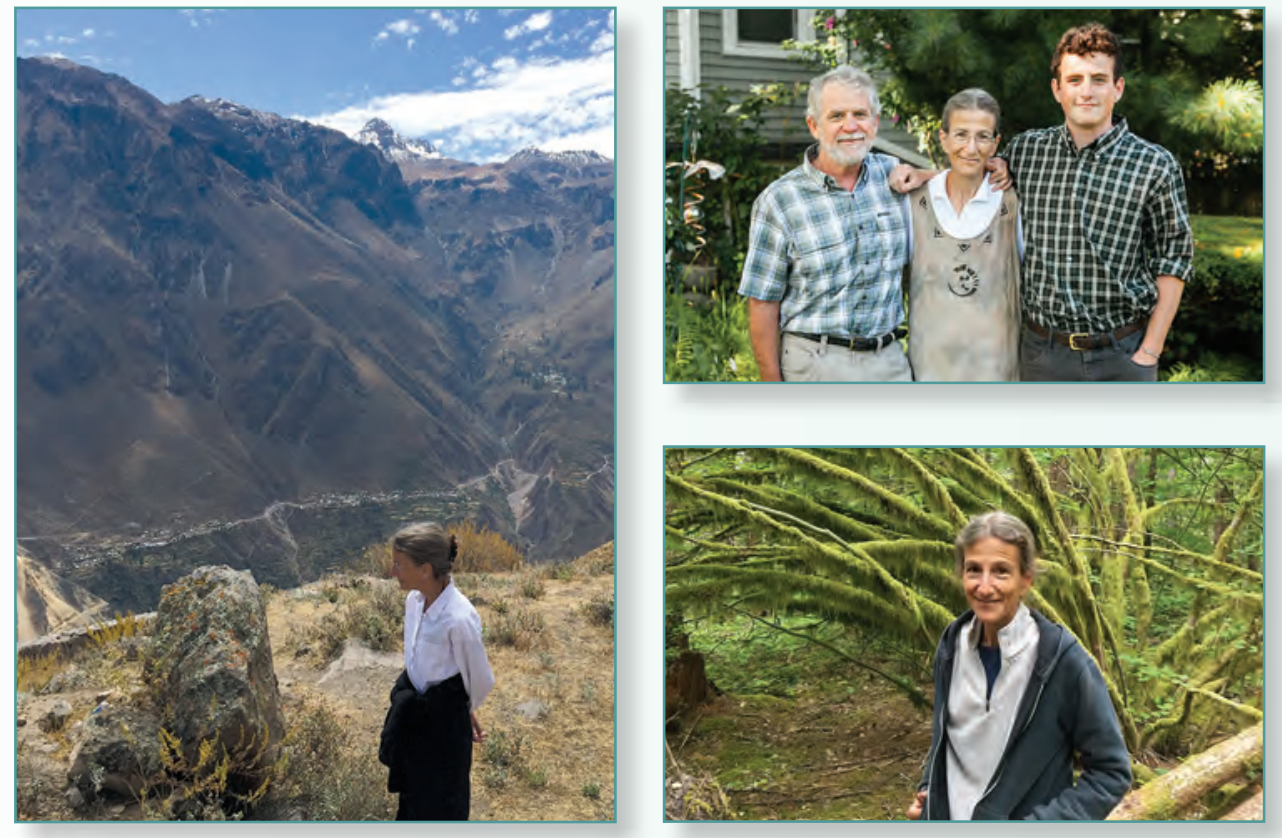

Joan Gomberg has a bachelor's degree in earth science from the Massachusetts Institute of Technology and a doctorate in geophysics from the University of California, San Diego.

https://www.usgs.gov/staff-profiles/ joan-gomberg

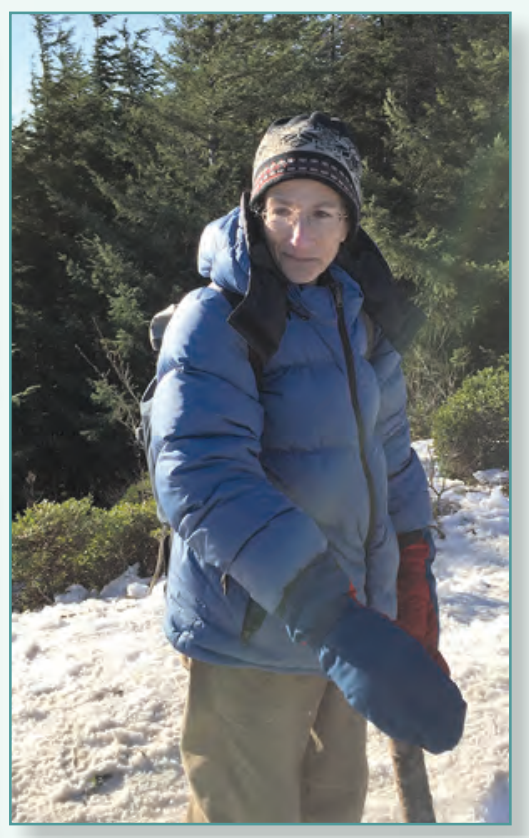




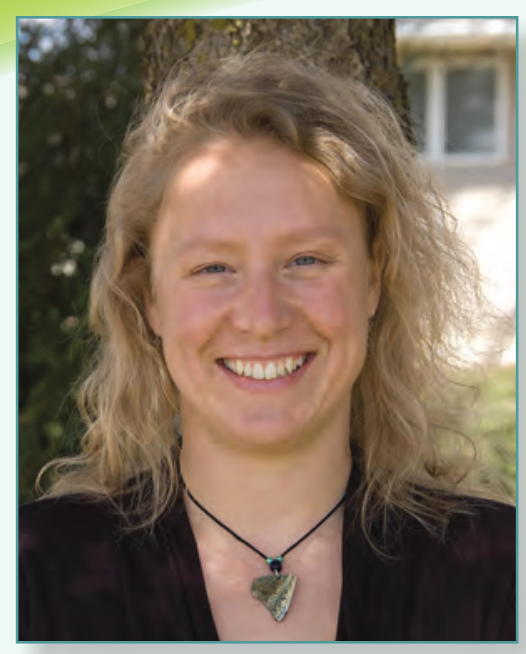

I love it when the research I've conducted is used to make management decisions, help species recover, and teach people about our amazing world.

Tabitha Graves has a bachelor's degree in German literature from the University of Wisconsin, Madison, a master's in wildlife biology from the University of Montana, and a doctorate in forest science from Northern Arizona University. https://www.usgs.gov/staff-profiles/ tabitha-graves

\section{Tabitha Graves}

\section{Research Ecologist at the Northern Rocky Mountain Science Center in West Glacier, Montana}

"I'm very conscious of the fact that you can't do it alone. It's teamwork. When you do it alone, you run the risk that when you are no longer there nobody else will do it." - Wangari Maathai

My introduction to research was in high school, when I worked with a scientist on the genetics of yeast mitochondria. I came away from it thinking that I hated research. It took me 8 years to figure out that it was lab work that I didn't enjoy and to understand that research is actually solving puzzles, which I love, and that doing research didn't necessarily require pipetting over short lab benches! My rejection of research led me to explore international relations and alternative transportation planning before I found my way to wildlife biology, which lets me do work that can make a difference, connect ideas from different fields, and sometimes even work outside!

Grizzly bears, bighorn sheep, and elk are at the center of the science questions that my research answers about how humans influence wildlife populations. My work helps decision makers consider choices about land use and conservation that balance the needs of wildlife and humans. In my recent research, I have been evaluating what drives bighorn sheep and elk to move across the landscape, and I track diseases that affect these species. I use the genetics of grizzly bears in a family tree to learn about dispersal, estimating how many grizzly bears live in northwestern Montana and how many bighorn sheep live in the Grand Canyon. I also study the way interactions between weather patterns and site conditions affect the growth and lifecycle of huckleberries, which are a key food source for wildlife and humans. I am very interested in developing new ways of doing this research so that it can be done for the lowest cost and to gain the most information. I really enjoy the creativity of this work; trying to understand rare and elusive animals across large areas means developing new ways of collecting and synthesizing data, whether that is involving the public directly in data collection, refining remotesensing tools, or applying new statistical techniques.
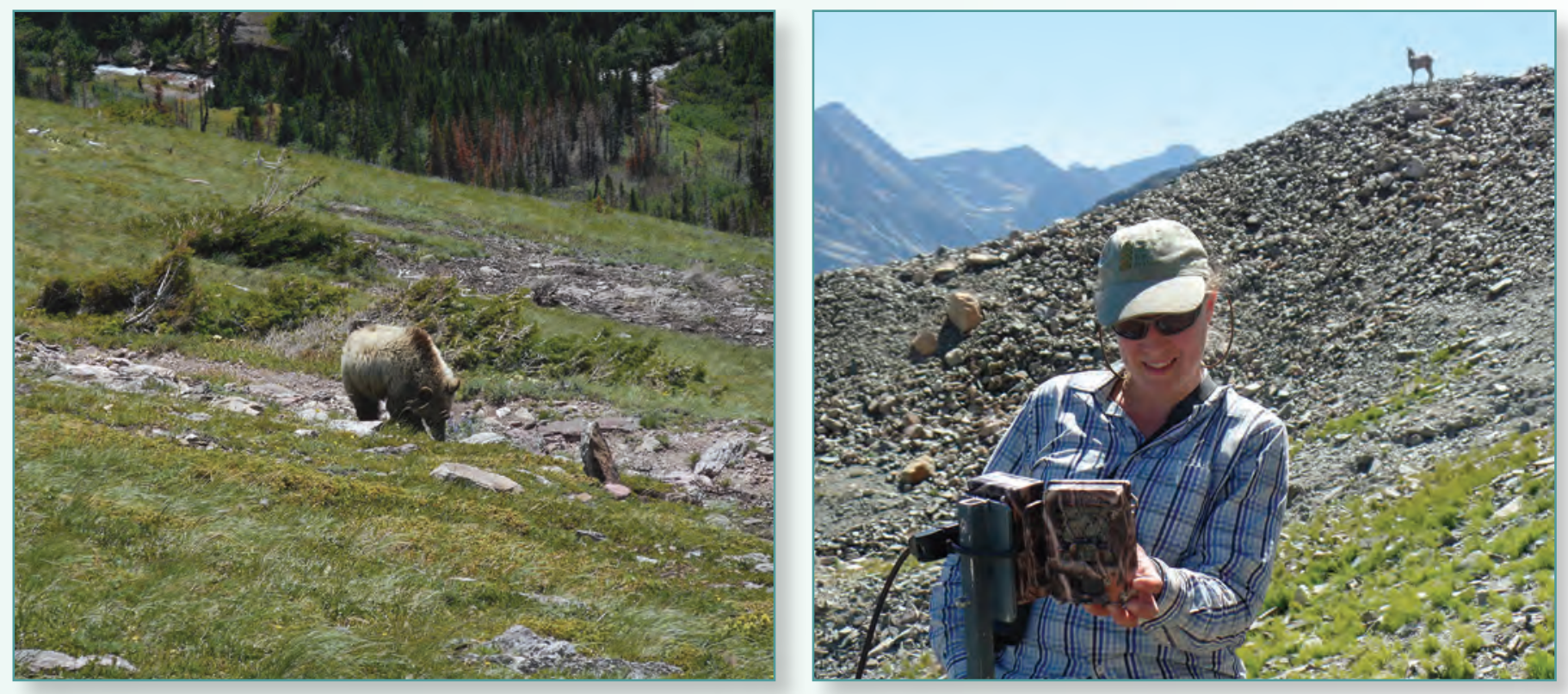


\section{Susan Haig}

\section{Supervisory Wildlife Ecologist at the Forest and Rangeland Ecosystem Science Center in Corvallis, Oregon}

"Why not?" —-Lewis Oring, doctoral advisor

I have wanted to be a biologist for as long as I can remember. When I was 5 years old, I walked alone to a store to buy a butterfly field guide. My parents were frantically looking for me while I was in the garage trying to figure out how to make a net from a hanger and a broom handle!

My research at the USGS revolves around understanding factors that contribute to the decline of endangered and threatened species, including the piping plover, northern spotted owl, redcockaded woodpecker, and California condor. For many years, I have also researched shorebirds and the need to maintain habitats for them throughout the annual cycle. I am currently designing monitoring strategies and population assessments for wildlife in Saudi Arabia and Namibia.

My favorite parts of my job are evaluating animal behavior and populations, writing proposals and papers, designing projects, brainstorming with students, and thinking of new initiatives. I am also a professor of wildlife ecology at Oregon State University and a research associate of the Smithsonian Institution.

When I'm not working, I enjoy photography, birdwatching, kayaking, and travel in Africa.
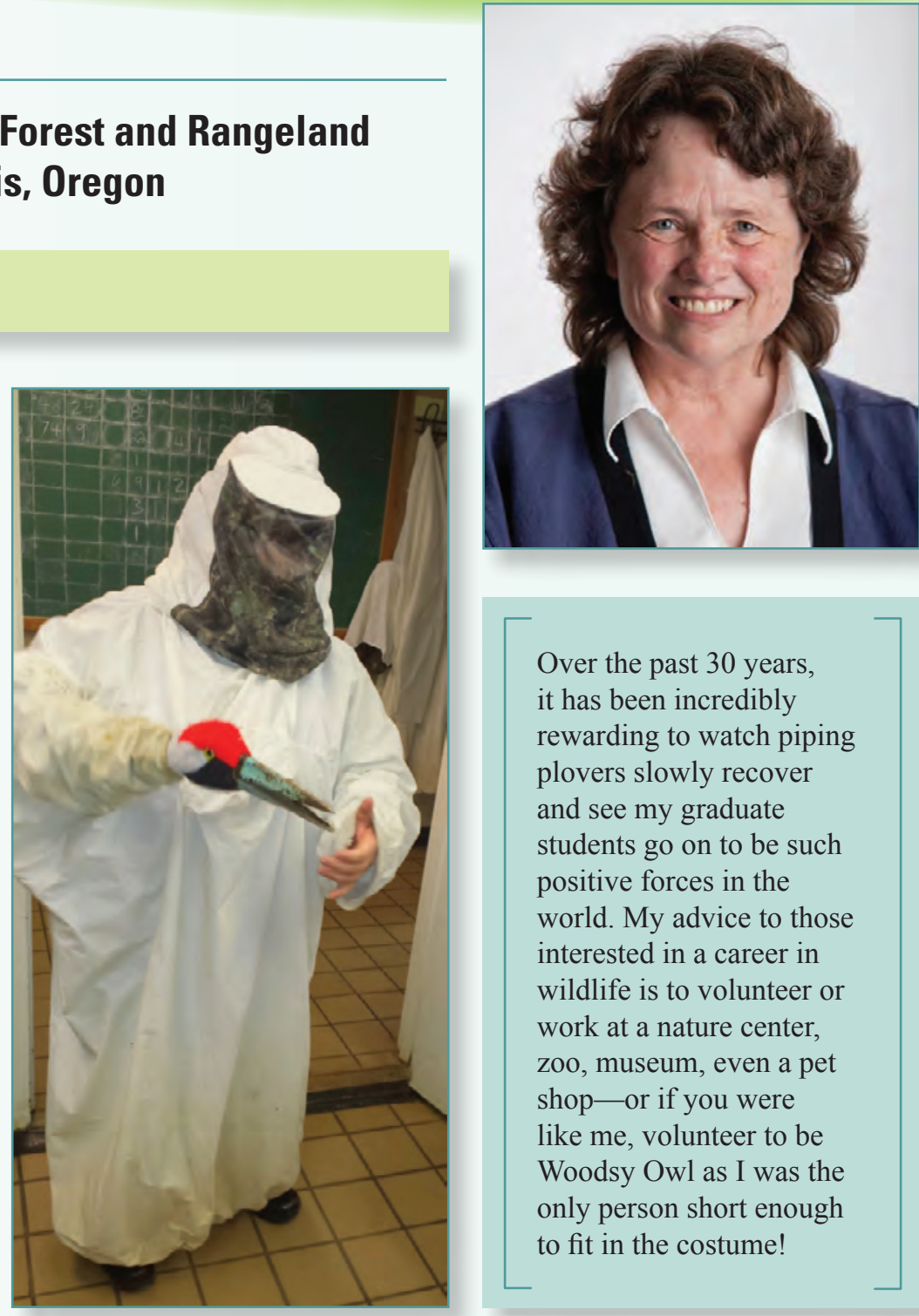

Over the past 30 years, it has been incredibly rewarding to watch piping plovers slowly recover and see my graduate students go on to be such positive forces in the world. My advice to those interested in a career in wildlife is to volunteer or work at a nature center, zoo, museum, even a pet shop - or if you were like me, volunteer to be Woodsy Owl as I was the only person short enough to fit in the costume!

Susan Haig has a bachelor's degree in biology from Northland College and a doctorate in biology from the University of North Dakota.

https://www.usgs.gov/staff-profiles/ susan-m-haig

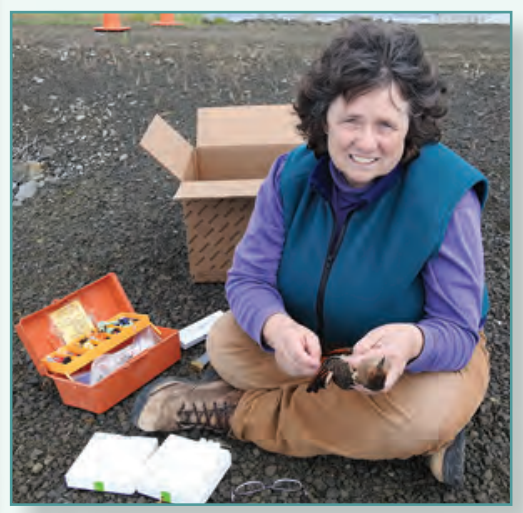




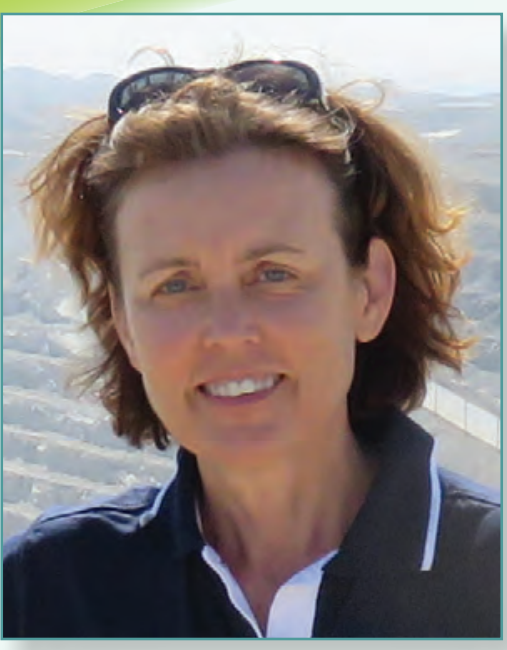

I am married to a geologist, and we enjoyed driving our daughters crazy during family holidays as our favorite roadside attractions were the stories exposed in road cuts - not at all of interest to our young girls.

Susan Hall has a bachelor's degree in geology from Smith College, a master's in geochemistry from the University of California, Davis, and a doctorate in geochemistry from the University of Ottawa.

https://www.usgs.gov/staff-profiles/ susan-m-hall

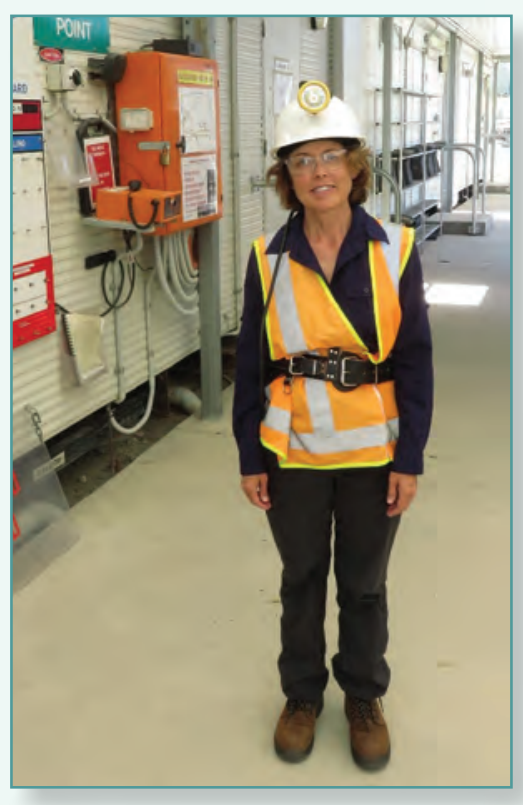

\section{Susan Hall}

\section{Geologist with the Central Energy Resources Science Center in Denver, Colorado}

I grew up in a house in northern California that was built on the Hayward Fault. I woke up more than one night to a shift, twist, and rumble of an earthquake. I suppose those early experiences began my geologic journey. Our home was at the edge of a large nature preserve, and I spent most of my spare time wandering the hills of the open space, building forts, turning over logs to see what lived underneath, climbing trees, and playing on rope swings. As I grew older, I found a Junior Ranger group and spent every Saturday exploring regional parks and learning about Native American life, natural history, and geology.

When I went to college, I gravitated to science classes, finally settling on geology. In these classes I began to more fully understand the science behind my childhood observations of natural history: why granite peels off or "exfoliates" in layers, why the coastline at Point Reyes near San Francisco has such high cliffs, and what causes the earthquakes I grew up with.

I have worked most of my career as an economic geologist, a geologist who studies mineral deposits such as gold, silver, and copper. When I worked as an exploration geologist early in my career, I was excited each time I started working in a new area. There was always the possibility that I might discover a new deposit, which is both a scientific achievement and an economic success. Now my main area of expertise is uranium deposits, and the program that I lead has been successful because we developed open, collaborative teams of research scientists from academia, industry, and government organizations. My research has allowed me to travel around the world to study deposits in Argentina, Australia, Canada, Namibia, and Ukraine.

As a child I enjoyed collecting minerals, never dreaming that one day I would discover a new one. While analyzing samples from a uranium deposit in northern Texas, I recognized that the chemistry of one mineral I was studying had a distinctive composition. Mineralogy not being my expertise, I was able to convince experts in mineralogy, geochemistry, and spectroscopy to prove that this was a unique mineral. A team of colleagues and I identified the first hexavalent form of a strontium and uranium mineral ever identified and have applied to name this new mineral finchite, after a long-time USGS uranium geologist.

I enjoy oil painting, mostly natural subjects: flowers, trees, and landscapes. I am attracted to the range of color and texture found in nature and try to capture that in my paintings. Interestingly, I find painting rocks very difficult, perhaps because I am focused on getting each cluster of mica or grain of quartz just right, which is simply impossible.
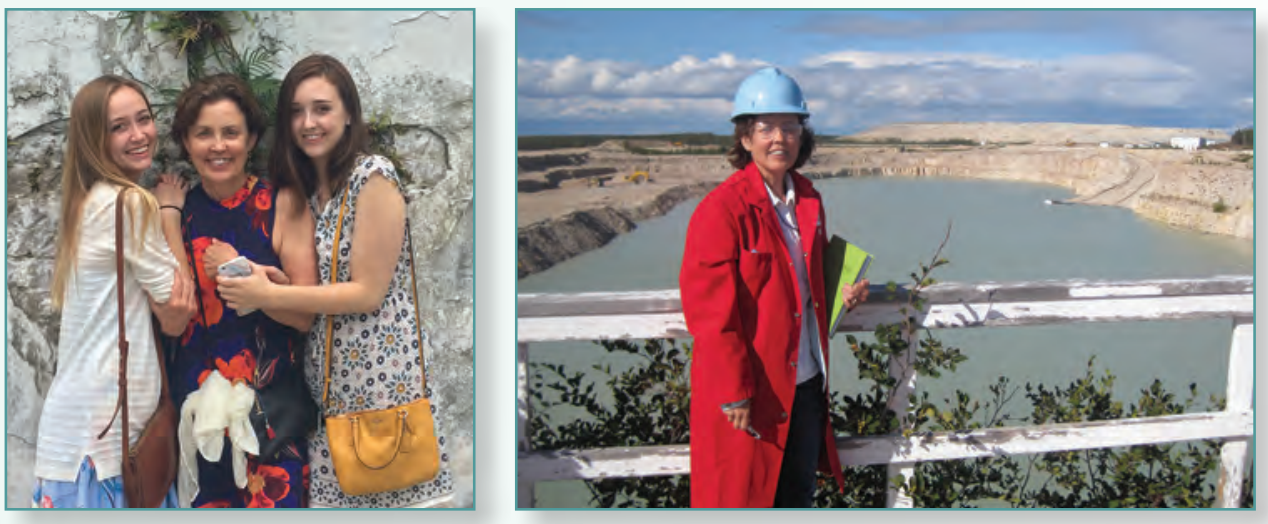


\section{Hannah Hamilton}

\section{Public Affairs Specialist with the Office of Communications and Publishing in Reston, Virginia}

"Life's most persistent and urgent question is, "What are you doing for others?" -Martin Luther King, Jr.

My mother might say that once I learned to talk I didn't stop, so it only makes sense that I am now a professional communicator. It wasn't a path I found myself on right away, though. In college I was on the newspaper staff, and my communications professor encouraged me to change my major from psychology and biology to communications. I took that as a compliment, but did not change my major. I got into communications when I was working at a biological research center of the U.S. Department of the Interior in Florida and became the go-to person for public and media inquiries. I was able to get my graduate degrees while working for the USGS. I loved being able to communicate the science being done at the center and make it matter to people.

My work as a public affairs specialist for the USGS involves sharing the work of USGS scientists in a way that allows everyone to access the great work the USGS does and what it means to society. I provide communications and media training to USGS scientists, technicians, and managers and advise USGS science centers on communication issues. I also write and edit pieces such as feature stories and news releases on water, geology, geography, coastal and marine geology, and ecosystems science from research centers from Virginia to Maine.

In my free time I'm part of a great group of quilters. Quilting allows me to communicate using a different medium, and people can actually touch or wrap themselves up in something that is an expression of love. I also like to get out and explore nature, be it a forest, botanical garden, or State, local, or national park. It's a joy to stumble upon a creek, pollinators in action, or the stillness of a forest.
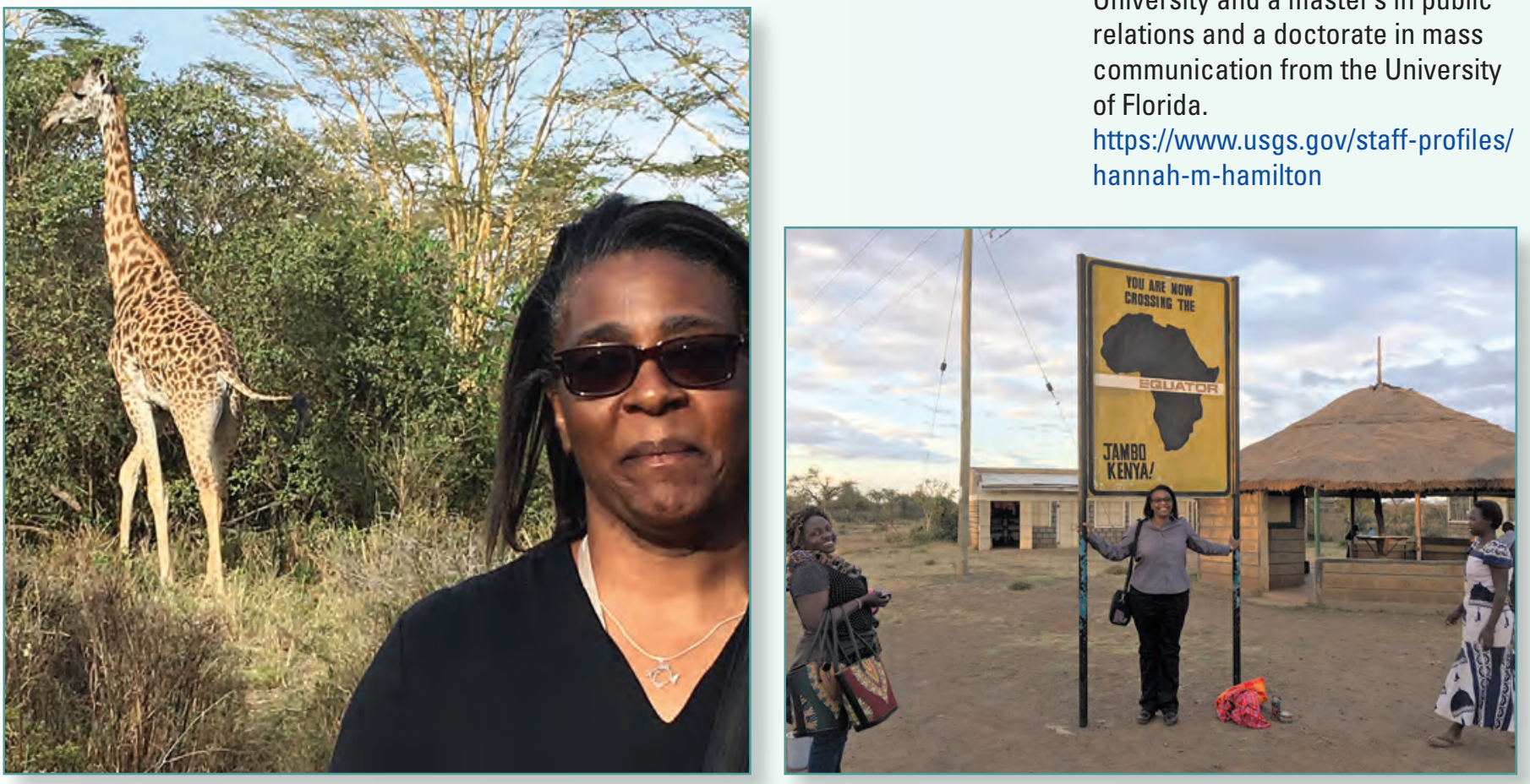


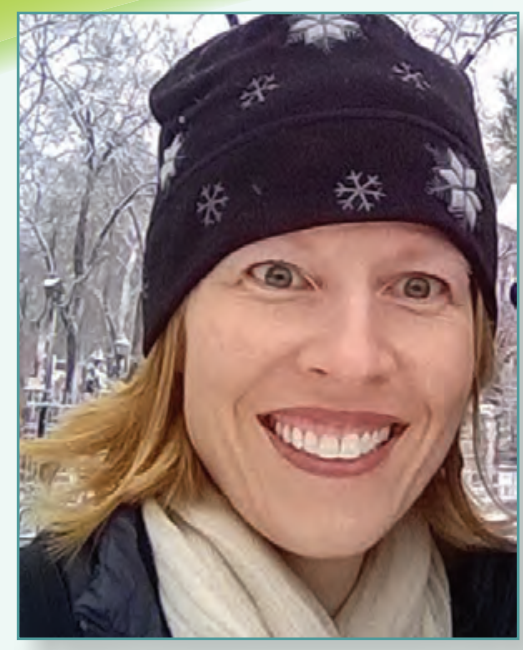

God's amazing creations inspire me. People inspire me. Connections with those people inspire me. The opportunity to connect with people is always there. People want to talk, and their stories are amazing if you take the time to listen.

Jo Ellen Hinck has a bachelor's degree in biology from the University of Central Missouri and a master's in zoology from Miami University.

https://www.usgs.gov/staff-profiles/ jo-ellen-hinck

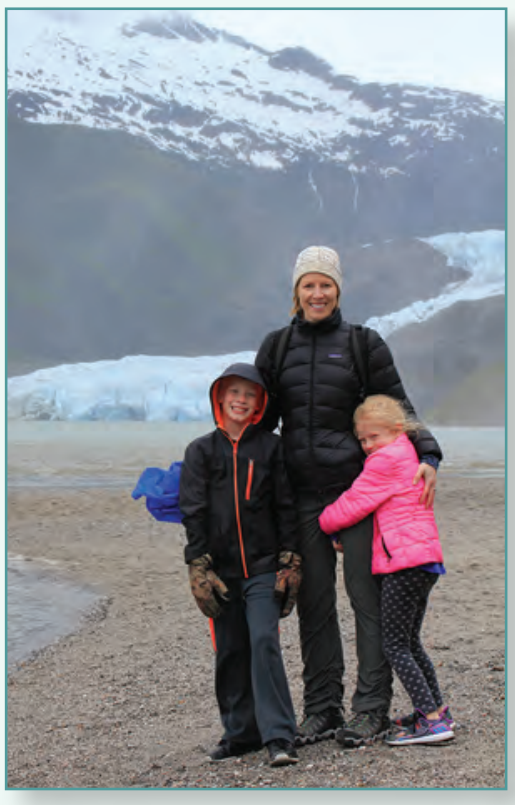

\section{Jo Ellen Finck}

\section{Contamination Biologist at the Columbia Environmental Research Center in Columbia, Missouri}

“Uniqueness isn’t a virtue. It’s a responsibility.”- -Mark Batterson

I grew up in a family that had strong ties to natural resources; my father was a bulldozer operator and my grandparents were all farmers. I think my family's ties to the land influenced my desire to conserve and preserve natural resources and analyze how we as humans affect those resources. My grandmother was shocked when I told her about one of my first projects with USGS: dissecting largemouth bass and carp as part of a health monitoring program. She commented that I hated to get my hands dirty as a child.

When I started my graduate work, I was lucky enough to be part of a field research team examining the toxic effects of petroleum byproducts on the alpine lakes of the Sierra Nevada Mountains. This was an opportunity to develop my own toxicological research while working in an environment I really enjoyed.

As a biologist for the USGS, I have traveled across the United States to evaluate the effects of pollution on a variety of species from diverse ecosystems. I also research the risks of uranium mining on natural and tribal resources in the Grand Canyon watershed. My job allows me to experience new places and meet and work with new people and learn new stories. It also provides me the opportunity to work with Federal, State, and Tribal natural resource managers and policy makers. I also coordinate activities on assessing and restoring natural resources at municipal, State, or national parks and wildlife refuges injured by contamination from mining sites, industrial areas, and oil spills; every problem is unique in terms of geographic setting, type of pollutant, and natural resource injured, which means that the science required is also unique.

I live in my home State of Missouri, near family and friends, and love gardening, hiking, and traveling with my family, visiting national parks, trails, forests, and monuments; I want to get my kids to all 50 States before they graduate high school! I am also passionate about including more science in primary and elementary schools to inspire the next generation of researchers. I hope that my children develop the love of science that has been with me since a young age. I volunteer for STEM activity time at local schools, and I am an active voice in the school district on how to integrate more STEM into the daily curriculum.
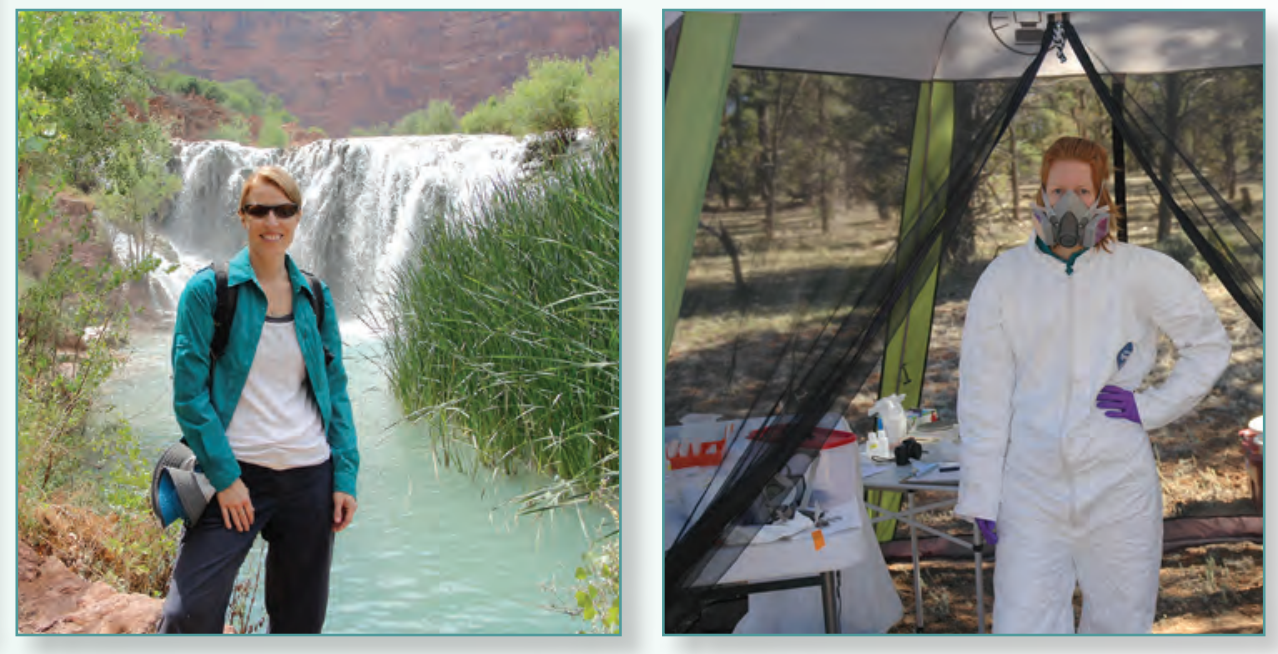


\section{Michelle Hladik}

\section{Research Chemist with the California Water Science Center in Sacramento, California}

I grew up in Arvada, Colorado, and growing up in a landlocked State with a limited water supply led me to develop a love of water both personally and professionally. Having parents who always supported my scientific interest definitely influenced me to pursue science in college.

As an undergraduate, I started researching aluminum chemistry in streams. This work allowed me to hike to small streams in New York to collect water samples, and it was at this point that I realized that I could combine my interest in chemistry with my love of the outdoors and water. Since moving to California, I've come to love the beauty and complexity of California water, which starts as snow in the Sierra Nevada Mountains, provides a wealth of recreational activities, and then feeds the diverse agriculture of California's Central Valley.

My research is on the fate, transport, and effects of pesticides that are being used these days in agriculture, water treatment, and pest control in urban areas and the byproducts they produce in water systems. This research helps us understand the effects that chemicals in our water have on wildlife and on human health. I also oversee a research laboratory that is focused on developing new methods to measure pesticides and their byproducts in water, the soil, and animal and plant life.

I love being outdoors, whitewater kayaking, swimming, including open water swimming, paddle boarding, snowshoeing, and cycling.
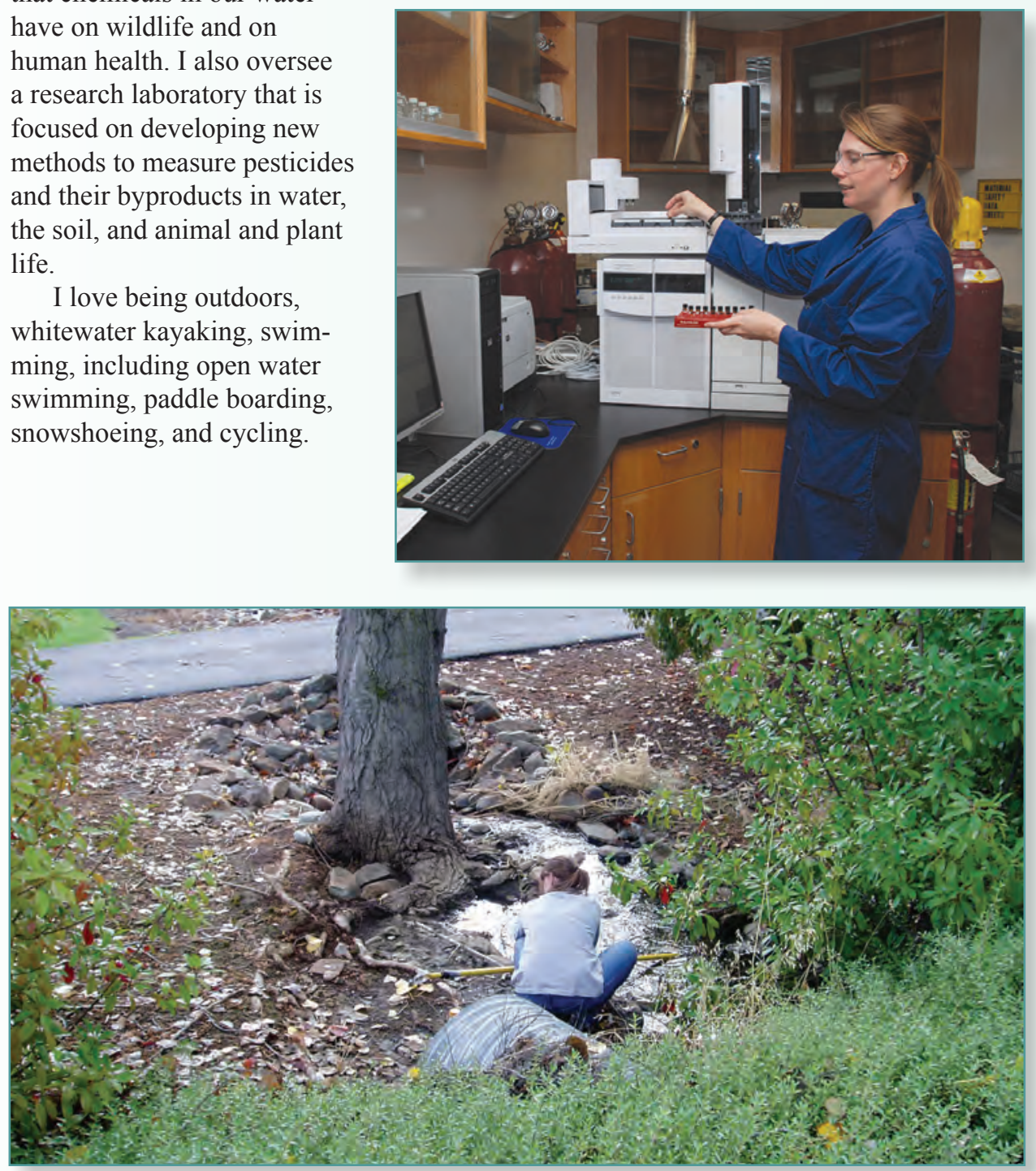

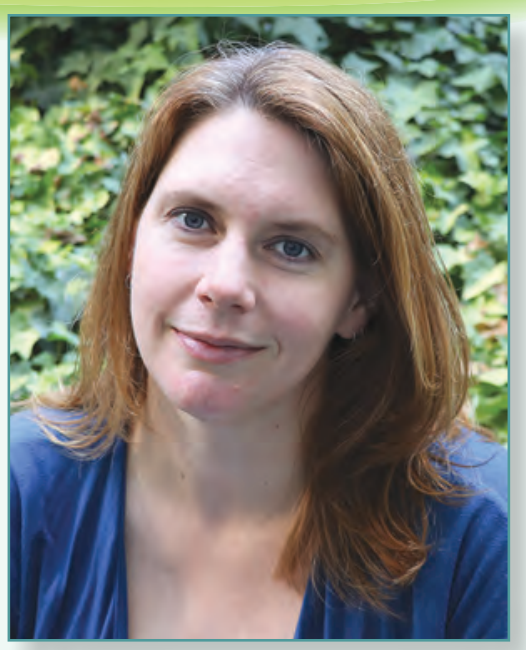

I enjoy pursuing topics that balance the needs of humans with those of the environment. My first research experience was as an undergraduate student measuring aluminum in small streams. Being able to combine field research with laboratory analysis was and still is the best of both worlds.

Michelle Hladik has a bachelor's degree in chemistry from Vassar College and a doctorate in environmental engineering from Johns Hopkins University. https://www.usgs.gov/staff-profiles/ michelle-I-hladik

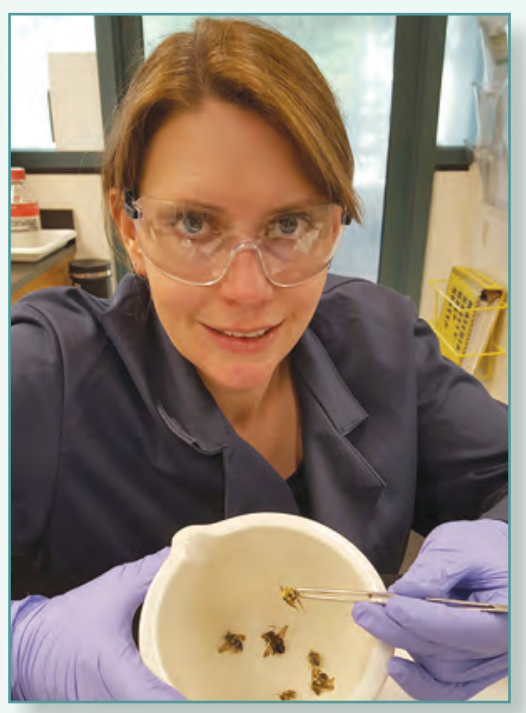




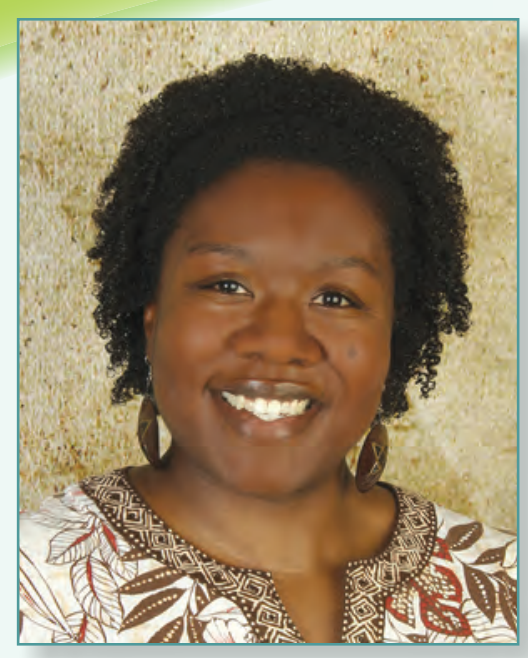

eamille Hopkins

\section{Wildlife Disease Coordinator with the Ecosystems Mission Area in Reston, Virginia}

"I love to think of nature as an unlimited broadcasting system, through which God speaks to us every hour, if we will only tune in." - George Washington Carver

I have always been fascinated by wildlife and am passionate about the well-being of wild animals. I grew up wanting to work with wildlife as a scientist. After completing a Girl Scout Wider Opportunity experience with the Wildlife Conservation Society at the Bronx Zoo, I focused on becoming a wildlife veterinarian. My clinical veterinary career included caring for wildlife in the Republic of South Africa as well as in the United States at the Wildlife Center of Virginia and the Smithsonian Institution's National Zoo-

Camille Hopkins has a bachelor's degree in biology from Cornell University, a master's in wildlife population medicine and a doctorate in veterinary medicine from Mississippi State University, and a doctorate in disease ecology from the Virginia Polytechnic Institute and State University (Virginia Tech). https://www.usgs.gov/staff-profiles/ m-camille-hopkins
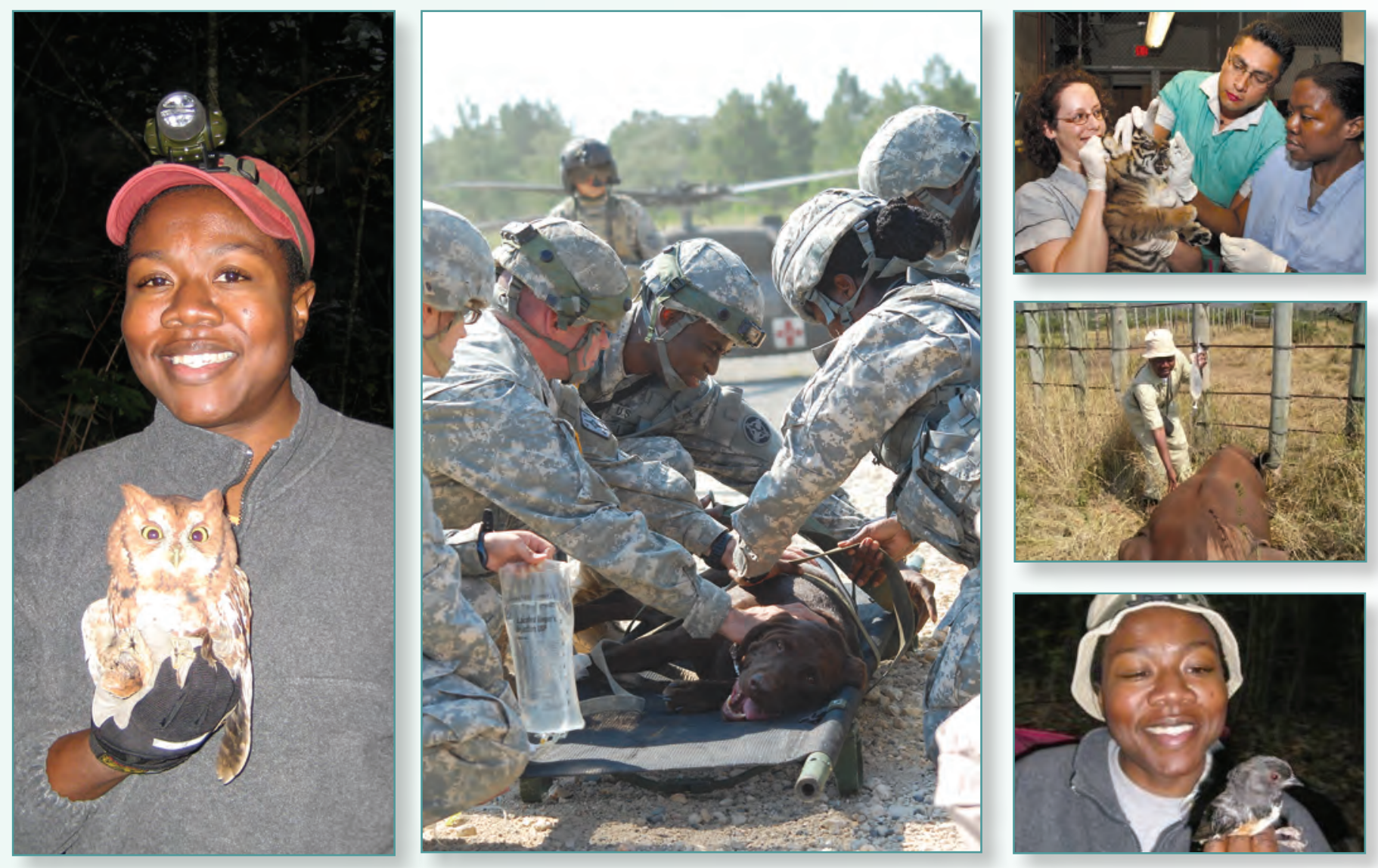
logical Park. I also had the honor of caring for military working dogs as an officer in the U.S. Army Veterinary Corps.

After completing my graduate studies, I joined the USGS, where I could apply my clinical and research experience as the wildlife disease coordinator. I manage research activities of the Ecosystems Mission Area related to diseases of aquatic and terrestrial wildlife and support USGS disease research and surveillance at departmental, interagency, and international meetings. Because diseases such as chronic wasting disease in deer and white-nose syndrome in bats can negatively affect wildlife populations, research priorities include the development of tools and strategies for a robust response to these pathogens.
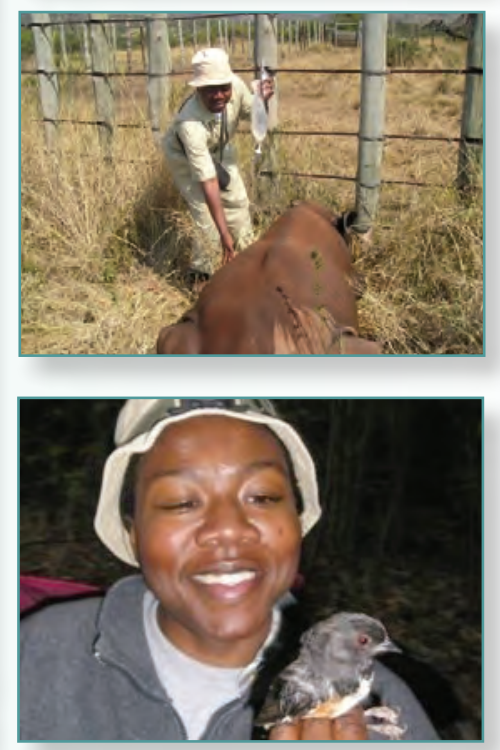


\section{Susan gough \\ Research Geophysicist at the Earthquake Science Center in Pasadena, California}

"A life has to move or it stagnates. Even this life, I think. Every tomorrow ought not to resemble every yesterday." —-Beryl Markham

I did not have an "aha!" moment that drew me to earth sciences. I first read descriptions of courses about earthquakes in the University of California Berkeley catalog and thought they sounded interesting. I did always love numbers and math, though, even from a young age. I remember my father standing behind me while I worked on a sheet of math homework problems and saying to me, "Math is fun, isn't it? It's more like getting to play than having to work." I thoroughly agreed, even then. What most influenced my story is the fact that my father was an academic who was determined to teach his children about the world and who encouraged my early interests in math and science. It might not sound like a big deal now, but this was sadly not the norm for little girls born in the 1960s.

Through my undergraduate degree and even through grad school, I remained a mathematician at heart. My postdoctoral years at Lamont-Doherty Observatory provided my first experience with fieldwork, including my first experience leading an aftershock deployment following the 1989 Loma Prieta earthquake. Standing beside the collapsed Nimitz Freeway in Oakland, Calif., and piecing together that it had failed because of shaking amplified by the San Francisco Holocene Bay Mud, made the science suddenly very real.

As a research geophysicist, I have worked in a number of earthquake-prone areas, including California, Virginia, Haiti, Nepal, and Burma, to research the nature of ground motion generated by earthquakes, historical earthquakes, and earthquakes that are triggered by other earthquakes. I have studied how earthquake shaking can be amplified by hills and ridges and how earthquakes can be potentially induced by human activities. I have led a number of deployments of portable instruments to record aftershocks of notable earthquakes.

I love to travel, to remote corners as well as well-trodden paths. The world is a fascinating place, and nothing broadens one's horizons like appreciating that there are enormous strengths to be found in areas where the eye first sees only challenges. I have three amazing grandsons who are more fun than a barrel of monkeys. I love teaching them and seeing their intense curiosity about the world. I also enjoy mentoring young women in sciences who are trying to find a balance between the demands of work and family life.

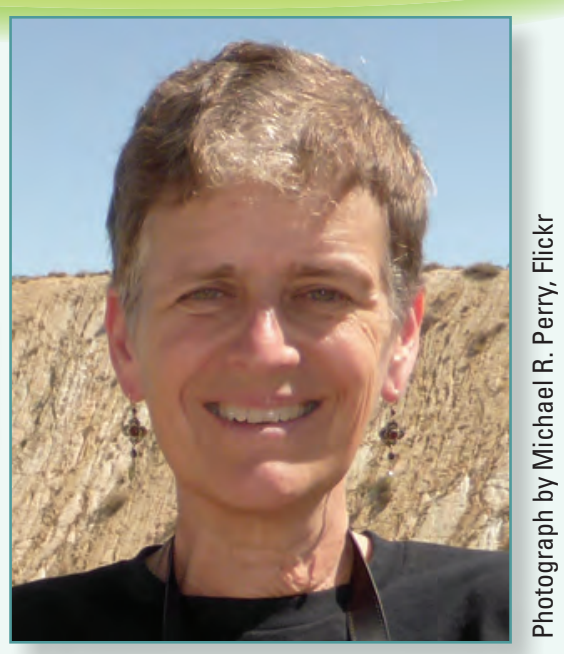

The Earth can still surprise us. We need to get the science right so that people can prepare for future earthquakes. The study of the ground motions generated by earthquakes is where the seismology rubber meets the riskreduction road.

Susan Hough has a bachelor's degree in geophysics from the University of California, Berkeley, and a doctorate in earth sciences from the Scripps Institution of Oceanography.

https://www.usgs.gov/staff-profiles/ susan-hough
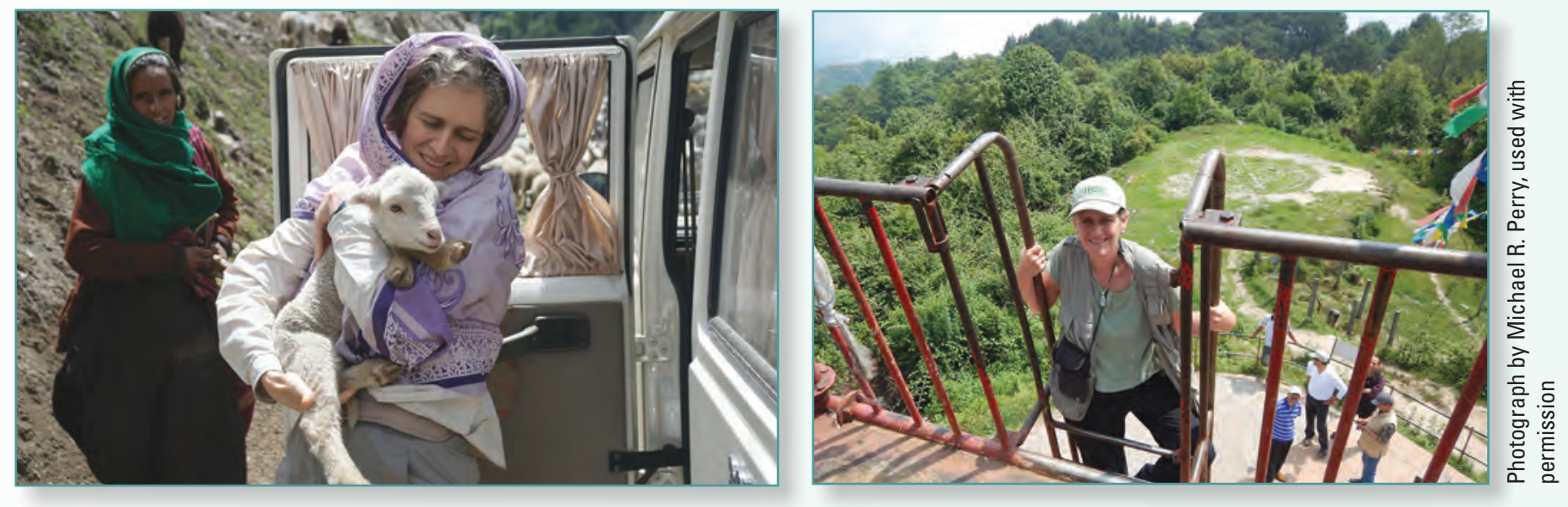


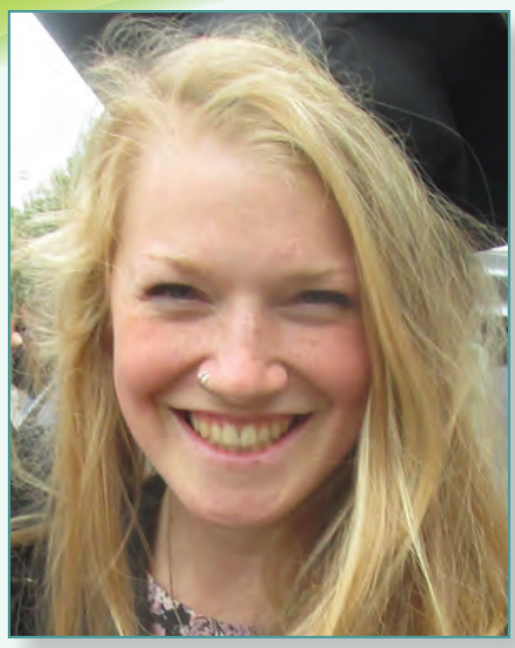

My forest hydrology professor in college used stream gauges to assess a watershed's response to weather events and snowmelt runoff; he had a few grad students who loved visiting the scenic data collection sites, and I joined them sometimes for field experience. Each of them mentioned that the professor had planned on retiring a couple of years earlier but kept agreeing to advise each of them for their thesis as one last project. If you find something you love so enthusiastically that you don't want to quit, stick with it.

Kate Jones has a bachelor's degree in environmental science and a track certificate in hydrologic engineering from Oregon State University.

https://www.usgs.gov/staff-profiles/ kate-k-jones

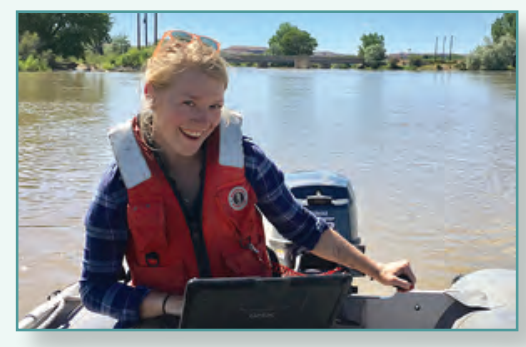

Kate Jones

\section{Hydrologic Technician with the Utah Water Science Center in Salt Lake City, Utah}

"Optimism is a strategy for making a better future. Because unless you believe that the future can be better, you are unlikely to step up and take responsibility for making it so." - Noam Chomsky

I grew up in western Oregon where the lush rainforest shaped my love of the outdoors. The sun peeking through the trees after a storm not only meant blooming flowers but beckoned a chance to get outside, inviting a game of capture the flag or a walk in the fresh air. This led me to complete my bachelor's degree in my home State.

I spent a summer in Dakar, Senegal, when I was an undergraduate student, and this gave me a fresh take on the way a community can come together to collectively manage their water supply. The dense and vibrant city, even though afflicted by many persistent socioeconomic issues, has managed to launch powerful programs to tackle water sanitation problems by using careful planning and an impressive ability to collectively compromise to take steps forward.

As a hydrologic technician for the USGS, I spend a lot of time out in the Green River Basin, taking measurements for water flow and water quality and surveying topographic changes to ensure the integrity of data collected. Otherwise I am in the office, writing data analysis reports, preparing data to be published, and working with State and county cooperators and other scientists to help them get the data they need.

Living in Salt Lake City, I enjoy the unique landscape of breathtaking cascading mountains just a few miles from the city and from the office. I am very lucky to live in a place where in just minutes I can be up at the mountain skiing, hiking, or biking, or can hop in the car with some friends and in a few hours be in one of Utah's majestic national parks. I also play fiddle in a band we've created in the office to play for retirement and holiday parties.
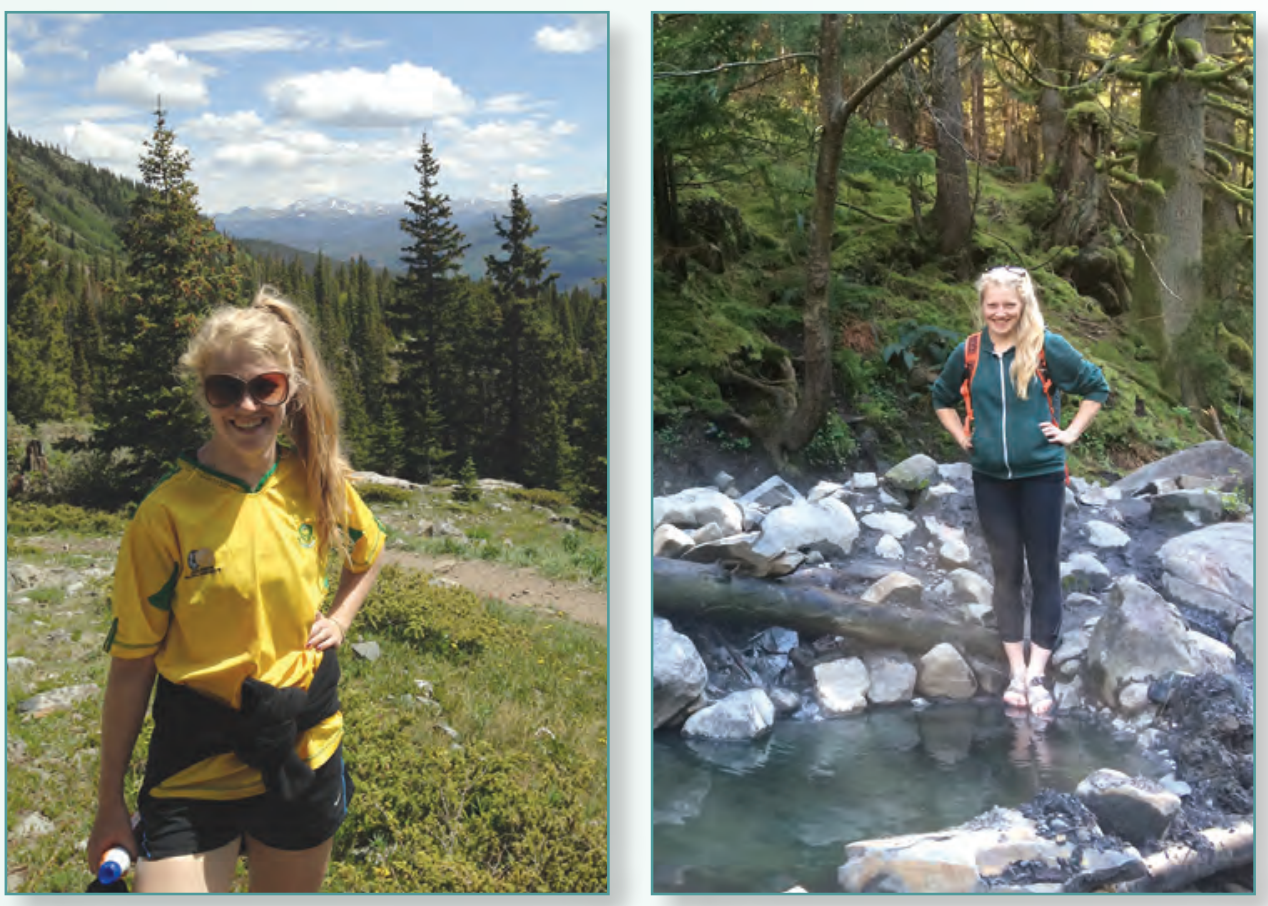


\section{Leslie Gones}

\section{Deputy Associate Director for Communications and Publishing and Chief of the Science Publishing Network in Reston, Virginia}

"We can judge the heart of a man by his treatment of animals." —Immanuel Kant

As a child, I collected all kinds of treasures from nature - sea shells, bird's nests, unusual rocks, fossils, leaves, and flowers - and at age 10 received a gift of a real microscope. My first exposure to geology in ninth grade science class was fascinating, learning about the layers of the Earth and the powerful processes that made mountains and moved continents.

In college, I took geology and biology courses. During finals week of freshman year, a woman scientist from the USGS called, asking if I was interested in a summer job curating her fossil collection. I imagined myself with picks and brushes, delicately exposing T. Rex skeletons from Cretaceous rock and immediately accepted! Though the reality was labeling plastic vials of dirt containing nannofossils, I found myself supporting a team of scientists studying paleoclimates using ostracodes, foraminifera, and nannofossils. I performed lab analyses and field work, and I even became quite proficient with the scanning electron microscope. I had my own research projects and co-wrote several articles that were published in journals.

However, I realized after 6 years that, while we were very good at communicating with fellow scientists, there was a growing need for people who could verbally and visually translate our complex scientific research into language that helped nonscientists understand and value our work. I spent several years in scientific publishing, creating new products designed for lay audiences. I developed some of the first websites the USGS ever had, finding new channels through which to deliver our story. A colleague and I created a new type of briefing series for Congress in which we invited end users of USGS science to speak about the importance of our information and data to their decision making. I founded one of the first employee communications programs in the Federal Government, including deployment of an intranet with social media features like blogs and podcasts from USGS leaders. Now, as the manager of the science publishing arm of the USGS, I work with my team to make USGS science more accessible. New technologies we are employing not only streamline production and delivery of our scientific publications, they also help the public in discovering and using our information and data.

My husband and I live with our three rescue dogs on a 73-acre farm in Virginia where we raise horses, hay, berries, and bees.
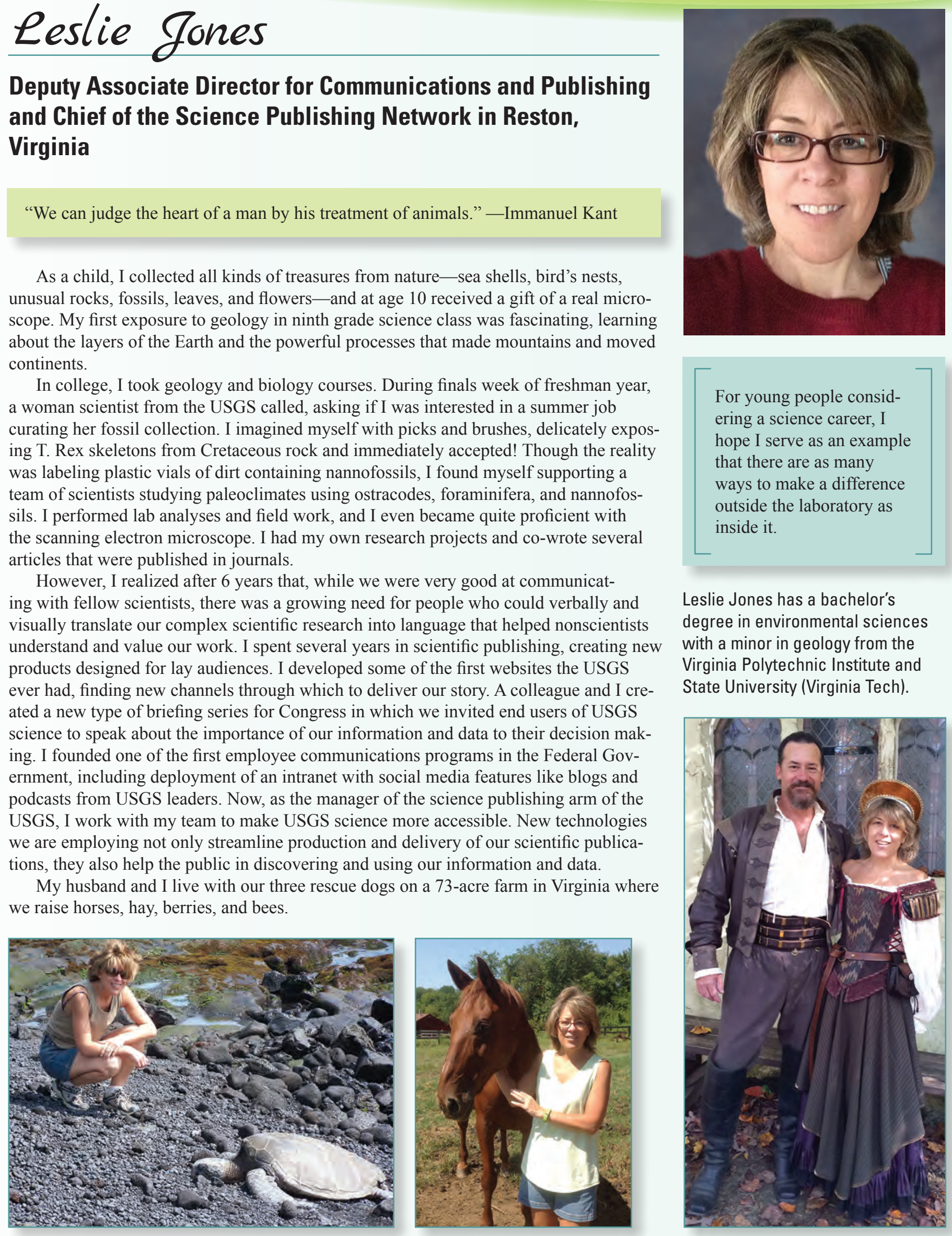

For young people considering a science career, I hope I serve as an example that there are as many ways to make a difference outside the laboratory as inside it.

Leslie Jones has a bachelor's degree in environmental sciences with a minor in geology from the Virginia Polytechnic Institute and State University (Virginia Tech).

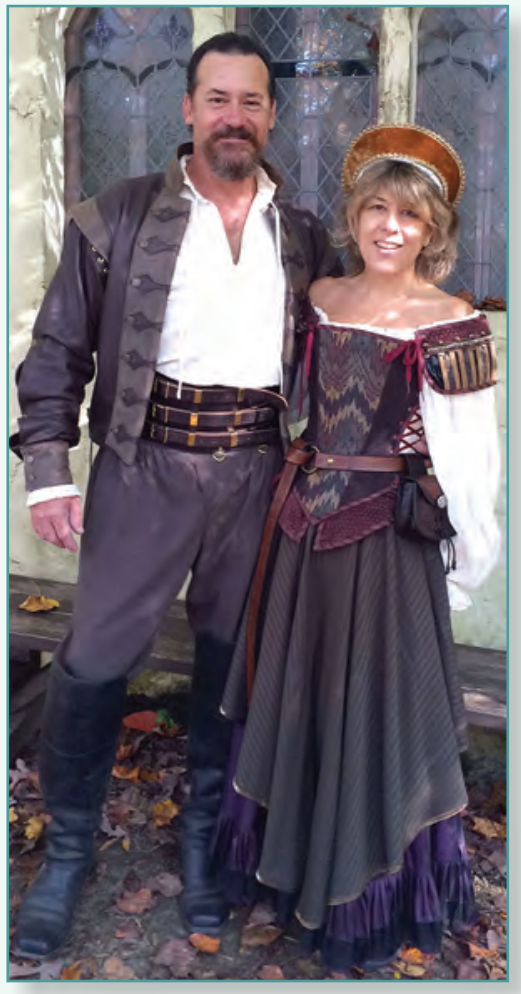




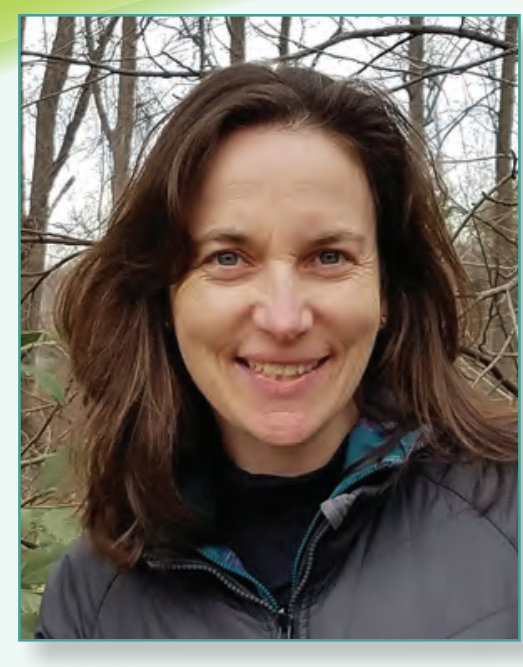

People may think that to work in the sciences, to work for the USGS, you have to be one of those people who loved all of their science classes and never wanted to be a writer or a ballerina. But that's not true. I didn't start out in this field. Eventually, my other interests led me to it. I was really intimidated at first, but it feels great to do something that really matters.

\section{Jeni Keisman has a bachelor's} degree in history from St. Mary's College of Maryland, a master's in sustainable development and conservation biology from the University of Maryland, College Park, and a doctorate in ecology and evolutionary biology from Princeton University. https://www.usgs.gov/staff-profiles/ jeni-keisman

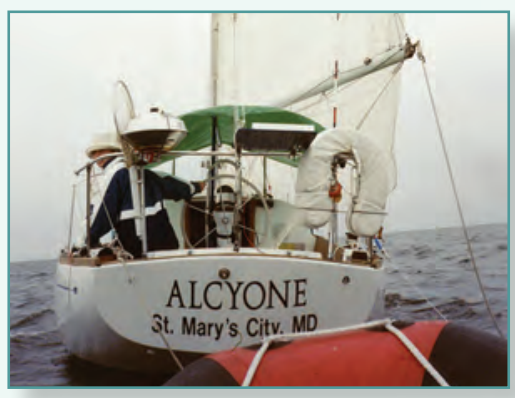

\section{Jeni Keisman}

\section{Biologist in the Maryland, Delaware, and District of Columbia Water Science Center in Baltimore, Maryland}

"Never let your fear decide your fate." —-Awolnation

As a child, I loved to be outside. My brother and I would spend hours playing in the woods around our house. The forests in Connecticut are strewn with boulders left behind by ancient glaciers. We would chip pieces of quartz off of the boulders with a chisel and pretend that they were precious stones, caching them like hidden treasure. My mom also loved to garden, and I often helped her with her planting and weeding. I learned to love the feel of soil on my hands and under my bare feet. Even though I'd yet to even hear of ecosystem ecology, I was already drawn to the nature that I would end up studying years later.

When I was young, everyone told me that I was going to be a great writer someday. That was where I excelled in school. Even when I was working on my Ph.D. at Princeton University, a well-meaning committee member asked me if I was sure I wouldn't rather be a science writer than a scientist! My undergraduate degree was in history, and my first job out of college was as a technical writer at an information technology company where I wrote online user help manuals. The tedium of typing "click OK to continue" over and over again motivated me to learn how to code the software instead. This experience definitely smoothed my transition into a career in science.

One of the skills that I picked up as a technical writer was the ability to communicate with technical and nontechnical audiences alike, which I have been able to use when working with fellow scientists as well as when sharing my science with the public, policy makers, and natural resource managers. I focus my time on the Chesapeake Bay, researching the effects of natural forces and human activities on the watershed and estuary. I am inspired to learn how the watershed and estuarine ecosystems have changed over time and to use that knowledge to help those who manage these resources do so in a sustainable way.

My diverse background has led to an equally diverse array of interests and hobbies. I love talking to people and traveling to new places as much as I love just curling up with my laptop, crunching numbers, and turning them into stories. I love living, working, and playing on the Chesapeake Bay and the Atlantic Ocean. I enjoy sailing, boogie boarding, hiking, and skiing with my husband and son. My favorite project at home right now is a pollinator- and bird-friendly garden. I recently planted some milkweed, and I'm hoping that it will eventually attract some monarch butterflies!
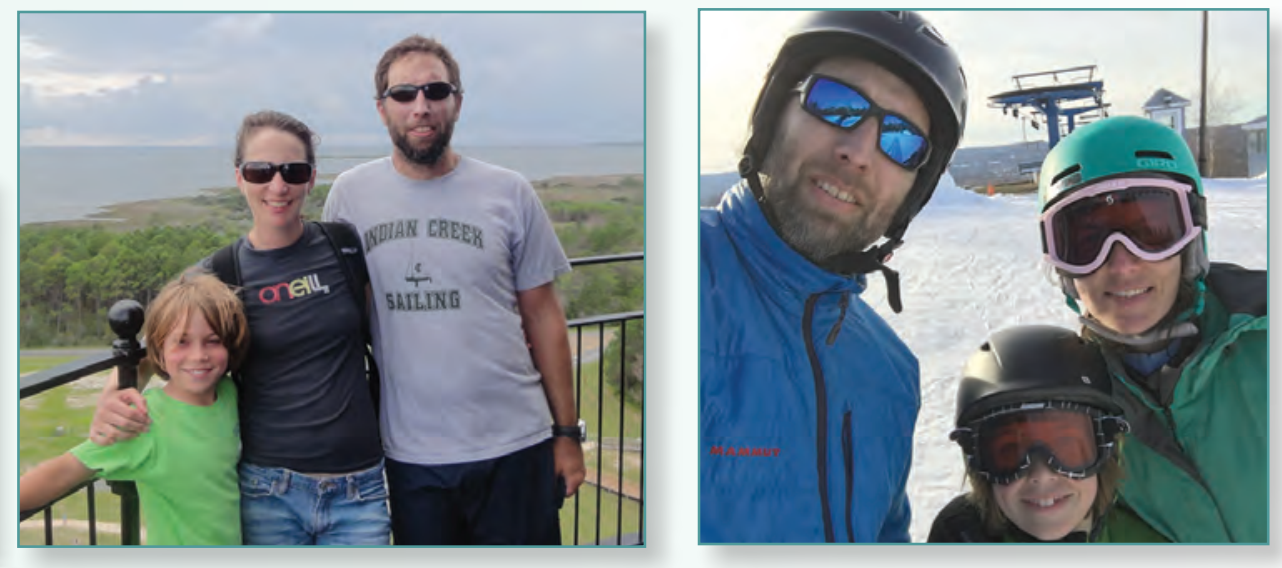


\section{Gulie Kiang}

\section{Chief of the Analysis and Prediction Branch of the Water Mission Area in Reston, Virginia}

"Hope is like a path in the countryside. Originally, there is nothing - but as people walk this way again and again, a path appears." — Lu Xun

My family moved from Illinois to California when I was in junior high school. The bone-dry summers in California made an impression, especially when the local newspapers began talking about the need to be careful about water use. It is no coincidence that I was attracted to and spent my early career working on water supply issues. In college, courses in fluid mechanics and hydrology spurred the realization that the field of water resources would allow me to spend my career working to understand how natural processes work and applying that knowledge to problems of fundamental importance to humans, including predicting hazards such as floods and droughts.

Before coming to the USGS, I helped manage water supply for the Washington, D.C., metropolitan area during droughts as a water resources engineer. I also worked as a consultant to water suppliers in other parts of the country. At the USGS, I have worked on topics spanning floods, droughts, streamflow modeling, and the effects of climate and land-use change on water resources. I believe that understanding the limits of our data will lead to better data programs and better water solutions for a thirsty world. I lead national projects that seek to use streamflow and other data to better understand the availability of water in the United States and to quantify risks from natural disasters such as floods and droughts. I work with both young and experienced hydrologists throughout the USGS water science centers; the exchange of ideas within our community keeps the job fun and exciting.

In my free time I love to be out on the water canoeing and kayaking. I have even built my own wooden kayak! Even though my work doesn't involve a lot of field trips, I'm glad that I can spend my days thinking about a topic that is near to my heart. I also spend a lot of free time on musical pursuits; I play fiddle in a string band and dabble with the mandolin and the piano.
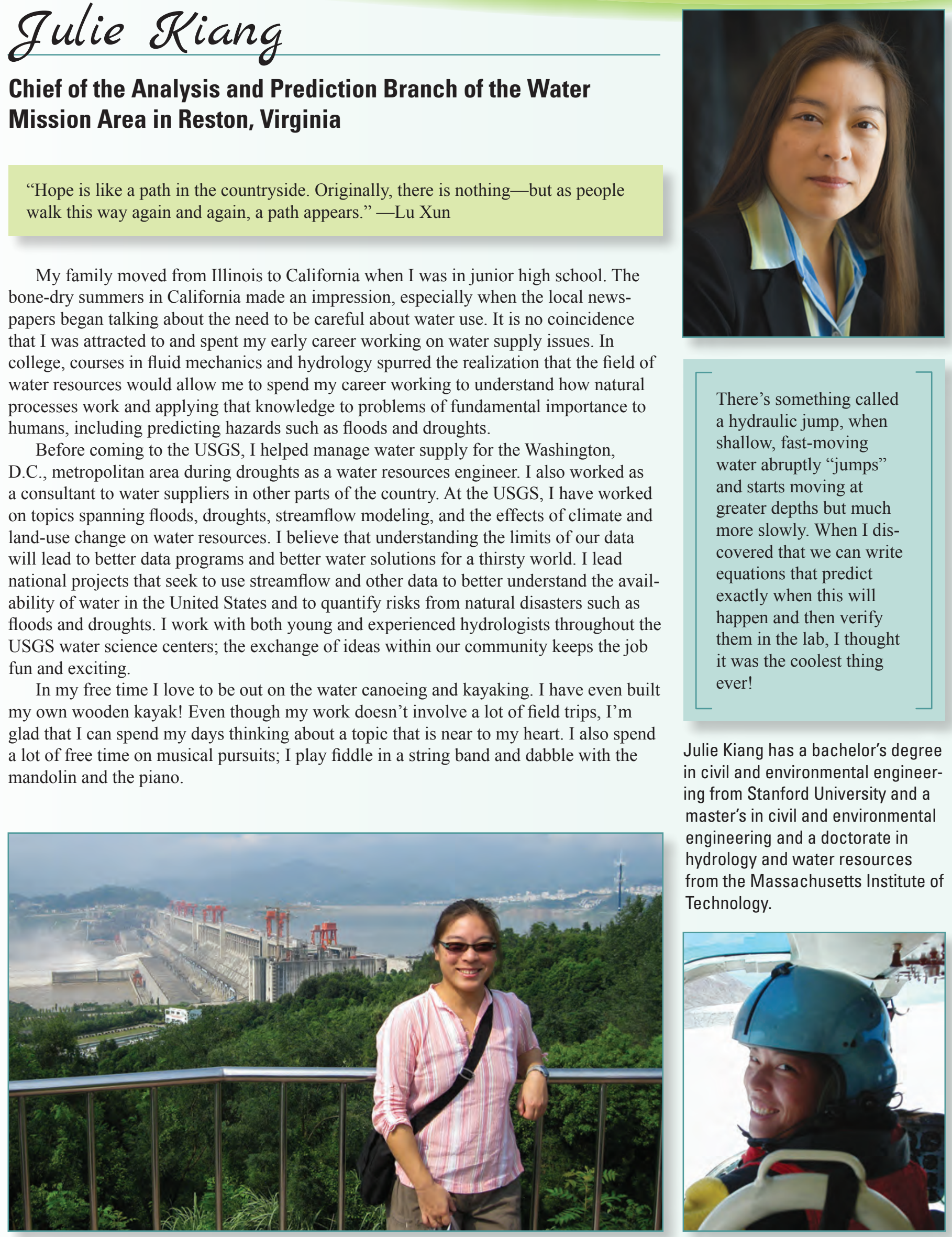

There's something called a hydraulic jump, when shallow, fast-moving water abruptly "jumps" and starts moving at greater depths but much more slowly. When I discovered that we can write equations that predict exactly when this will happen and then verify them in the lab, I thought it was the coolest thing ever!

Julie Kiang has a bachelor's degree in civil and environmental engineering from Stanford University and a master's in civil and environmental engineering and a doctorate in hydrology and water resources from the Massachusetts Institute of Technology.

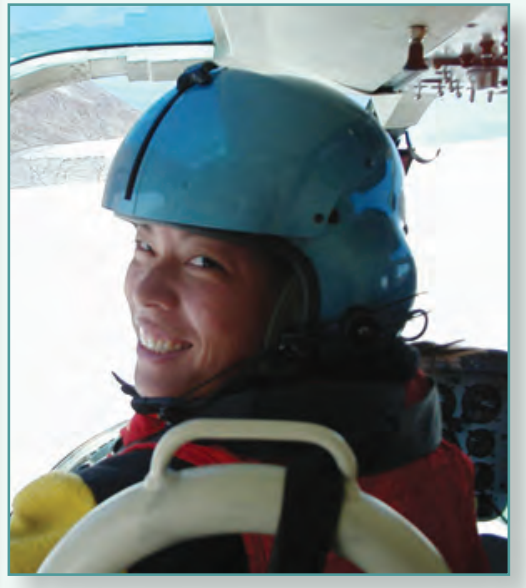




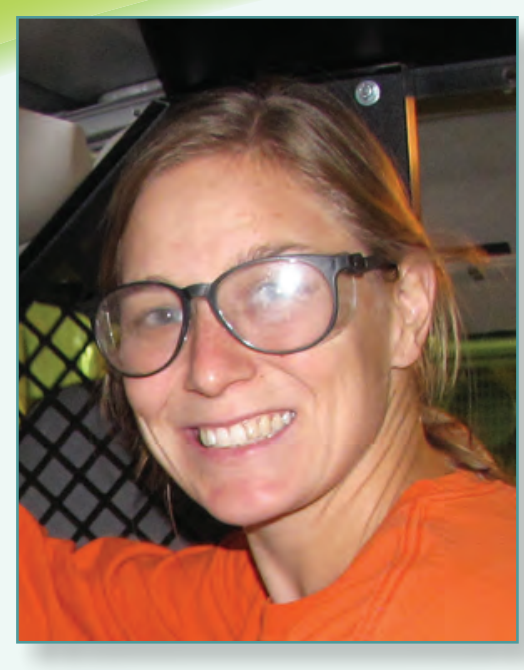

When you feel strongly about something or feel a deep connection to a particular thing, pursue it. Be open to changing your mind, but explore the options you are drawn to. You can have many passions, which may change, but there are few things that bring more happiness than spending your time doing things that are important to you.

Heather Krempa has a bachelor's degree in chemistry from the Benedictine College and a master's in biology from the University of Central Missouri. https://www.usgs.gov/staff-profiles/heather-m-krempa

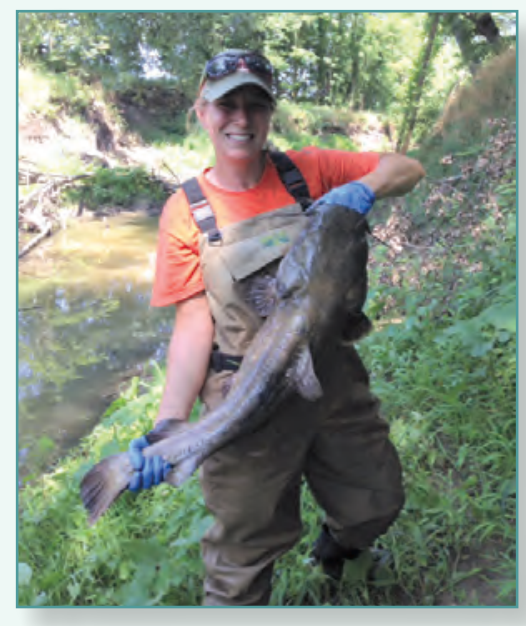

Heather Krempa

\section{Hydrologist with the Missouri Water Science Center in Lee's Summit, Missouri}

My passion for biology and drive to further understand the natural world was launched by my high school biology teacher. He used his time and resources to bring students outdoors to experience and explore the world that we were studying. He was a role model to look up to not only professionally but also as a kind, compassionate, and encouraging person.

During undergraduate school I traveled to the Amazon rainforest in Peru with the biology department at my university and was able to experience the amazing social culture and biological diversity of the rainforest. This experience opened my eyes to a way of life that was previously unknown to me. I spent a lot of time with villagers whose main resources were limited to what was available naturally, and they spent a great amount of time with family and as a community. The children were the most generous individuals I had ever met. Our native guides were intimately connected to their environment and were able to help us forage meals and construct shelter on a camping excursion. The plant and animal diversity was awe inspiring, and the whole experience instilled in me a passion for adventure, exploration, and understanding of new cultures and habitats.

At work, my research tries to understand the effects that proposed water control structures have on the water quality, flow, and stream health and on the communities of amphibians at wetlands that dry up during hot seasons and long droughts. I also assess the effects of conservation practices and agricultural activities on stream and river quality.

My hobbies include mountain bike riding, rock climbing, and hiking mountains. I have met irreplaceable friends during these adventures who inspire me to continue to get out there and explore and never give up on pushing myself to be better and go further. I camp a lot during these adventures and love great conversation around a campfire after a hard physical day of exploring. I also enjoy gardening and hunting for ecologically sustainable food resources and to be more connected to our environment. The cliffs of the Ozarks hold a special place in my heart. This is where I first learned to rock climb and where I discovered that the world holds secret wondrous views reserved for the adventurers that push limits and travel the roughest and hardest paths. I try to bring this mentality to all things that I pursue, remembering that the hardest roads bring you the greatest rewards.
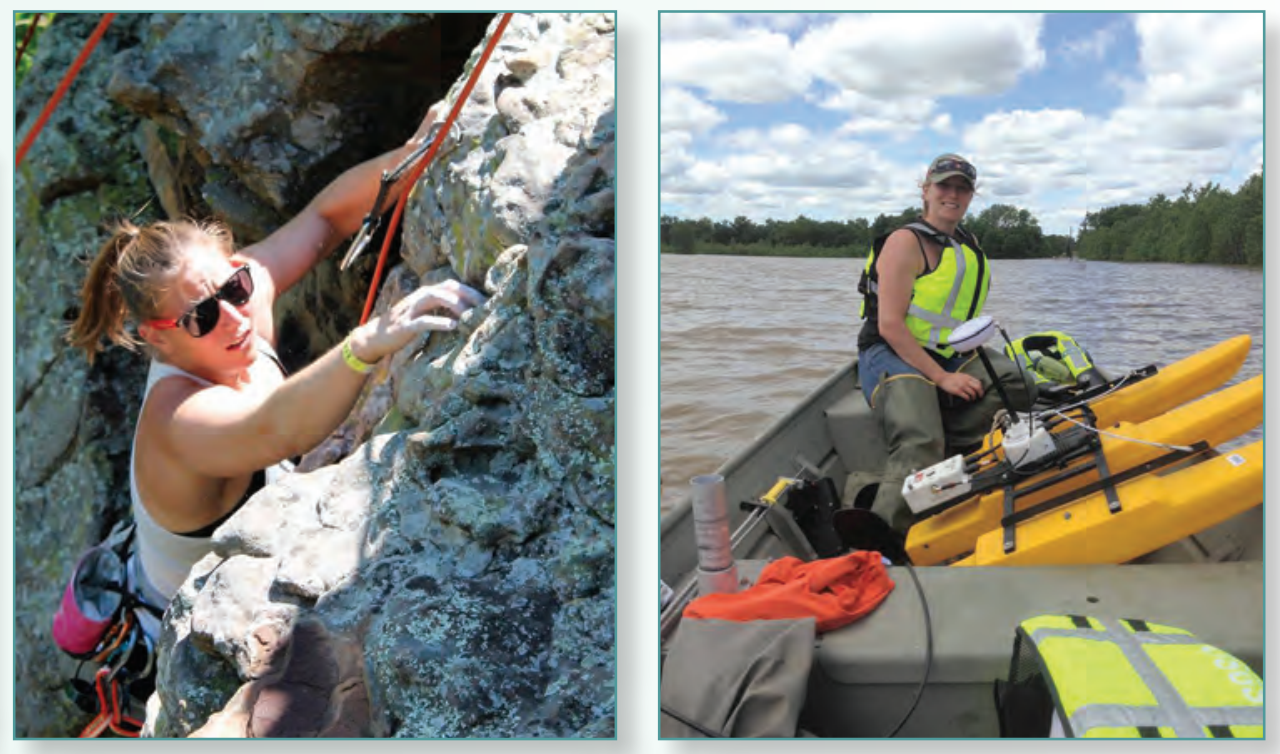


\section{Gennifer Lacey}

\section{Observing Systems Branch Chief with the Earth Resources Observation and Science Center in Sioux Falls, South Dakota}

"We must have perseverance and above all confidence in ourselves. We must believe that we are gifted for something and that this thing must be attained." - Marie Curie

As a child, I knew that little girls in South Dakota grew up to be teachers, nurses, or maybe even lawyers like my two uncles. The thing was, I liked mathematics; I liked the calculus of figuring out angles for scrambling over rocks and up hillsides. In high school, I loved the way one of my teachers turned math problems into witty, funny stories. So I pursued a math degree in college and was all set to pursue a career as an actuary when a chance visit with my college Math Club to the USGS Earth Resources Observation and Science (EROS) Center near Sioux Falls, South Dakota, changed all that. Talk about love at first sight! At EROS, my passion for math was inflamed by the possibilities of working with satellites, algorithms, and earth science data. Before our visit, I had no idea such a place existed, so I submitted my resume to the center - the only one I ever sent out - and have been enthralled ever since with the work of data processing and archiving, project management, and software development.

With the USGS, I oversee the operations of the Landsat satellites, including two Mission Operations Centers located at the National Aeronautics and Space Administration's Goddard Space Flight Center in Maryland. I was at Vandenberg Air Force Base in California for the launch of the Landsat 8 satellite; that was one of my proudest moments. For the first time, the USGS was involved in developing and helping to launch a Landsat satellite, and I was on the front lines of that effort. Today, I lead the team that collects, catalogs, and archives Earth imagery, and I oversee the daily operations of the Landsat 7 and 8 satellites, working with flight operations teams and other staff to efficiently and effectively ensure that these valuable assets continue to enable world-class science. We are now also working on the Landsat 9 mission, which is scheduled to launch in December 2020. It is exciting to be a part of the continuation of our unprecedented land imaging record of the world!

It has been an exciting career for the girl who loves equations. Turns out knowing numbers is handy outside the office, too, whether calculating the miles for the traveling I love to do or squeezing faster times out of the road races I run. In fact, my husband and I are trying to run in all 50 States. The math is getting easier on that one; we only have five left!
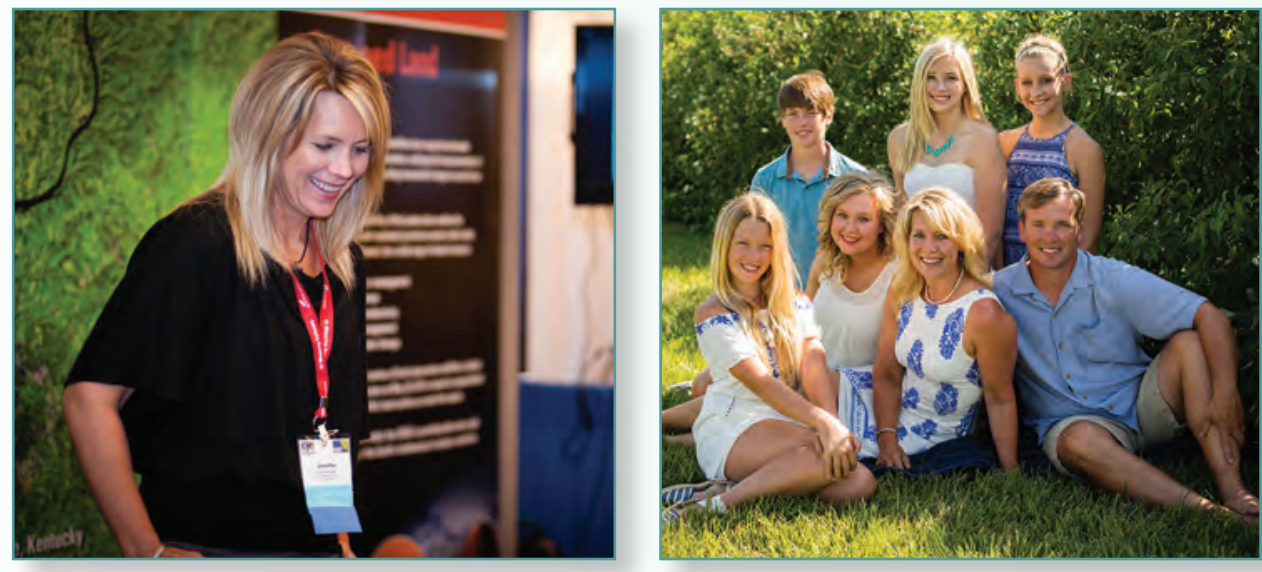
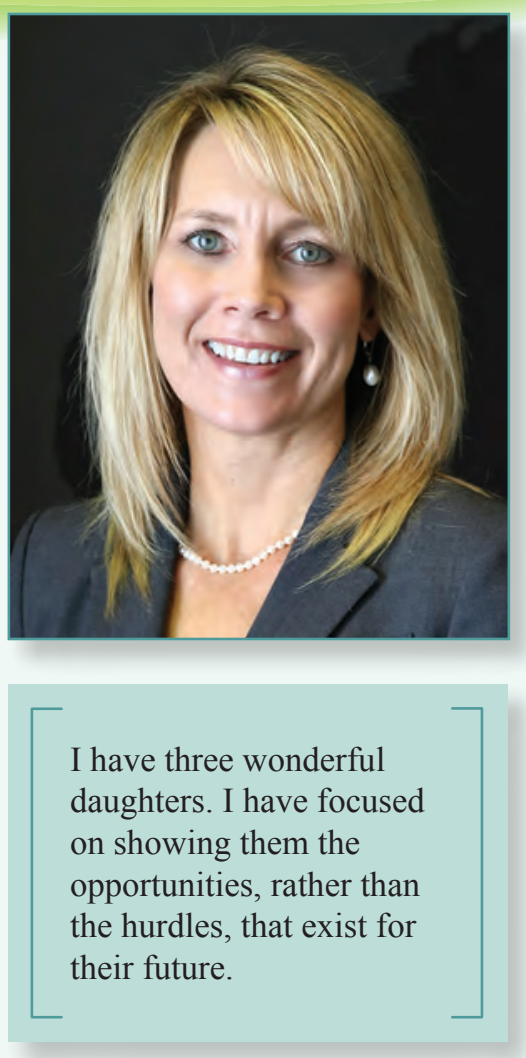

Jennifer Lacey has a bachelor's and a master's degree in mathematics from the University of South Dakota and has worked toward her doctorate in geospatial science and engineering at South Dakota State University.

https://www.usgs.gov/staff-profiles/ jennifer-lacey

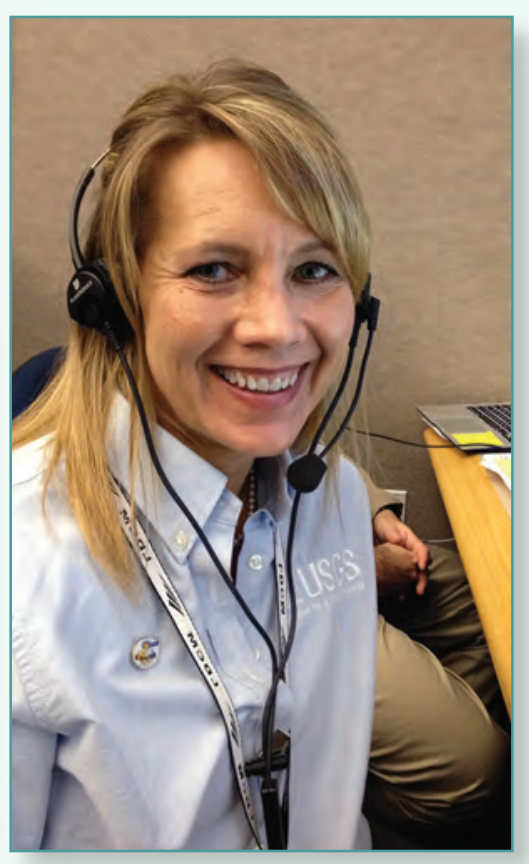




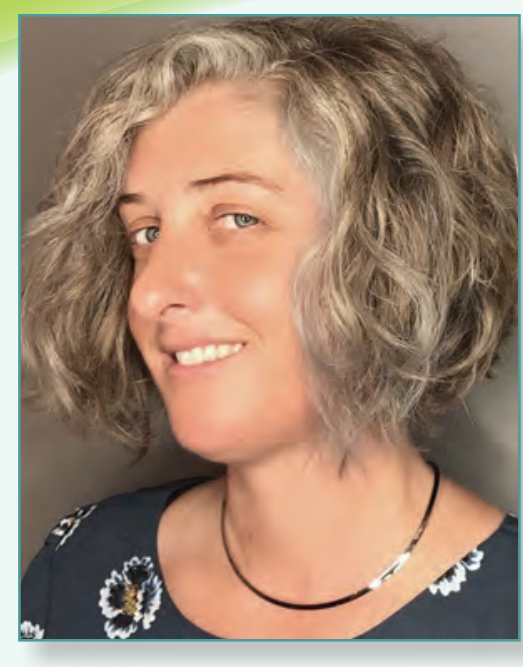

Great careers are curated and developed. The path you start on may not be the path you end on, and that is okay. Science and science support is one of the most cross-disciplinary career domains you'll find, and that's why it is a lot of fun to be working in this profession.

Cassandra Ladino has a bachelor's degree in geography and environmental science and master's degrees in information systems and geographic information systems from the University of Maryland, Baltimore County.

https://www.usgs.gov/staff-profiles/ cassandra-ladino

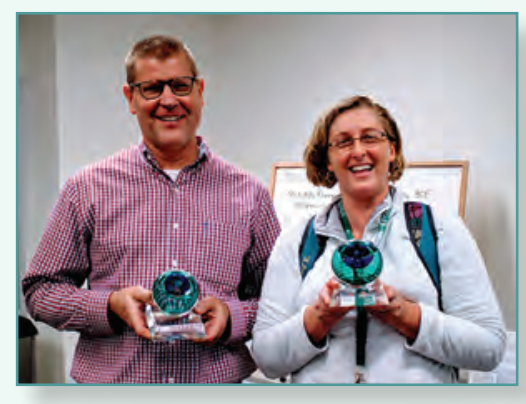

\section{eassandra Radino}

\section{Physical Scientist with the Office of Enterprise Information in Reston, Virginia}

"Learn every day, share what you know!" —Anonymous

I started at the USGS as a student volunteer. At the time, I was very young and not sure about the profession I wanted to pursue. However, I quickly came to love working at the USGS because it was a really creative environment. I began my career as a geographic information systems (GIS) specialist and enjoyed solving questions that didn't always have straightforward answers. My work at the USGS also gave me a way to connect to my own backyard in the Chesapeake Bay watershed. My supervisor was highly influential in my career and encouraged team mentoring and opportunities to learn new skill sets. As a result, I progressed from being a GIS specialist, to being a software developer and a lead data management expert for the agency.

Today, I enjoy working for the Office of Enterprise Information and supporting scientists with enterprise data management needs. My role involves providing expertise in information management and technology and representing the USGS at Federal Open Data meetings.

Work-life balance is important, and in my free time I enjoy traveling and photography. I find that being creative in my personal life helps me be more creative at work. I also have a group of friends that I've made through getting to know other recent graduates who have taken positions at the USGS. We do out-of-office activities like playing volleyball and going to baseball games.

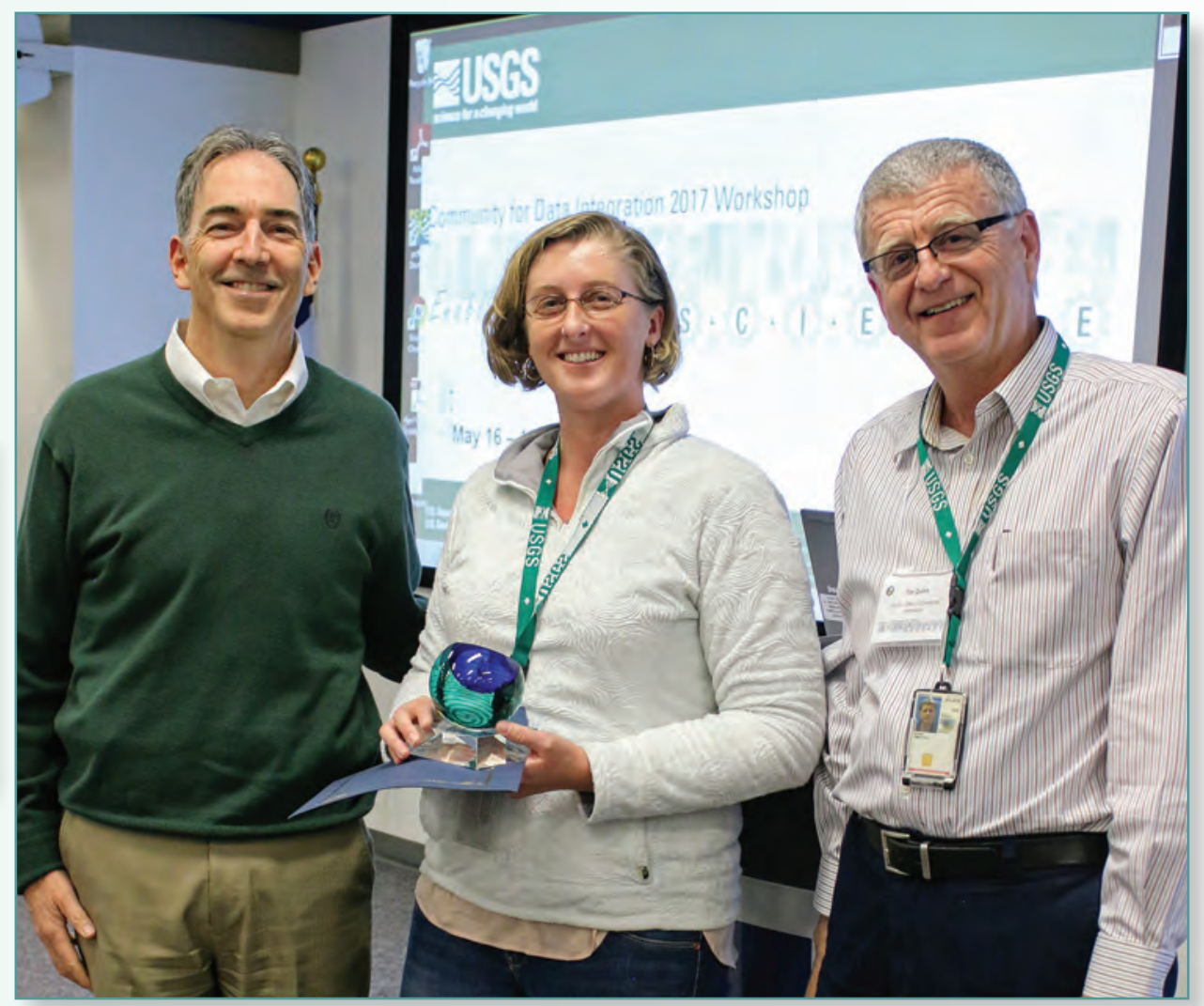




\section{Kathy Lee}

\section{Deputy Program Coordinator of the Toxic Substances Hydrology Program in Reston, Virginia}

"Life is not easy for any of us. But what of that? We must have perseverance and above all confidence in ourselves. We must believe that we are gifted for something and that this thing must be attained." - Marie Curie

My curiosity and love of science developed during childhood. Much to my parents' chagrin, I recall digging ditches in my backyard as a child to understand water movement. I spent hours exploring local streams observing the animals and plants that reside there. Throughout my life, I was lucky to have many teachers who fostered my love of science. I can't say enough about the influence teachers have had in the formation of my career.

I started working with the USGS as a graduate student, studying how different types of vegetation in wetlands influence how quickly pesticides break down in water. I continued as a hydrologist, working with and leading teams researching the effects of chemical and physical stressors on animal and plant life in aquatic systems. I spent many cherished hours in the field collecting water samples and aquatic organisms from streams and lakes throughout the country.

Because of the support of my colleagues and supervisors at the USGS, I have had the opportunity and freedom to pursue my career goals in balance with my family life. I'm proud to have been able to pursue science throughout my career at the USGS that has provided information essential to prioritizing health issues arising from exposure to contaminants in the environment.

My husband and I live with our two children in the Northwoods of Minnesota. We intentionally chose a house outside of town to enjoy the natural surroundings and to encourage our children to explore. We kayak, boat on the local lake, hike, cross-country ski, and of course play hockey! We take every opportunity we can to explain the natural environment to our children and to give them information to help them understand the ecology of the area. I hope that like me they will also have wonderful teachers that open the world for them in their pursuits.

I love the cool mornings and evenings watching the wildlife. The mayfly hatches from the lakes and rivers here in northern Minnesota, and the tandem dragonfly and mosquito emergence is truly a site to see! They are a reminder of our interconnectedness with the physical environment and other living organisms.

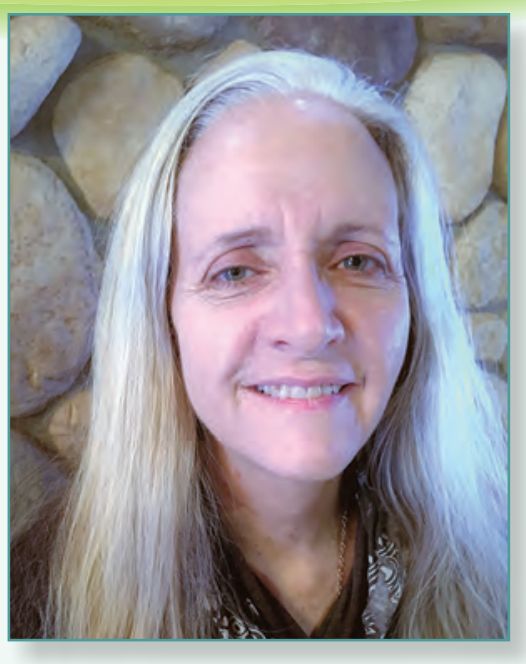

I am honored to work as part of a team at the USGS to provide scientific data critical to protect the health of our Nation.

Kathy Lee has a bachelor's degree in environmental science and a master's in aquatic ecology from the University of Kansas. https://www.usgs.gov/staff-profiles/ kathy-e-lee
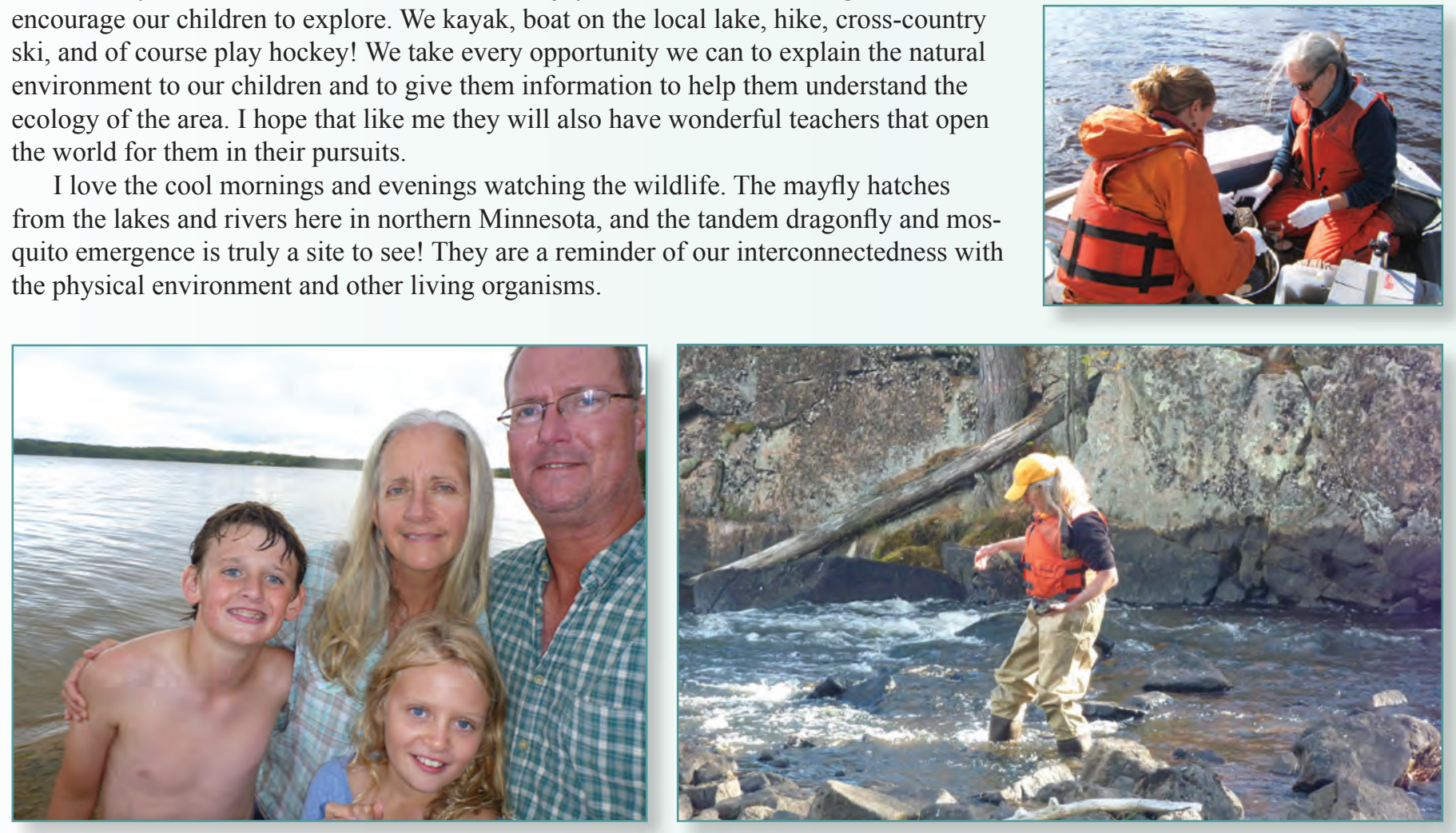


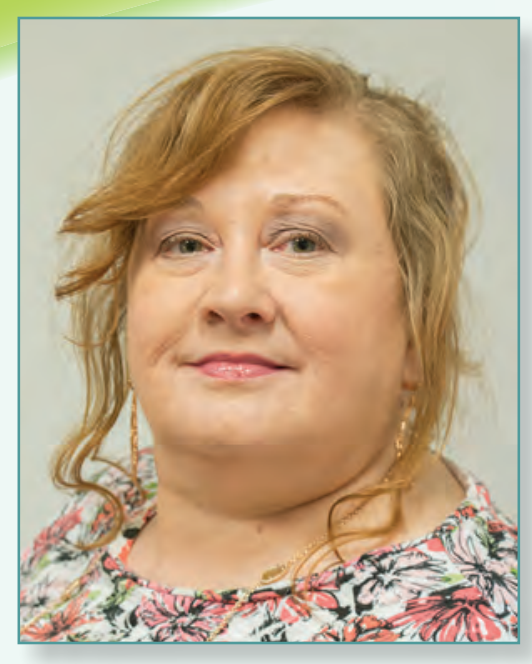

It is nice to know that the science that I support in my work is so important for protecting lives and property and for managing natural resources. In addition, the public has such a positive response to the work we do at the USGS. I love working for the USGS because there is a strong family friendly work environment.

Cindy Lonergan has a bachelor's degree in business administration from George Mason University.

\section{Eindy Eonergan}

\section{Supervisory Human Resources Specialist with the Office of Human Capital in Reston, Virginia}

Service to the country runs in my family. My father was a Navy chaplain, and listening to the stories of my dad helping people inspired me to want to make a difference in people's lives. In college, I had two professors that made human resources management interesting and fun. They are the reason that I majored in management with a concentration in human resources, and one of my professors was instrumental in helping me get my first government job in human resources.

I started working for the Government in human resources, providing services that included staffing, employee benefits and relations, and other human resource functions. I was drawn to the USGS because of the mission of the agency; I have been a program manager, providing human resources policy and services for senior leaders of the USGS, and now lead the team that provides those services.

With all three of our children having moved out of the house, my husband and I enjoy traveling and have made a number of trips to Napa Valley, California, to do wine tastings. Wine tasting has become a fun hobby for us to do together (but unfortunately has nothing to do with my job!).

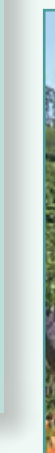

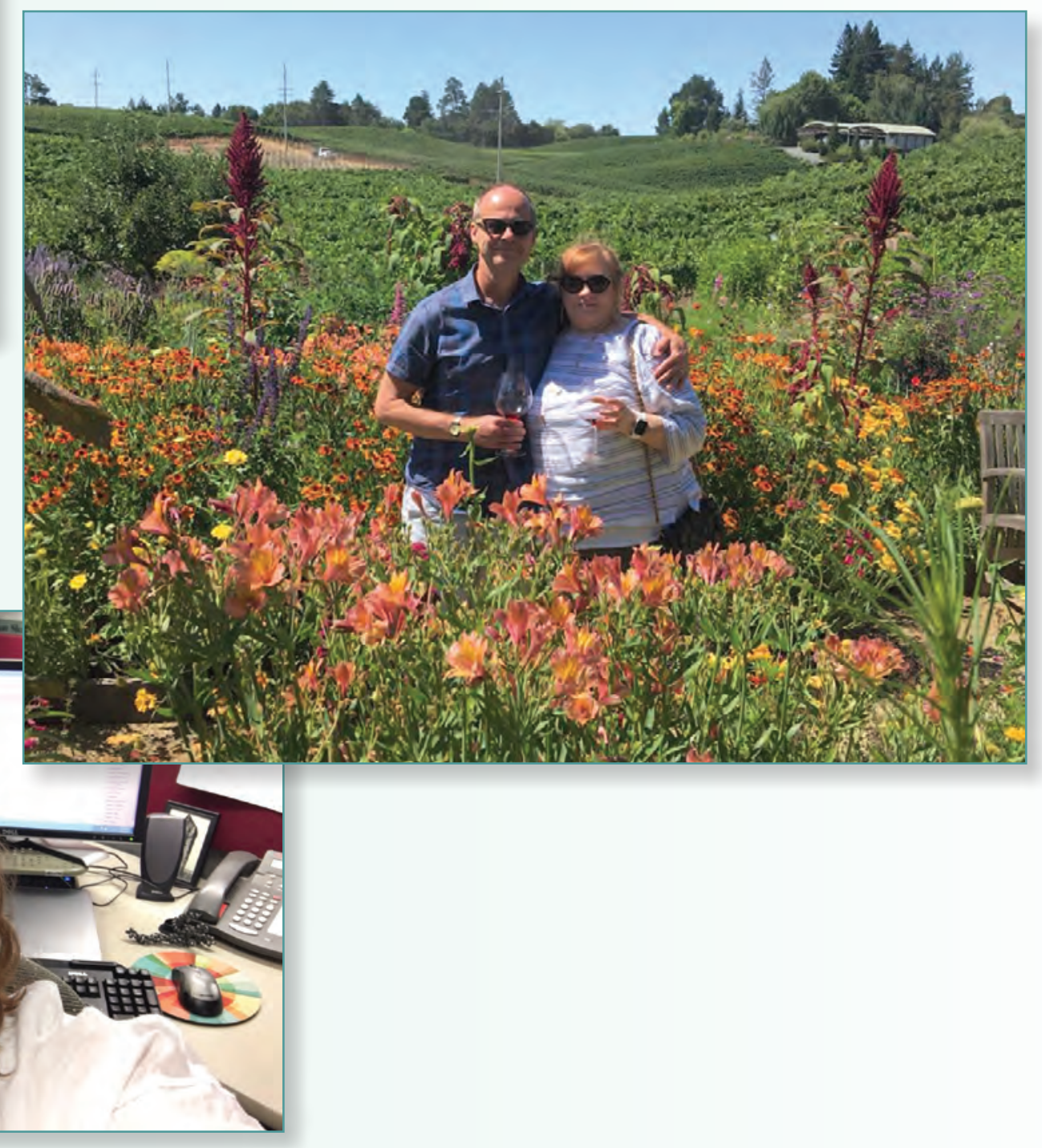




\section{Michelle Eorah}

\section{Research Hydrologist at the Maryland, Delaware, and District of Columbia Water Science Center in Baltimore, Maryland}

"Those who dwell, as scientists or laymen, among the beauties and mysteries of the Earth are never alone or weary of life." —-Rachel Carson

My father started rock and mineral collecting when I was 4 years old, and I spent many weekends throughout my childhood traveling with him to different places to hunt for specimens. His collection quickly took over our basement. I loved being outside, free to play in the dirt and enjoy all the beautiful places that we went to. Along the way, I learned so much from my dad about the Earth, mineral formations, and mining history, as well as how much fun it can be to discover new specimens. I was overjoyed when I later understood that geology could be a career, and people actually get paid to search for rocks!

I grew up in Slatington in eastern Pennsylvania, along the Lehigh River. I loved walking along the river and the view of the mountains from our small town. I undertook a science project in eighth grade to measure zinc concentrations along the Lehigh River, and I found high concentrations that were likely leaching from waste piles at a zinc-smelting plant upstream of our town. Another major influence on my career path was a marine sciences program that I did as an undergraduate student where we spent a semester living at Wallops Island, Va., learning coastal geology, ecology, and oceanography. The wetlands studies that we did were my favorite part of this field-based program and were an early influence on my interest in wetland contamination as a major area of research. In my last year as an undergraduate student, I took a hydrogeology class that I loved, which led me to apply to grad schools to focus on the study of water flowing through rocks. Combined with my earlier experiences, I knew that I wanted to focus on groundwater contamination.

I have spent my career working on solutions to eliminating hazardous waste contamination, and I enjoy doing research on real-life problems. Some of my work involves looking at microbes that can break down contaminants that have been in the soil for several decades. When I work with sensitive ecosystems, I try to disturb them as little as possible. I'm able to bring together my knowledge of groundwater and coastal and marine environments to help protect the ecosystems and habitats of wetlands and streams.

Outside of my career, my greatest joy has been raising two children (now 18 and 19 years old and studying science and engineering) with my husband, and our new favorite activity has become traveling to their college tennis and music events. I still enjoy hiking and birding, and I keep multiple feeders supplied on our property and at the office. I love to walk in the early morning hours, anywhere that I can see trees and hear birds. Yoga has also become a favorite activity in the past 20 years. No matter how busy I am, taking time for yoga keeps me happy and rejuvenated.

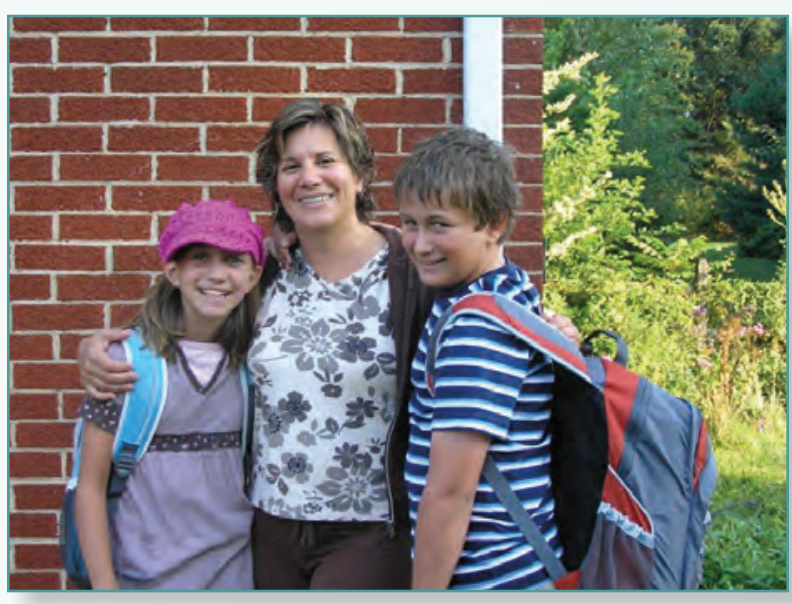

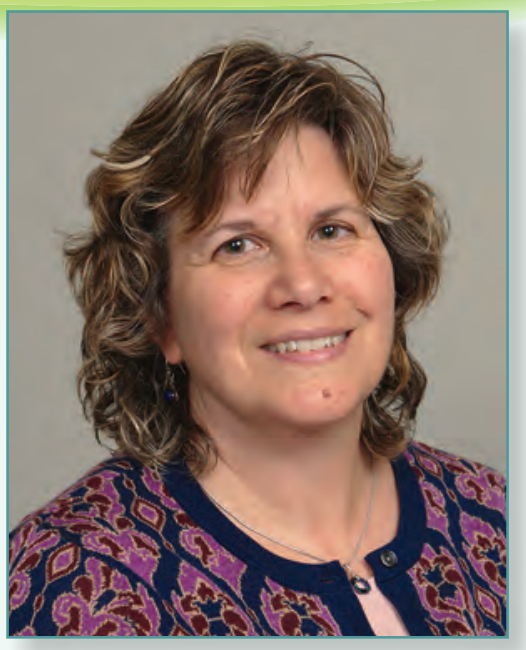

The same excitement in discovering something new and analyzing it, and determining what it is, all of which I experienced with my dad as a rock hound, is what has driven my career.

Michelle Lorah has a bachelor's degree in geosciences, with a minor in marine sciences, from Pennsylvania State University, a master's in environmental science from the University of Virginia, and a doctorate in environmental chemistry from the University of Maryland.

https://www.usgs.gov/staff-profiles/ michelle-lorah

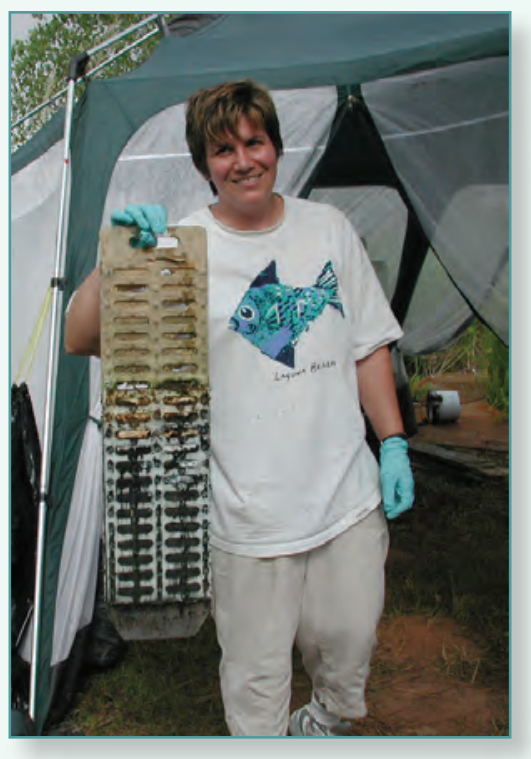




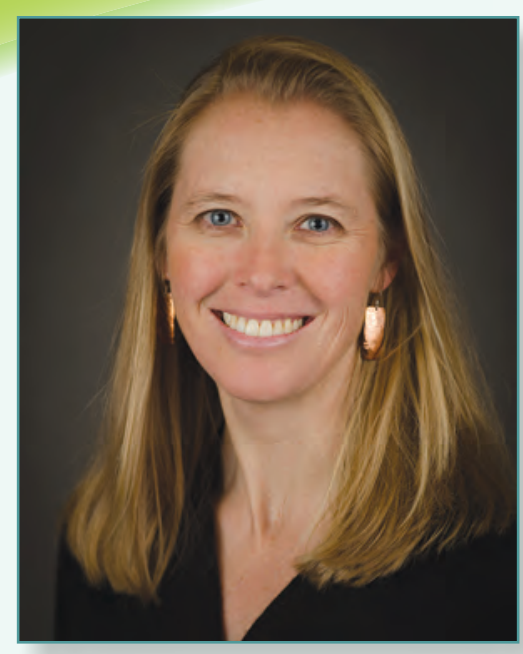

One of the things I enjoy the most about my work is the opportunity to work with so many bright, motivated people from different disciplines and sectors. On almost a daily basis, I cross disciplinary boundaries, take in new information, and forge new collaborations to apply science to socially relevant issues.

Kristin Ludwig has a bachelor's degree in earth systems from Stanford University and a master's and doctorate in oceanography from the University of Washington.

https://www.usgs.gov/staff-profiles/ kristin-ludwig

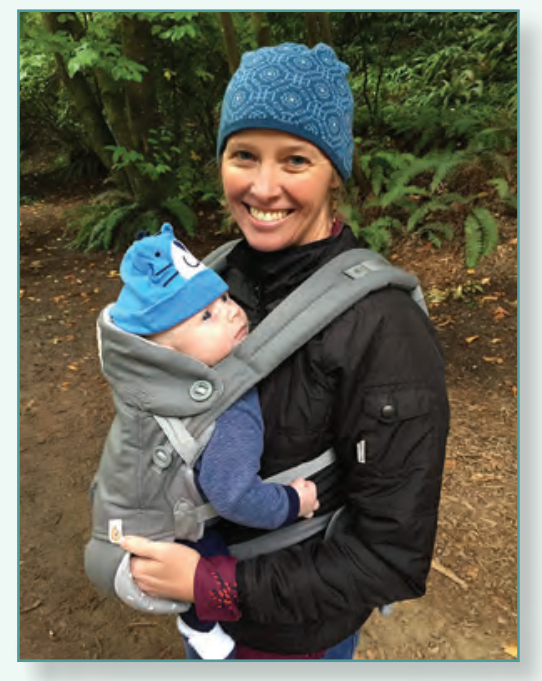

\section{Kristen Rudwig}

\section{Staff Scientist in the Natural Hazards Mission Area in Seattle, Washington}

I spent much of my childhood at the Denver Museum of Nature and Science; from building "twinkisaurs" (dinosaurs made out of Twinkies and toothpicks) to catching crayfish in the nearby City Park pond, I enjoyed any hands-on science class I could take at the museum. When I was a high school student, I had the opportunity to participate in my first oceanographic research expedition as part of the K-12 STEM program of JASON Learning. I spent a week at sea learning about submarine technology, studying rock samples, and dissecting tubeworms collected from hydrothermal vents located 6,500 feet below our ship in the Gulf of California. This inspired me to pursue a graduate degree in marine geology and a career in the earth sciences. While still in high school, I volunteered at the Denver Museum of Nature and Science and helped to design exhibits, which introduced me to new ways to work at the intersection of science, art, and public engagement.

I became interested in hazards and science policy during the Deepwater Horizon oil spill in 2010, when I realized my expertise in deep sea geology had relevance to a national crisis. At the time, I contributed to the academic community's response to the spill, and it spurred a desire to better understand the role of science and technology in informing response to natural- and human-caused disasters. Following that, I helped establish the U.S. Department of the Interior Strategic Sciences Group, which was created to quickly organize teams of experts in all sorts of fields to assess the short-term and long-term environmental, social, and economic consequences of a crisis and to identify possible interventions; this information would then be used to help those making decisions during environmental crises affecting resources stewarded by the Department. Two months after I started at the USGS, Hurricane Sandy barreled into the East Coast, and I found myself co-leading a field deployment to support recovery from the storm.

I love exploring new areas under my own power, whether it be on my skis, on my bike, or by foot. I've enjoyed cross-country skiing in places ranging from Nordic centers in the western United States to the National Mall in Washington, D.C., and McMurdo Station, Antarctica. I've gotten into road biking in the last couple of years and appreciate both the challenge of long-distance riding as well as the simple joy of cruising on a paved trail on a nice day. My husband and I enjoy spending time with our son, and when we're not on the trails, we are usually playing ultimate Frisbee, taking in a movie or ballgame, or chasing our dog at the dog park.
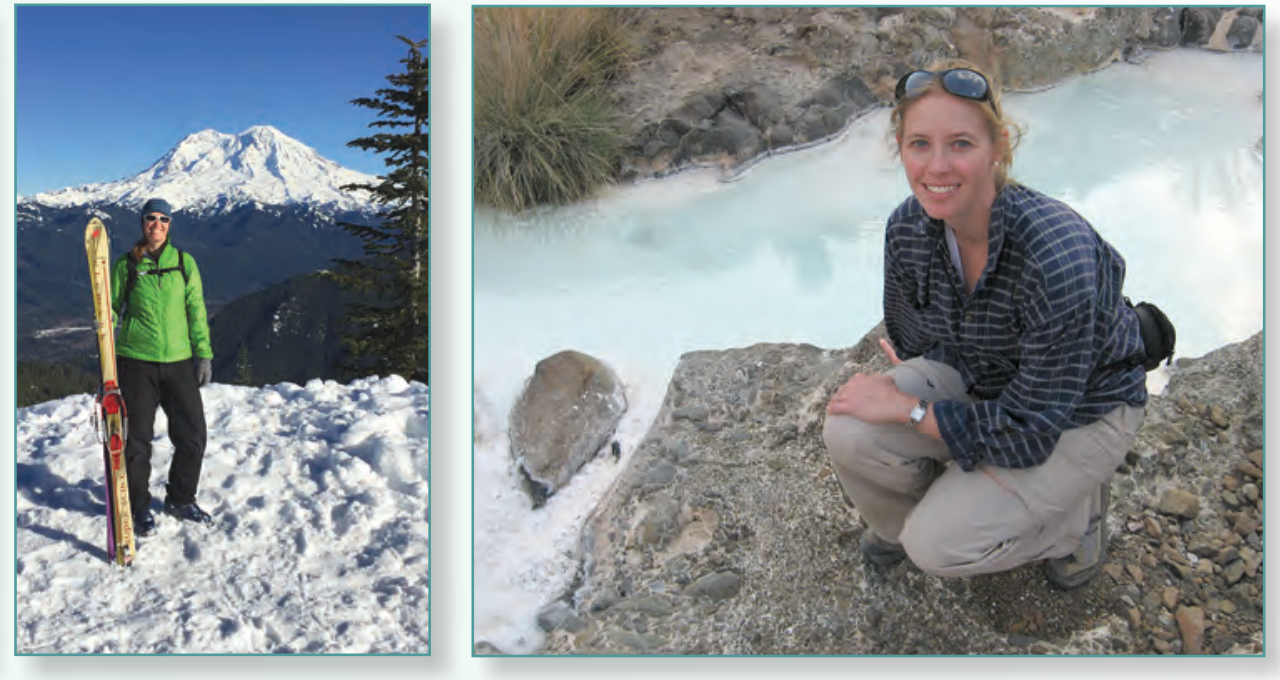


\section{Arista Maher}

\section{Budget Coordinator with the Energy and Minerals Mission Area and the Environmental Health Mission Area in Reston, Virginia}

\author{
"A genuine leader is not a searcher for consensus but a molder of consensus." \\ -Martin Luther King, Jr.
}

My interest in the intersection of policy and science started with great professors I had in undergraduate and graduate school. On the science side, my graduate professors and mentors at George Washington University sparked an interest in public health and health policy. In particular, learning about the environmental and public health crises in the aftermath of Hurricane Katrina and the graduate studies I did on public health policy after the emergence of the bird flu in Asia inspired me to look for a career that combined the skill sets needed for understanding complex policy and scientific issues. My experience working in the U.S. Senate during my graduate studies was influential in giving me a unique perspective of how policy shapes science and vice versa, especially as it relates to health care.

I have been a part of the USGS since 2001, when I began as a student employee. I currently lead the budget activities for energy and mineral resources and for environmental health programs in the USGS. I work with leaders at the USGS, the U.S. Department of the Interior, and the Office of Management and Budget, and with congressional staff to put together a budget for the USGS in the scientific fields of energy and mineral resources and environmental health. Much of my job focuses on supporting USGS science, working at the intersection between science and policy to increase awareness of the great work being done at the USGS and its relevance to the public interest. Working in various parts of the USGS has not only given me a diverse background in everything from geospatial policy to energy and mineral resources management, but it has also reinforced my respect for this great organization.

In my spare time, I enjoy spending time with my husband and two children. I am an avid reader and have been a member of the same book club for almost a decade. I also love traveling, experimenting on my family and friends with ambitious recipes, going to concerts, listening to and playing all different kinds of music, running, and horseback riding.

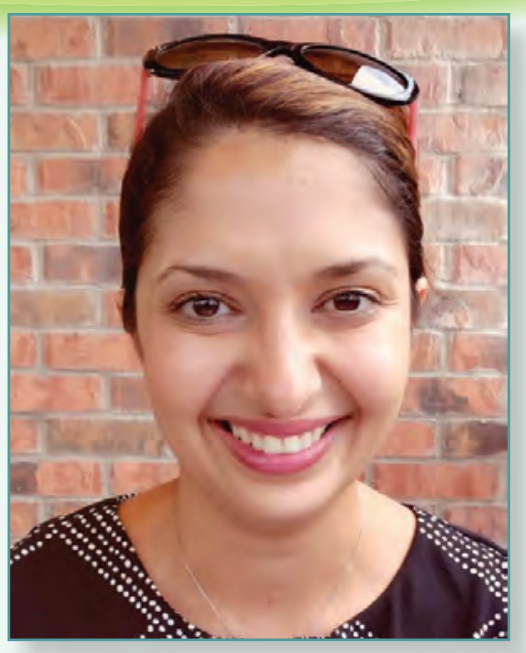

Arista Maher has a bachelor's degree in government from The College of William and Mary and a master's in public health policy from George Washington University. https://www.usgs.gov/staff-profiles/ arista-maher

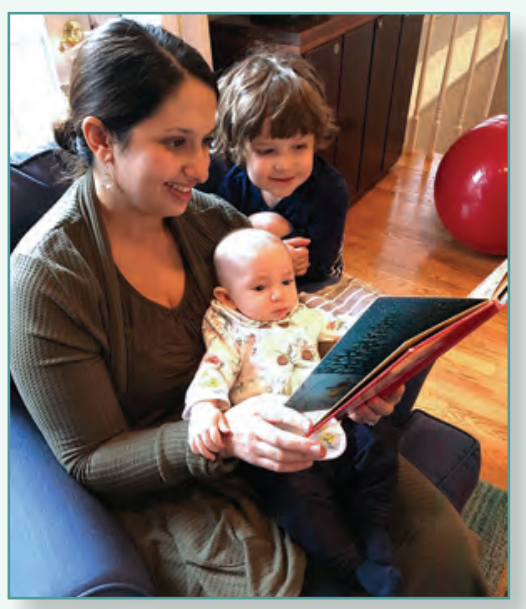

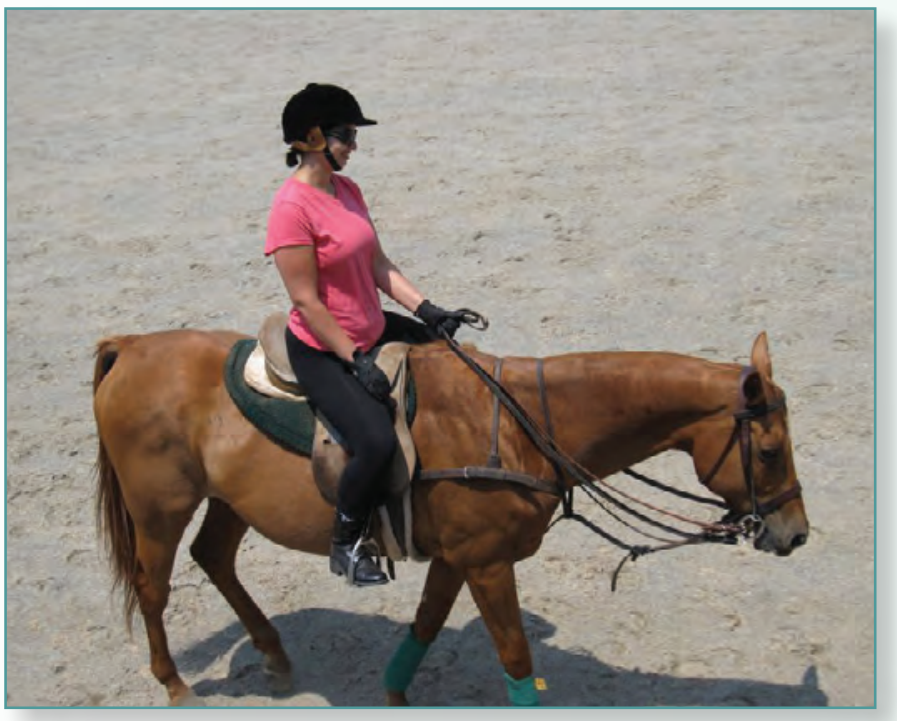

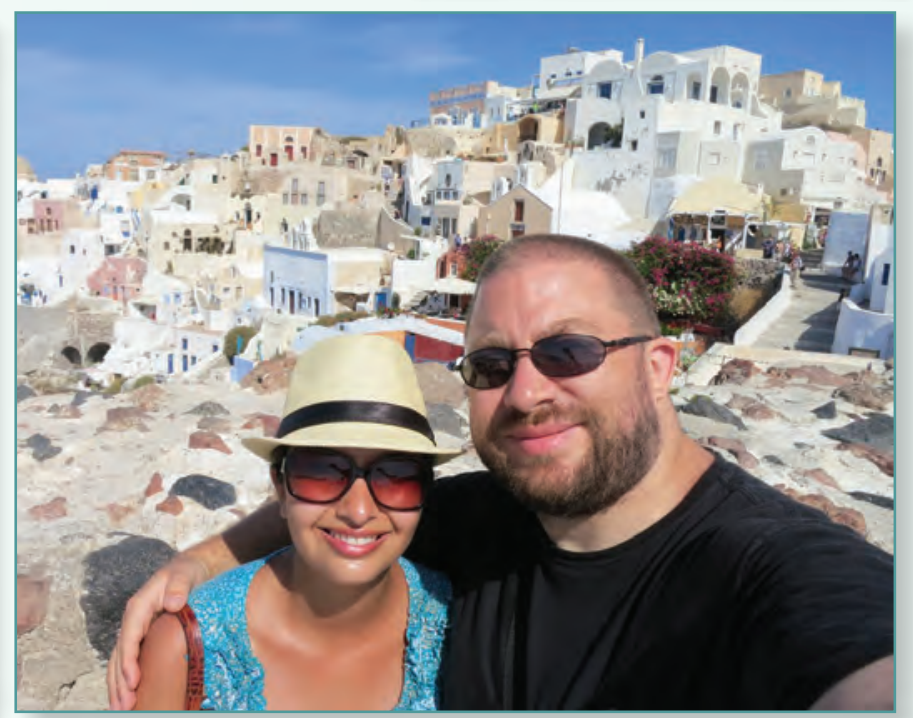




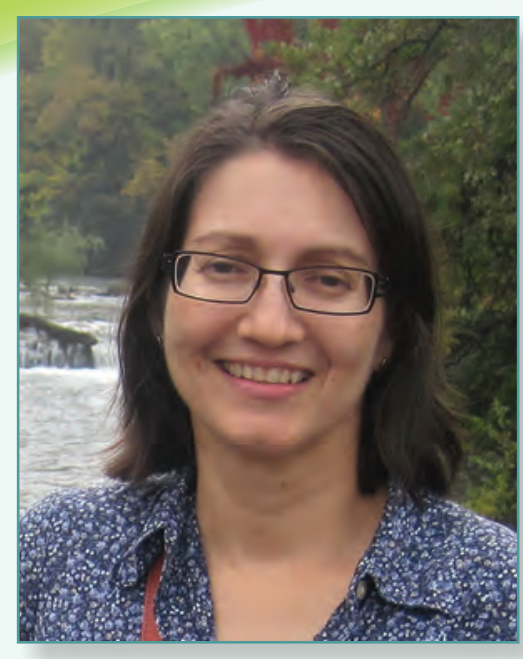

I am often drawn to questions and activities arising at the boundaries and intersection of scientific disciplines and professional cultures. The potential for generating new insights and novel applications that may help bridge gaps in knowledge and cultural divides are exciting aspects of the work that I do at the USGS.

Elizabeth Martín has a bachelor's degree in biology from the University of Puerto Rico and a master's in biological science from Florida State University.

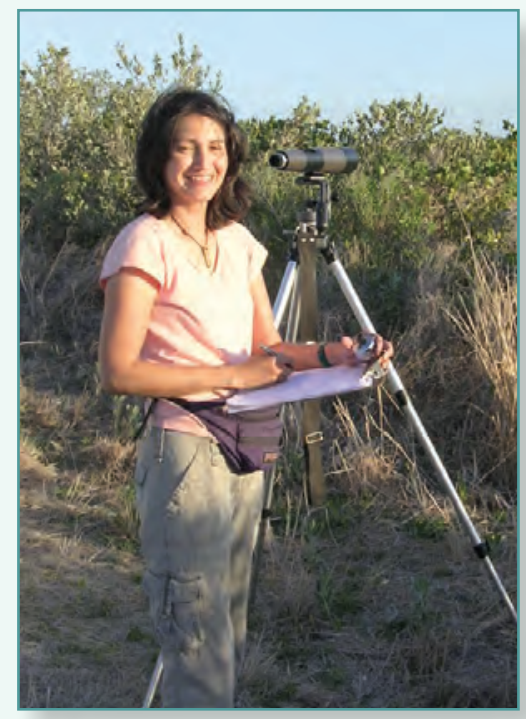

\section{Elizabeth Martin}

\section{Biologist with the Core Science Analytics, Synthesis, and Libraries Program in Gainesville, Florida}

My career trajectory has been more of an evolution than one major "aha!" moment. As a child, my parents often took us to the beach, and I spent a good portion of my childhood by the ocean. That piqued my curiosity about the ocean and its living creatures and led me to pursue an undergraduate degree in biology. For my master's degree thesis, I conducted field work on a marine snail that lives in seagrass beds and coral reefs of the Bahamas, and after that I worked on assessing how pollution from farming affects the Florida Everglades. While doing field work in the Everglades, I remember looking at some of the marshes that were less affected by nutrients and thinking about how beautiful they were. These research activities highlighted to me the importance of conserving biological resources, and the realization that ultimately conservation requires an understanding of the relations of humans to nature.

I went on to work with managers of protected areas in Latin America, assisting with data and technology transfer. It became more apparent to me that I could be of greater service and contribute more to natural resource conservation by helping bridge professional and scientific discipline divides and by considering the human dimensions not only of research but also of data and information dissemination and transfer. These experiences led to a new interest in more applied types of research and scientific information dissemination activities that support decision making about natural resources and biodiversity. Currently, my work involves providing biodiversity data and information for online systems and researching how professionals use biodiversity information system resources in their work.

I am an avid bird watcher. I became interested in the hobby when I started working on providing data and information to support bird conservation in North America. I started birding to become more familiar with birds and some of the methods used to study them. The result was that I became fascinated by birds. Observing birds in the wild brings me peace and joy, it is a very soothing activity when life gets hectic, it challenges me to improve my bird identification skills, and I am always learning something new about birds and wildlife behavior. In animals and nature I see beauty and a spiritual connection to something much bigger and more important that transcends my life.
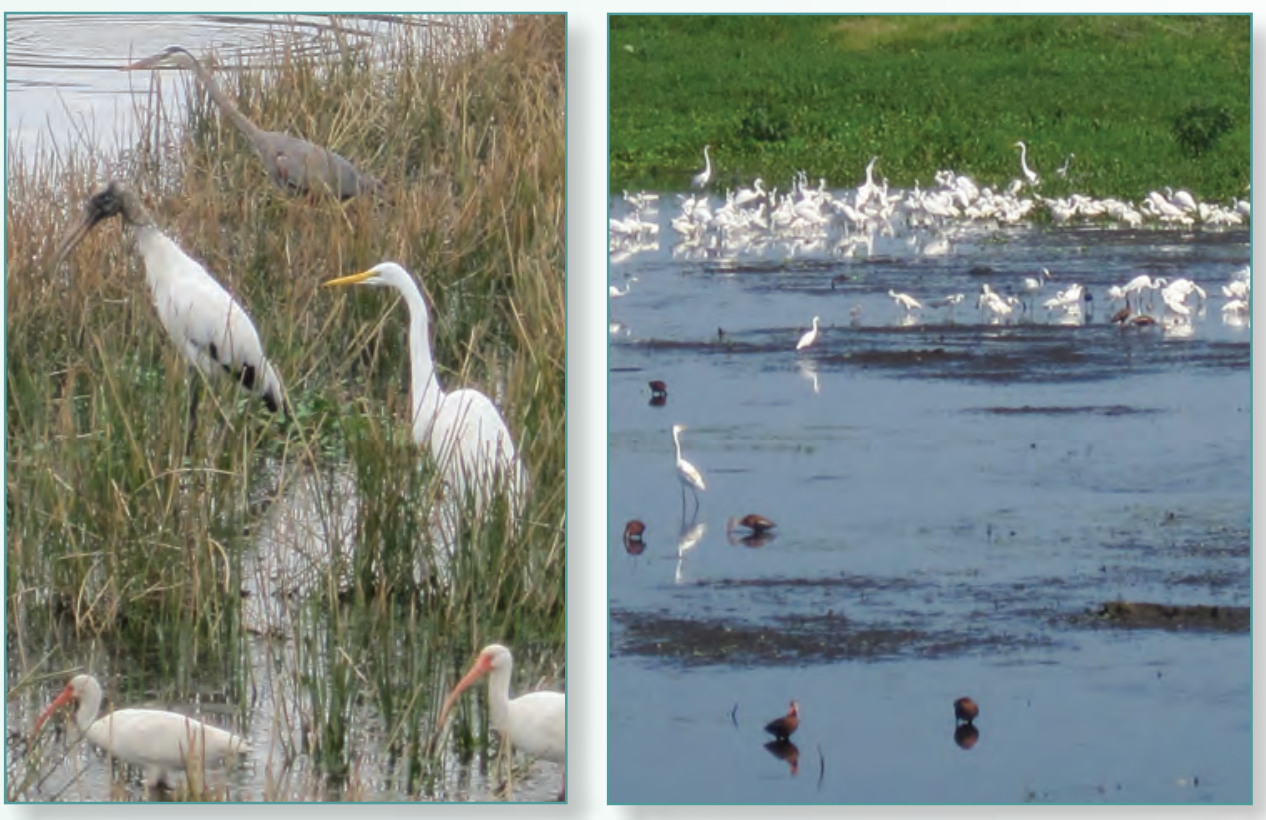


\section{Melanie Mathesz}

\section{Hydrologic Technician at the Maryland, Delaware, and District of Columbia Water Science Center in Baltimore, Maryland}

"The most beautiful experience we can have is the mysterious. It is the fundamental emotion that stands at the cradle of true art and true science." - Albert Einstein

I grew up in Annapolis, Maryland. On weekends, I would go sailing on the Chesapeake Bay or bike riding at a park within a day's driving distance. There was no one event that lead me into my career at the USGS - it was a childhood spent enjoying nature. In school, I grew particularly interested in environmental science, especially in relation to the Chesapeake Bay. My time sailing, kayaking, and windsurfing on the Chesapeake Bay led me to care deeply for the health of the bay. In middle and high school, I participated in the science club to grow and then plant the bay grasses in a restoration area. During this process, I learned how important the grasses were to the Chesapeake Bay. I wanted to contribute to monitoring the bay's waters in order to provide decision makers with the information necessary to create the proper environmental policies to improve the health of the bay's waters.

In addition to my love of the Chesapeake Bay, I have a great love of volcanoes in the Pacific Northwest of the United States. The earth processes required to make them and destroy them fascinates me. They were one of my favorite topics to learn in school and to teach as a teaching assistant for my geography department in college. They inspire me to want to understand the geophysics behind how the earth was made and is continually shaped. Volcanoes have such beauty, yet can become extremely dangerous without a lot of warning. They inspire innovation in monitoring capabilities in order to predict eruptions before they happen.

At my job with the USGS, I work on the Chesapeake Bay, collecting water samples and analyzing water-quality data collected from in-stream equipment. I am the leader of a team, organizing how and where samples are to be collected to monitor the effects of storms and keeping up the equipment that constantly monitors water quality in streams and the bay. I also train hydrologic technicians in water-quality sampling and processing simultaneously.

I enjoy kayaking, windsurfing, and paddle boarding in the Chesapeake Bay watershed with my husband. We hit it off over our love of watersports when we first met, and our first date was kayaking on the South River near Annapolis. In the past few years, I have started participating in sprint triathlons. This will be my third year competing in Iron Girl, where we swim, bike, and then run.
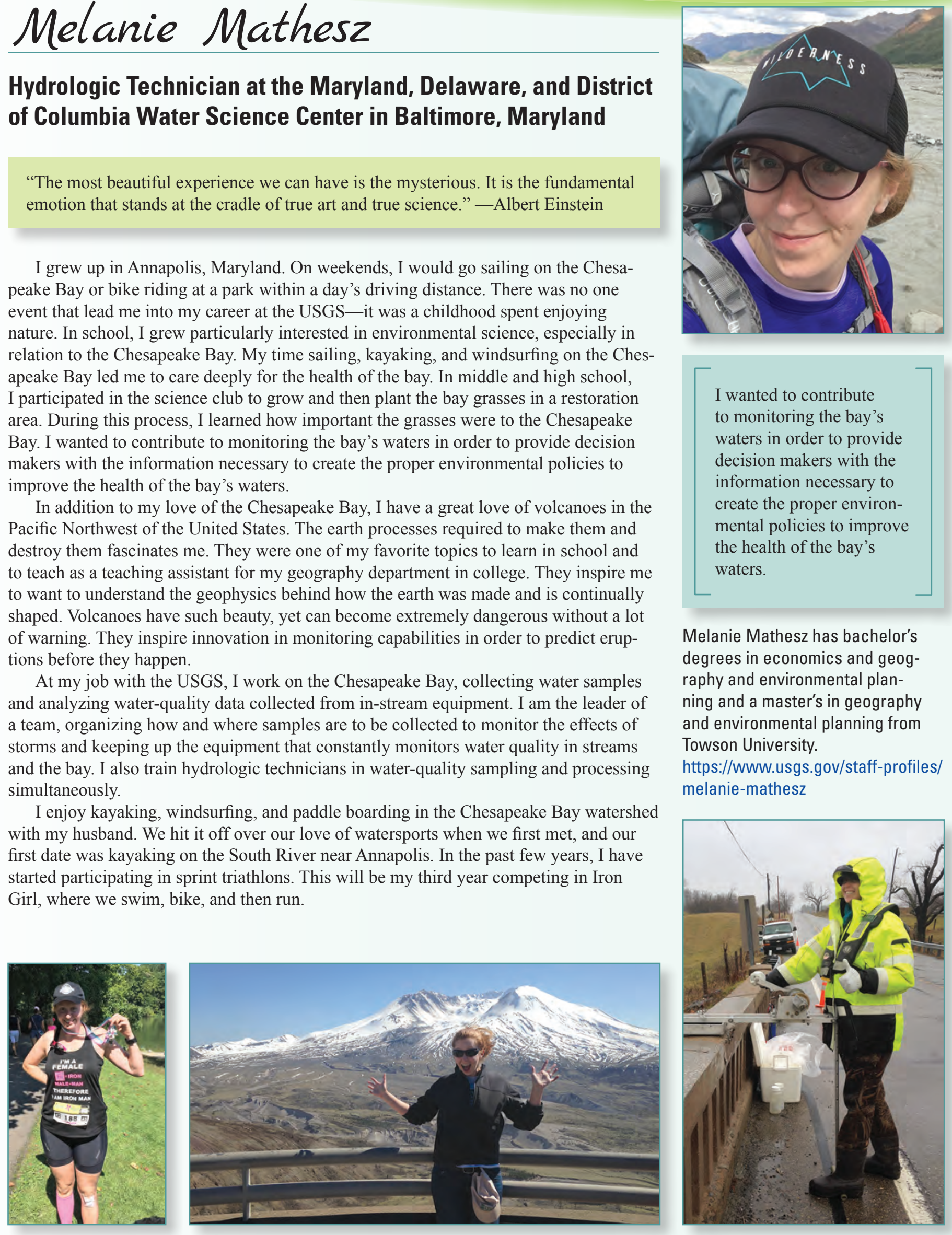

I wanted to contribute to monitoring the bay's waters in order to provide decision makers with the information necessary to create the proper environmental policies to improve the health of the bay's waters.

Melanie Mathesz has bachelor's degrees in economics and geography and environmental planning and a master's in geography and environmental planning from Towson University. https://www.usgs.gov/staff-profiles/ melanie-mathesz

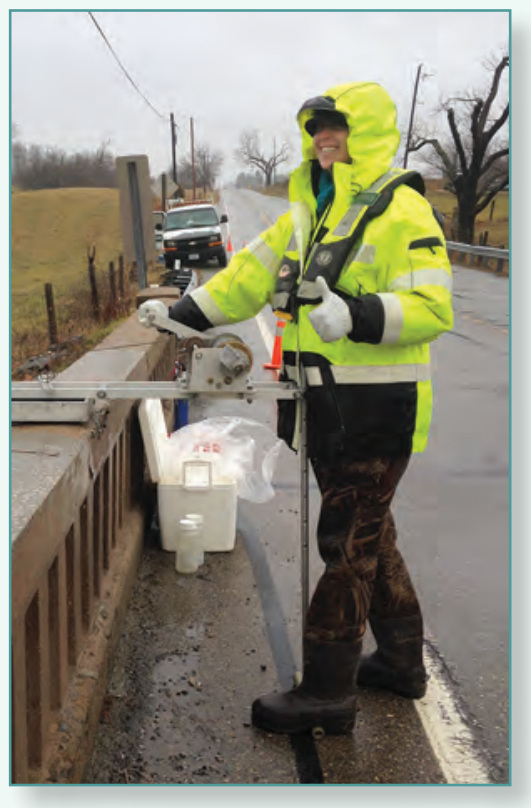




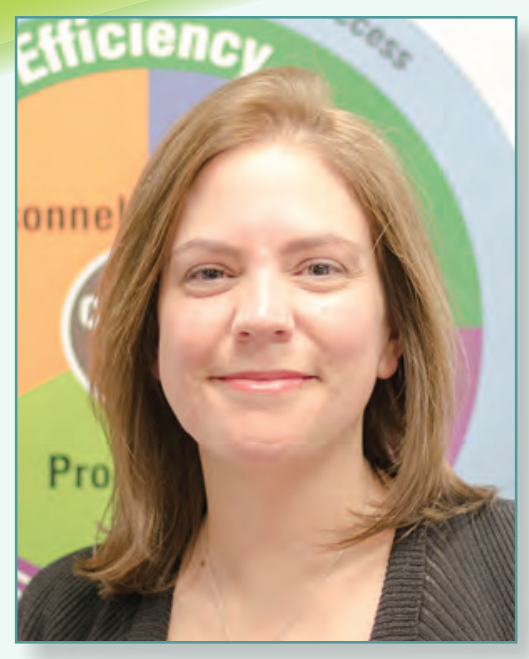

Leadership can take place from any part of the organization; it only requires a person to raise their hand to want to take action on an issue and inspire others along with them.

Katie McCulloch has a bachelor's degree in finance from Pennsylvania State University.

https://www.usgs.gov/staff-profiles/ katherine-mcculloch

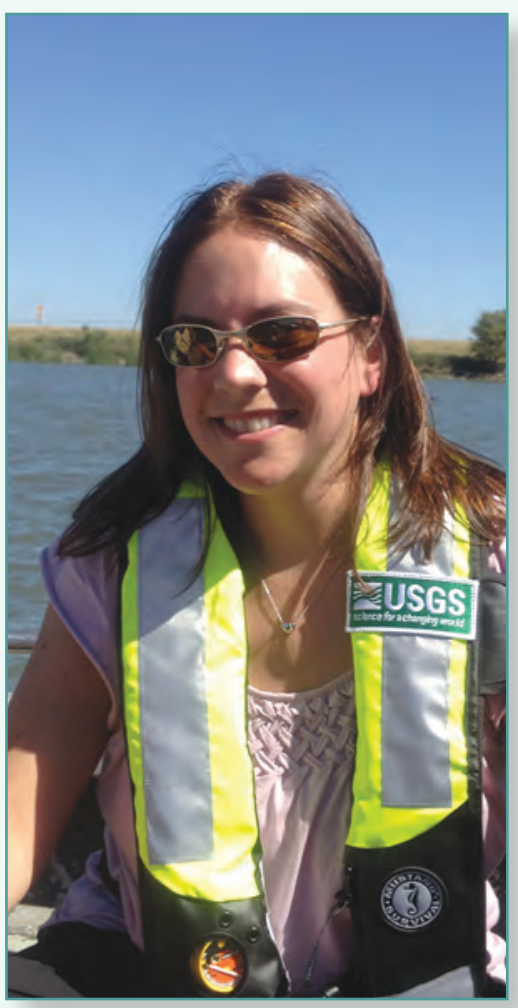

Katie Mceulloch

\section{Deputy Associate Director for the Office of Administration in Reston, Virginia}

"Success is not final, failure is not fatal; it is the courage to continue that counts." -Winston Churchill

I've always had an interest in numbers. Math and science were always so intriguing and exciting to me, and this interest led me to study finance in college. After graduating from college, I moved to the Washington, D.C., area and worked in the private sector. After a number of years consulting for the Federal Government, I had an extremely strong desire to become a public servant. I was inspired by those around me, and rather than continuing to work for a large corporation, I felt a deep-rooted desire to use the skills I had developed to serve my country.

While I am not on "the science side of the house," my organization provides the backbone that supports the incredible work that the USGS does. In briefings with the Office of Management and Budget, I'm always fascinated to hear about all the various types of science and the vast portfolio of the USGS. I joke that those days are like watching the Discovery Channel all day long. I am continuously amazed and inspired by the scientists at the USGS and their passion for their work, which reflects the passion that I have for supporting the science and working for the USGS.

My work at the USGS has been under the umbrella of customer service. Part of my job is to foster an environment where the administrative support, budget, and finance communities help advance the science and mission of the USGS. Articulating requirements and obtaining needed funding for scientists, identifying efficiencies in business or planning processes, and providing outstanding support and advice make it easier for managers to focus on the technical aspects of their projects. I take pride in working toward the most efficient and effective way to implement a process and the clearest and most transparent way to provide additional information for decision making and in providing exemplary support.

I live in Vienna, Virginia, with my husband, two young boys, and two new puppies. I enjoy cooking, boating, visiting wineries, and cheering for my Penn State Nittany Lions.

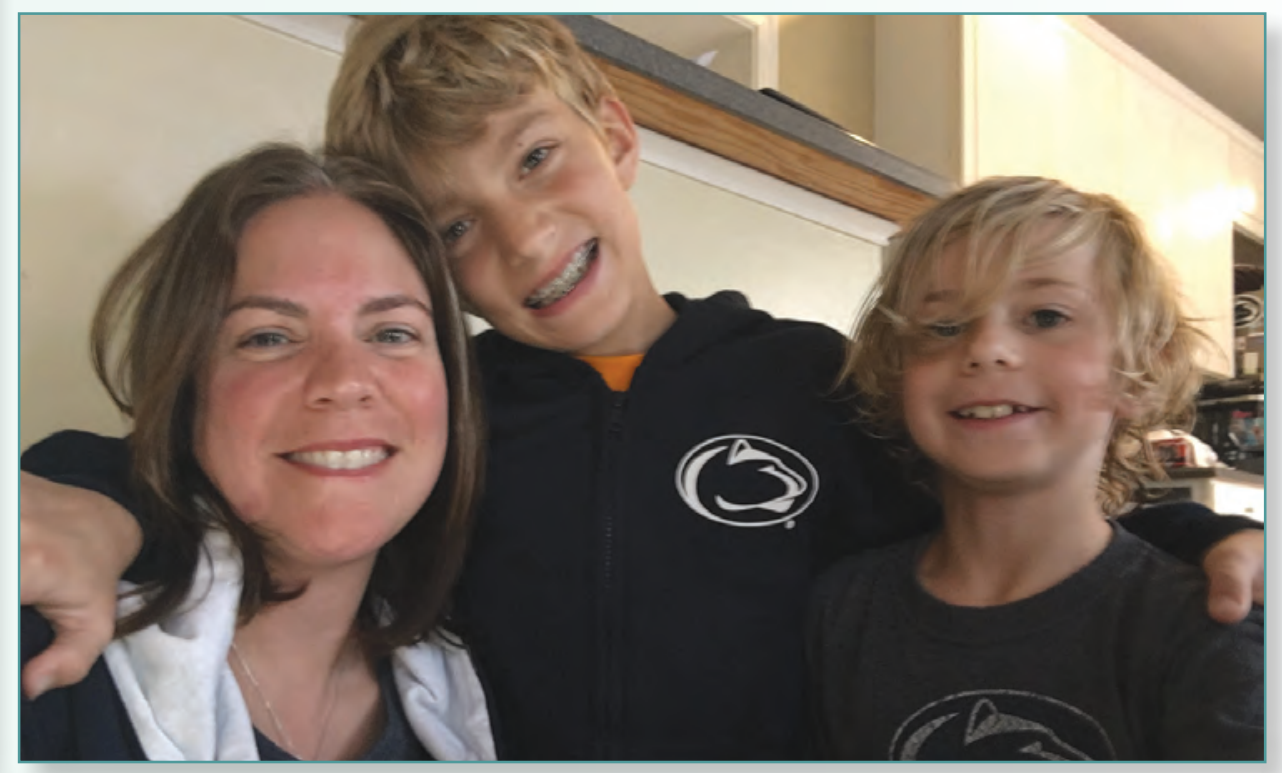




\section{Firut Mengestu}

\section{Executive Assistant with the Energy and Minerals Mission Area and the Environmental Health Mission Area in Reston, Virginia}

"Tell me and I forget. Teach me and I remember. Involve me and I learn."

-Benjamin Franklin

I was born and raised in Addis Ababa, Ethiopia, by parents who believed that education is the best investment one can make. Who I am today is thanks to the influences of my mother and father. Growing up, I was always interested in sketching and designing clothes; I spent a lot of time designing and stitching clothes by hand for my dolls, and I started designing and making my own clothes when I was 15 years old. When deciding what I wanted to study, however, I was limited by the choices available at my university. I was not interested in studying geography, economics, mathematics, or medicine, and the only other option I had was the field of executive assistant.

While I was in college, I spent summers working for Ethiopian Airlines, which gave me the opportunity to work on my English-language skills and exposed me to visitors from different parts of the world. That's also how I met my husband who was also working for the airline at the time. After I graduated college, my husband and I moved to the United States, and eventually, I joined the USGS.

I have been the executive assistant for several senior executives at the USGS. I spend the majority of my time managing the schedules of the senior executives, making travel arrangements, organizing their records, coordinating office activities, and representing USGS management to a wide range of external entities. I use my strategic problem-solving skills to come up with solutions to problems across all levels of senior management and make sure those solutions are carried out as efficiently and effectively as possible. I enjoy working with changing situations and organizing and prioritizing work in highpressure environments.

I love spending time with my husband and our children and grandchildren, and I spend my free time coming up with designs and playing with fabrics. I also enjoy reading, swimming, and cooking, and I volunteer teaching the Amharic language to young Ethiopian-American children.
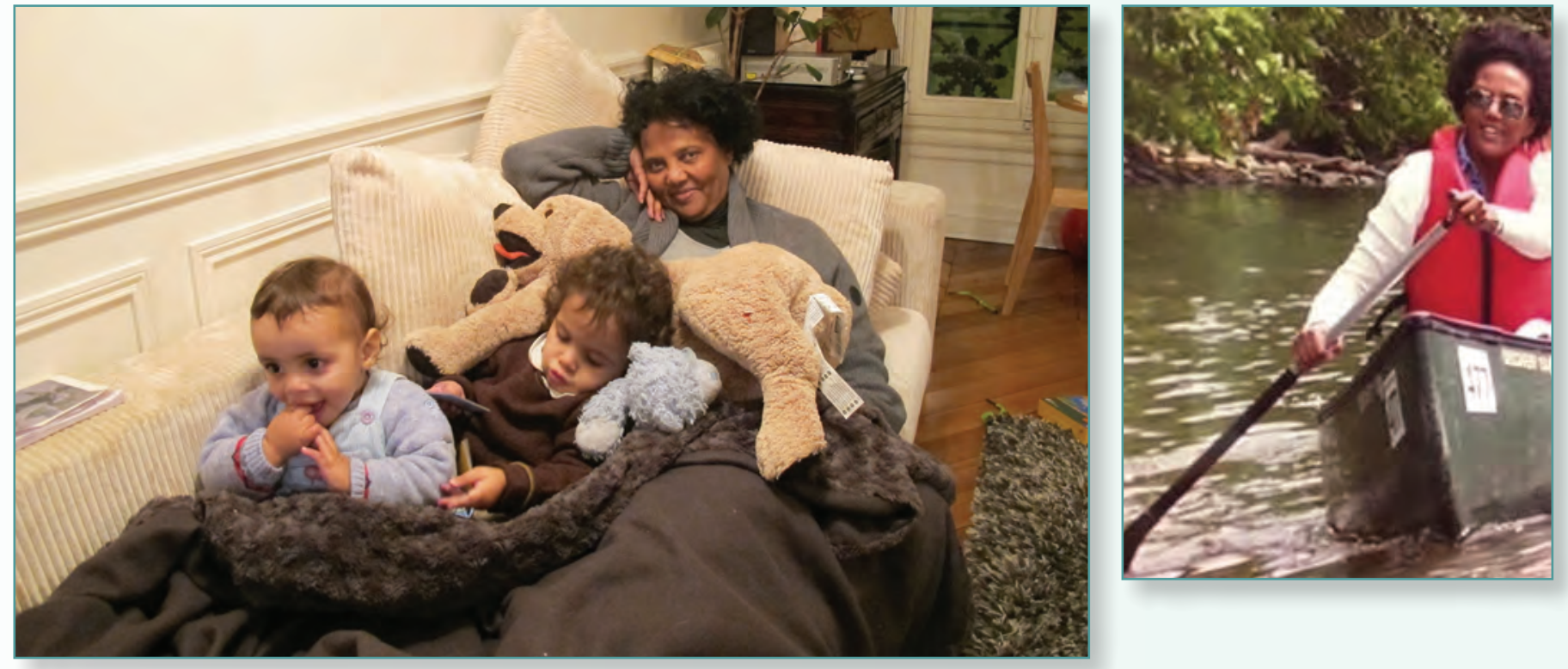

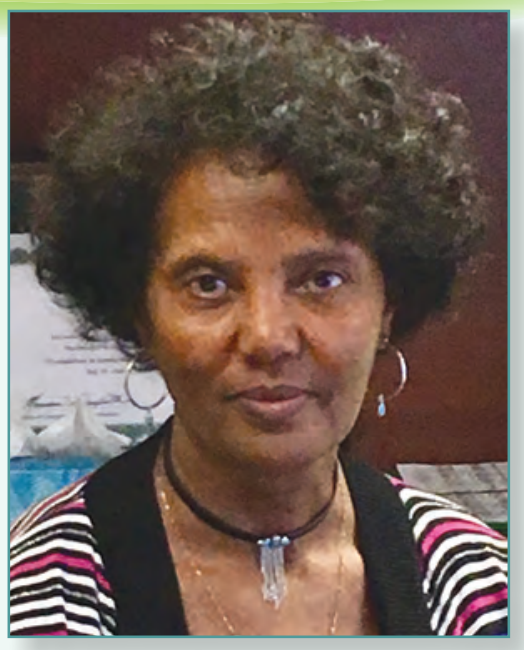

Hirut Mengestu has a diploma in executive assistant studies from Haile Selassie I University, Addis Ababa, an associate's degree in liberal arts from Illinois Central College, and a bachelor's in fashion and design from the International Academy of Design and Technology. 


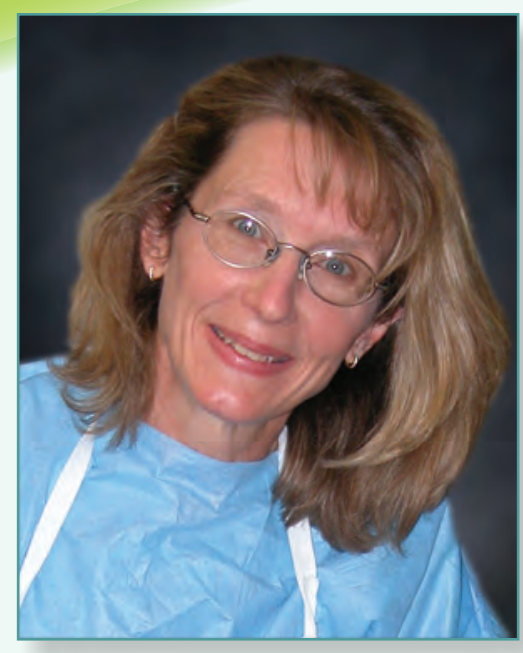

My professional goal has been to contribute in some way to the health and sustainability of wildlife populations and their habitats and to the well-being of the public. As we wrangle with increasingly complex problems, the solutions require teams with more diverse perspectives, knowledge, and insight. As each of our pieces of the puzzle fall into place, it is obvious that these teams, not individuals, are what allow us to make a difference, and to make a difference is really why we are here.

Carol Meteyer has a bachelor's degree in biology, chemistry, and education from the University of lowa and a doctorate of veterinary medicine from lowa State University. She is also board certified by the American Academy of Veterinary Pathologists.

https://www.usgs.gov/ staff-profiles/carol-u-meteyer

\section{Carol Meteyer}

\section{Senior Science Advisor with the Environmental Health Mission Area in Reston, Virginia}

"Until he extends his circle of compassion to include all living things, man will not himself find peace." —-Albert Schweitzer

Growing up in the 1950s and 60s in a Mississippi River town in Iowa, I would disappear to some nearby swamp, creek, woods, or expanse of grass with neighborhood kids. This is when my wonder of the small, the feathered, the cold blooded, and invertebrate began. We spent hours searching for crawdads, catching bugs, building forts, and following animal tracks in the snow.

As an undergraduate research assistant, I studied leaf-cutter ants in the forests of Costa Rica. After graduating, I taught high school ecology, biology, geology, and chemistry before entering veterinary school. After completing veterinary school, a residency in pathology, and working as a veterinary pathologist for U.C. Davis, I was hired as the wildlife forensic pathologist with the National Wildlife Health Center first for the U.S. Fish and Wildlife Service and later for the USGS. I was interested in the charismatic megafauna (large, popular animals like wolves and sea otters), but as others stepped back when asked to investigate the causes of amphibian malformations and disease, I couldn't have been more excited to step in. I spent hours photographing and classifying bone changes in frogs that were illuminated by radiographs and looking at changes in microscopic limbs that might signal errors in future development. I spoke with such excitement to my daughters about what I was finding that the youngest asked, "Do you like the frogs more than you like us?" As a 4-year-old, there was nothing unkind behind her simple question asked casually while riding in the car, but I made a point after that to focus more on their interests and talking a bit less about my discoveries at work!

My investigations have contributed to defining the causes of white-nose syndrome in bats, Newcastle disease in young cormorants, conjunctivitis in finches, and the near extinction of Gyps vultures, previously common on the Indian subcontinent, because of a drug used in cattle. As a wildlife pathologist, I was part of teams that focused on effects of environmental toxins in birds, diseases in corals, monkeypox in rodents, plague in prairie dogs, and Asian bird flu in North American raptors and shore birds.

I enjoy being outdoors and over the years have immersed myself in scuba diving; mountain climbing; whitewater kayaking; swimming, cycling, and running, individually and in triathlons; downhill and cross-country skiing; bird-watching; beach-combing; native plant gardening; photography; and camping with my two daughters. Raising my girls has been the ultimate test of my skills of observation, communication, and "adaptive management" and the job that has given me the most joy.
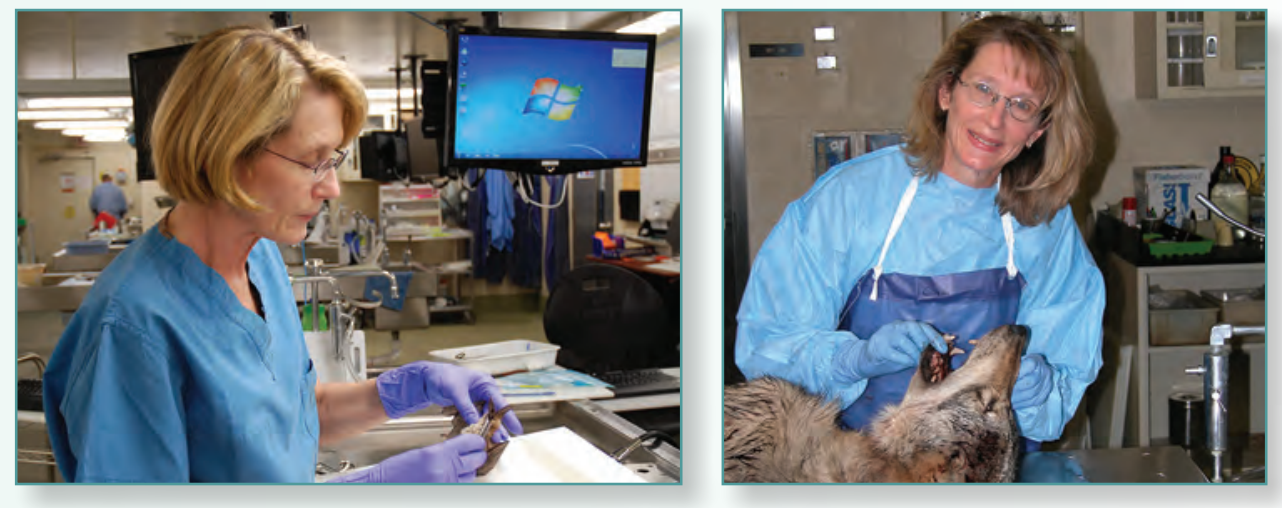


\section{Sarah Minson}

\section{Research Geophysicist at the Earthquake Science Center in Menlo Park, California}

"[Science is] the teamiest of team sports." - Ivan Oransky and Adam Marcus, "The Problem With Nobel Prizes"

I grew up in rural northern California where I could explore outdoors every day. But I was also a math and science nerd and a theater geek. Geophysics is the thing that combines everything I love. I get to use math and science to model how a natural phenomenon like earthquakes shapes the world around us, and then I get to tell the stories of these events.

My work as a research geophysicist with the USGS ranges from the basic science of understanding the physics of how, where, and why faults rupture to applied projects aimed at reducing seismic risk. An overarching theme of my research is quantifying the uncertainty in our models of how earthquakes rupture: we do not get to directly observe earthquake ruptures that occur deep underground. The earthquake deforms the Earth in space and time; all we can observe is the motion of the Earth's surface in response to an earthquake, and from that we must attempt to infer how the earthquake rupture evolved and the physics of that process. Because of this, there is significant uncertainty in what we think we know about how faults behave. A key to understanding the physics of earthquakes is understanding what we do and do not know about earthquake ruptures. In order to quantify this uncertainty, I have used supercomputers to work on large-scale Monte Carlo probability simulations of earthquake ruptures. On the opposite extreme from costly computations to learn about the basic physics of earthquakes, I have also worked on computationally inexpensive applied problems to reduce seismic risk.

I am part of the USGS ShakeAlert earthquake early warning project. The goal of earthquake early warning is to detect the beginning of an earthquake and provide alerts that strong ground shaking is expected before that strong shaking arrives at your location. People and automated systems could then take action to prevent injury and infrastructure damage from the earthquake. Devices such as smartphones contain low-cost (and lowaccuracy) versions of the scientific sensors we use to study earthquakes. In the future, we could use crowd-sourced observations to contribute to earthquake early warning or even basic science research. I am also collaborating on a project in Chile to provide earthquake early warning using dedicated smartphones.
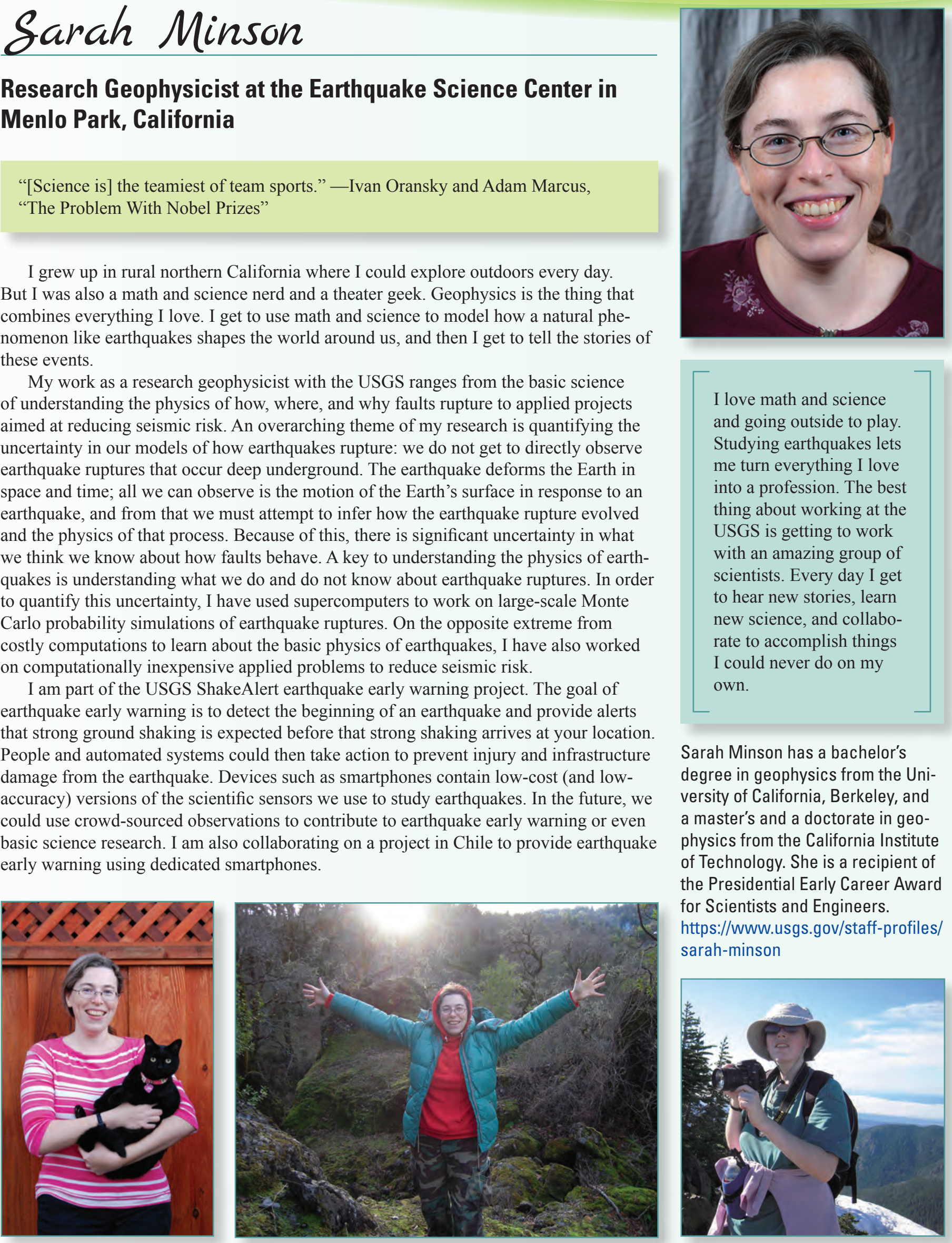

I love math and science and going outside to play. Studying earthquakes lets me turn everything I love into a profession. The best thing about working at the USGS is getting to work with an amazing group of scientists. Every day I get to hear new stories, learn new science, and collaborate to accomplish things I could never do on my own.

—

Sarah Minson has a bachelor's degree in geophysics from the University of California, Berkeley, and a master's and a doctorate in geophysics from the California Institute of Technology. She is a recipient of the Presidential Early Career Award for Scientists and Engineers.

https://www.usgs.gov/staff-profiles/ sarah-minson

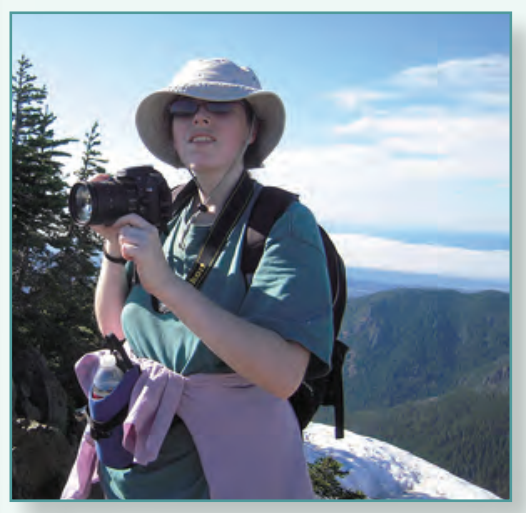




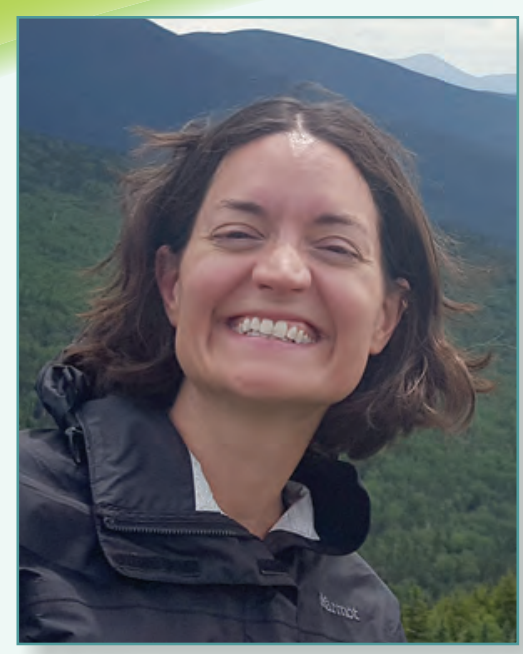

A science career involves effective communication skills, thoughtful mentoring, a collaborative personality, writing discipline, and imagination. You can be good at all of these things or just excellent at some and be a successful scientist.

Toni Lyn Morelli has a bachelor's degree in zoology from Michigan State University and a doctorate in ecology and evolution from Stony Brook University.

https://www.usgs.gov/staff-profiles/ toni-lyn-morelli

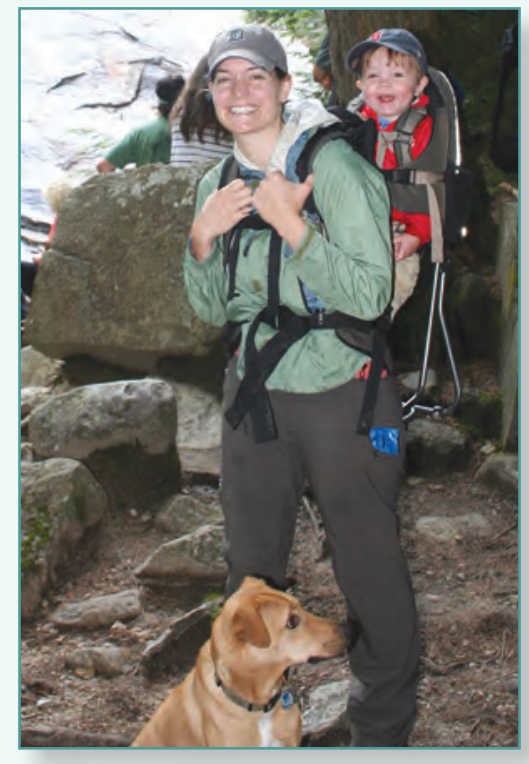

\section{Toni eyn Morelli}

\section{Research Ecologist with the Northeast Climate Science Center in Amherst, Massachusetts}

"The pursuit of truth will set you free; even if you never catch up with it." - Clarence Darrow

I grew up chasing rabbits in our backyard instead of taking dance class. I also went to an all-girls high school, and I often wonder how that affected my trajectory because, at a key developmental age, I wasn't being told that boys were better in math and science than girls. Perhaps most importantly, I had key female mentors throughout my education, strong women who believed in me and showed me by example that women could accomplish great things as professionals in science. A turning point for me was when my professor took me to Kenya to assist her hyena research while I was an undergraduate student. It was one of my first times camping and my first experience with fieldwork. I fell in love with wildlife research and with working in Africa. I went on to do my graduate work on lemurs in Madagascar and later worked for the U.S. Forest Service in the Democratic Republic of the Congo.

I am still doing research on habitat and species conservation; now, though, it involves studying the effects of climate change on wildlife, mostly in the mountains of New England, and helping land managers protect and identify areas that might be more resistant to climate change and, as a result, the species that may find refuge in them. I am also more and more engaged in efforts to increase the presence of women and underrepresented minorities in science.

When I have free time, I enjoy spending it with my husband and our 4-year-old son. I also enjoy gardening, hiking with our dog Kivu, whom we brought back from the Congo, and the local food, music, and outdoor activities of western Massachusetts. I look to wide-open, isolated spaces to recharge, but I balance that with fun and games with friends and family.
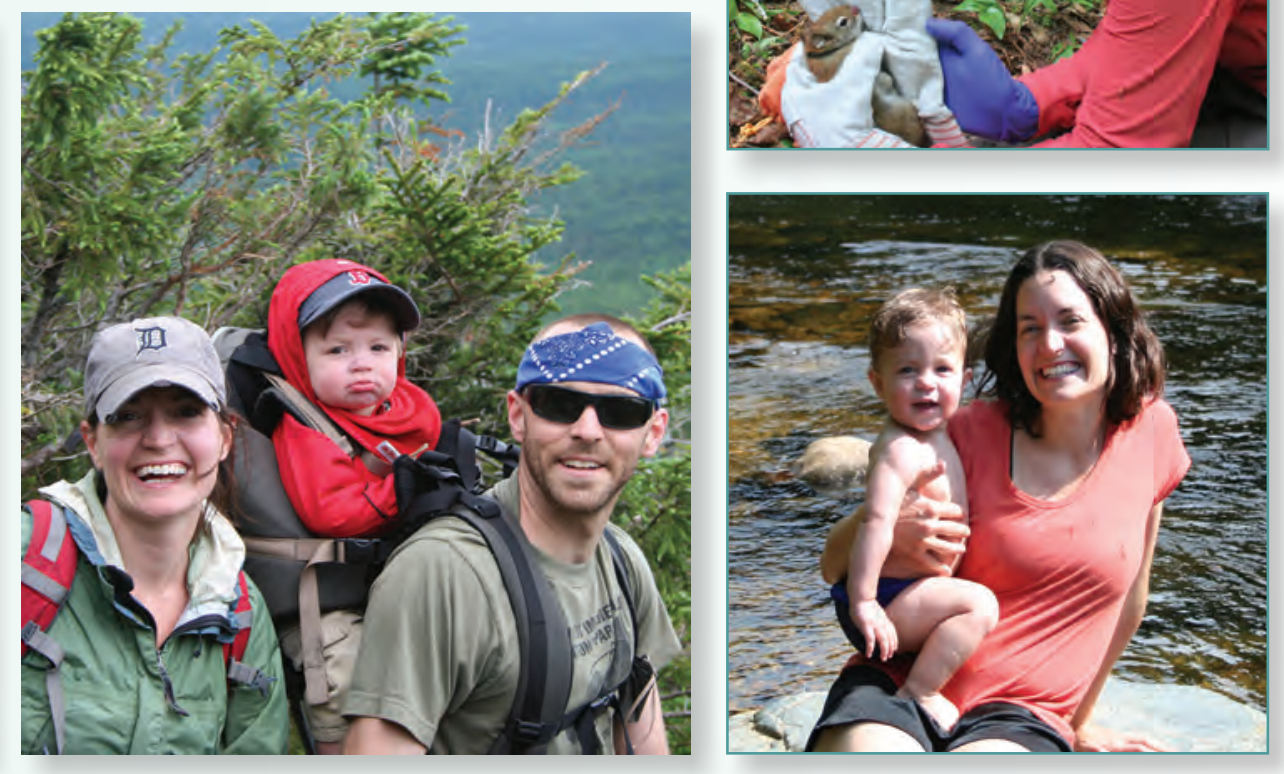


\section{eheryl Morris}

\section{Coordinator for the Science Synthesis, Analysis, and Research Program in Lakewood, Colorado}

"Twenty years from now, you will be more disappointed by the things that you didn't do than by the ones you did do. So throw off the bowlines. Sail away from the safe harbor. Catch the trade winds in your sails. Explore. Dream. Discover." -H. Jackson Brown, Jr., "P.S. I Love You"

All through school my teachers told me that I was good at math and should do something with that skill. When I chose a college major, I wanted it to be something that I would be good at, that I would enjoy, and that would provide good employment opportunities. I ended up choosing engineering. I'm very proud of earning an engineering degree at a time when women were a minority in the field, and it has opened many doors for me throughout my career. Since graduating, I have worked for the U.S. Navy, the U.S. Fish and Wildlife Service, and now, the USGS.

Currently, I lead a team of more than 80 staff and contractors in characterizing the patterns and relationships between living organisms and ecosystems, advanced research computing, science data management, and information science. My team develops national datasets that can be used by scientists all over the country and creates innovative tools and technologies for scientific discovery and rapid response to societal issues.

I'm proud to be part of the important mission to preserve the data of the USGS that cannot be reproduced because they were collected at a certain place, at a specific point in time, and under unique conditions. It is rewarding to be part of the effort to save data so future generations can study and understand the changing Earth.

Living in Colorado allows me and my family to enjoy the outdoors year round. My husband, two sons, and dog enjoy hiking and just being outdoors when we're not busy at our older son's hockey games or watching our younger son perform as an actor/stunt man; there's never a dull moment in our home! I love the beach, and almost any beach will do. Many of our family vacations have been at the beach, and our boys are just as comfortable in the water as they are in the snow at home in Colorado. We enjoy all water sports like paddle boarding, kayaking, riding wave runners, and just taking in the surf and sun. A day at the beach fixes everything!
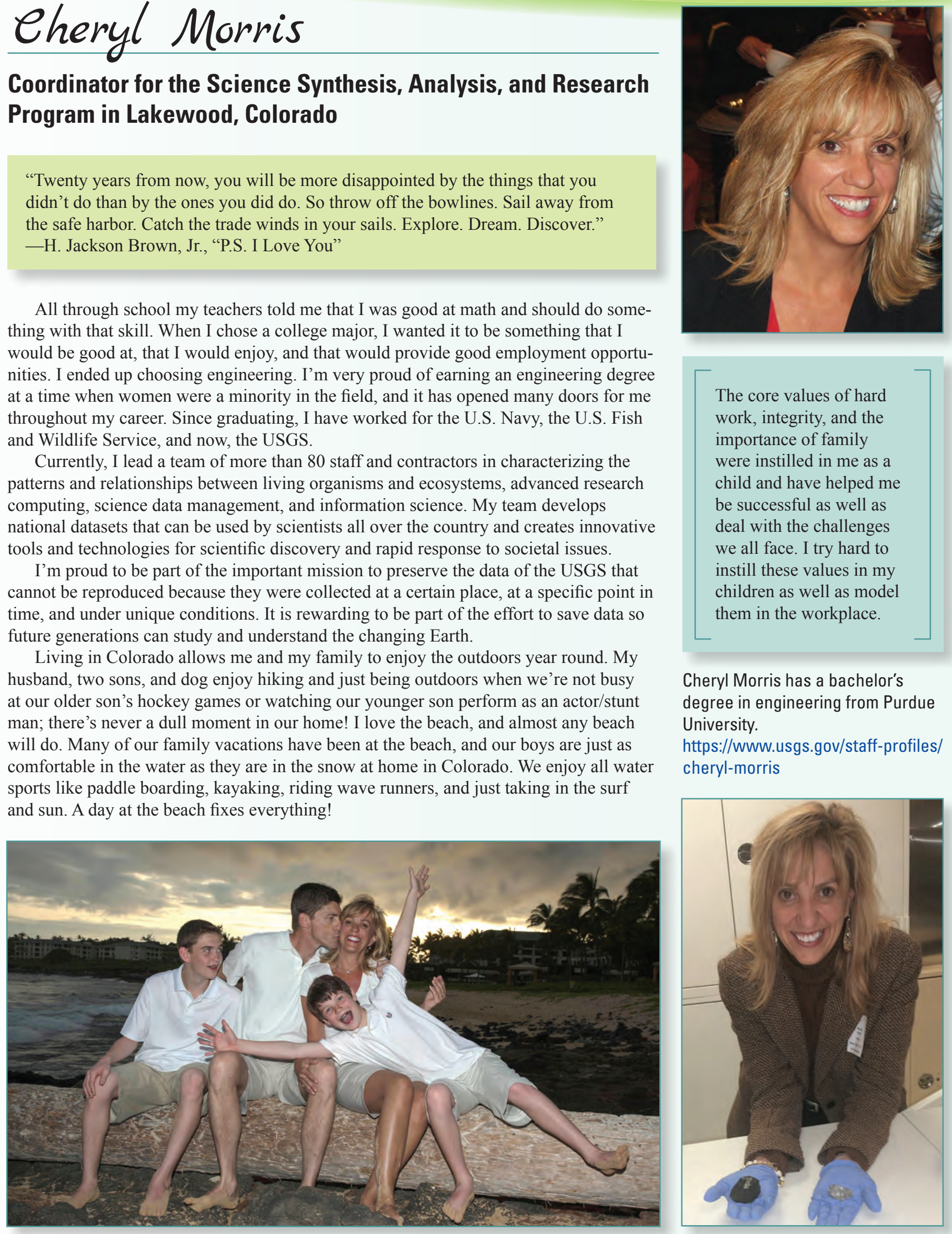

The core values of hard work, integrity, and the importance of family were instilled in me as a child and have helped me be successful as well as deal with the challenges we all face. I try hard to instill these values in my children as well as model them in the workplace.

Cheryl Morris has a bachelor's degree in engineering from Purdue University.

https://www.usgs.gov/staff-profiles/ cheryl-morris

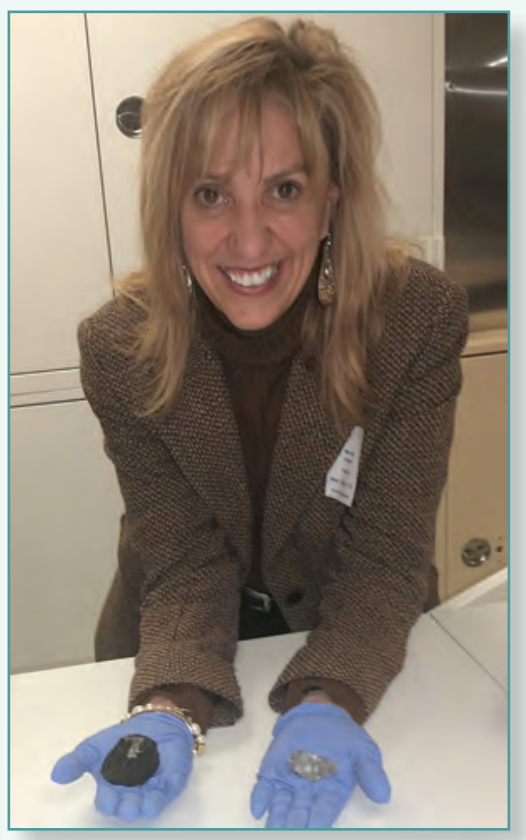




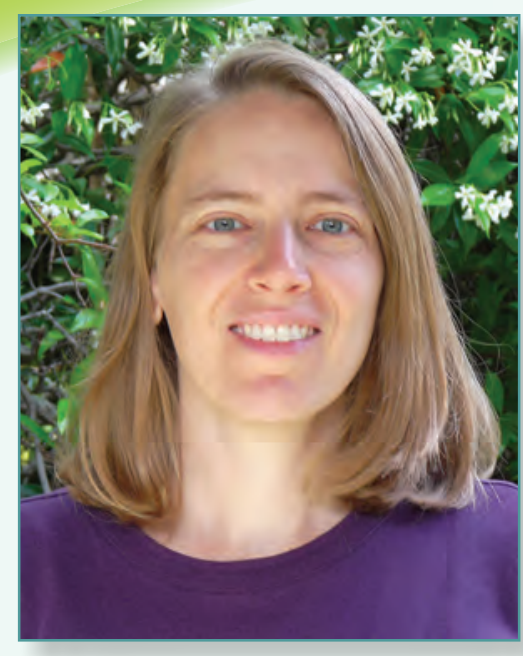

The best part about my job is having the opportunities to pursue research topics I am passionate about, to work with colleagues at the USGS and at other institutions, and to have a direct effect on the science that the USGS provides for hazard assessments and warnings, postearthquake recovery efforts, and improved understanding of the processes that underlie seismic activity.

Jessica Murray has a bachelor's degree in earth sciences from Dartmouth College and a master's and a doctorate in geophysics from Stanford University. https://www.usgs.gov/staff-profiles/ jessica-murray

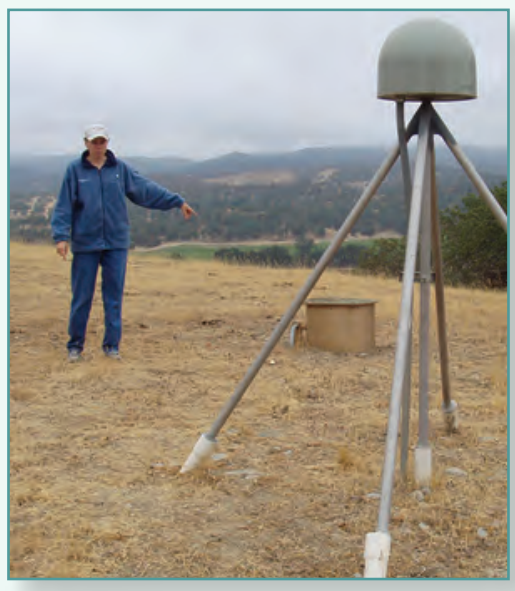

\section{Jessica Murray}

\section{Research Geophysicist at the Earthquake Hazards Program in Menlo Park, California}

After college, I wanted to do something where my work would not only have scientific relevance but could directly benefit the public at large. I decided to pursue graduate work in earthquake studies, a specialization that built upon my interest in structural geology and offered broad societal relevance.

I came to the USGS as a postdoctoral scholar and eventually became a research geophysicist where I have been investigating where and how fast strain builds up in the Earth's crust and the processes by which this strain is released by movement across crustal faults. Much of my work has focused on developing models that use Global Positioning System (GPS) data to describe how the Earth is deformed through space and over time in seismically active regions. GPS and related techniques are uniquely suited to recording signals caused by aseismic fault slip or motion that is too slow to generate seismic waves, yet may release stored strain and increase stress on neighboring areas of the fault. This work is directly relevant to the USGS National Seismic Hazard Map, the Earthquake Early Warning System currently under development for the West Coast, and other efforts to mitigate the impact of earthquakes. As the geodesy coordinator for the Earthquake Hazards Program, I provide subject matter expertise to the program's leadership, prioritizing the research and operational activities that will enable us to most effectively carry out our mission.
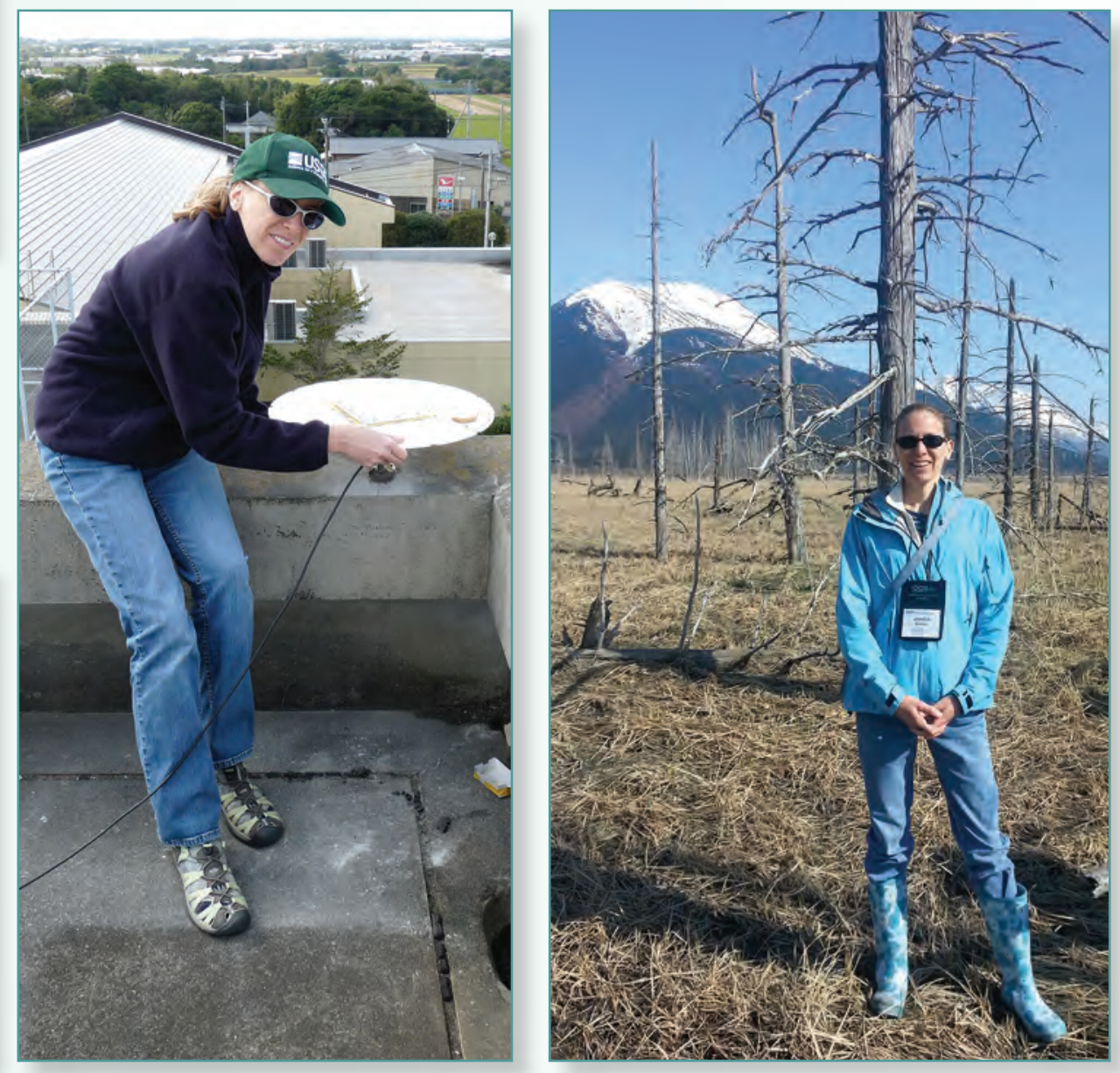


\section{Research Physical Scientist at the Southwest Biological Science Center in Tucson, Arizona}

As a child, I dreamed of becoming an archeologist. Growing up in Atlanta, Georgia, near the foothills of the Appalachian Mountains, and being a Brownie and Girl Scout gave me many opportunities to attend overnight nature camps in and around the Appalachians. I played outside my entire life it seems. I chose to study people and places by majoring in geography in college and was rewarded forever after by my experiences gained during an internship with the National Geographic Society. I never became an archaeologist, but I still dig in the dirt!

Over the course of my career, I have had the opportunities to plant rice for the Agriculture Ministry in Japan, capture photos from a Cessna over the delta of the Colorado River in Mexico, measure seaweeds in native Hawaiian fishponds on Molokai, plant native bushes to release pollutants from uranium mines on Navajo lands, and study how water and ecosystems influence each other around the banks of the River Murray near its end, close to Adelaide, Australia, for a year. I've also become known as "Tammy Pammy" because of my research on tamarisk water use. Helping to balance the health of aquatic ecosystems with meeting environmental needs for recreation and human uses has been a big focus of mine. Having been mentored by scientists and inspired by my parents from the time I was in high school, I'm also passionate about being a mentor and working with students from high school through postdoctoral levels.

My hobbies include getting into our national parks as much as possible with my three young kids. I have a passion for traveling to new places, particularly abroad, and can't wait to continue sharing these experiences with them as they grow. I'm drawn to places that look like the Great Smoky Mountains. My favorite spot that is oddly similar is on Molokai, Hawaii, down by Halawa Valley. Really any place that is isolated from people a bit and surrounded by mountains, trees, waterfalls, and streams brings me peace and happiness.

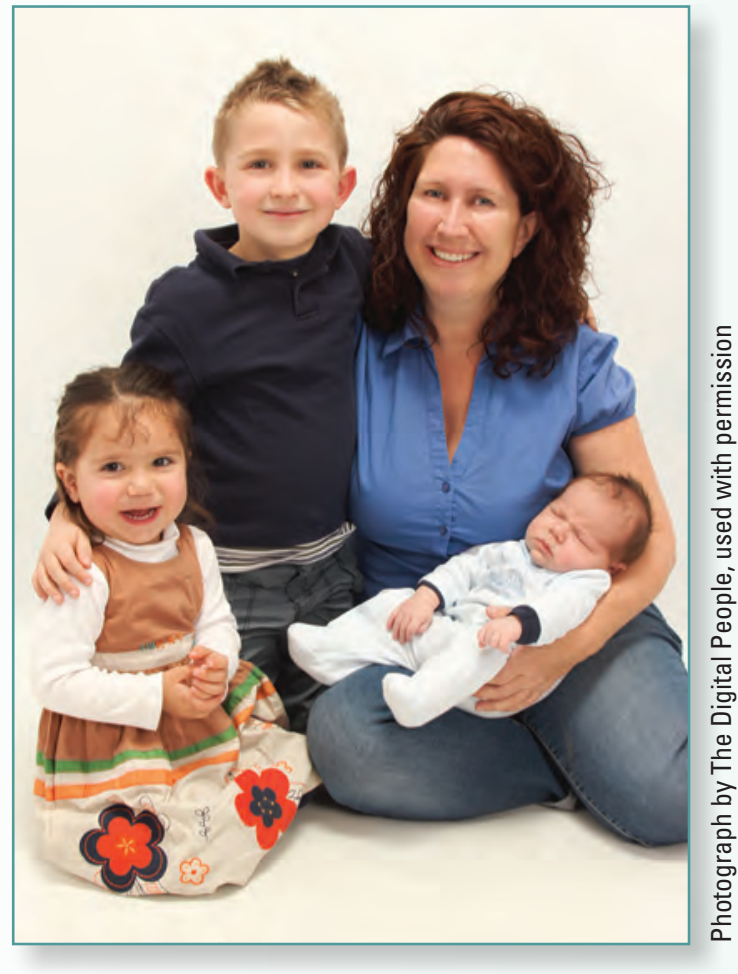

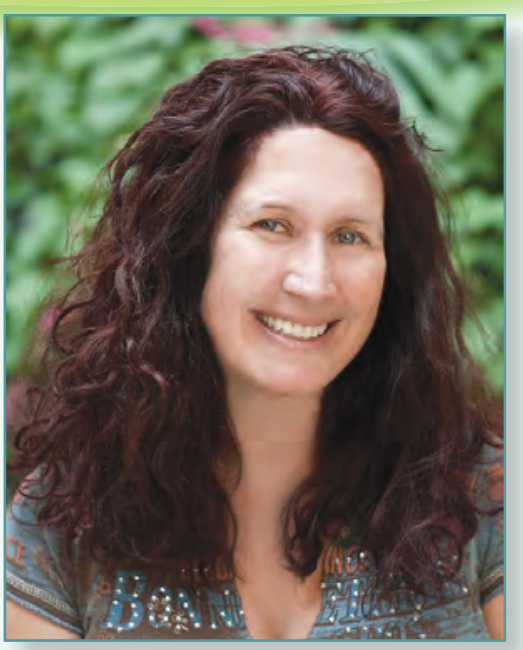

My mentor, Professor Edward P. Glenn from the University of Arizona, said to me just before he died (suddenly) in November 2017, "You are now at the point in your career when you can look back and know that your greatest achievement has been helping to bring life to the delta of the Colorado River in Mexico through engaging people on both sides of the border with a shared interest and the scientific knowledge to make the restoration and monitoring of this special area a reality."

Pamela Nagler has a bachelor's degree in physical geography from the University of Florida, Gainesville, a master's in physical geography from the University of Maryland, College Park, and a doctorate in soil, water, and environmental science with an interdisciplinary program specialty degree in remote sensing and spatial analyses from the University of Arizona, Tucson.

https://www.usgs.gov/staff-profiles/ pamela-nagler 


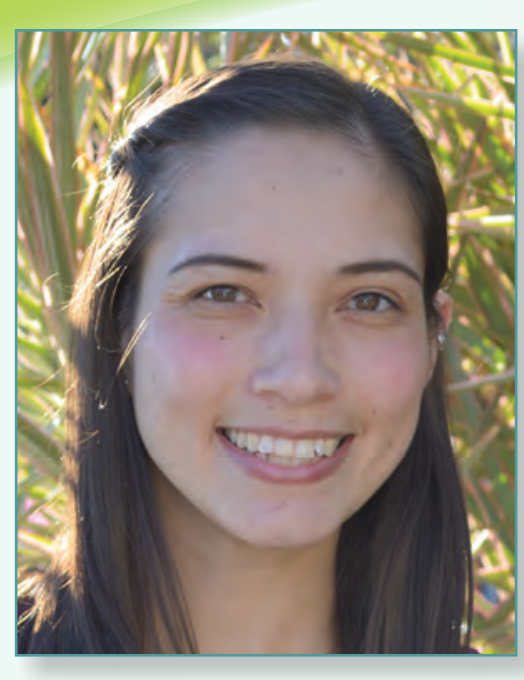

As beings living on Earth, I believe it is our essential duty to protect and conserve the health of people, animals, and the environment.

Natalie Nguyen has a bachelor's degree in biological sciences from the University of California, Irvine, a master's degree in public health from the University of Minnesota, and a doctorate in veterinary medicine from the Western University of Health Sciences. Natalie is the first Presidential Management Fellow at the USGS National Wildlife Health Center.

https://www.usgs.gov/staff-profiles/ natalie-t-nguyen

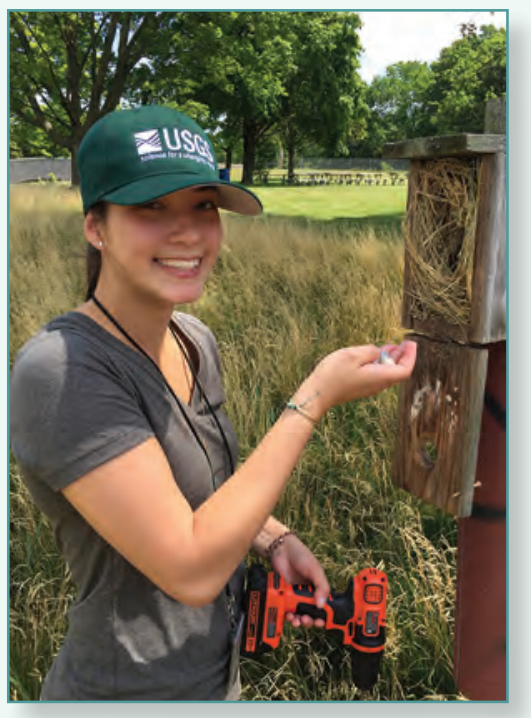

Natalie Nguyen

Veterinary Medical Officer with the National Wildlife Health Center in Madison, Wisconsin

"The man who follows the crowd will usually go no further than the crowd. The man who walks alone is likely to find herself in places no one has been before." -Alan Ashley-Pitt, "On Creativity"

From the time I was 4 years old, I knew I wanted to become a wildlife conservation scientist. While I was growing up, my mother was my biggest supporter. She would bring me to National Geographic exhibits and allow me to buy all the marine animal books I could find. When I was in high school, she supported my love of scuba diving and supported me in becoming rescue certified. I didn't have a car when I was an undergrad, and she would drive me to aquariums and zoos all weekend so I could volunteer between studying and track and field practice. The love and support of my family has inspired me to be the change I want to see in public, environmental, and wildlife health.

I started gymnastics when I was 2 years old and continued as a Junior Olympic gymnast until the age of 16 . Gymnastics and school were my life, and they taught me perseverance, dedication, and a strong work ethic, all skills I would need in pursuing my goal of becoming a leader in science. In high school, I was also a track and field athlete, with the triple jump as my main event. This brought me outdoors every day, and running and training outside brought me closer to nature. I began to appreciate the incredible wildlife surrounding me. I continued track and field in college as an NCAA Division I triple jumper, and I remember always looking for wildlife while training outdoors.

My life and work have taken me around the world; I was born and raised in southern California, but I lived in Vietnam for 3 years growing up and would visit family in Europe. I have traveled to and lived in Southeast Asia, the Middle East, and South Africa. Living outside the United States has given me an appreciation for the cultural differences across the globe and has influenced how I approach my goals toward wildlife conservation and public health.

I work with scientists throughout the world on collaborative research on wildlife diseases. During a research trip to Hawaii, I had the unique opportunity to travel on a 6-day boat trip to and from Johnston Atoll and spend a week with researchers working on eradicating invasive species of ants that affect the local seabird populations.

I continue to run, and have picked up long-distance running, which allows me to explore and appreciate the outdoors to an even greater extent than ever before. Every chance I get, I'm either fishing with my husband, running miles along a trail, hiking up a waterfall, scuba diving in the deep blue ocean, or traveling the globe. I find it hard to sit still during my free time because there is so much more to explore.
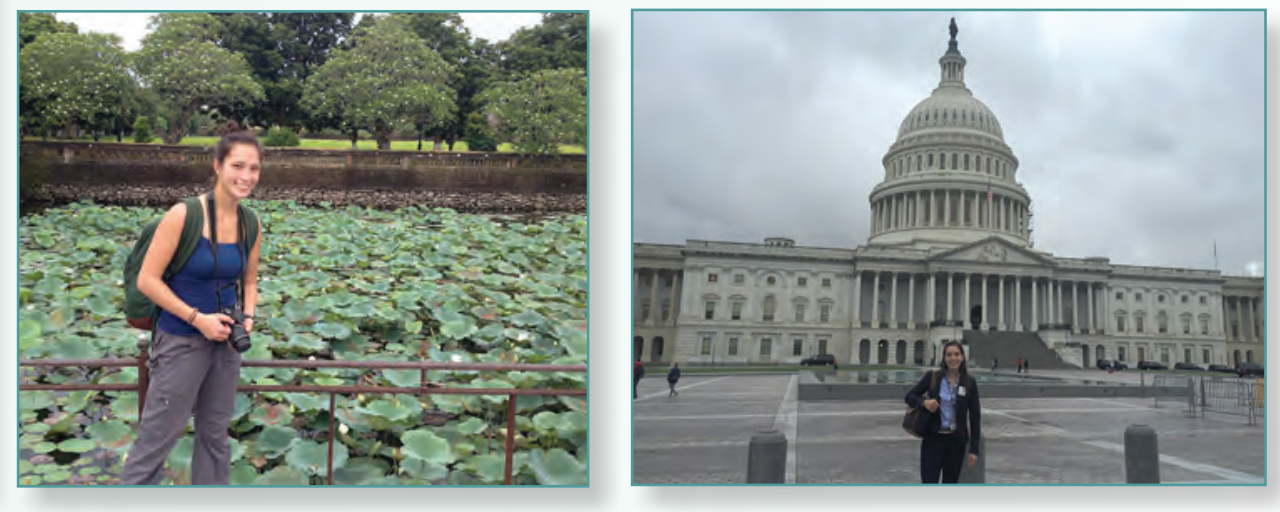


\section{Điane Nicks}

\section{Biologist with the Columbia Environmental Research Center in Columbia, Missouri}

"Somewhere, something incredible is waiting to be known." - Carl Sagan

Growing up in rural southeast Missouri, I developed a burning curiosity to learn about all of the wonders I encountered just playing and exploring the 27 acres that I and my seven older siblings called home. I needed to learn and understand how living things function and why they do what they do. The biodiversity, geology, karst topography, and weather extremes of this area provided constant inspiration to a developing scientist. The four-room, Catholic grade school I attended from first through eighth grade was fortunate to have a science teacher who fostered our curiosity, and she and the Ursuline sisters there encouraged self-learning in a time before the internet. My mother had purchased a set of "Time Life" science books that served as my "recreation" reading. I was able to attend a college preparatory high school and enrolled in all the science classes I was allowed; there, I began to focus on the biological sciences. When "Cosmos," hosted by Carl Sagan, aired on PBS in 1980, I realized that a research scientist was not just a person of learning but should also be a communicator of that knowledge.

As an undergraduate student, I had the opportunity to be employed as a research assistant, working in muscle physiology research and then in reproductive physiology. I realized that doing research was the career for me. I began to develop microscopy and microdissecting skills that lead me to a research specialist position at the University of Missouri where I became proficient in research data collection, micromanipulation, and animal surgery. This unique skill set in the early 1990s made me the perfect candidate

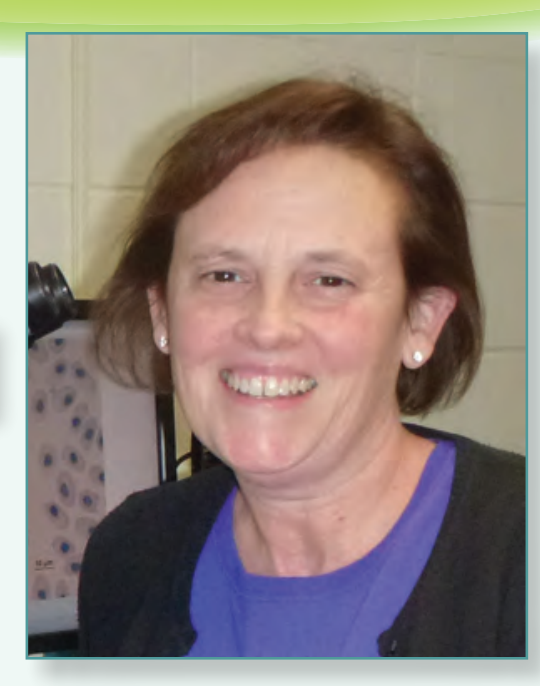

A career in scientific research is a lifetime of building personal knowledge and sharing that knowledge with others.

Diane Nicks has a bachelor's degree in biology from Lincoln University. https://www.usgs.gov/staff-profiles/ diane-nicks when Don Tillitt of the Columbia Environmental Research Center was looking for someone to further develop microinjection techniques for fish eggs.

I have found great personal accomplishment in my research position, which allowed me to work cooperatively with other scientists - biologists, ecologists, toxicologists, chemists, and veterinarians - to develop my own skills and knowledge, and then to use this knowledge to support such a dynamic group of researchers at the USGS and throughout the U.S. Department of the Interior. Working with young scientists and graduate and undergraduate students allows me to share all that I have learned with the upcoming group of researchers.

I really enjoy fishing and turning wild-caught fish or wild game into amazing gourmet meals. My husband, a retired fisheries research assistant from the Missouri Department of Conservation, is an avid white-tailed deer and turkey hunter and fisherman so I have plenty of supplies for my cooking endeavors. We also enjoy camping, canoeing, hiking, and traveling to beautiful natural places in Missouri and throughout the United States.
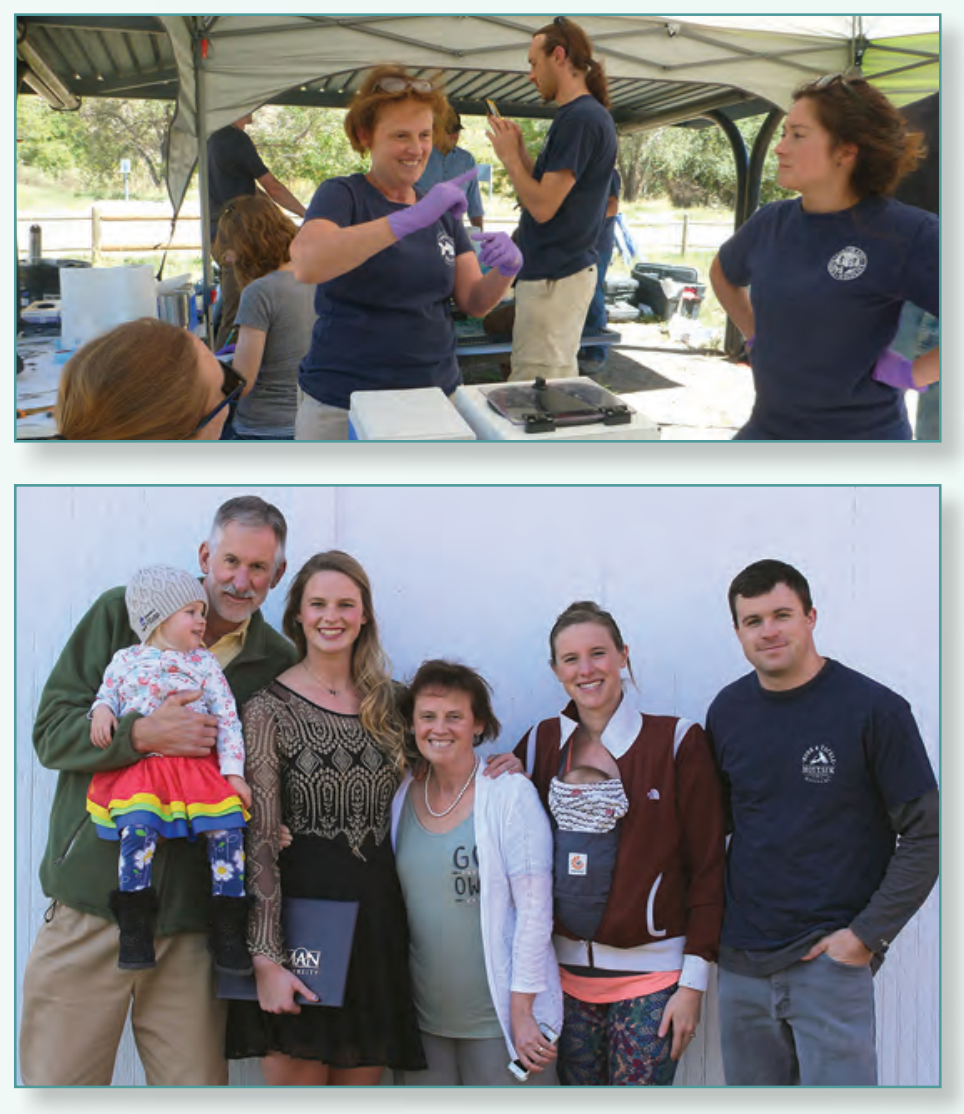


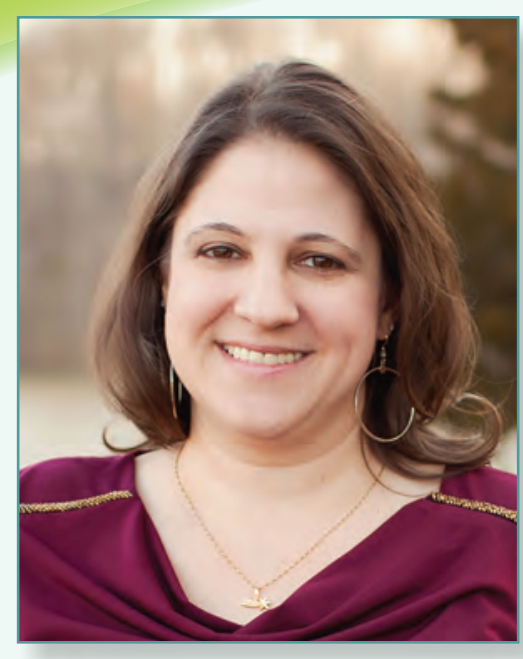

The deep connections with my friends, colleagues and mentors, my supportive husband and family, and my true inspirations, my children, empower me to feed my passions. They are the ones who have taught me to truly listen, celebrate our individual strengths, and realize the power of our collective human spirit to not see obstacles and to achieve great things.

Andrea Ostroff has a bachelor's degree in agricultural sciences from the University of Delaware and a master's in environmental biology from Emporia State University. https://www.usgs.gov/staff-profiles/ andrea-ostroff

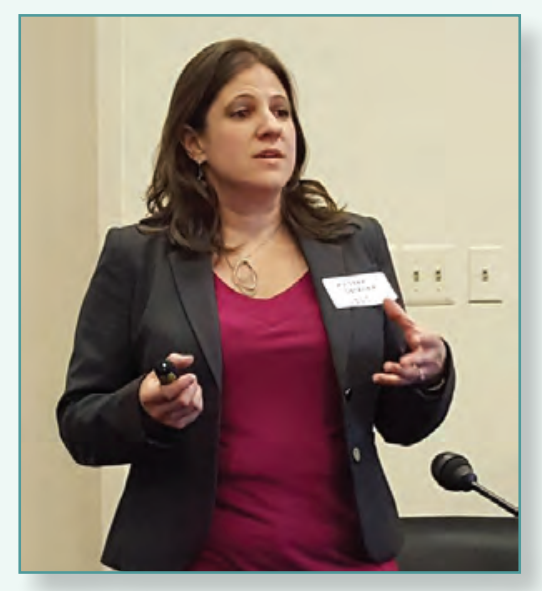

\section{Andrea Ostroff}

\section{Manager of the Fisheries Program in Reston, Virginia}

"Even if you're on the right track, you'll get run over if you just sit there." -Will Rogers

I grew up in Maryland near a wooded area with a small stream where I would often take solace during my childhood. My appreciation for the healing aspects of nature was instilled upon me at an early age, and every summer job I took as a teenager was aimed at maximizing time outdoors.

I discovered my fascination with ecology through a winding path that started with a general interest in biology and slowly narrowed to conservation biology. My wildlife biology professor in college sparked my interest in the field, and my advisor in graduate school extended my academic training beyond what you can learn in a traditional classroom or field lab. Every work experience and relationship built along the way had an impact on me, and many of those relationships have turned into long-time colleagues and friendships that I value deeply.

My career started in New Jersey, where I managed and mapped the data for programs on black bear populations and freshwater fisheries. This knowledge and experience was a tremendous advantage to my next job where I collected aquatic conservation project information provided by State agencies and helped get a national fish habitat partnership started. When I joined the USGS, I managed biological information and led the development of an online geospatial delivery system to provide open access to fisheries data. I am still motivated by mapping the intersections of science, data, and people and by developing these connections. This motivation guides my daily activities when identifying and developing new projects in response to needs expressed by Congress and other agencies. I lead my teams to work together toward the mission of the Fisheries Program and to process and archive aquatic ecology data in a consistent manner so they can be used by as many researchers throughout the world as possible.

My husband and two children share my appreciation for nature; we love to hike and canoe as a family on the lake where we currently live and in parks where we go camping. My children often help remind me to slow down and notice the details of our surroundings.
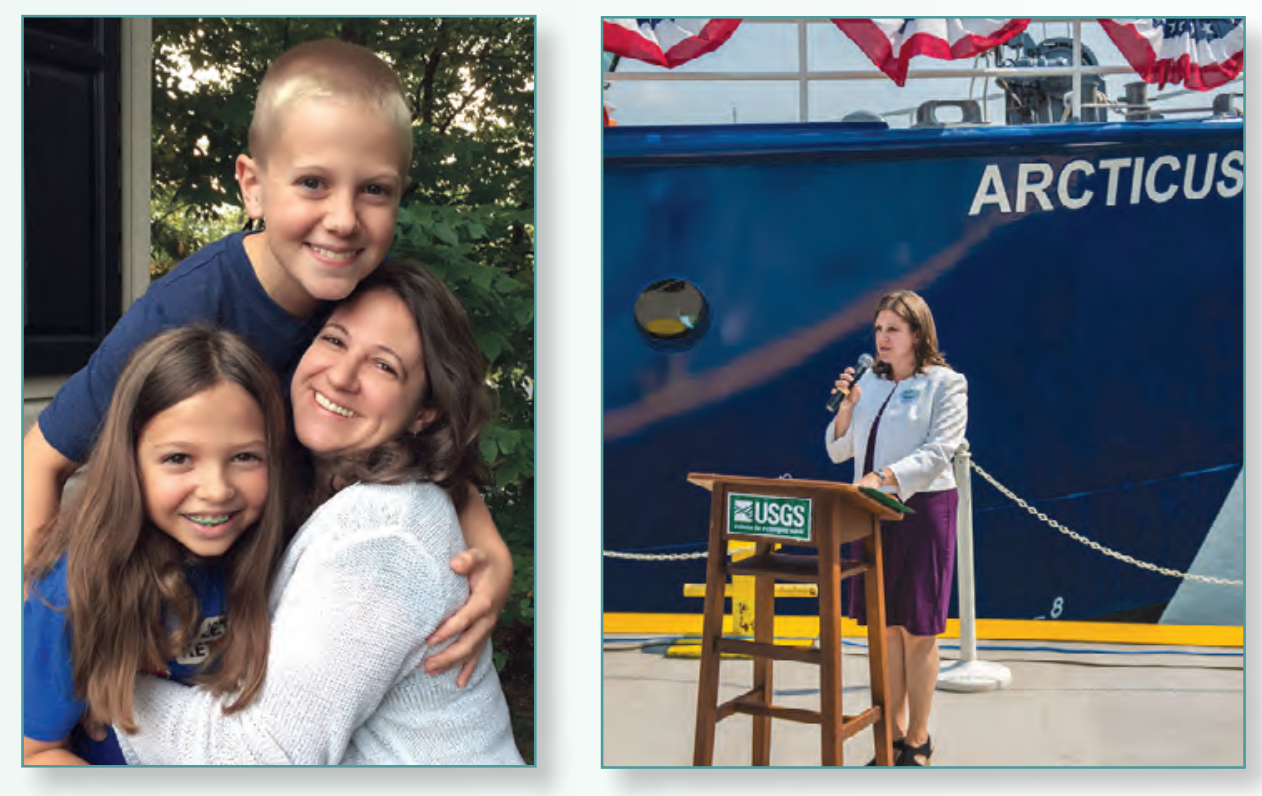


\section{Jaime painter}

\section{Geographer at the South Atlantic Water Science Center in Norcross, Georgia}

"Do not go where the path may lead; go instead where there is no path and leave a trail." — Ralph Waldo Emerson

When I was six, my family and I traveled across the United States from Georgia to Seattle, Washington. I remember noticing the variety in the landscape along the way, from vast corn fields in Indiana to the large urban center of Chicago to the forest and mountain terrain of the Dakotas and westward and finally to the hot springs and animal life of Yellowstone National Park. As a 6-year-old, I wasn't aware that this would lead to my adult vocation, but those memories have come back several times when I think about how humans, animals, and environmental processes interact over space and time.

As a freshman in college, I took an introductory geography class and learned that geography was so much more than the capital and country names I had to memorize in primary school. I learned about physical geography and a newly emerging field of geographic information systems. I instantly knew I wanted to learn more. At that time, I was a computer science major, and I was struggling with relating my major to something I actually wanted to do for a career. I wanted to write programs that had meaning beyond some business logic. Learning about geographic information systems and how they can help us understand connections between humans and the natural environment was exciting, and it allowed me to combine my initial career path with my passion for nature.

I have created maps and prepared three-dimensional models for investigations of fresh groundwater in coastal Georgia, of water use in agriculture, and of inland storm tides and flooding from Hurricanes Irene, Isaac, and Sandy. I have also participated in a national effort to document high-water marks to measure the effects of storms nationwide.

My husband and I and our two boys enjoy hiking, biking, and jogging at community parks and on trails on weekends; I like to experience the natural geography in the region as well as observing how people use the green space. I also enjoy traveling and seeing how landscapes and cultures change and vary, from the volcanic islands of Hawaii to the glaciers in Alaska to the deserts of Arizona. These environments make me wonder about the connections that exist to make these geographies what they are and how humans and animals interact and use that space to shape the future of those regions.

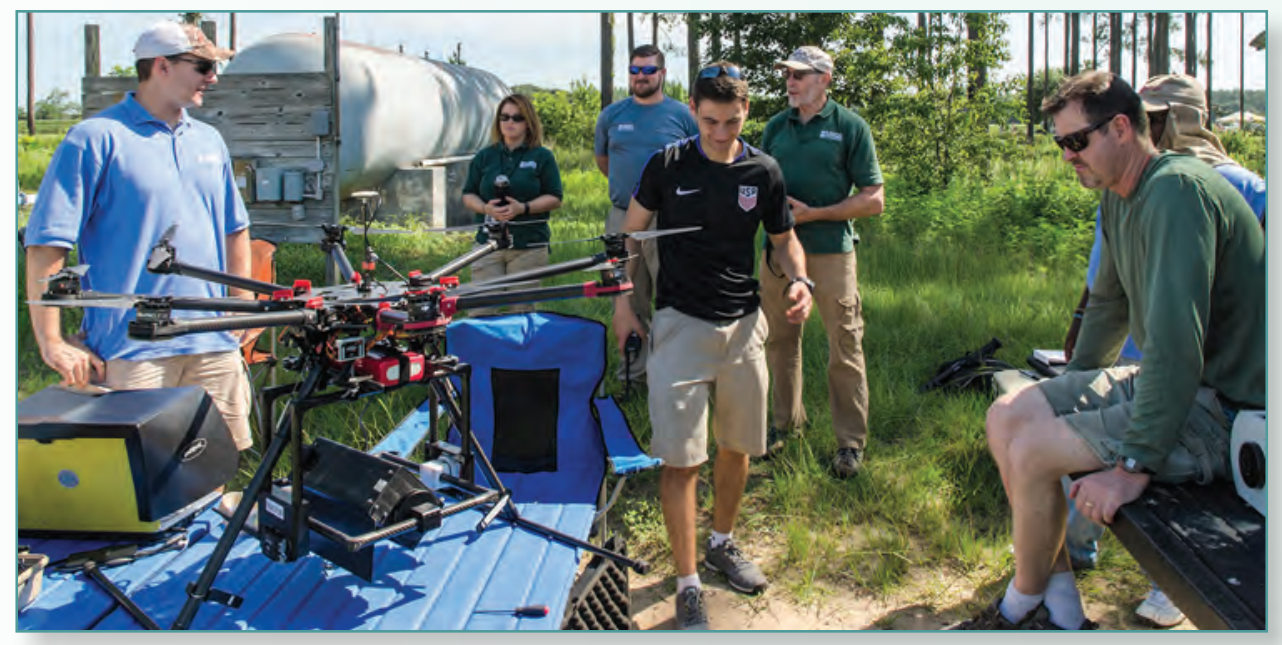

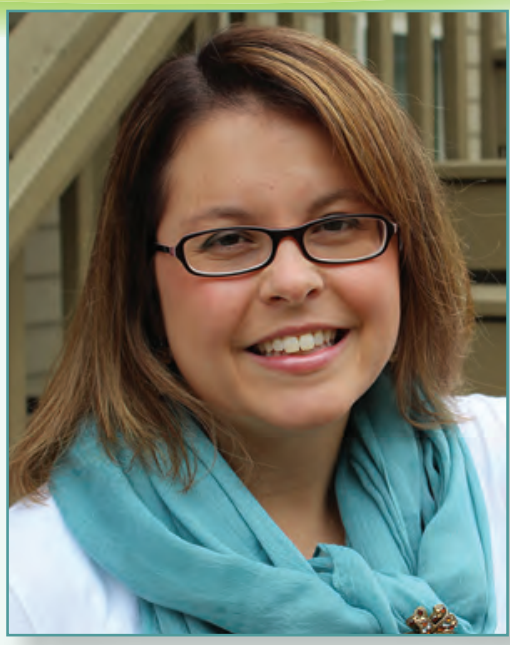

As a child, my family and I traveled around the country visiting family, and I was able to experience human and natural geography in different spaces. I think this allowed me to be able to see connections between things and ask questions of why these connections exist or how those relations vary over space.

Jaime Painter has a bachelor's degree in geography from the University of West Georgia and a master's in geography from the University of South Carolina. https://www.usgs.gov/staff-profiles/ jaime-a-painter

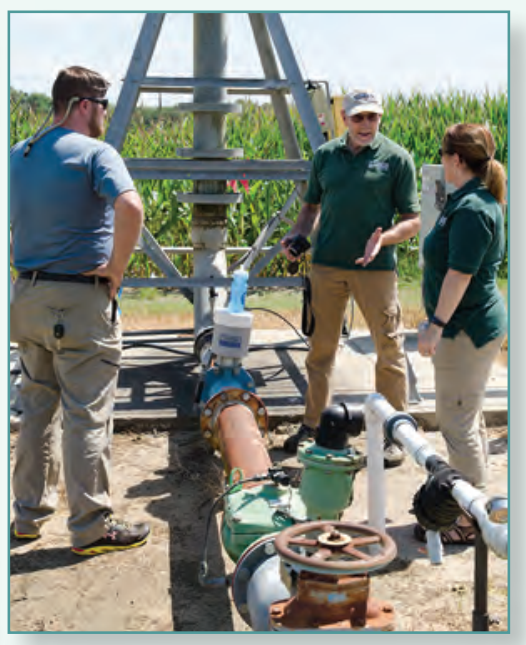




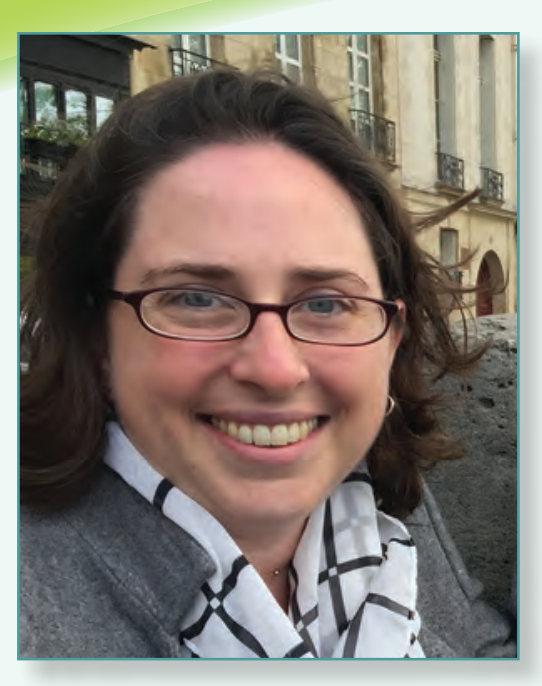

Be open to opportunities in unexpected places; you never know what doors will be waiting for you. And sometimes you are going to have to crawl through a tiny window and get stuck and scratched up in the process. Don't worry, you will fit!

Marie Peppler has a bachelor's degree in geography, with emphasis in physical processes, and a master's in geography-fluvial geomorphology from the University of Wisconsin, Madison.

https://www.usgs.gov/staff-profiles/ marie-c-peppler

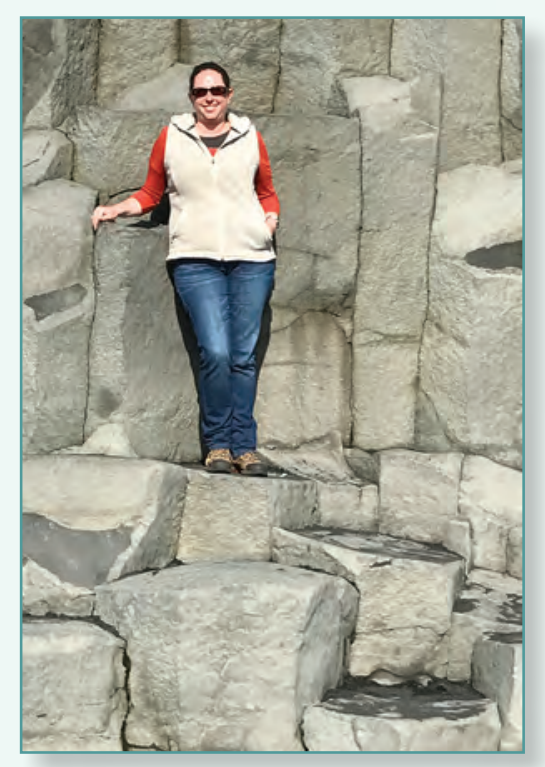

Marie Peppler

\section{Deputy Director of the Integrated Information Dissemination Division of the Water Mission Area in Reston, Virginia}

"To those devoid of imagination a blank place on the map is a useless waste; to
others, the most valuable part." - Aldo Leopold, "Conservation Aesthetic"

On the first day of class, my sixth grade science teacher lit the lab table on fire, and I knew then and there that I wanted to be a scientist. I found my direction in geography in college, when I took an introductory earth science class. As my teacher lectured us emphatically on the 12 soil orders, my mind just exploded. I had no idea that there were so many processes and types and colors and sizes and maps! If I had made it all the way to the age of 19 without knowing about soil orders, what else didn't I know? There was so much else to learn and discover.

When I decided to switch my field of study to geography from education at college, my mom required me to get a summer job as a geographer to make sure that it would be something I really wanted to do long term for a living. So I joined the USGS as a student and spent my time hiking deep into the woods to survey erosion at streams and how it affects the morphology of the stream. I was naturally drawn to water, but the flood of June 2008 in southern Wisconsin propelled me in a new direction: flood mapping and flood hazard programs. I was an integral part of the team that standardized methods to map areas that are at risk of flooding and produced an online mapping application to help the public understand local flood risks.

It is natural to be drawn to water: we need it to live, we want to live by it, and yet it can be a fickle friend. I could spend hours watching a river or ocean. I once read Mark Twain's Mississippi Writings in which he discusses how he used to see beauty on the river, peace and calm, but after living with the river and learning about its secrets, he could only see the perils of a snag or a tricky pool. I try very hard to understand the water but to still see beauty and find the tranquility in its power. When I get too deep into work and stressed, I try to remember to step back and just watch the water flow by and see why I was drawn to this science in the first place.
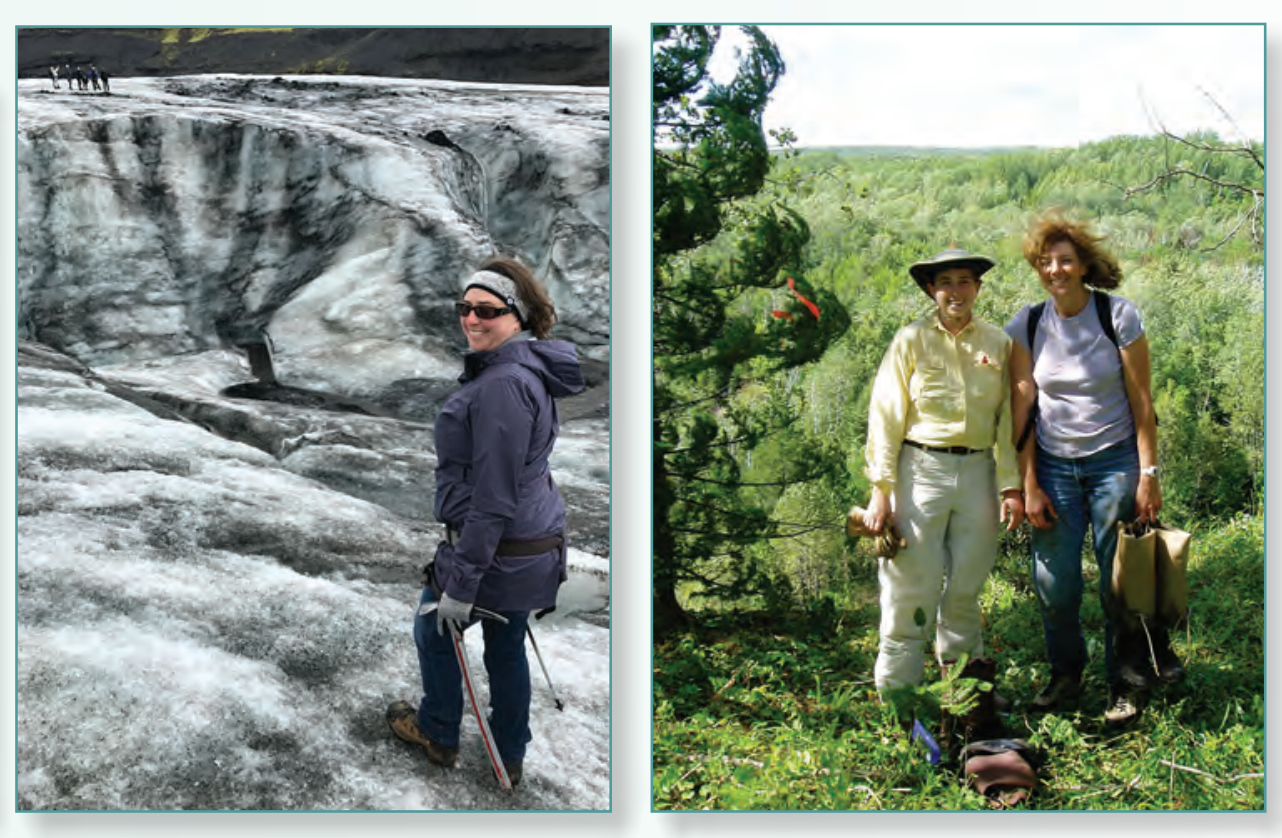


\section{Geographer with the Earth Resources Observation and Science Center in Sioux Falls, South Dakota}

My father was a farmer for most of his life, and he always seemed to have some type of map or atlas around our farmhouse. When I was little, he would pull out paper maps and show me how to find places on them. To this day, I rarely travel anywhere without looking at a paper map first, and I credit my father with inspiring me to become a geographer.

After high school graduation, I visited my brother in Las Vegas, Nevada. He took me to see the Hoover Dam. After that visit, I read several books about the dam and other books on water rights in the West. That visit, along with a memory of our farm pasture flooding during my childhood, drew me to water science.

My work has me deriving bathymetry from satellite imagery, generating hydrography from digital elevation models, and analyzing the effects of land change based on remotesensing research. I was part of a team that developed a database of networks to describe streams and watersheds based on a nationwide elevation dataset, and I am part of a team that is developing topographic and bathymetric models in coastal regions of the United States.

I might be biased, but I do love living in South Dakota. Although cold in the winter, the countryside is diverse and beautiful with many friendly people. I consider myself a "flat-lander" because I like to look outside and see for many miles. However, I enjoy the diversity of the Black Hills of South Dakota as well. I also have an interest in aircraft, having taken fixed wing flight lessons in my twenties. Again, I think my father was an inspiration as he, along with his Army buddy, gave me my first airplane ride in my teens. My husband and I enjoy the peacefulness of gardening, bird-watching, mowing the lawn, and just being outside in general. On average, I read about 20 books a year, so one of my hobbies is definitely reading.

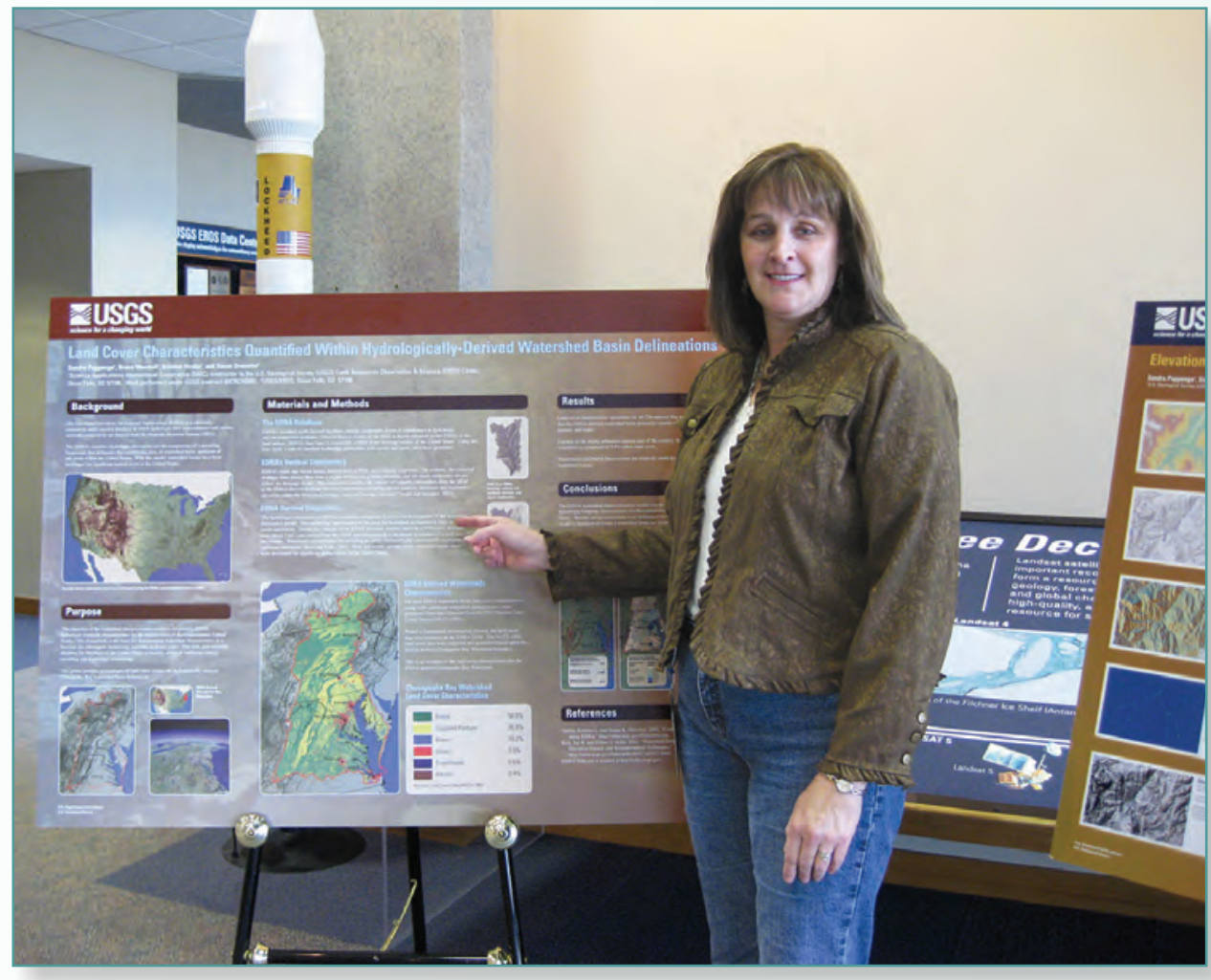

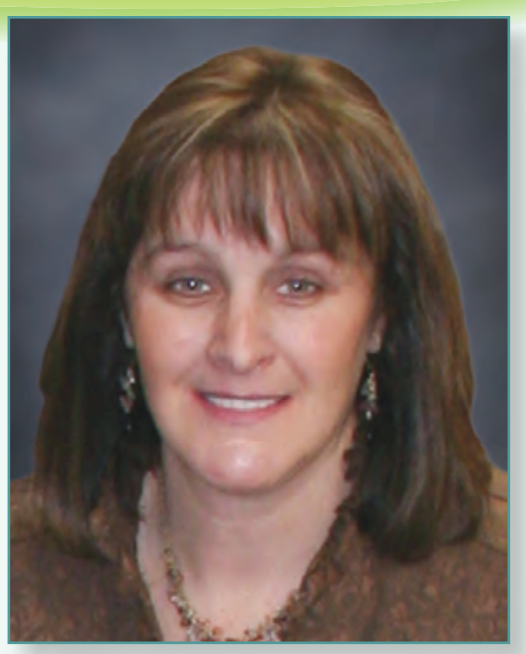

Having the opportunity to see the countryside every day gave me a better understanding of directions, geography, and the physical landscape.

Sandra Poppenga has a bachelor's and a master's degree in geography from South Dakota State University.
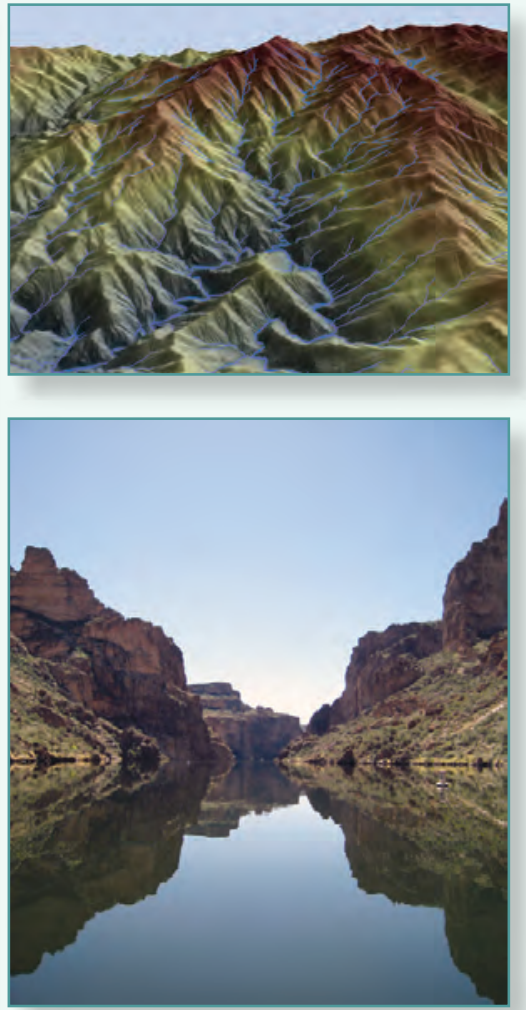


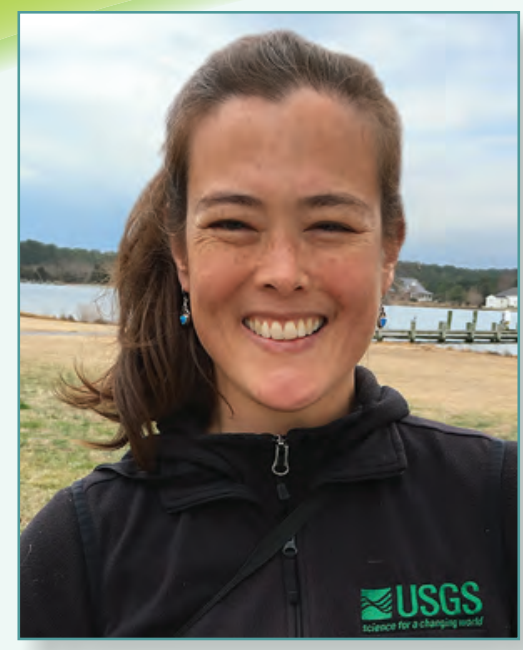

My mom always told me that you can do anything that you strive to as long as you work hard and put all your effort into it. Her words are true!

Diann Prosser has a bachelor's degree in wildlife and fisheries science and a master's in ecology from Pennsylvania State University and a doctorate in marine, estuarine, and environmental sciences from the University of Maryland. Diann has hosted scientists visiting from the Chinese Academy of Sciences and has worked closely with multiple international partners.

https://www.usgs.gov/staff-profiles/ diann-prosser

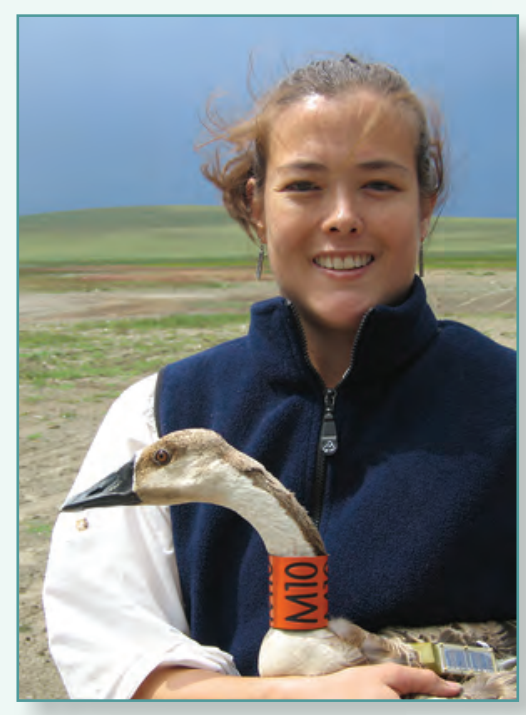

\section{Điann Prosser}

\section{Research Wildlife Biologist at the Patuxent Wildlife Research Center in Beltsville, Maryland}

"Enthusiasm is one of the most powerful engines of success. When you do a thing, do it with all your might. Put your whole soul into it. Stamp it with your own personality. Be active, be energetic, be enthusiastic and faithful, and you will accomplish your object. Nothing great was ever achieved without enthusiasm." - Ralph Waldo Emerson

I grew up in New Jersey and Pennsylvania, but I spent a lot of time in the Catskill Mountains of New York with my family. This area was true to my dad's heart, and as children, my siblings and I spent many hours on the local lake or hiking the beautiful rocky bluffs. We also learned to ski in this area. These experiences are gifts that I cherish and that have helped shaped the person I am today. It wasn't until college that I decided to study wildlife science and took a job at the USGS Wetlands Center where I really began to explore the natural world in a scientific setting. I also conducted an independent project on an amazing forested stream bird, the Louisiana waterthrush (check it out!). I was hooked!

As a wildlife ecologist at the Patuxent Wildlife Research Center, I now study a broad spectrum of issues related to avian ecology. One of the main themes in my research program is to integrate remote sensing and modeling with field research to study spatial questions related to wildlife, such as effects of climate change, advantages of restoration, and implications of disease. One of these projects required me to study birds in a completely new location: China. When the lethal avian flu virus, H5N1, came on the world scene, I was really interested in improving our understanding of how wild birds might be affected by and potentially involved in the spread of such viruses. The virus originated in China and did not exist in the United States, so I began working with local scientists to study this question. We made several important discoveries, including identifying connections between routes used by migratory birds and how the interactions of wild and domestic birds can affect the risk of transmission between populations.
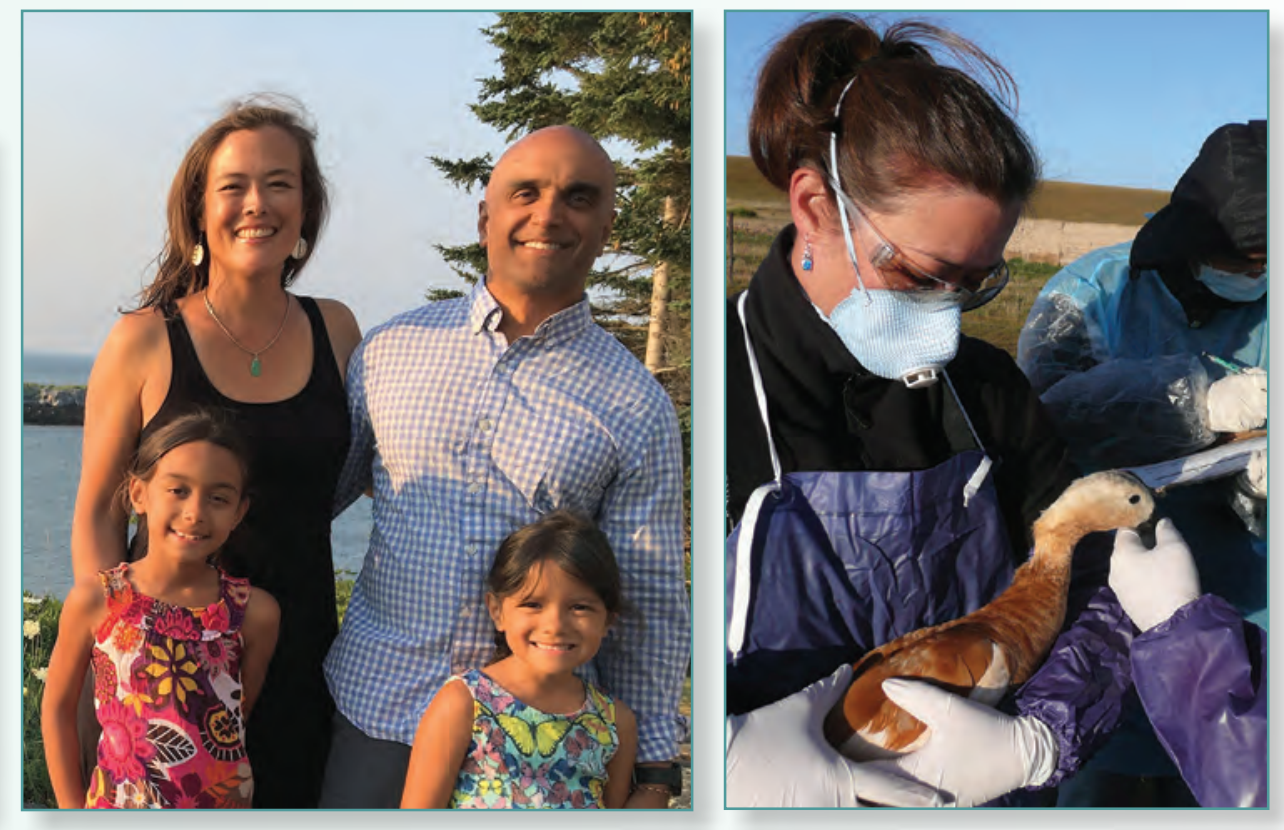


\section{Maureen Durcell}

\section{Microbiologist at the Western Fisheries Research Center in Seattle, Washington}

I grew up in rural Michigan, and I spent my childhood camping, fishing with my father, and swimming in Michigan's many lakes. I think that spending my childhood outdoors drew me to biology. I could have never imagined a career as a research scientist. I feel very fortunate to have chosen a large land-grant college like Washington State University because it exposed me to many different science fields and showed me how science can be used to address real-world problems.

Because of my love for birds and other wildlife, I initially enrolled in the zoology program at Washington State University. I fell in love with fish while conducting undergraduate research on sockeye salmon, and I moved to the University of Maine to study population genetics of Atlantic haddock in the Gulf of Maine. After receiving my graduate degree, I worked on genetics research on heart disease in humans at The Jackson Laboratories. Although the research was interesting, I missed working on fish, so I moved to Seattle for a job with the National Oceanic and Atmospheric Administration and started working on my doctorate degree.

For the past decade, I have been researching infectious diseases in fish in western North America. I use cutting-edge genomic tools to better understand how fish are resistant to disease based on their genetics and the effects of climate and environment.

The demands of work, homeownership, and parenting keep me and my family busy, but we grab any time we can out of our busy lives to go bike riding, hiking, and camping as a family. We also spend a couple of weeks each summer in my husband's native Devon in the United Kingdom; the ruggedly beautiful coastal areas of Cornwall and the area's history are among my favorite vacation spots.
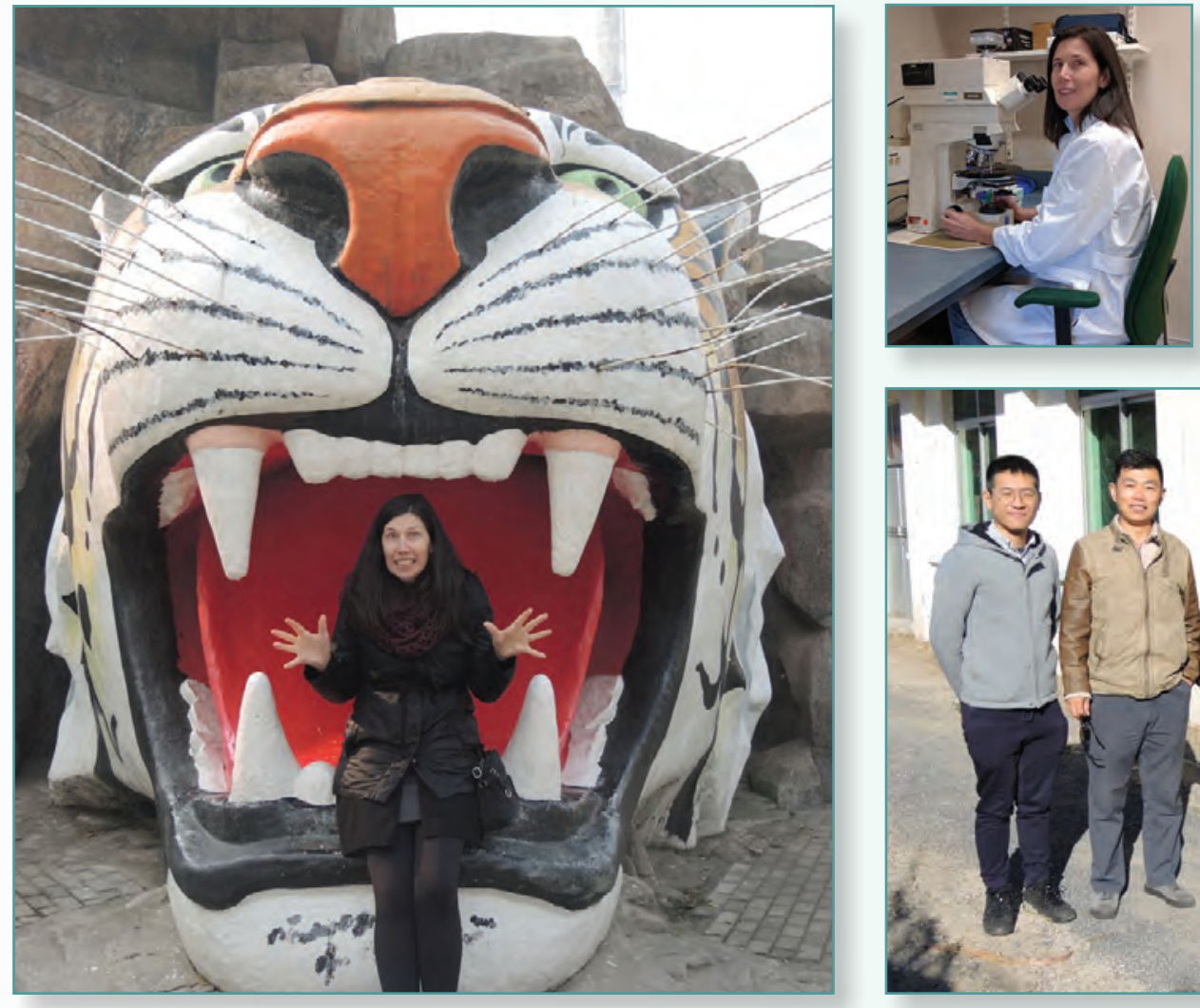

Maureen Purcell has a bachelor's degree in zoology from Washington State University, a master's in zoology from the University of Maine, and a doctorate in aquatic and fishery sciences from the University of Washington.

https://www.usgs.gov/staff-profiles/ maureen-k-purcell

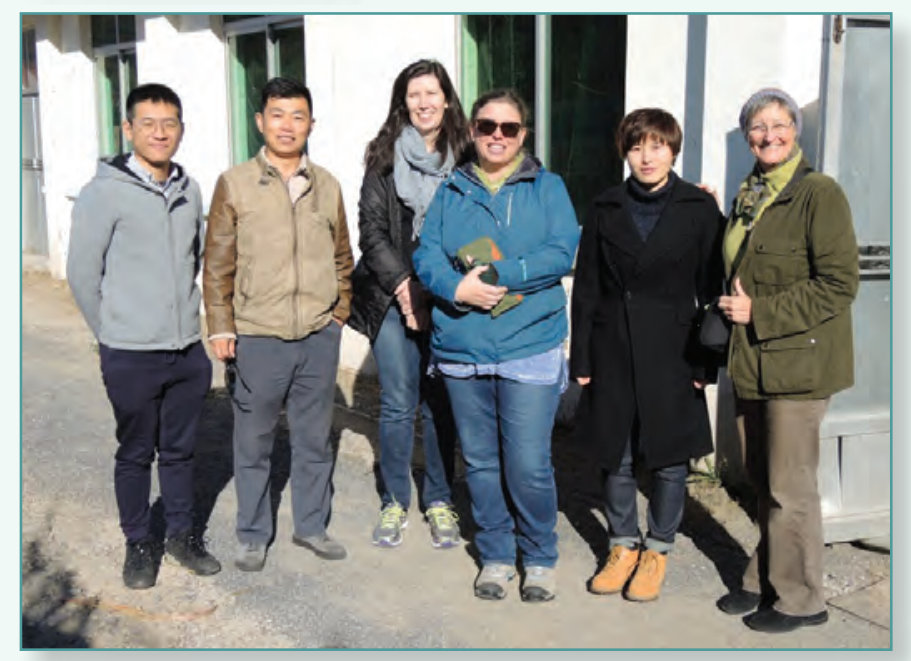




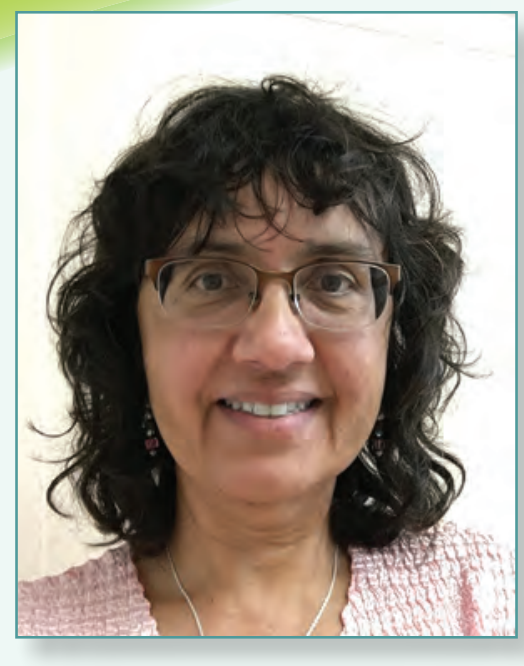

I have always loved nature and animals. From an early age, I would stay outdoors as long as I could, wandering the woods and streams around our home. I would do my best to catch wildlife, wanting a closer look. The beauty in the wild speaks both to my intellectual interests and the need to connect to something larger than myself.

Mary Ratnaswamy has a bachelor's degree in biology from Carleton College, a master's in oceanography from the University of Rhode Island, and a doctorate in forest resources from the University of Georgia. https://www.usgs.gov/staff-profiles/ mary-ratnaswamy

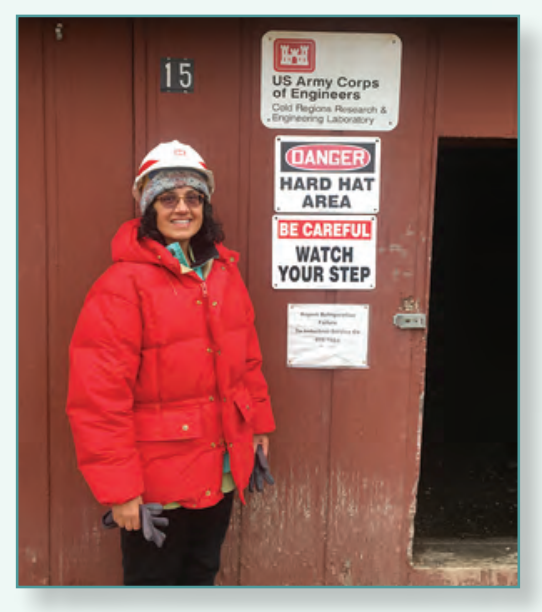

\section{Mary Ratnaswamy}

\section{Director of the Northeast Climate Science Center in Amherst, Massachusetts}

I recall my junior high teacher, Mrs. Slowicek, who challenged us in biology class to read rigorous scientific literature, do well-designed experiments, and truly function as scientists. She was a Russian immigrant and a true mentor to many young people. As a result, I ended up taking an advanced class in high school a year early. I won an award for high marks in that class but, more importantly, had an outlet for my passion for nature, biology, science, and learning.

In my senior year at Carleton College, I participated in a wonderful international program through the Associated Colleges of the Midwest. I spent 6 months in Costa Rica, first living with a local family in San Jose, then traveling to Guanacaste Province, where I designed a study of a mangrove estuary in the dry tropical forest. It was a truly beautiful and wild location, and I had the chance to do everything from the ground up, culminating in a senior thesis.

These experiences in Costa Rica led to an interest in marine and coastal ecosystems and marine mammal and sea turtle conservation. I went back to school and worked on fin whales along the Atlantic coast and then worked for the National Oceanic and Atmospheric Administration in Alaska, California, Hawaii, and the Caribbean. I went back to school again, where I worked on an important conservation problem: destruction of sea turtle nests by raccoons.

One of my goals has always been to support in others an excitement and enthusiasm in science, conservation, and the outdoors. As the Director of the Northeast Climate Science Center, I spend much of my time mentoring young scientists and building partnerships with universities. I advise students who are studying the effects of climate change on mammals in far-northern landscapes and help provide science that natural and cultural resource managers need to help them with problems, from climate change to other major environmental issues.

I enjoy creative writing and gardening, although I end up sharing most of my produce with rabbits, squirrels, and other wild "neighbors." Through it all, my love of water persists: I love the ocean after having worked on the Atlantic and Pacific Oceans and traveling through the Indian Ocean and other seas, I am inspired by serene lakes having grown up in Minnesota with its thousands of lakes, and I am moved by clean, running brooks.
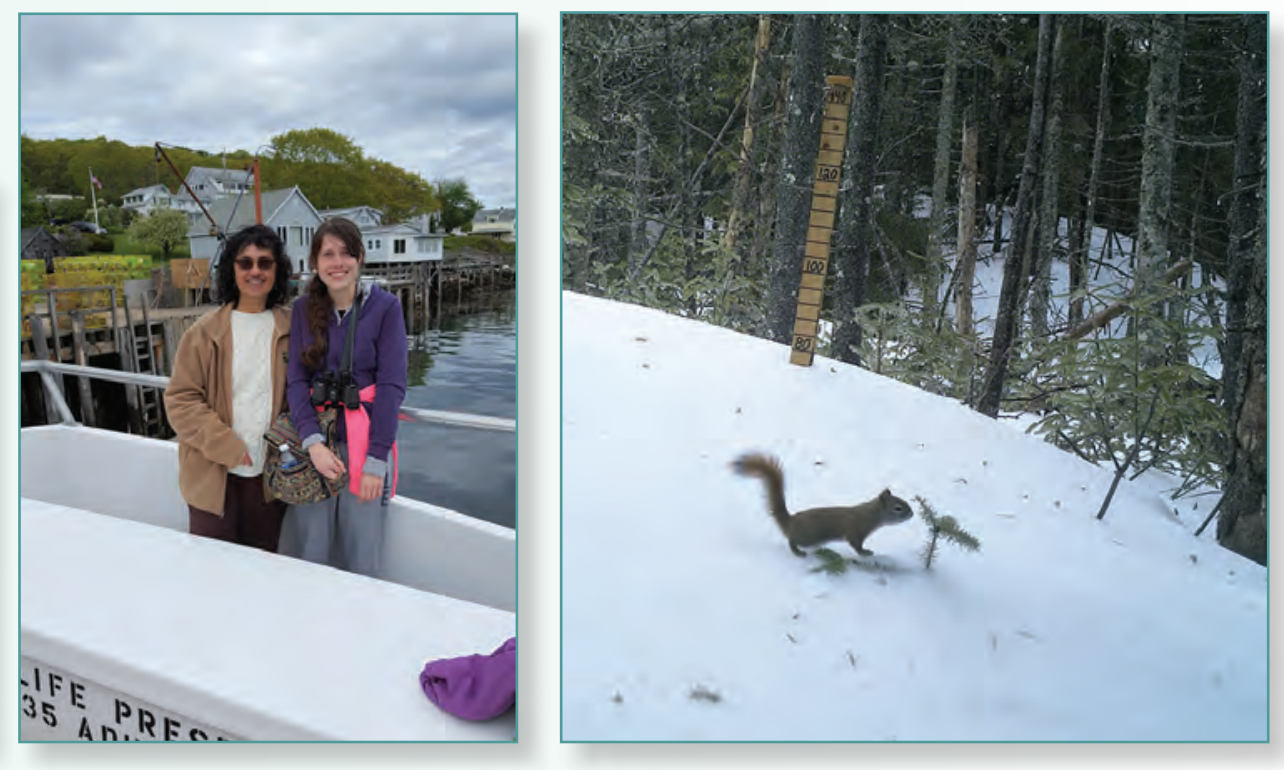


\section{Sasha Reed}

\section{Terrestrial Biogeochemist at the Southwest Biological Science Center in Moab, Utah}

"Science knows no country because knowledge belongs to humanity and is the torch that illuminates the world." - Louis Pasteur

I grew up in Elmira, New York, a town in southern New York State quite close to Pennsylvania and not very close to New York City. In high school I had a chemistry teacher, Mr. Mitchell, who seemed serious and no nonsense on the first day of class. Mr. Mitchell also had a passion for chemistry, and that passion was a gift he gave to me. Probably against his better judgment, Mr. Mitchell let our class conduct hands-on experiments, and he didn't just ask us to memorize facts, but really explained how things worked. I picture myself as I was then, a freshman with a big wall of permed hair and zinc pink lipstick, and Mr. Mitchell treated me and the others in my class with such respect, as if we were young scientists worthy of his scholarship. A few years later, this seed planted by Mr. Mitchell was powerfully nurtured by Dr. Modarelli, an incredible chemistry professor, advisor, and mentor at Colgate University. Chemistry is like physics in action, with a hidden beauty that underlies all of our planet's processes. Mr. Mitchell and Dr. Modarelli instilled this perspective in me and let me see the chemistry happening behind the scenes. I'm so grateful for this view.

My experiences in science have allowed me to meld my love of chemistry with my curiosity about how ecosystems work in order to provide critical information that helps address pressing societal challenges. As its name suggests, biogeochemistry brings together perspectives from biology, geology, chemistry, and other fields of study, and I enjoy crossing these disciplinary boundaries to follow elements such as carbon, nitrogen, and phosphorus as they move through plants, soils, microbes, and the atmosphere. My research has taken me to the wilds of Bolivia, the tall forests of Costa Rica, and the expansive deserts of the southwestern United States.

I love kayaking, rafting, mountain biking, and skiing, and I spend a lot of time outside because it keeps me connected to the world. I also love being with friends and family, particularly my husband. There is nothing better than being on the river with my husband, our dog Arlo, and friends and family.
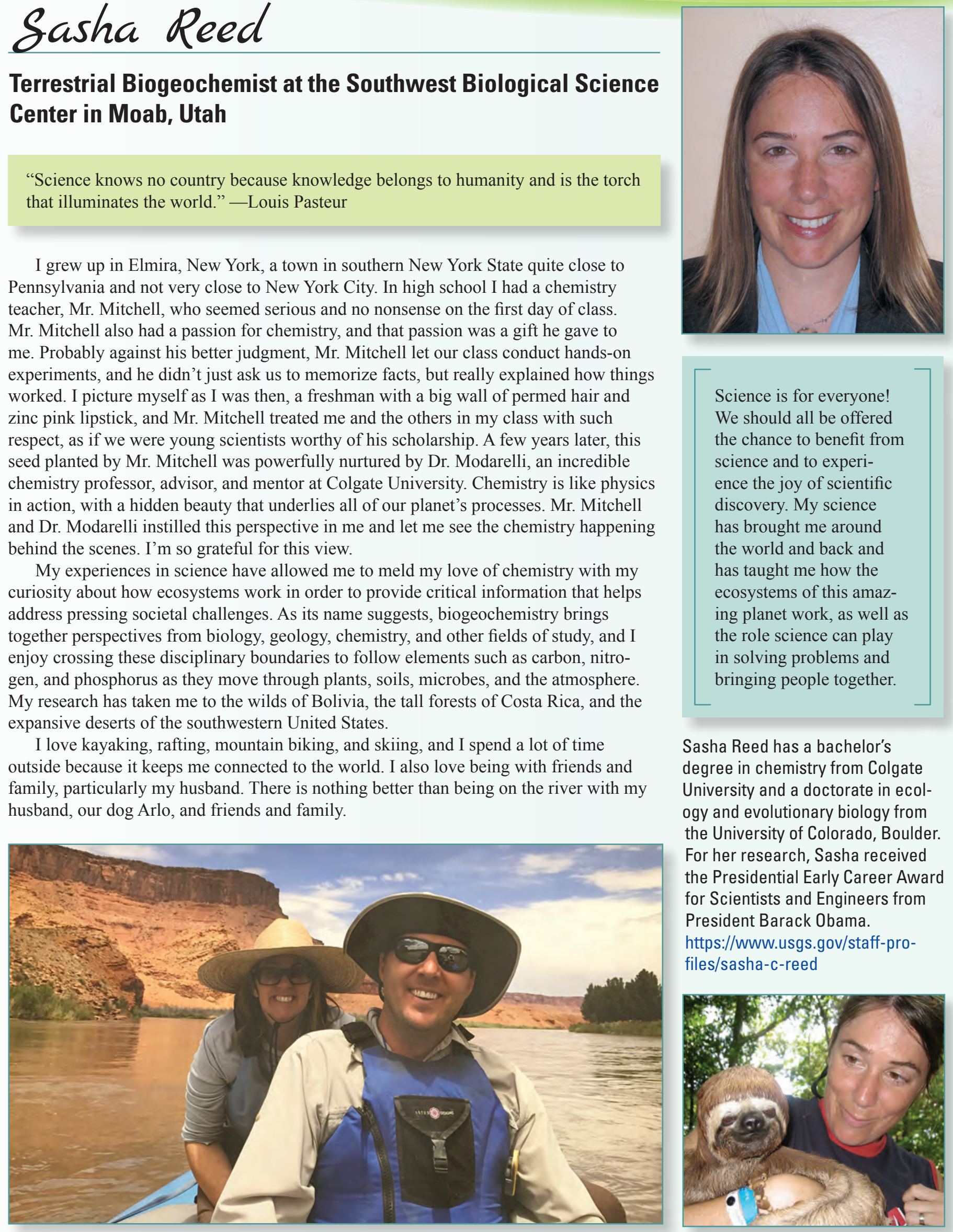

Science is for everyone! We should all be offered the chance to benefit from science and to experience the joy of scientific discovery. My science has brought me around the world and back and has taught me how the ecosystems of this amazing planet work, as well as the role science can play in solving problems and bringing people together.

Sasha Reed has a bachelor's degree in chemistry from Colgate University and a doctorate in ecology and evolutionary biology from the University of Colorado, Boulder. For her research, Sasha received the Presidential Early Career Award for Scientists and Engineers from President Barack Obama. https://www.usgs.gov/staff-profiles/sasha-c-reed

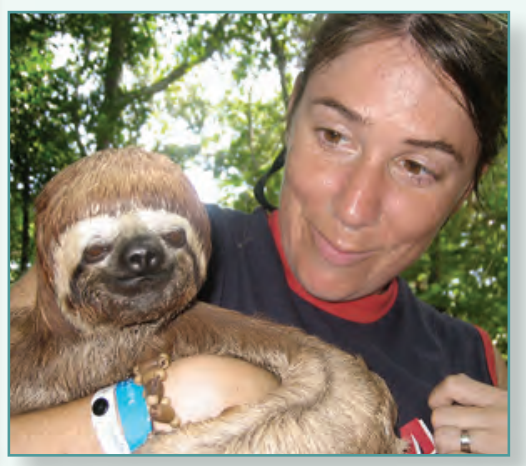




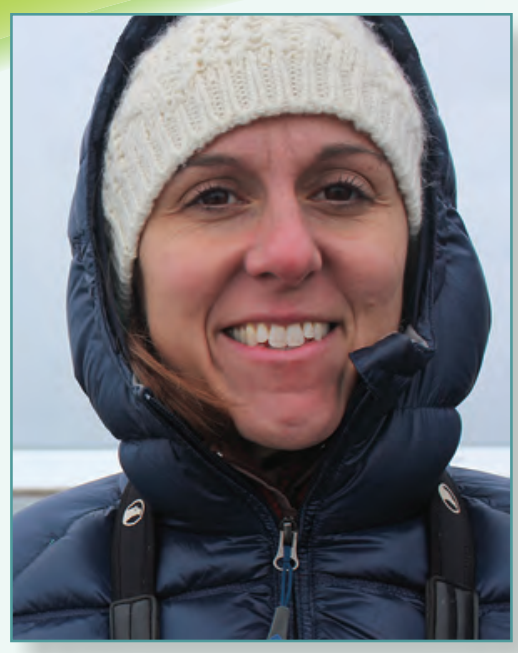

I'm extremely fortunate to study species that people care so much about. I want to go to the places where we know the least and study the issues. Being able to provide results to inform wildlife conservation and management decisions is the ultimate reward.

Karyn Rode has a bachelor's degree in wildlife biology from Colorado State University and a master's and doctorate in zoology from Washington State University. https://www.usgs.gov/staff-profiles/ karyn-rode

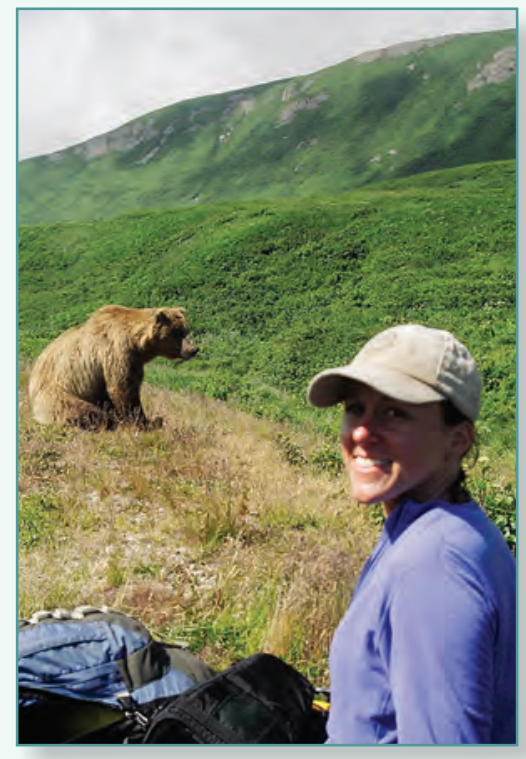

Karyn Rode

\section{Research Wildlife Biologist at the Alaska Science Center in Anchorage, Alaska}

"Everybody is a genius. But if you judge a fish by its ability to climb a tree, it will live its whole life believing that it is stupid." - Matthew Kelly, "The Rhythm of Life: Living Every Day with Passion and Purpose"

I grew up in Kentucky with a creek down the street from my house where I'd catch tadpoles and crawfish, explore under rocks, and eat honeysuckles off a fence (and get a ton of chigger bites in the process). But by the time I got to college, I had decided to major in chemical engineering. During my third year of engineering school, I needed a break from my engineering studies and entered an exchange program to study for a semester in Malaysia. While touring parks and natural areas in Malaysia and Thailand, I realized my passion had always been animals. When I returned from Malaysia, I changed my major to wildlife biology.

The effects of human activities on wildlife ecology have been a consistent theme of much of my research. Before coming to the USGS, I worked in Africa studying relations between human activities and the ecology of primates and forest elephants, and in North America, I studied the nutritional ecology of brown bears. Most recently, my work has taken me to Alaska to better understand the population status and health of polar bears in the Chukchi Sea. In trying to identify how polar bears are affected by loss of sea ice, I work in the field and with zoos to develop new tools for monitoring the behavior and ecology of polar bears. My research has provided information to decision makers and managers who work with endangered species, marine mammal protection, and an international cooperation on polar bears.

My favorite pastime is spending time with my family, including my husband and my two kids. We like to hike, go beachcombing and exploring tidepools when we can, bake, play games, do art projects, and read books. I also like to run, which is usually when I figure out solutions to problems I'm having with my work or think of new ideas to pursue. I love any dirt path leading through a natural area that is safe to run on-the less developed, the better. There is something about the solitude of natural places that lack views of the changes humans have made to the landscape that always rejuvenates me. I particularly love runs in the fall when the leaves have changed color and have just started falling and the air is crisp and a perfect temperature for running.
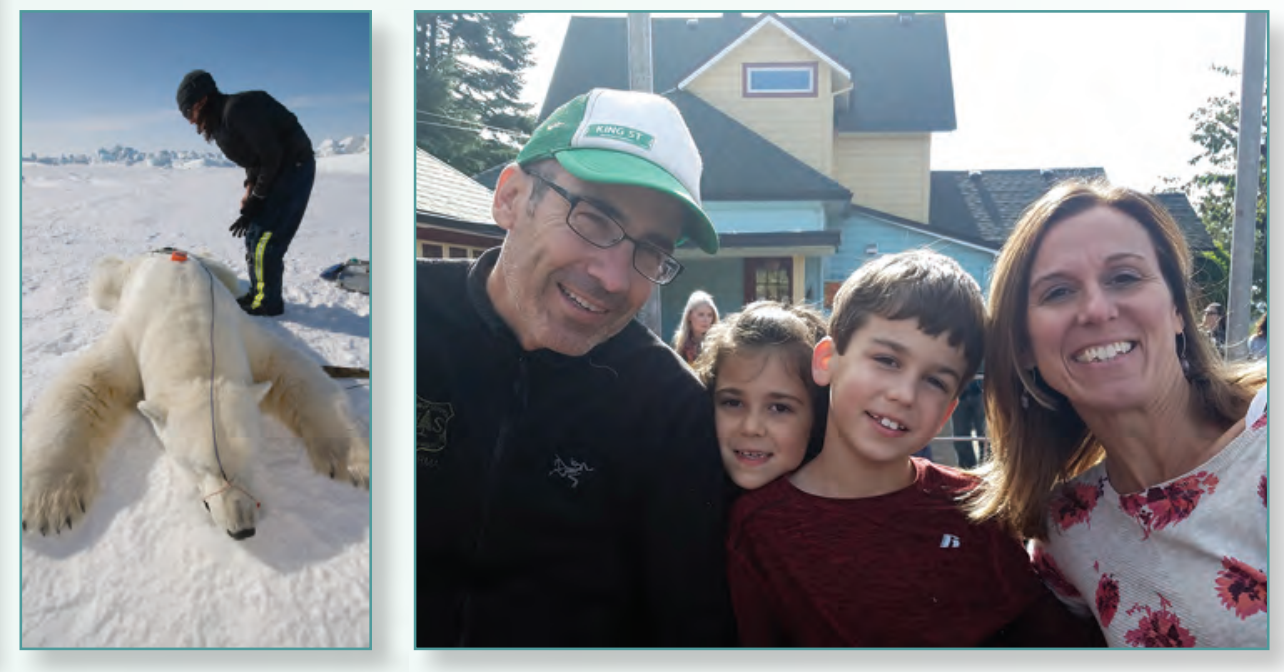


\section{Eoral Roiggilva}

\section{Physical Scientist with the Eastern Geographic Science Center in Reston, Virginia}

"To avoid situations in which you might make mistakes may be the biggest mistake of all." —Peter McWilliams

I am originally from Puerto Rico, and my love of learning goes back as far as I remember. As a child I was always drawn to books. We had an encyclopedia at home (this was before the internet and a computer at home were the norm!) that I would spend hours reading. It didn't matter what subject it was, I was still curious. Reading that encyclopedia is my first memory of doing "research." In the ninth grade, we moved to a different town, and the school's only science class was earth science. That class was all it took for me to love geology! We learned how to read topographic maps, and the teacher took us outside the classroom to show us a normal fault in the school's backyard. It was destiny! That year I made up my mind that I wanted to become a geologist.

I worked to support myself during college at the University of Puerto Rico, and couldn't afford to do an internship. I focused on working in the summer and getting involved in student groups like the Association of Student Biologists. Through the group I made many friends and got to explore and visit places in Puerto Rico I had no idea even existed. During my graduate studies, I was able to participate in summer internships and traveled for the first time off of the island. After spending a summer interning in the Washington, D.C., area, I knew I wanted to come back. I was selected for a USGS internship in 2008, and I've been at the USGS ever since!

In college I tried to get involved in research being done on the island whenever possible. Some of the research I did was on earthquake-related topics, including the North Boquerón Bay and the South Lajas Valley Faults in Puerto Rico, seismic waves, and ancient beaches that have been raised above the seawater level because of earthquakes. I have studied bacteria and minerals and about how wind moves them in sediments and into rivers and streams. I've also studied issues related to forest deforestation and reducing harmful emissions from the environment and issues related to land use and land cover. I am working to help understand how changes in land cover from oil and gas drilling in Pennsylvania may be affecting natural resources and ecosystems and evaluating the accuracy of land-cover measurements from satellite data.

I recently moved to West Virginia, and while my commute to Reston, Virginia, is longer than I'm used to, I am enjoying the change in environment. We have a big piece of land we can work, and I enjoy gardening. I've been learning about wild edible plants and how to maximize the resources provided by our own land.
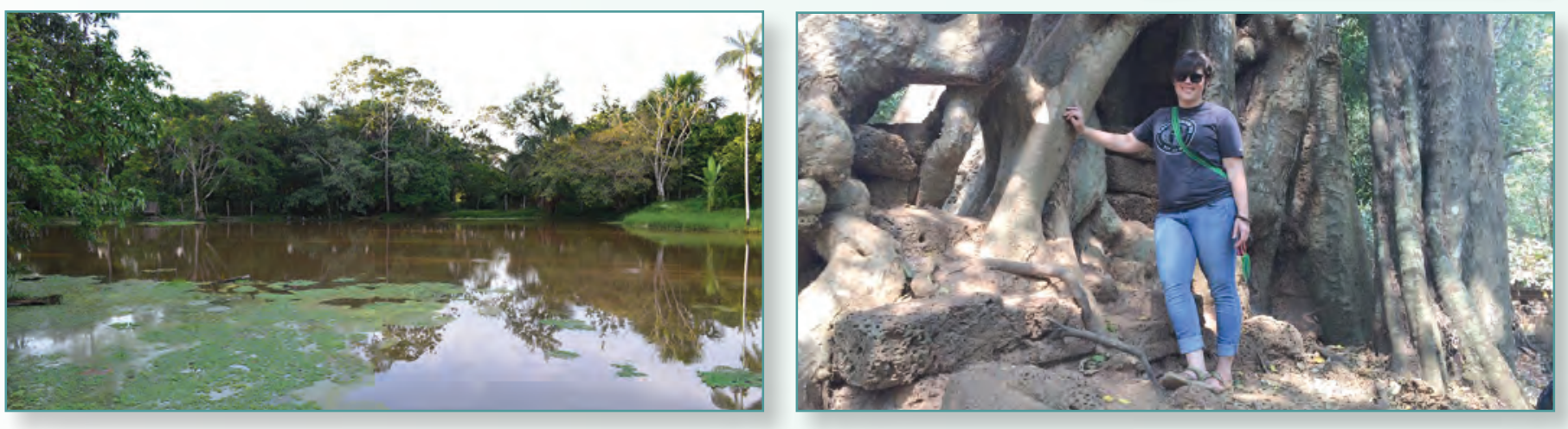


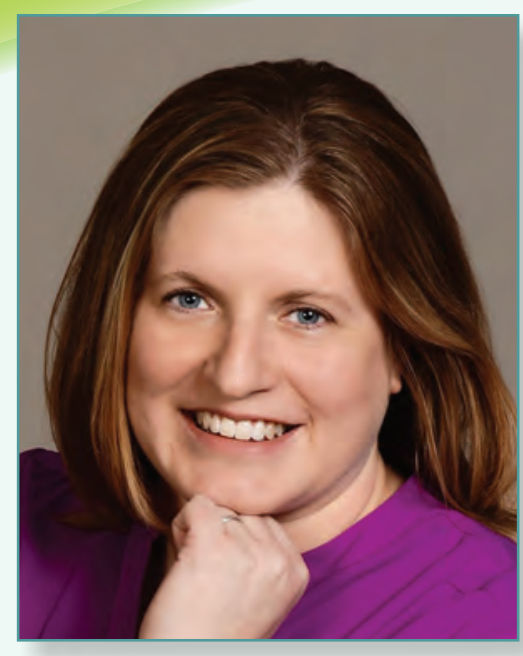

In thinking about and planning a career in science, do not overlook the importance of communication skills. As scientists, we are professional communicators. A science project is not complete until it is communicated to the stakeholders.

Karen Ryberg has a bachelor's degree in mathematics from Luther College, an associate's in computer support from Bismarck State College, a master's in statistics from Colorado State University, and a doctorate in environmental and conservation sciences from North Dakota State University. https://www.usgs.gov/staff-profiles/ karen-r-ryberg

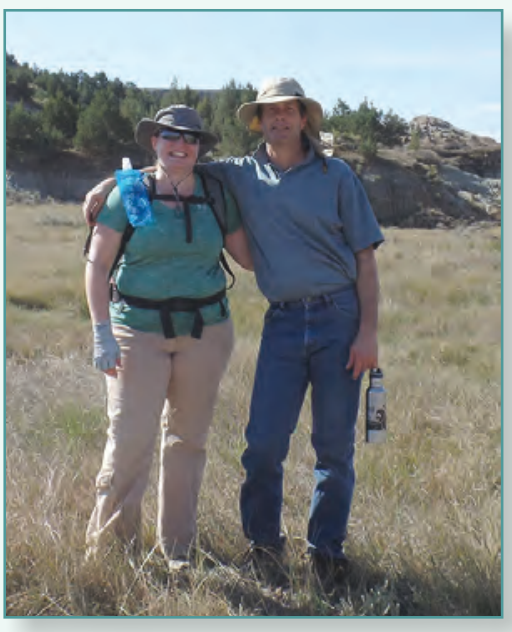

Karen Ryberg

\section{Research Statistician at the Dakota Water Science Center in Bismarck, North Dakota}

"When we try to pick out anything by itself, we find it hitched to everything else in the Universe." — John Muir

I am originally from a farm and ranch, in an area that met the definition of American frontier (less than 2 people per square mile), 8.5 miles from a town of 50 people. I went to a two-room school for 8 years. My first through fourth grade teacher was excellent, and I received a fantastic education, also thanks to the influence of my parents. Growing up, my family enjoyed going to events at State and national parks and historic sights. We learned about natural resources, Native American cultures, and the history of the Dakota Territory. I appreciate that my parents took time for those activities, and they shaped my love of life-long learning.

I was very involved in $4-\mathrm{H}$, doing projects on everything I could from embroidery and baking to tractor maintenance and showing $4-\mathrm{H}$ steers. The $4-\mathrm{H}$ program encourages a project-oriented view, which has served me well at the USGS, and gives one constructive feedback. Accepting and incorporating feedback is important to scientific success.

My work involves analyzing data for various topics, including analyzing trends in concentrations of pesticides in the waters of rivers, streams, and lakes; analyzing the effects of climate change and variability on rivers, streams, and lakes; and graphically showing scientific data so that they can be easily understood by all audiences. I am also a teacher and a mentor of young scientists, teaching applications of statistics in scientific analysis.

I enjoy hiking, backpacking, kayaking, snowshoeing, and cross-country skiing. I am the co-organizer of an outdoor adventure group, and while it is hard to find enough time for such adventures, I have made many friends through the group. My husband and I get together regularly with a group of friends to cook meals based on regional cuisine from around the world. We explore other cultures through food and fellowship. For years, I have attended a monthly gathering called Feminist First Friday, which was started to provide a venue for casual discussion of socioeconomic and cultural issues. This group is an important social outlet for me, and I always look forward to these Fridays.
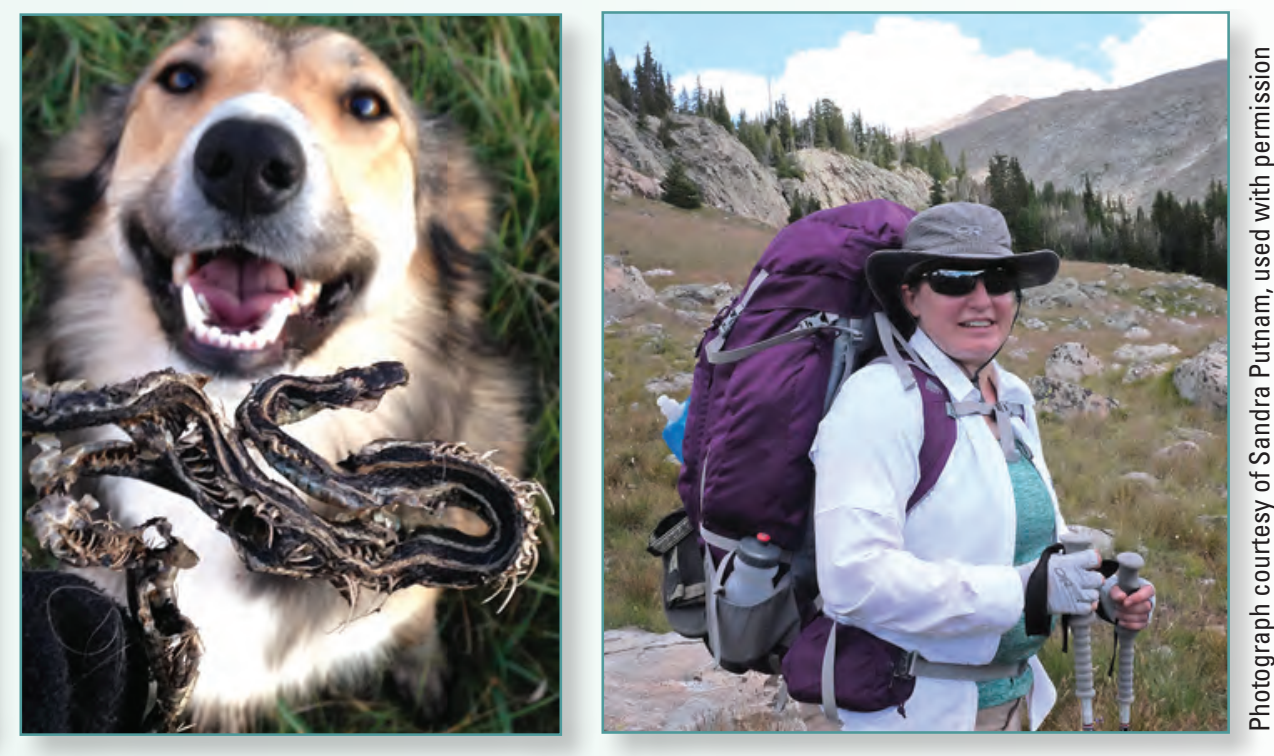


\section{Kristi Sayler}

\section{Physical Scientist with the Earth Resources Observation and Science Center in Sioux Falls, South Dakota}

As a student, I didn't really know what I wanted to do after college. I knew I was interested in computers and liked math, but that was about it. Once I applied for the internship with the USGS at the Earth Resources Observation and Science Center, that's when I fell in love with remote sensing and looking at how the world is changing through the eyes of satellite images. Once I got hooked on imagery and geography and learning about the Nation and how the landscape is changing, I knew that's what I wanted to continue to do with my career.

Early in my career, I helped scientists studying land cover by creating algorithms to analyze image data to create land-cover maps and by programming web-based applications to provide imagery to the public. I'm lucky to have been able to take part in a large project that studied how land cover and land use in the United States changed between 1973 and 2011. The team documented changes in land cover and then analyzed that information to figure out what drove those changes and what the consequences of the changes were. I had the opportunity to go out into the field and had the chance to see many areas of the country with which I had not been familiar. It was a great experience being able to learn about the differences in land use and culture across the Nation and how land cover affects these differences. My projects since then have been extensions of that project, as part of the team projecting land cover into the future and producing timelines of land cover from 1938 to 2011 for the entire United States.

I've been married to my husband, Jason, for 22 years, and we have two daughters. We like to travel as a family as much as we can now that our kids are older. I tend to use all my spare time to attend my kids' activities and just spend time with them. I also like to read and try to fit that in as much as I can when I have down time. I do really love living in South Dakota; it's a great place to raise kids and to be in a larger city without the troubles usually associated with big-city life. Living in South Dakota also inspires me to travel and see other places of the world because they are so different from where I live.

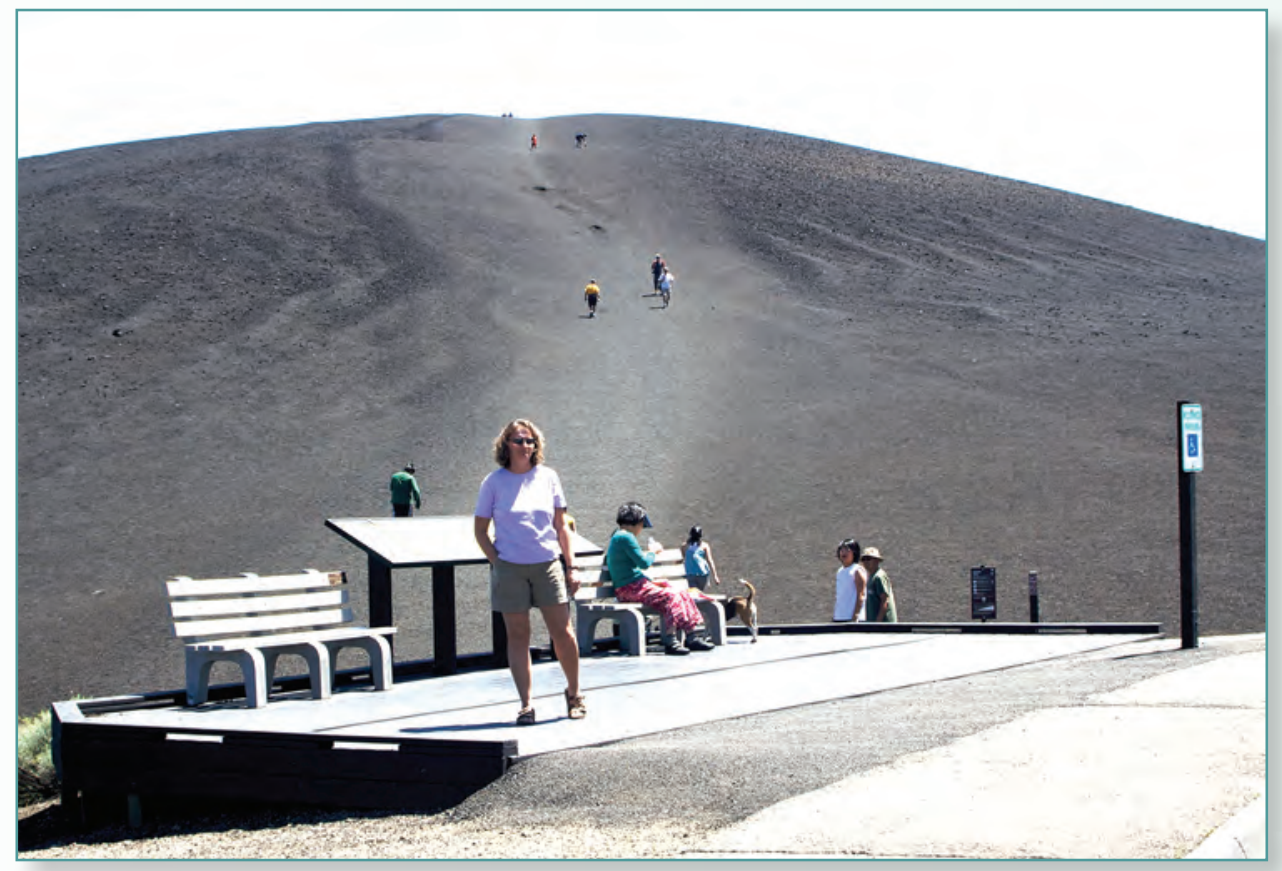

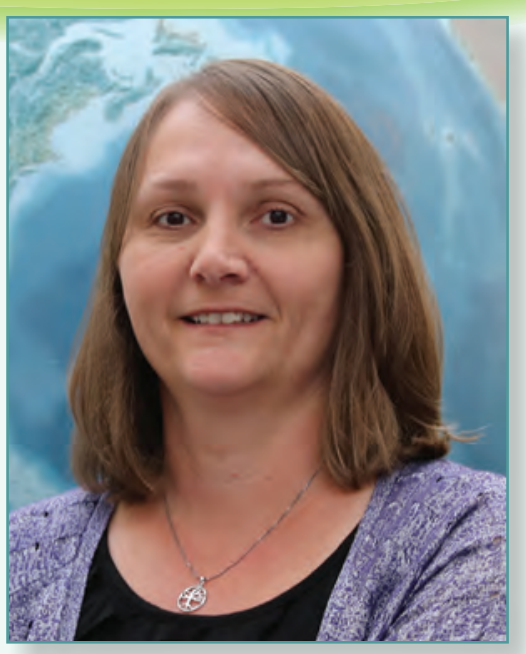

I always tell my daughters you can be and do anything you want. You just have to work hard to achieve it.

Kristi Sayler has a bachelor's degree in mathematics with a minor in computer science from the South Dakota School of Mines and Technology and a master's in geography from South Dakota State University. https://www.usgs.gov/staff-profiles/ kristi-sayler

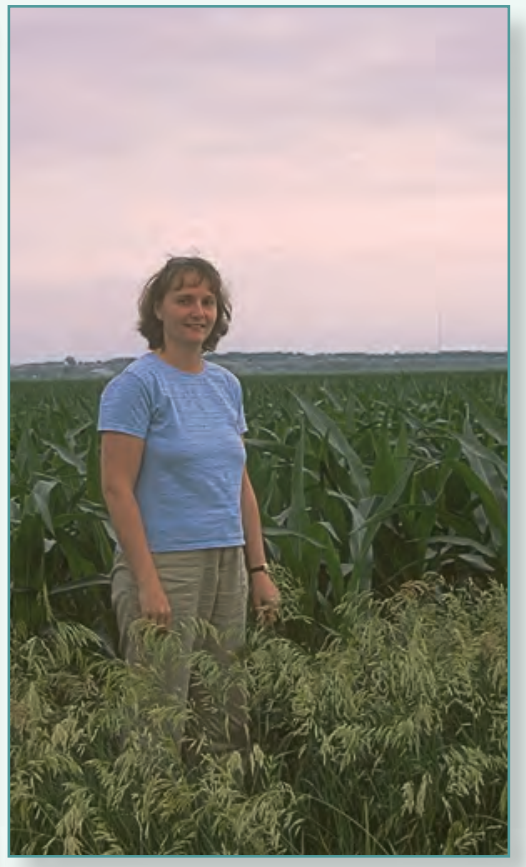




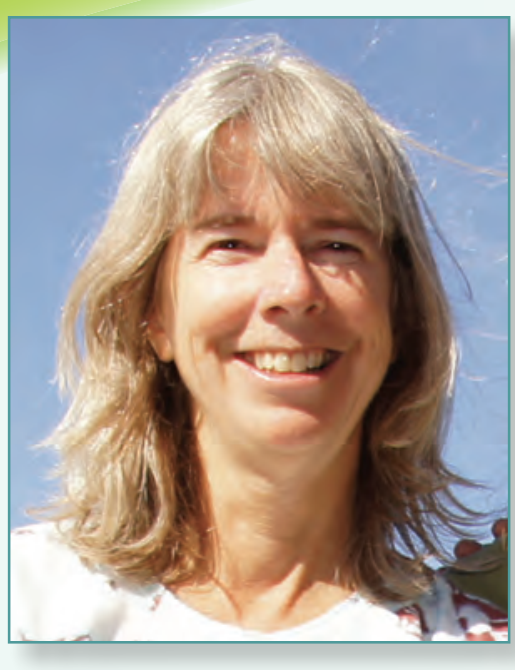

I knew since elementary school that I wanted to work with wildlife in some capacity. I was very much in the "save the world" camp and still am, although my efforts today are focused on getting relevant science into the hands of people making management and conservation decisions.

Carol Schuler has a bachelor's degree in wildlife biology from Eastern Kentucky University and a master's in wildlife science from Oregon State University.

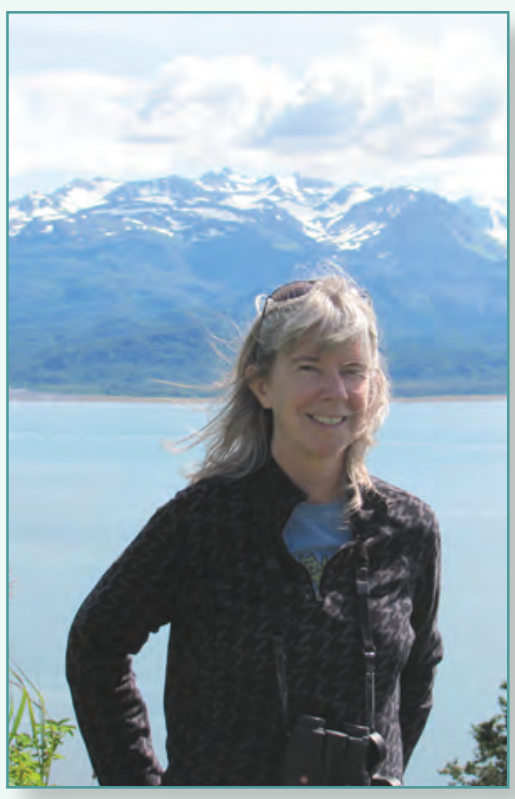

\section{earol Schuler}

\section{Senior Science Advisor for the Ecosystems Mission Area in Reston, Virginia, and Corvallis, Oregon}

"Knowing what I do, there would be no future peace for me if I kept silent."

- Rachel Carson

I grew up as a "military brat," which meant we moved often; during my childhood, we moved eight times. With each move came a new school, making new friends, and exploring new areas. Moving this often helped me develop into a strong and independent woman, with a greater reliance on myself. I spent every summer as a child on my grandparents' farm in Iowa. All day was spent outside working around animals, picking strawberries, baling hay, collecting eggs, weeding, riding horses, fishing, or whatever chores my grandparents could come up with to keep me and my siblings out of trouble. My grandparents were also into watching birds. Their farm and love of birds got me interested in wildlife.

As an undergraduate, I read "Silent Spring" by Rachel Carlson and "A Sand County Almanac" by Aldo Leopold. Both books helped me realize, as I still believe today, that each of us, no matter the job, can make a difference. I keep Rachel Carson's quotation on my wall.

I have spent more than half my career leading programs on endangered species, ecological issues, fisheries, and refuges, mostly in the Pacific Northwest and the Pacific Islands. More recently, I was the director of wildlife and ecological research programs, working with great scientists researching issues on natural resources in the Pacific Northwest and the Pacific Islands. I have always kept in mind that the science has to be relevant, can be understood, and can be used to inform resource managers and conservation decision makers. I am currently developing and leading large national efforts to bring science and management together to address high-profile natural-resources issues, including the altered sagebrush steppe and greater sage-grouse, the effects of renewable energy on wildlife, and science for rare and declining species.

My husband is an ornithologist, so between his obsession with birds and my wildlife and botanical interests, we spend a lot of time outdoors. I enjoy hiking, kayaking, horseback riding, and swimming. I love to walk in the woods. There's something spiritual about trees and the surrounding forest. It doesn't matter if these are the Oregon Douglas firs, white oaks, California redwoods, or eastern deciduous forests. All give me a sense of peace and rejuvenation. I also love to garden and to grow our own food. The process of planting a seed, watching a plant grow, being able to harvest a vegetable, and then making it part of your meal is truly wonderful.
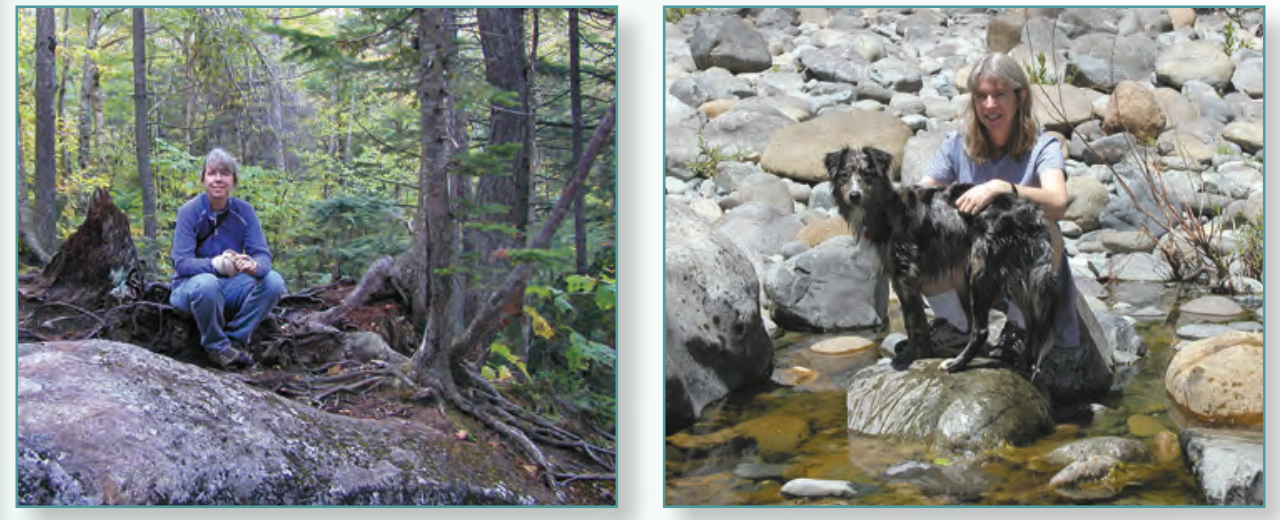


\section{Kim Scott}

\section{Program Analyst in the Office of Enterprise Information in Reston, Virginia}

\begin{abstract}
"It is our choices... that show what we truly are, far more than our abilities." -J.K. Rowling, "Harry Potter and the Chamber of Secrets"
\end{abstract}

Probably the biggest influence in my life that has shaped who I am today was that I grew up in the military. Being an "Army brat," I had many opportunities to travel and live overseas, immerse myself in other cultures, and meet amazing people from all over the world. I learned to become comfortable with change and to be open to new experiences. I often describe myself as a lifelong learner.

My professional career began as a middle school teacher, teaching mathematics, language arts, and social studies. After 4 years, I left teaching to pursue my master's in business administration, which then led me to become a consultant and project manager. What I have enjoyed most about my field is the diversity of projects I have worked on, such as budgets and financial support, capital planning, strategic planning, and management of information technology. I have continued my teaching tradition, teaching basic computer skills when I was a graduate student, training coworkers by providing writing classes, and mentoring young scientists and administrators.

Outside of work, I am an active member of the Daughters of the American Revolution. I enjoy staying active, volunteering, reading, and cooking.
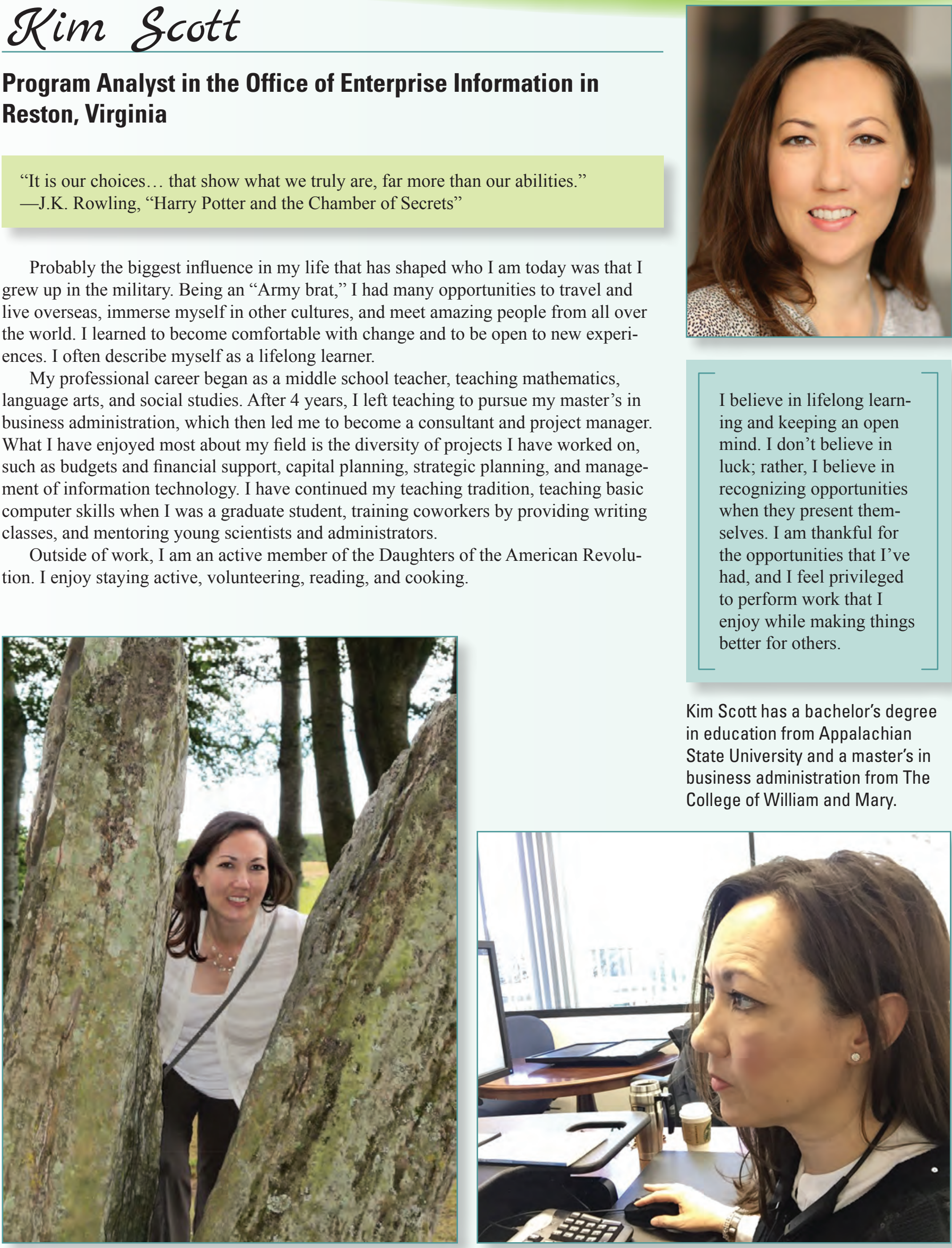

I believe in lifelong learning and keeping an open mind. I don't believe in luck; rather, I believe in recognizing opportunities when they present themselves. I am thankful for the opportunities that I've had, and I feel privileged to perform work that I enjoy while making things better for others.

Kim Scott has a bachelor's degree in education from Appalachian State University and a master's in business administration from The College of William and Mary.

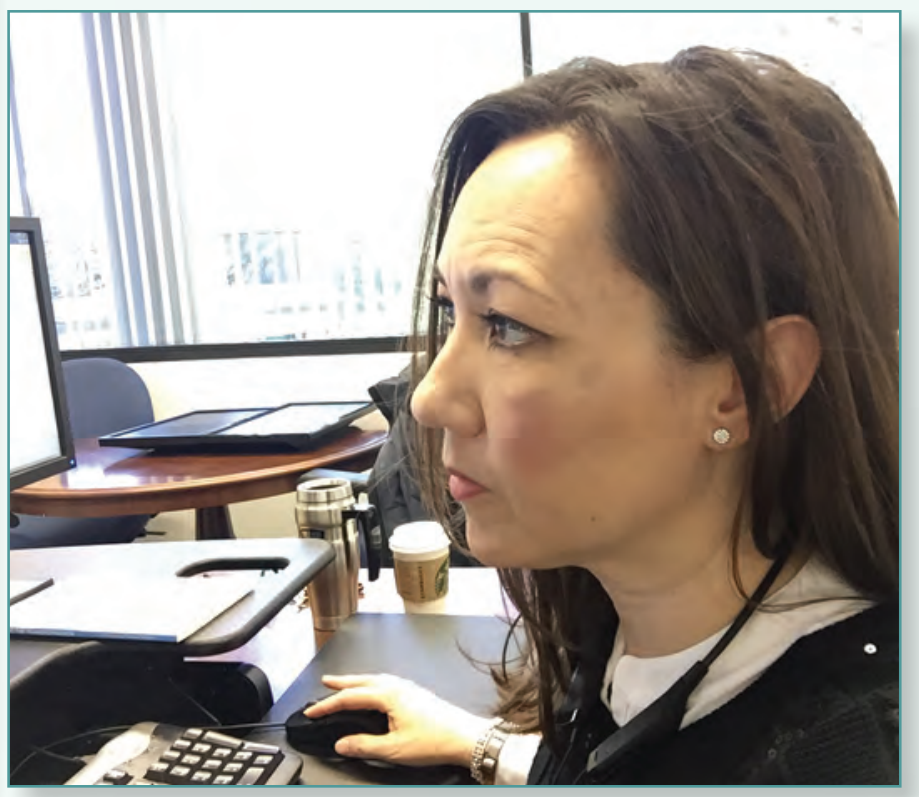




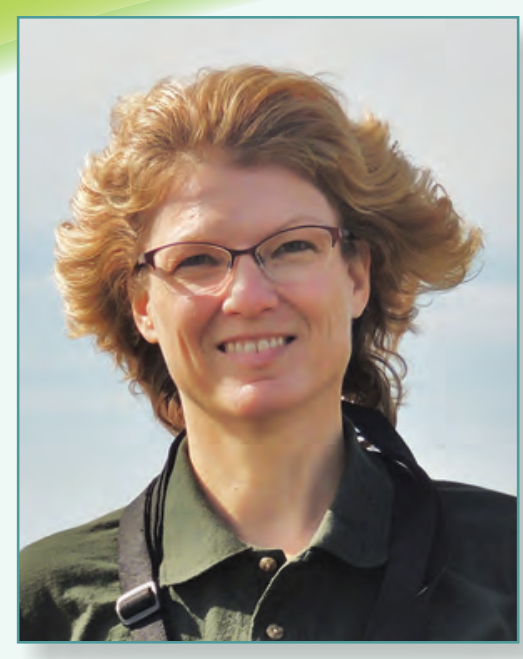

It is sobering to be working in an ecosystem more endangered than the tropical rainforests.

Jill Shaffer has a bachelor's degree in biology from the University of Wisconsin and a master's in zoology from the University of Arkansas. https://www.usgs.gov/staff-profiles/ jill-a-shaffer

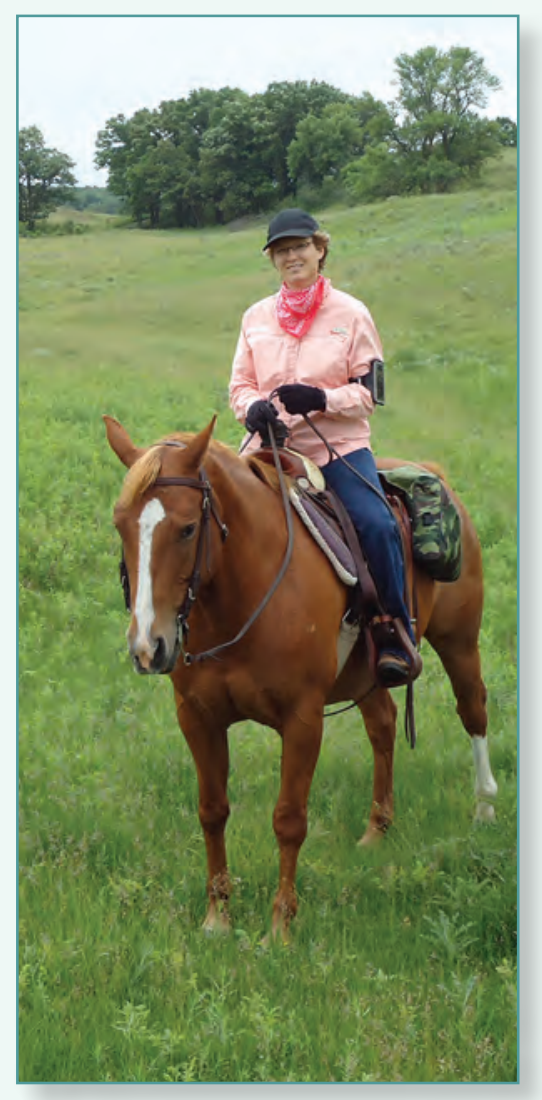

Gill Shaffer

\section{Ecologist with the Northern Prairie Wildlife Research Center in Jamestown, North Dakota}

"You are capable of more than you know. Choose a goal that seems right for you and strive to be the best, however hard the path. Aim high. Behave honorably. Prepare to be alone at times, and to endure failure. Persist! The world needs all you can give." -E.O. Wilson

I am from Sparta, a small Wisconsin town in the heart of dairy country and in the beautiful geological zone called the Driftless Area. My grandparents on both sides were dairy farmers, as are many aunts and uncles. Growing up in a rural lifestyle that engenders pride in hard work instilled a work ethic in me, and growing up in a beautiful natural landscape formed in me a love of nature and an almost innate drive towards stewardship of that beauty. A college ornithology class focused my understanding that learning about bird diversification would also enhance an understanding of resource partitioning and ecosystem function.

My research focuses on how disturbances by humans, such as wind-energy generation, cattle grazing, and fires, affect the bird populations of grasslands in the northern Great Plains. On the one hand, my research shows how bird populations continue to decline as human society increasingly affects other species; on the other hand, it is rewarding to realize that my research helps answer questions on how humans affect grassland birds and devise solutions to mitigate some of those effects.

My work showed that birds avoid areas where there are wind-generation facilities and led to the development of a method that calculates the amount of grassland habitat affected by these facilities. This research was pivotal in providing a scientifically defensible framework from which to discuss options to mitigate the effects of wind-generation facilities. I have supervised large field crews who worked over several States, and in so doing, have trained and mentored young people who aspire to be our future biologists.

My great passion is horseback riding, especially furthering my, and my horses', skills in the disciplines of English dressage and jumping. Riding is my stabilizing force in life because it inspires me to stay fit, embrace patience and understanding, accept failure, find reservoirs of strength and resolve to keep striving despite the inevitable setbacks, and to celebrate the victories. My other hobbies are birdwatching, flower gardening,

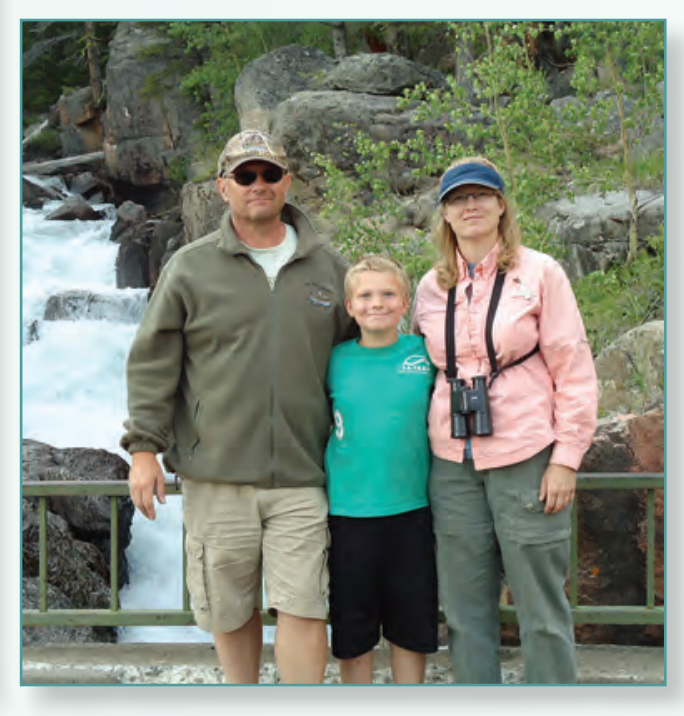
and physical fitness. Because North Dakota has both a short breeding season (for birds) and growing season (for flowers), spring and summer are a frenzy of trying to fit in birdwatching, gardening, and horseback riding. During the frigid winters, I engage in a variety of physical activities, including swimming, martial arts, and aerobic workouts. As a wife and mom, my husband and son should also be added to my list of hobbies - that is, trying to keep them on the straight and narrow! 
Allison ghipp

\section{Deputy Regional Director for Science for the Southwest Region in Columbia, Missouri}

"Nothing in life is to be feared, it is only to be understood. Now is the time to understand more, so that we may fear less." - Marie Curie

I am a child of the 1970s. I remember waiting in gas lines only to get three cars away from the pump and learn the station was out of gas. I remember my parents and grandparents making tradeoff decisions about whether to put gas in a vehicle or a tractor. I remember the Cuyahoga River fire, the Love Canal environmental pollution, and the Three Mile Island nuclear reactor accident. We were one of the first generations to be schooled in recycling and understanding that our actions have consequences on the world around us. These experiences led me to want to learn about the effects of human-influenced activities on the environment. This in turn led me to study biology. When I was an undergraduate student, I participated in a program to bring science to underserved elementary schools, and I used the outdoors as an extension of the classroom, which I continued to do as a high school teacher. I took my students on field trips to plant community gardens, monitor streams, explore caves, and spend time discovering how landscapes around them are managed and how the activities of humans affect these landscapes.

A few years into my teaching career, I learned of the environmental and water resources program at the University of Texas in Austin, and I knew I had found my calling. As a returning, mature student, I was going a little crazy in the classroom, so one of my professors suggested a work/study or cooperative program. I interviewed with several places, including the USGS. I learned that the USGS was the perfect place for me to put my 1970s upbringing to the test, and I was hooked. I wore my USGS lapel pin or shirt everywhere I went and would strike up conversations about how much I was learning and how much I loved working for the USGS. My role with the USGS was to provide quality scientific information to individuals, agencies, and organizations charged with making decisions. I provided this information so that they could make the best decision based on weighing the pros and cons. I think I'm proudest of the fact that we provide unbiased information to everyone from senators to citizens.

I love reading, movies, walking, and baking. If you come to my house for a dinner or if we have pot luck at church, I'll be baking for it. I challenge myself each year to make something complex that I haven't tried before. I love the chemistry and the challenge of making something beautiful that tastes wonderful too.
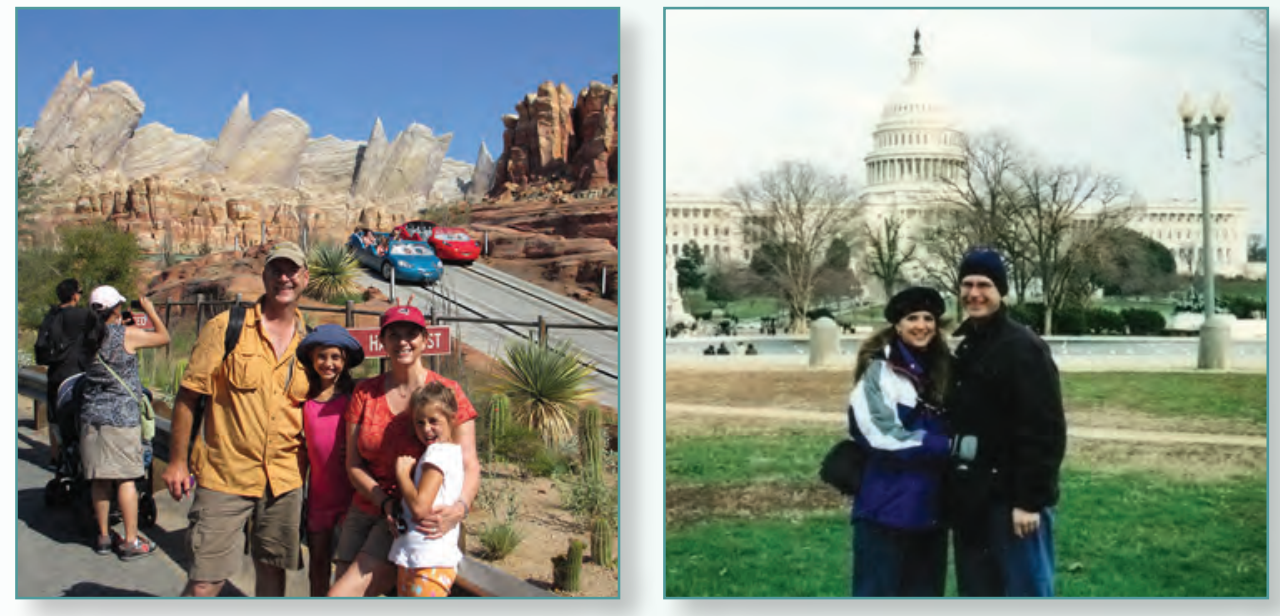

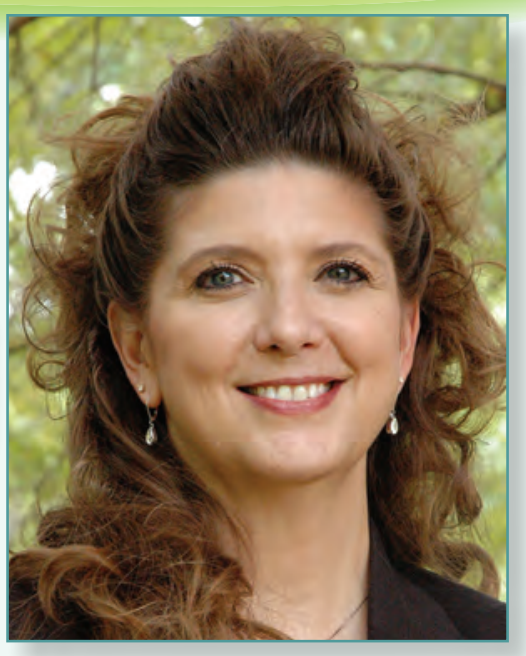

What I always wanted was to make a difference; the USGS has been my vehicle for that ambition. The breadth of research done at the USGS is at my fingertips, and I get the opportunity to support science and scientists and learn about the science during the process.

Allison Shipp has a bachelor's degree in biology and a master's in environmental and water resources engineering from the University of Texas, Austin.

https://www.usgs.gov/staff-profiles/ allison-a-shipp

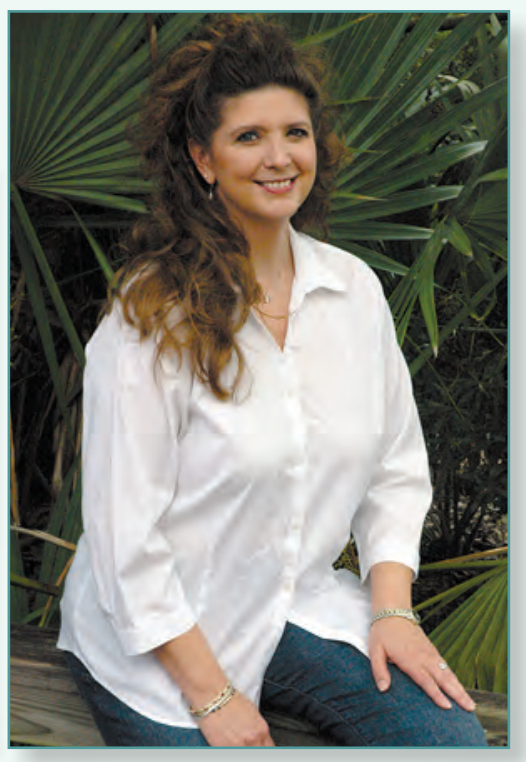




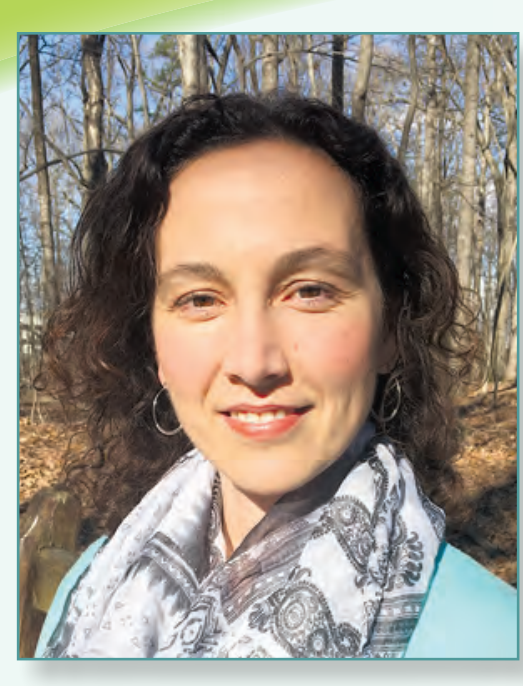

As a research hydrologist at the USGS, I have been provided with the diverse experiences of working in beautiful and remote field sites across the country, a laboratory to analyze samples, the office to analyze data. My work includes using remote-sensing applications, modeling, writing, and traveling to network and engage a variety of groups in my research. I feel like I have the best of all worlds.

Katherine Skalak has a bachelor's degree in environmental science from St. Joseph's University and a master's in geology and a doctorate in geological sciences from the University of Delaware.

https://www.usgs.gov/staff-profiles/ katherine-skalak

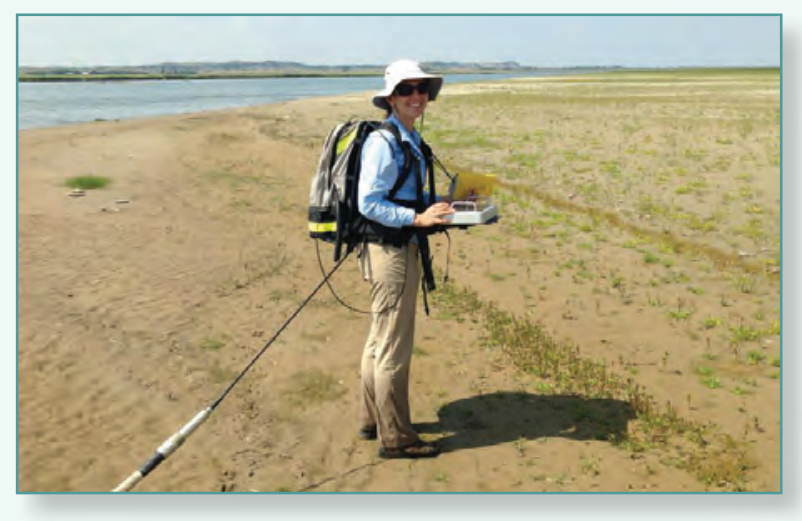
these interactions.

\section{Katherine Skalak}

\section{Research Hydrologist in the Hydrodynamics Branch of the Water Mission Area in Reston, Virginia}

"What is success? It is being able to go to bed each night with your soul at peace." -Paulo Coehlo

My interest in being outside and exploring the natural world started early; I grew up playing outdoors in the nearby woods and the creek. Family vacations were spent on the lakes and rivers of Canada, where my father and grandfather would take me fishing, as well as camping or at the beach. In middle school, I developed a keen interest in mathematics and science when I joined the Mathletes and the science club. I continued these activities in high school and took advanced mathematics and science classes. Growing up in a suburb of Philadelphia, Pa., I developed an understanding of how humans interact with their environment and saw the positive and negative influences that have arisen from

During an ecology course in college, we had a field-based lab that we took to the Pine Barrens. We learned techniques for measuring biomass and assessing tree age and health. We also learned the unique ecology of the Pine Barrens. It was the first time I had the revelation that I could make a career of being outdoors and studying the environment. As the first person in my family to attend and graduate college, I had been exposed to a very narrow range of career possibilities. I didn't know anyone who had studied earth science or gone to graduate school. Before this ecology course, I was a biology major with the intent to become a medical doctor. After the class, I changed my major and started on the path that ultimately brought me to the USGS.

My work at the USGS focuses on the processes and human influences that form and shape the landscapes near and around rivers and tidal and wetland environments. I have worked in the Cheseapeake Bay watersheds, the Upper Missouri River, the Florida Everglades, and the Prairie Pothole region in the northern Great Plains.

I spend free time with my family. I am married with a son and a daughter, ages 6 and 3. I love running, hiking, weight-training, and practicing yoga and meditation. I cochair a working group on work-life balance and am committed to advancing myself as an example that you can have a fulfilling and meaningful career and a rich and rewarding personal and family life.

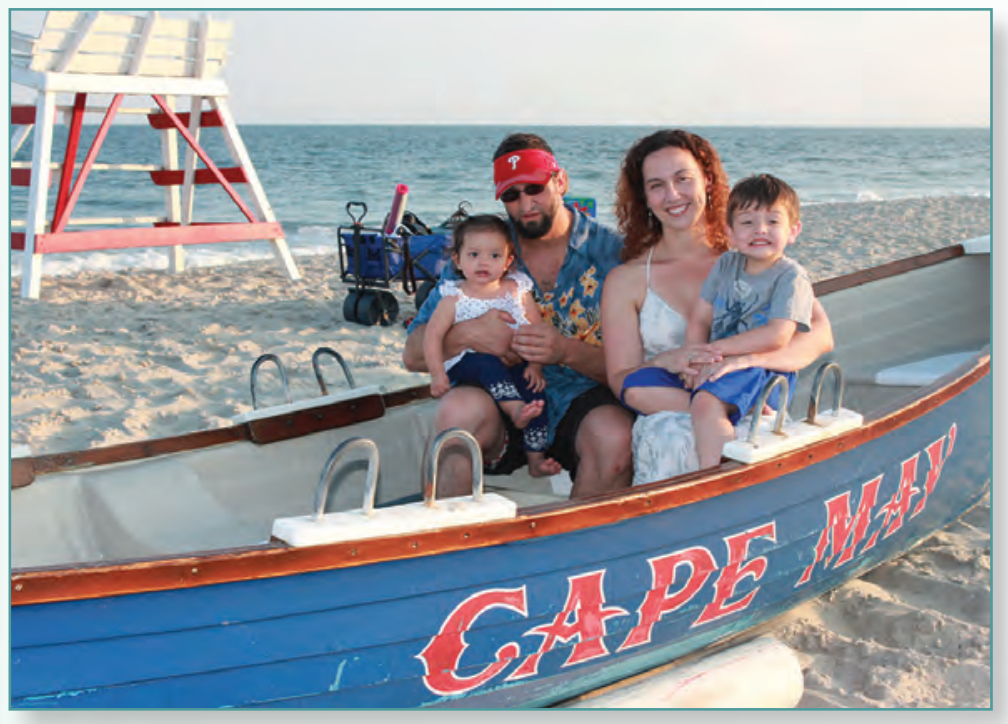




\section{Filda Smith}

\section{Lab Manager at the Southwest Biological Science Center in Moab, Utah}

"Don't let anyone rob you of your imagination, your creativity, or your curiosity." -Mae Jemison

I grew up on a farm in eastern Tennessee and have always enjoyed being out in nature, whether it was playing, working, or learning about something new that I stumbled upon. This cultivated in me a love of science and earned me a first-place ribbon in my eighth grade science fair.

I began my career with the USGS in 2006, and since that time, I have worked in multiple States and ecological environments and on numerous projects. I started out as a project lead on a national program for the Amphibian Research and Monitoring Initiative and migrated towards soil and plant ecology projects. Plant and soil science has given me experience with complex equipment and experimental design. I quickly took on leadership roles both in the field and in the laboratory and have been recognized numerous times during my career for my ability to organize projects and assets and to prioritize resources and tasks to meet deadlines in support of station activities, grant requirements, and center-level goals.

I use my experience and problem-solving skills to coordinate multiple projects for different principal investigators, postdoctorate fellows, technicians, and collaborators in the contiguous United States, Puerto Rico, Costa Rica, Brazil, Germany, China, and Antarctica.

My great loves are animals, hiking, snorkeling, and traveling. I have a myriad group of pets that keep me busy.

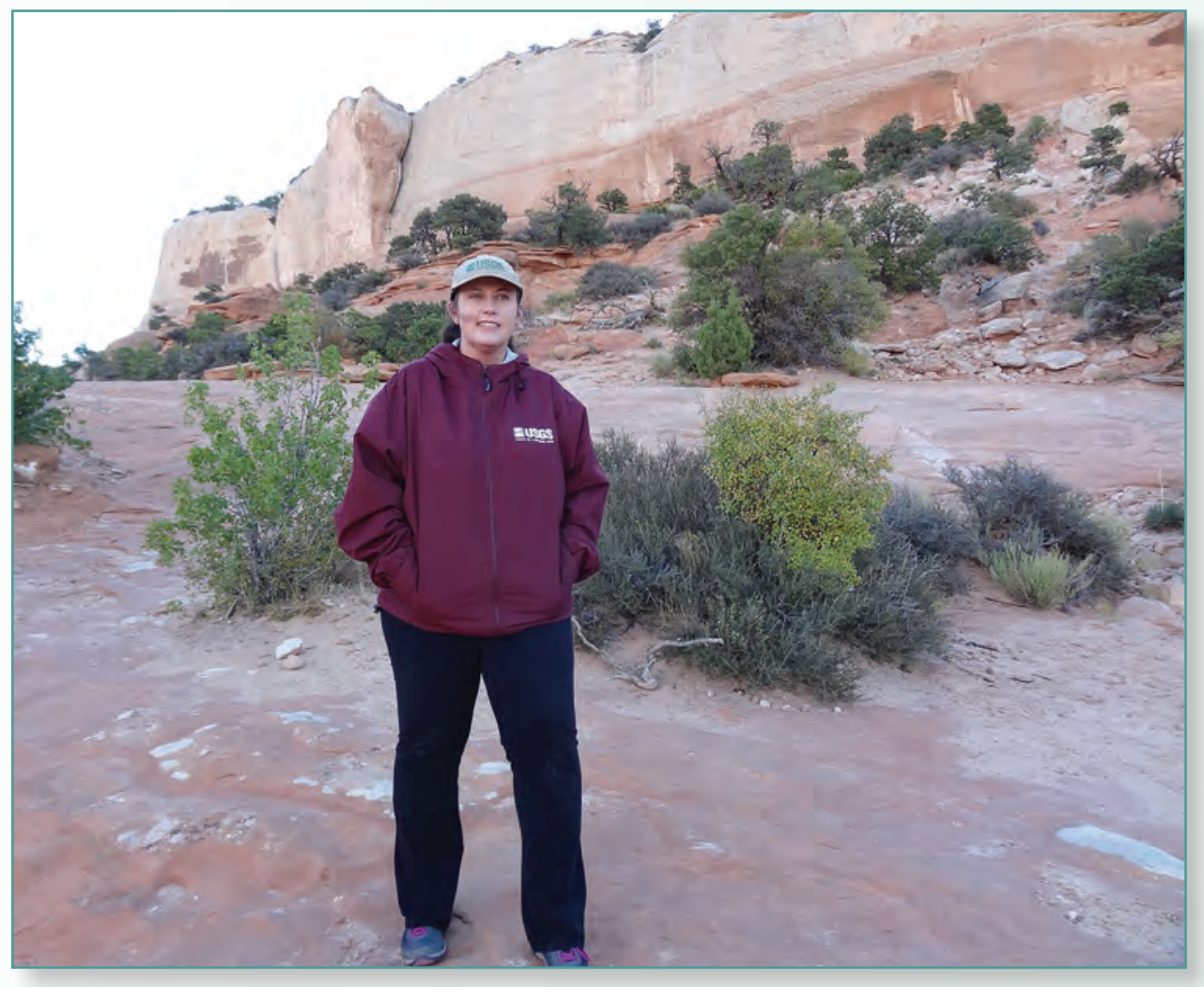

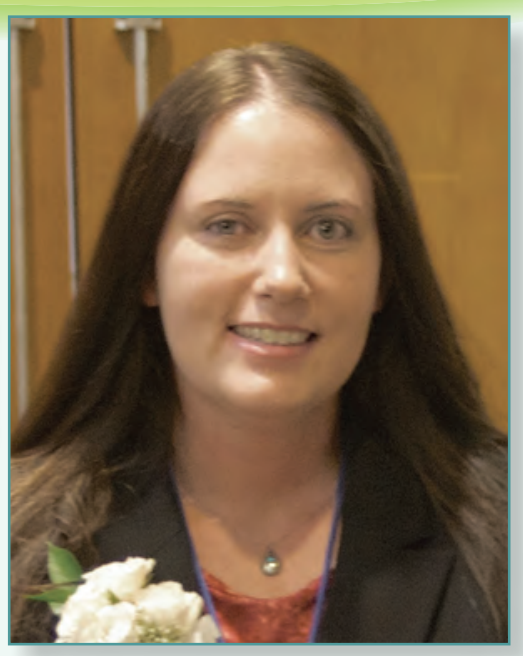

Hilda Smith has a bachelor's degree in biology with a naturalist concentration from Lees-McRae College. https://www.usgs.gov/staff-profiles/ hilda-j-smith
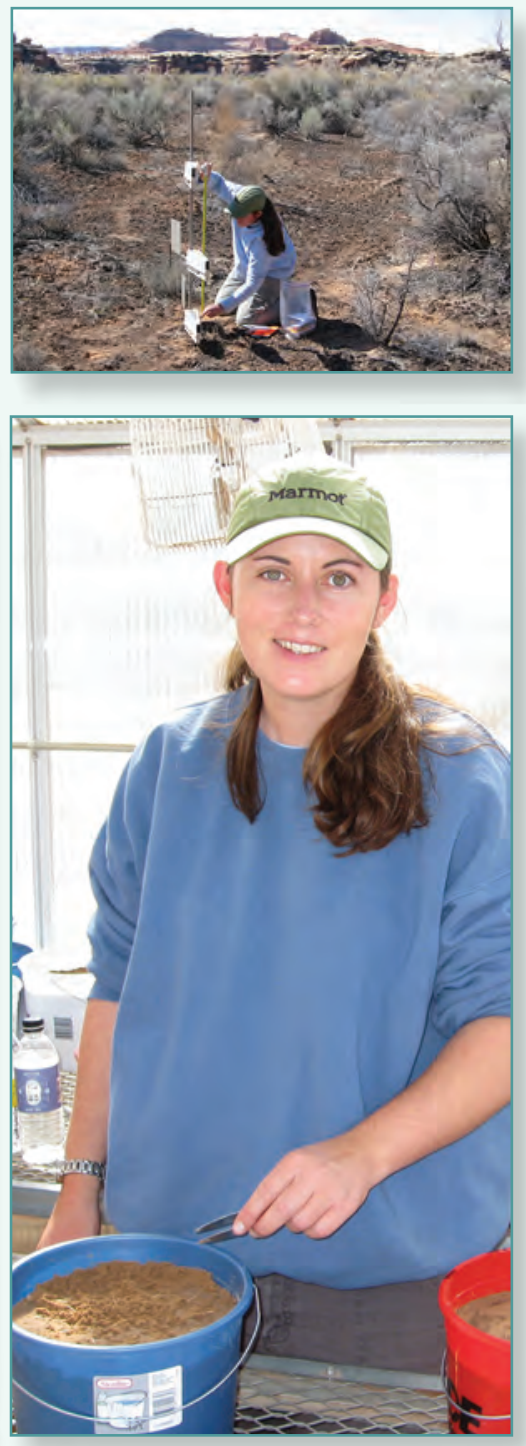


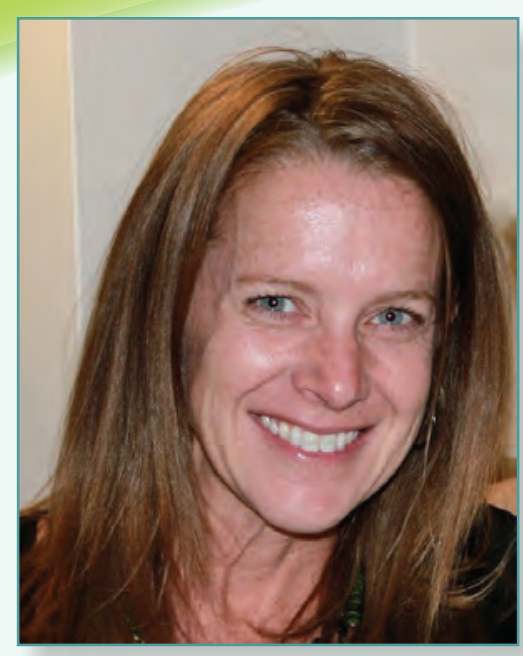

A driving force in my life has been to bring clarity where there is confusion, to find simplicity where others see complexity, and to help people live their truths. Scientific research and addressing societally important coastal issues allow me to do all of that as a career.

Hilary Stockdon has a bachelor's degree in geology from Duke University and a master's and a doctorate in oceanography from Oregon State University.

https://www.usgs.gov/staff-profiles/ hilary-stockdon

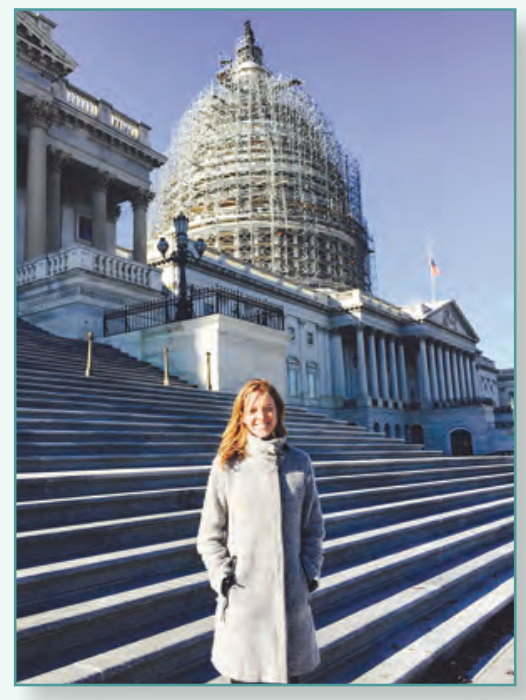

\section{Filary Stockdon}

\section{Research Oceanographer at the St. Petersburg Coastal and Marine Science Center in St. Petersburg, Florida}

\author{
"Tell me, what is it you plan to do with your one wild and precious life?" \\ -Mary Oliver, "The Summer Day"
}

Growing up, I was drawn to nature and often spent my free time exploring the woods, roaming along the James River, and swimming in the waves of the Atlantic Ocean. I have always loved the beach, and in college I chose to spend a semester at Duke University's Marine Lab where I focused on marine studies. Those months spent living and working on the beach helped me find my professional passion: the ocean. In graduate school, I had many opportunities to travel to far-flung places, such as South Korea where I participated in a mock invasion with the U.S. Marines. At the time, I was funded by the Navy to develop technologies to prevent Normandy-style disasters of fully equipped soldiers drowning in the surf zone. Experiences like this helped me see the practical, more human side of oceanographic research. Another adventure, this one much closer to home, changed the arc of my life; I was part of a field study in Duck, N.C., which lasted 3 months. There I met the researcher who would become my mentor, who encouraged me to pursue a Ph.D., and who ultimately hired me at the USGS.

With the USGS, I have studied the physics of waves and how they interact with beaches so that we can better understand how powerful storms shape our coastlines and affect our communities. My research on major storms, such as Hurricanes Katrina, Ivan, and Sandy, led to tools to help predict what might happen to beaches during future storms and to the first national assessment of potential coastal change hazards during hurricanes and nor'easters. A model I developed is now used to forecast shoreline water levels and potential erosion as storms make landfall, providing a necessary source of information for emergency responders and coastal managers. In my new position as science advisor, I am helping build a program for coastal change hazards at the USGS, and I am working with other Federal agencies to create the U.S. Coastal Research Program.

My favorite "pastime" is to escape from the scientific and bureaucratic method of my professional life and enjoy the wild freedom of music, the beauty of poetry, and the emotion of creative writing. I also enjoy exploring new cultures and raising awareness on social issues, all while balancing my personal life and career goals.
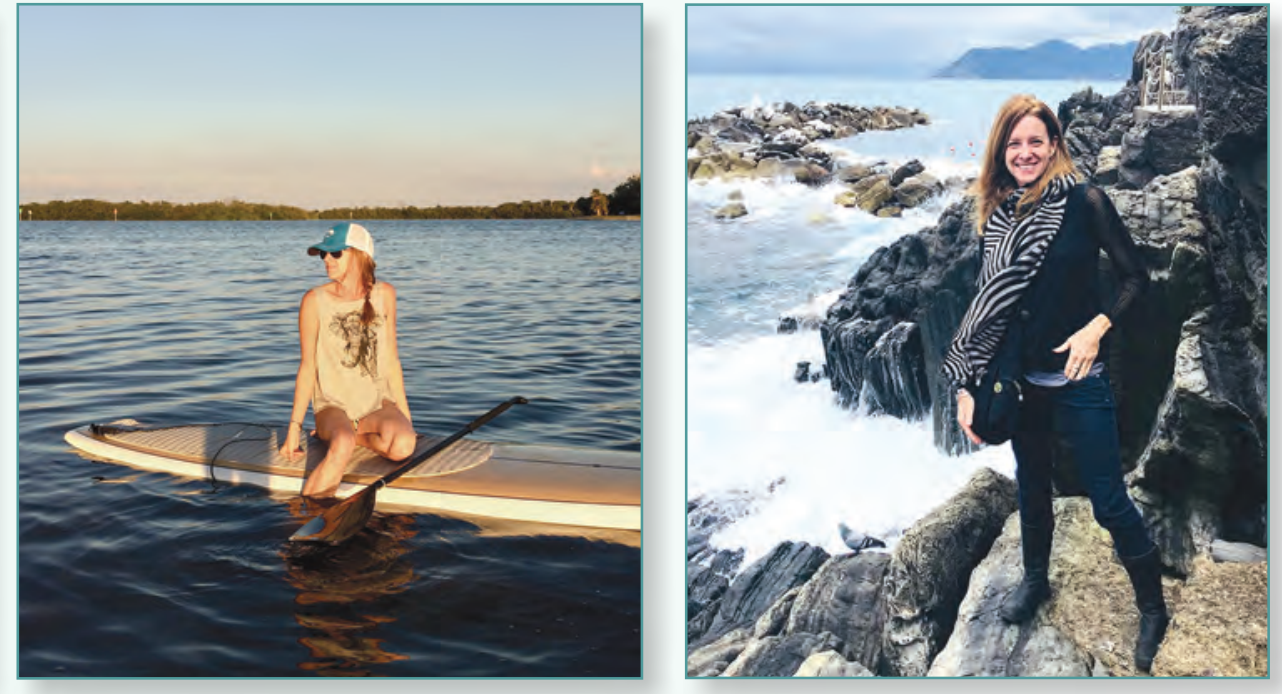


\section{Mandy Stone}

\section{Supervisory Hydrologist at the Kansas Water Science Center in Lawrence, Kansas}

"My hope still is to leave the world a bit better than when I got here." — Jim Henson

I grew up in Kansas and, although I have since lived in Europe and Alaska, I still think the tallgrass prairie in Kansas is the most beautiful and interesting ecosystem I've ever studied. My love of nature and the outdoors blossomed in high school, when I took a student naturalist class. My teacher, Mr. May, really got me into nature and the outdoors. I appreciated being able to take that class; even though I was strongly interested in my other science classes, this was the first time we were able to get outside and explore rather than sit in a classroom and simply complete lab exercises. Mr. May regularly took us out to collect things like insects and snakes, and his enthusiasm was inspiring.

Since becoming an earth scientist, I've done fieldwork in Alaska, Illinois, Kansas, Missouri, and Oregon, ranging from collecting samples of soils and insects in the prairies of the Midwest to trapping small mammals, amphibians, and reptiles in the Pacific Northwest. My aquatic fieldwork experience includes collecting crustaceans, water worms and insects, and fish in streams and lakes. I started working in public service by joining AmeriCorps, where I surveyed streams throughout Missouri in an effort to protect streams statewide. My subsequent research for the USGS has focused on freshwater science, including effects of disturbances on ecosystems. I have modeled minerals and chemicals that affect water quality, and I have used continuous water-quality measurements to quantify how energy is generated and used within stream ecosystems.

I enjoy hiking, camping, canoeing, and fishing with my husband and 3-year-old daughter. It's awesome to watch my daughter discover the natural world; she already has extensive rock, insect, and plant collections!

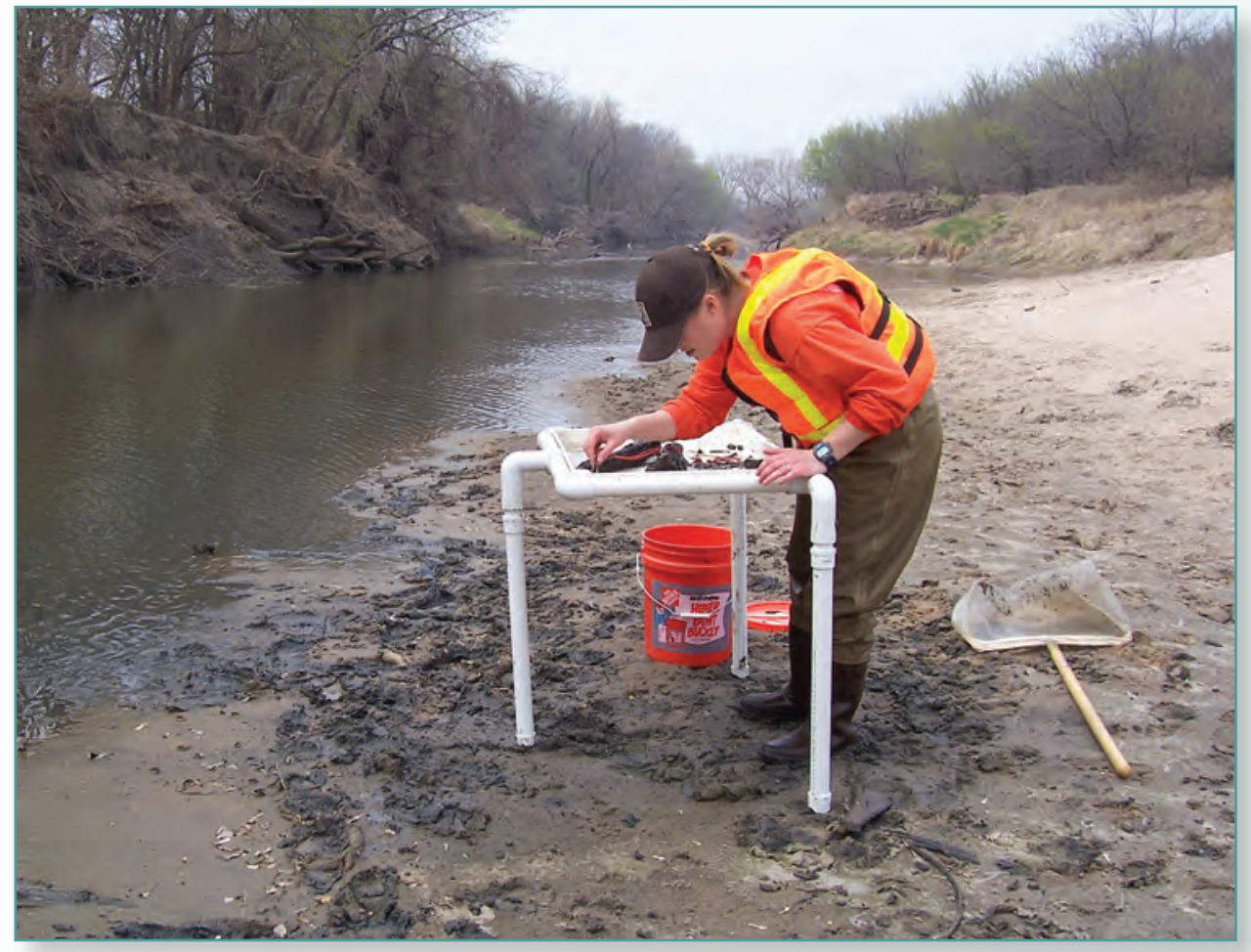

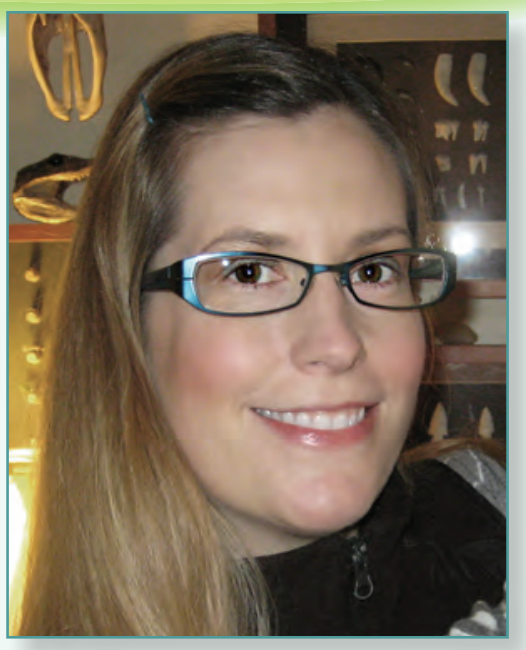

As a USGS scientist, unbiased and objective collection and interpretation of data on the quantity and quality of water provide me a sense of purpose and pride in the work I do.

Mandy Stone has a bachelor's degree in wildlife biology from Kansas State University and a master's in zoology from Southern Illinois University. https://www.usgs.gov/ staff-profiles/mandy-I-stone

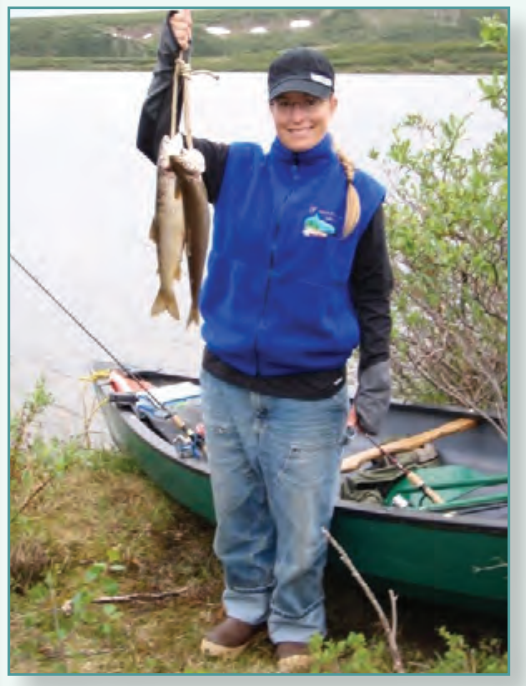




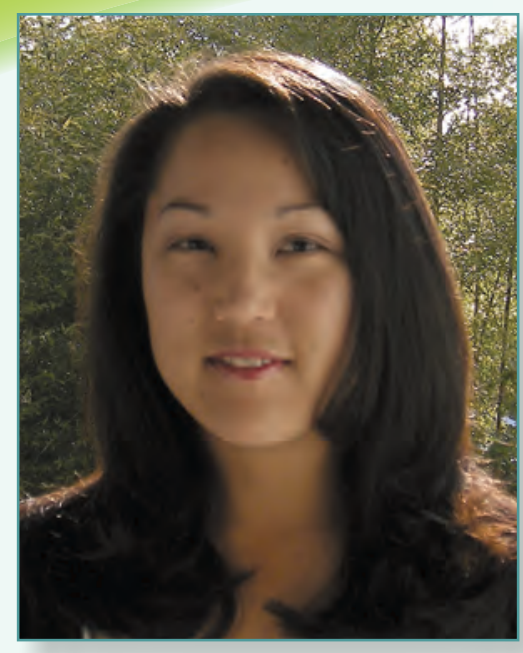

I live in a growing coastal town and see on a daily basis how my work with the USGS helps society understand how human activities affect coastal and marine systems whose functions are vital to the well-being and sustainability of communities.

Renee Takesue has a bachelor's degree in oceanography from Humboldt State University and a doctorate in chemical oceanography from Columbia University.

https://www.usgs.gov/staff-profiles/ renee-takesue

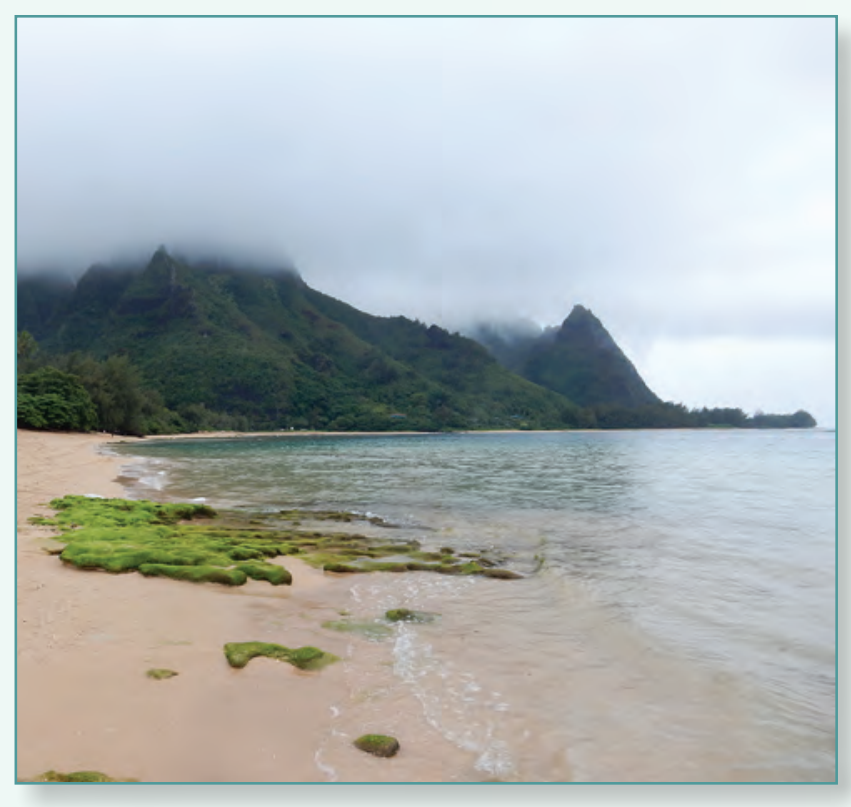

Renee Takesue

\section{Marine Geochemist with the Pacific Coastal and Marine Science Center in Santa Cruz, California}

"The most exciting phrase to hear in science, the one that heralds new discoveries, is not 'Eureka!' ('I found it!') but 'That's funny...'.”- - Isaac Asimov

I grew up spending weekends at the beach exploring tide pools and summers visiting Hawai $i$ where my family harvested limpets and seaweed and caught reef fish with throw nets, so it was natural that I decided early on that I wanted to become a scientist and study the oceans. In elementary school, I took a summer course in marine biology that culminated in a harbor cruise on a research vessel. We made plankton nets with nylon stockings and baby food jars and used a bottom trawl to dredge up fascinating sea creatures. I had the time of my life and knew that I wanted to be a marine scientist.

My research with the USGS takes me through a wide range of coastal settings: from glacier-carved Puget Sound in Washington where large rivers and storms deliver sediment-bound contaminants to marine animals, to tropical coral reefs where agriculture, grazing, and development in coastal watersheds have resulted in sediment and contaminant runoff that harms reefs.

I like to go running along the coastal bluff a few miles from my office after work where waves from the Pacific Ocean constantly vie against human engineering to reshape the coastline. Sand bars, sinkholes, and slipouts appear and disappear with storms, seasons, and public works projects aimed at protecting homes and roads. This continual reminder about the power of nature helps put into perspective long-term science, management, and conservation issues that are relevant to my work with the USGS.

Perhaps because I spend so much of my time working in marine environments, I enjoy visiting the arid American Southwest. Its warm colors, vast landscapes, and cultural history impart a sense of connectedness with our earth system. In some cases, that connectedness is through time. The fossilized oyster shells I found in Utah attest to the presence of an ocean there in the distant past.

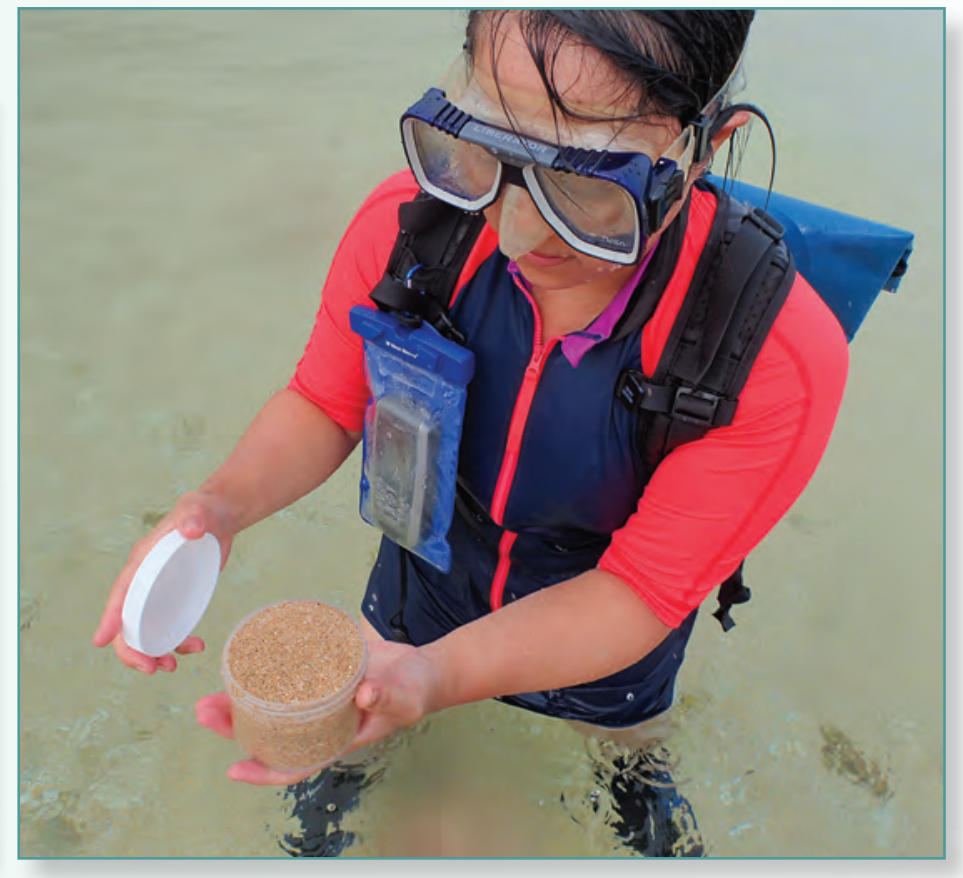




\section{Susan Thiros}

\section{Hydrologist with the Utah Water Science Center in West Valley City, Utah}

"Science is not a body of facts. Science is a method for deciding whether what we choose to believe has a basis in the laws of nature or not." - Marcia McNutt

I began working for the USGS right out of college in a role that involved collecting data for a groundwater study in central Utah. Because of the large amount of field work, I learned to use maps and equipment as well as how to develop conceptual models of the groundwater system. During my career, I have worked with well drillers to install monitoring wells, tested wells to estimate aquifer properties, collected water samples from streams and wells for laboratory analysis, and interpreted various types of data to describe how hydrologic systems work. Using emerging techniques and methods to help advance our conceptual understanding of groundwater systems is an exciting part of my work.

Another exciting part of my work is to share this understanding of groundwater systems with others. Many people are not aware that there is water in the subsurface and how important it is to the environment and our society. I have strived in my career to make this information available and understandable to the public. Early in my career, it was rewarding to present a see-through tank with layers of sand and clay to elementary school students and demonstrate what groundwater is and how it works. They were interested in seeing how the water moved through the layers when pumped, especially with fluorescent tracer added to it under a black light.

I have lived in Utah most of my life. The West has such interesting geologic, hydrologic, and archaeologic wonders that you can't help but think about the stories behind them. I enjoy looking at our natural world and finding the beauty that exists at all scales. It can be swirls in a muddy river eddy or lines of sandstone cliffs stepping off in the distance. I find it satisfying to try to understand the reasons and processes behind these wonders. The southwestern part of the United States is very scenic and fun to exploreeither by foot, bicycle, or boat. It is amazing how water has helped to form such beautiful landscapes.
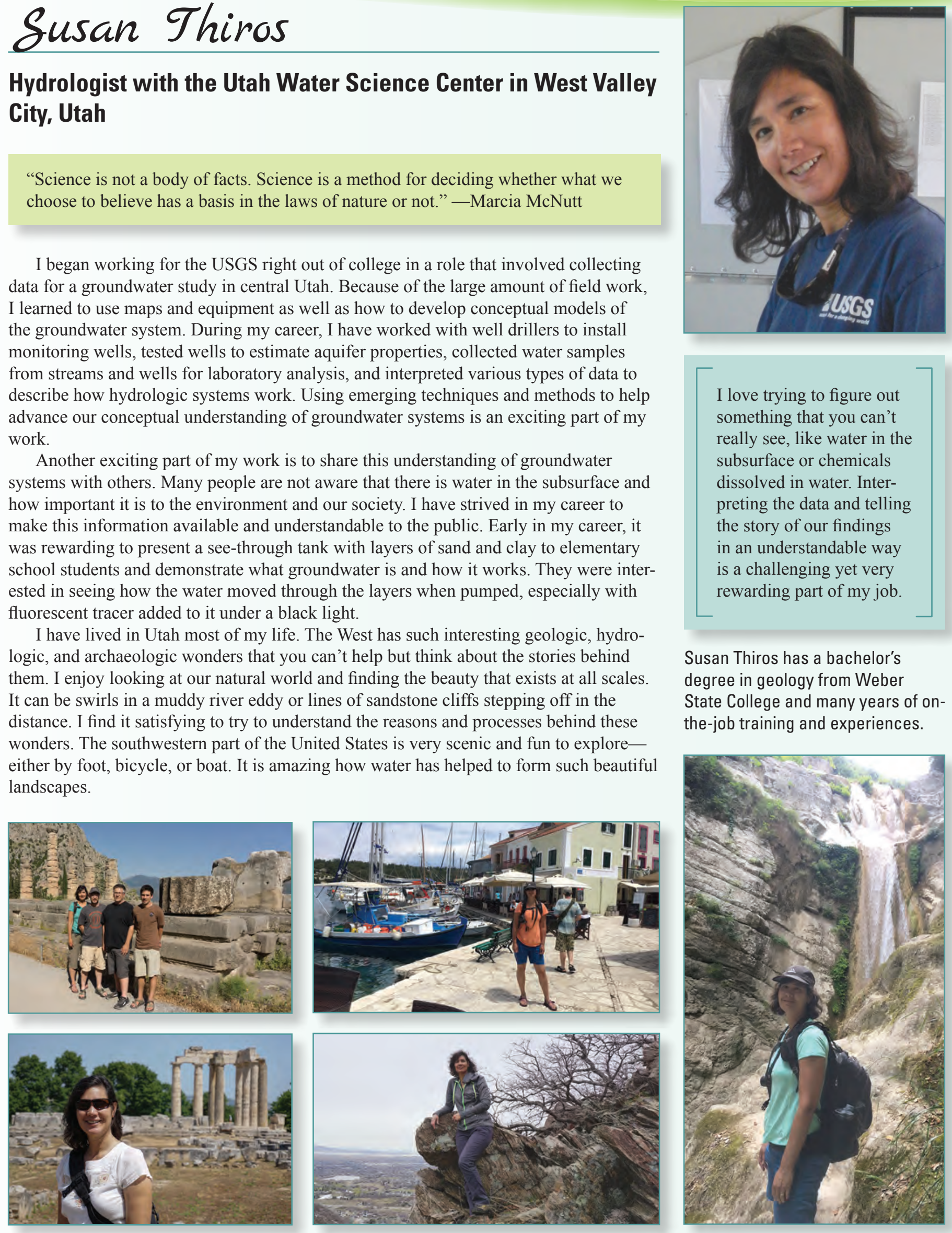

I love trying to figure out something that you can't really see, like water in the subsurface or chemicals dissolved in water. Interpreting the data and telling the story of our findings in an understandable way is a challenging yet very rewarding part of my job.

Susan Thiros has a bachelor's degree in geology from Weber State College and many years of onthe-job training and experiences.

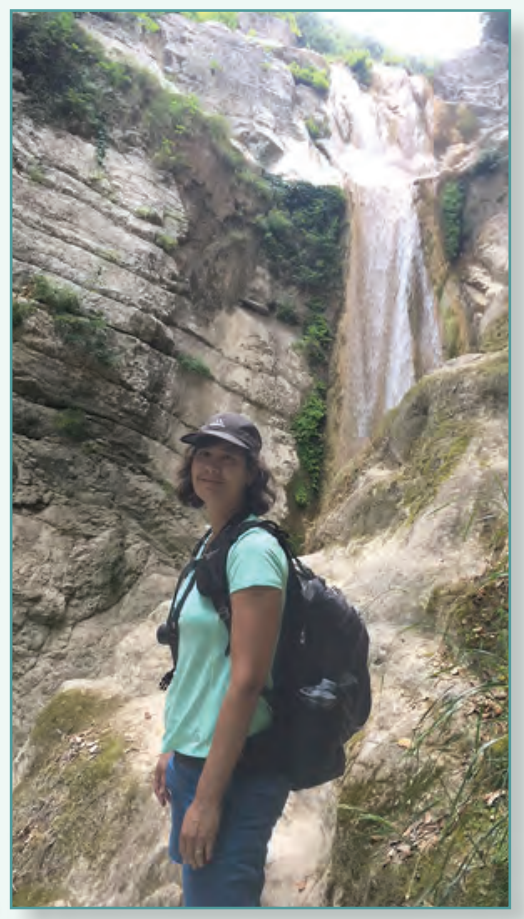




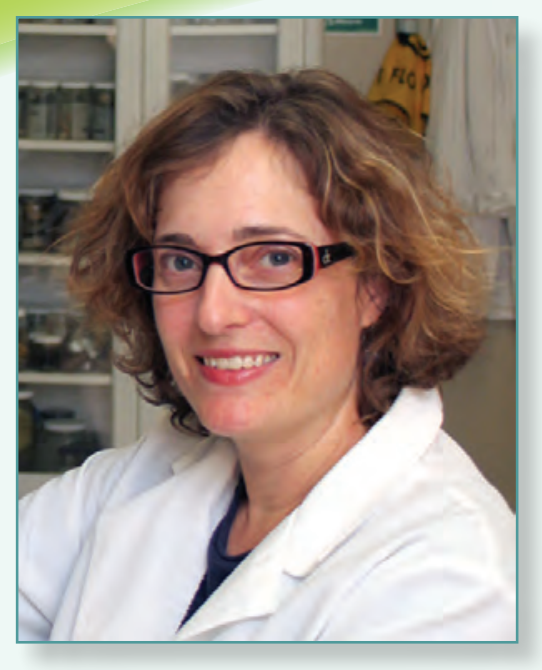

Just a decade ago, combining population genetics with spatial ecology and mapping was a new research avenue without a name. Now the field of study is called landscape genetics. One of the most exciting and challenging aspects of this work is designing research that directly contributes to conservation and management.

Amy Vandergast has a bachelor's degree in biology from the University of California, San Diego, a master's in zoology from the University of Hawaii, Manoa, and a doctorate in environmental science, policy, and management from the University of California, Berkeley. https://www.usgs.gov/staff-profiles/ amy-vandergast

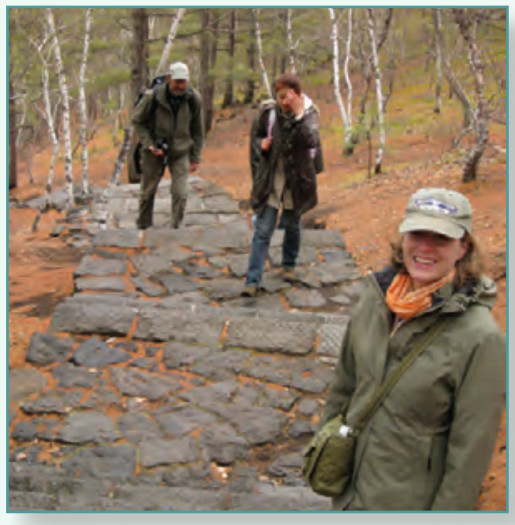

Amy Vandergast

\section{Research Geneticist with the Western Ecological Research Center in San Diego, California}

"Of all the questions which can come before this Nation, short of the actual preservation of its existence in a great war, there is none which compares in importance with the great central task of leaving this land even a better land for our descendants than it is for us." - Theodore Roosevelt

It might be surprising that I chose to study spider genetics and conservation as a graduate student. Spiders and insects scared me so much as a kid that any time I found one in the house I would yell for mom or dad to come squash it for me. It took some effort to overcome my squeamishness, but once I learned more about them, I realized how beautiful and amazing insects and spiders are. Now I'm the household spider rescuer.

There is no doubt that my interests in ecology and conservation formed while growing up in southern California. The State has so much natural diversity and beauty it would be hard not to be influenced by it. As an undergraduate, I was most interested in ecology and conservation classes, and I was able to go on a semester abroad program to Costa Rica. That was my first immersion experience in field ecology, and I loved it. The program was run by two very dedicated tropical restoration ecologists: Lynn Carpenter and Martha Rosemeyer. This experience helped steer me towards graduate school where I was mentored by other dedicated scientists, including my graduate advisor, Rosemary Gillespie.

As a research geneticist, I now lead a research program focused on a wide variety of species, including desert tortoises, coastal songbirds, tiny pocket mice, and even rare plants. The common thread is applying conservation and landscape genetic techniques to help understand how populations are connected and function in landscapes altered by human activities. Growing up in southern California, I've seen firsthand many of the changes that urban growth has caused here, but I've also seen that nature and open space are valued. It is rewarding to live and work here and to be a part of a dedicated conservation science community.

Having benefited from the mentorship of other scientists as a student, I mentor and advise graduate and undergraduate students and hope to pass on my knowledge and experience to them. I live in San Diego with my husband and three children. Some of my favorite activities with them are hiking and camping throughout California. I hope that by passing on what I know and love about these ecosystems, I can help my kids to value and appreciate nature and be environmental stewards when they are older.

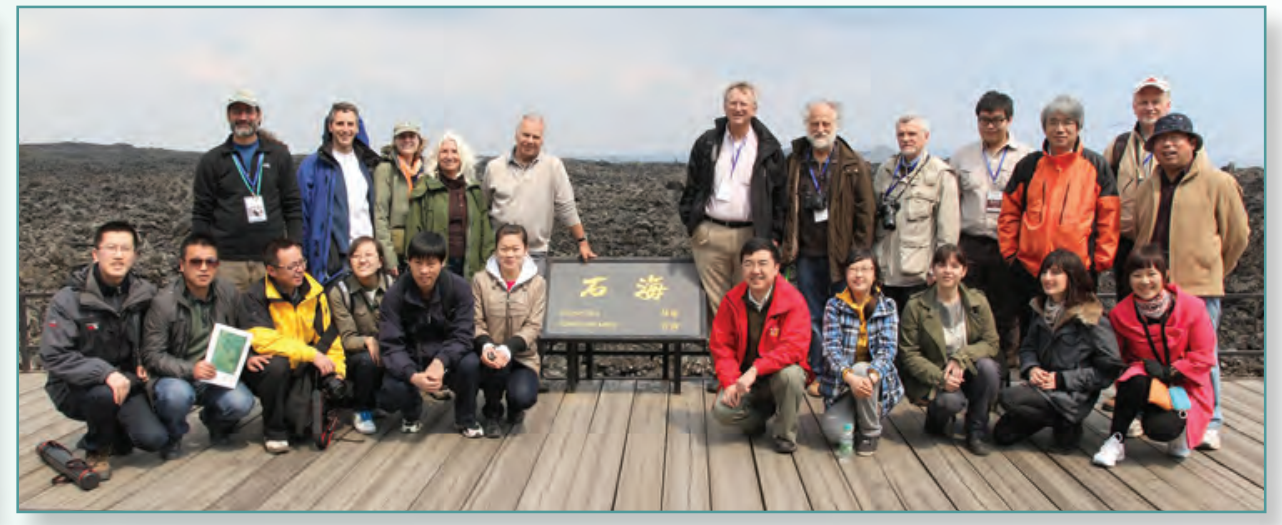




\title{
Alexa Van Eaton
}

\section{Research Geologist at the Cascades Volcano Observatory in Vancouver, Washington}

\author{
"Imagination is the highest form of research."-Albert Einstein
}

I was born and raised on the beaches of Florida, where volcanoes were about as mythical as unicorns or fairies. As a kid, you could generally find me climbing a tree, rescuing baby birds, or saving bugs in peril. Without knowing exactly what I wanted to do with my life, I knew it would involve discovery and exploration of the natural world. Yet I never could have predicted that volcanoes would end up being my calling.

My "unusual" interest in volcanoes led me to New Zealand to study one of the world's largest supereruptions for my doctoral research. That experience made me realize I wanted to do work that would help people and that would influence the way we view our role on this planet. When I returned to the States, I began research on hazardous, young volcanoes with the USGS.

Now my job as a volcanologist involves studying explosive eruptions in the Cascades of Washington and Oregon as well as in Alaska and abroad. I use fieldwork, computer models, and satellite images to understand what happens when volcanoes erupt. I have been involved in mapping volcanic lightning during explosions at the Sakurajima Volcano in Japan, backpacking into the wilderness at Glacier Peak Volcano in Washington, and flying by helicopter to Makushin Volcano in the Aleutian Islands of Alaska to collect new samples of volcanic deposits. This research on explosive eruptions is done to help keep people and airplanes safe from volcanic ash by improving the way we detect and characterize hazardous eruptions, and also to contribute to the understanding of the way our planet works.
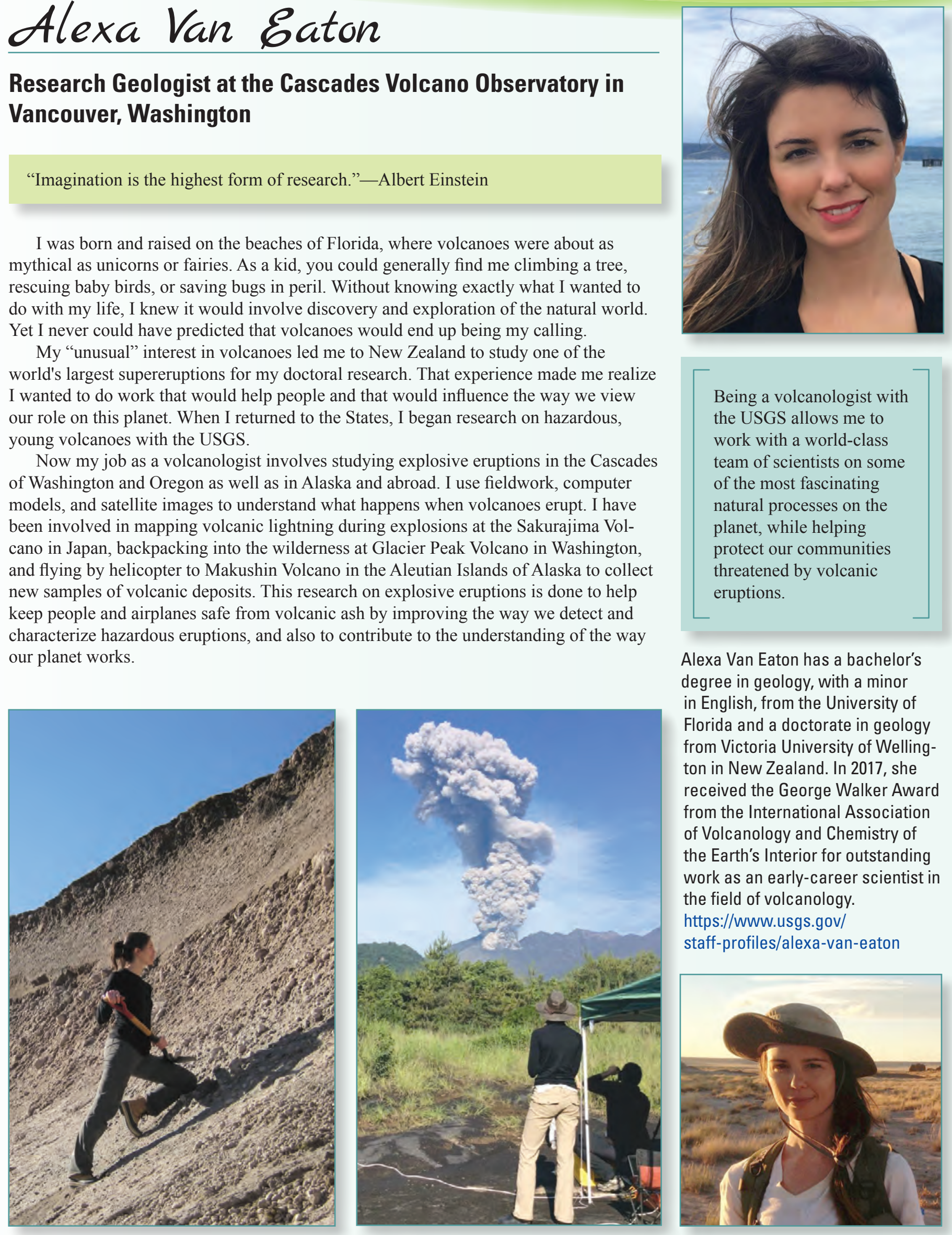

Being a volcanologist with the USGS allows me to work with a world-class team of scientists on some of the most fascinating natural processes on the planet, while helping protect our communities threatened by volcanic eruptions.

Alexa Van Eaton has a bachelor's degree in geology, with a minor in English, from the University of Florida and a doctorate in geology from Victoria University of Wellington in New Zealand. In 2017, she received the George Walker Award from the International Association of Volcanology and Chemistry of the Earth's Interior for outstanding work as an early-career scientist in the field of volcanology. https://www.usgs.gov/ staff-profiles/alexa-van-eaton

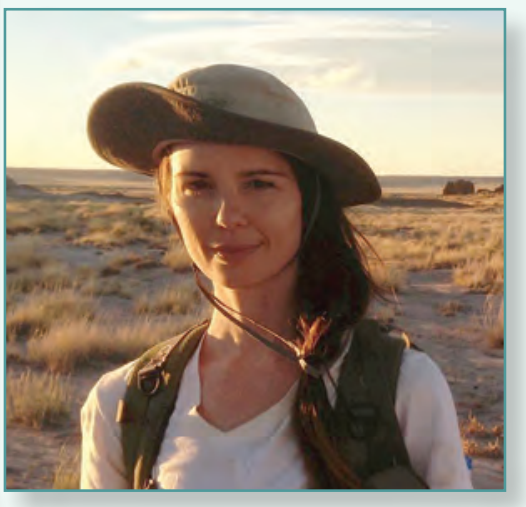




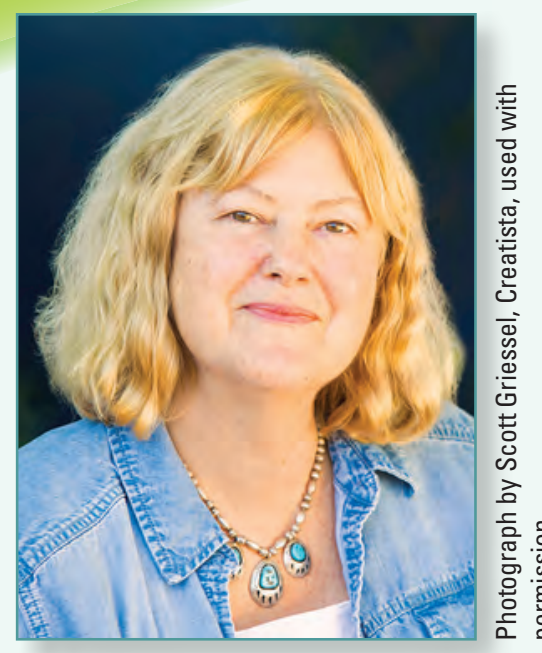

Don't be afraid to imagine a whole new future for yourself. Transitions can be hard. Having found myself in graduate school as a single parent with two young children, I can share two strategies that proved invaluable. The first is to schedule and honor "sacred time" each day for yourself. You will access some of your best insights during these times that allow for a deep breath. The second is to set aside and honor one entire day per week as "family day" to allow you and your children to imagine, plan, anticipate, and experience adventures together. Dusting can wait.

Cynthia Wallace has a bachelor's degree in mathematics and geology from the University of Minnesota, Duluth, a master's in geology from the University of Wisconsin, Madison, and a master's and doctorate in geography from the University of Arizona, Tucson.

https://www.usgs.gov/staff-profiles/ cynthia-wallace

\section{eynthia Wallace}

\section{Research Geographer at the Western Geographic Science Center in Tucson, Arizona}

My love of nature was sparked in childhood as I hunted for agates with family and friends, paddled a canoe in the Boundary Waters of northern Minnesota, and chased tornadoes with my dad. As an undergraduate, the fortuitous choice of a geology elective class turned into a major after the professor took the class outside to explore the Precambrian strata of the North American Craton. I was hooked, and went on to hunt for buried treasure as an exploration geologist in Alaska, Wisconsin, Nova Scotia, and Texas.

After more than a decade of locating economic mineral deposits, I realized that a career change was in order when I looked around a prospective area and thought, "What a pretty place. I hope we don't find anything." I returned to college to reinvent myself, and discovered the beauty of satellite images and the power of digital geographic data. I like to tell people that I study the color green, using satellite images to capture the dynamics and pattern of vegetation on the landscape, and linking those features to natural resource issues. My most recent research was on the invasive plant buffelgrass that fills in the natural spaces between desert plants. In its dried state, it forms a highly flammable fuel that dramatically increases wildfire risk, threatening the nonfire-adapted native vegetation of the Sonoran Desert, such as the iconic Saguaro.

I live in Tucson with my husband, who is the principal and cofounder of an innovative, alternative high school. We love to read, cook, travel, camp, and hike, and we are becoming avid birders. I am the mother of two amazing adult daughters and am excited to witness their futures unfold.
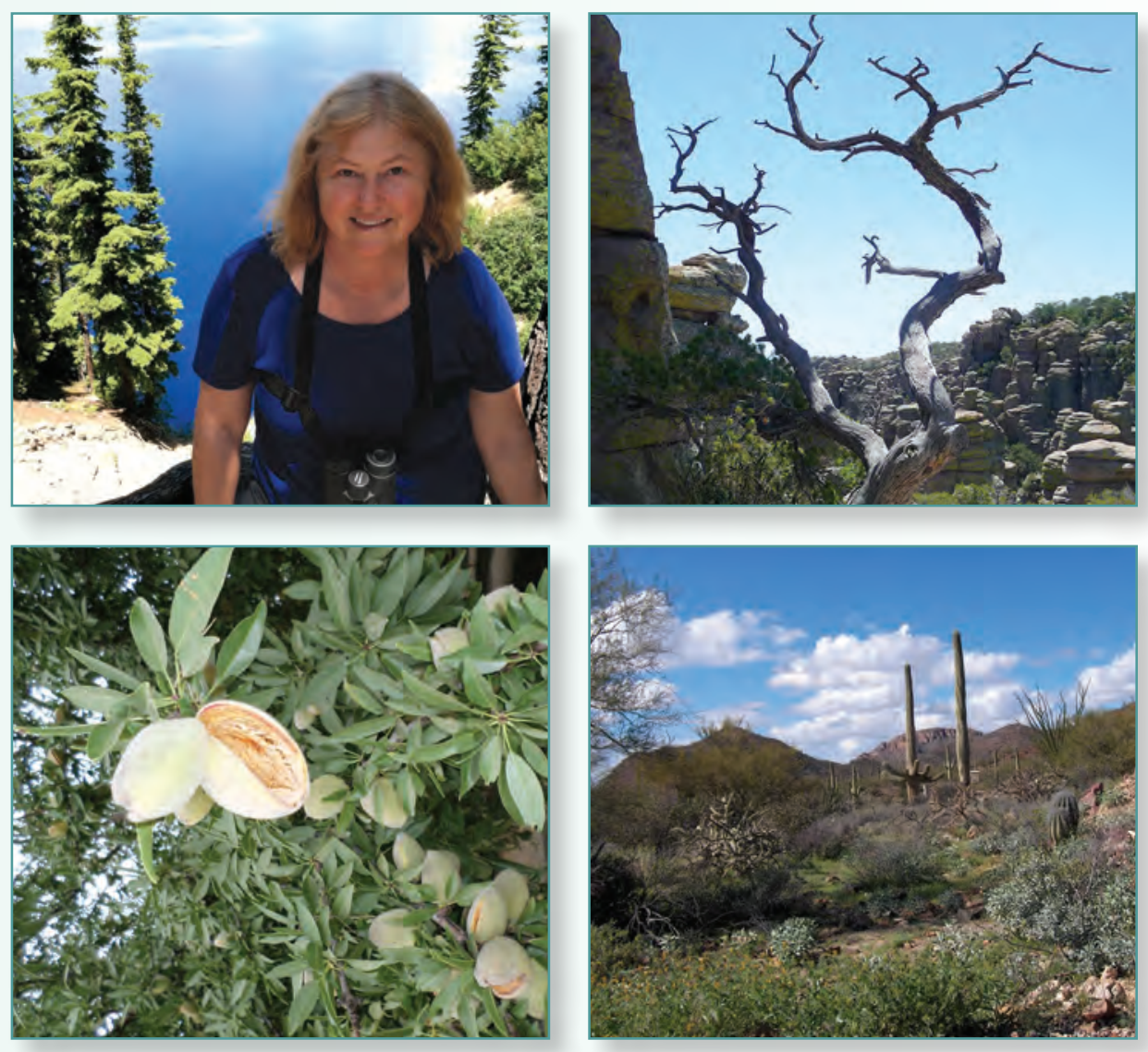


\section{Kelly Warner}

\section{Deputy Director of Investigations at the Central Midwest Water Science Center in Urbana, Illinois}

"Think like a man of action, act like a man of thought." —-Henri Bergson

I grew up in a small town along the banks of the Mississippi River. I was a Girl Scout, and I really wanted to earn the camper and hiking badges, so my friends and I would hike in the nearby woods and attend Girl Scout camp each summer. This grew into a tremendous love and appreciation for the natural world. Then, in 4-H club, I started a rock collection to show at the county fair. It was tough to collect unique rocks in the glacially buried plains of Illinois, but family and friends would bring me rocks for my collection, and I soon became enamored with studying rocks and visiting places where rocks were exposed.

Having grown up along the banks of the Mississippi River, I started realizing that the levels of the river as people remembered them did not necessarily match the measured levels of the river. I also realized that reliable data could help put floods into perspective in time and space, and my work with the USGS has enabled me to do just that. I've also been involved with researching water quality in the region. Most recently, I have led a team of scientists to find new ways to continuously measure water quality, providing information about impurities in water that are a concern for human health and the health of the ecosystems that rely on these sources of water.

Family vacations while my two children were growing up were centered around water activities or seeing new rock exposures. We would go on "science field trips," and my two children were my field assistants; they have been my inspiration and have been key to my success. I continue to be involved in local theater, and I have a great group of friends in my local book club. I love coming home to my partner and our Wheaton terrier, who greets me every evening by springing up to eye-level to say hello.
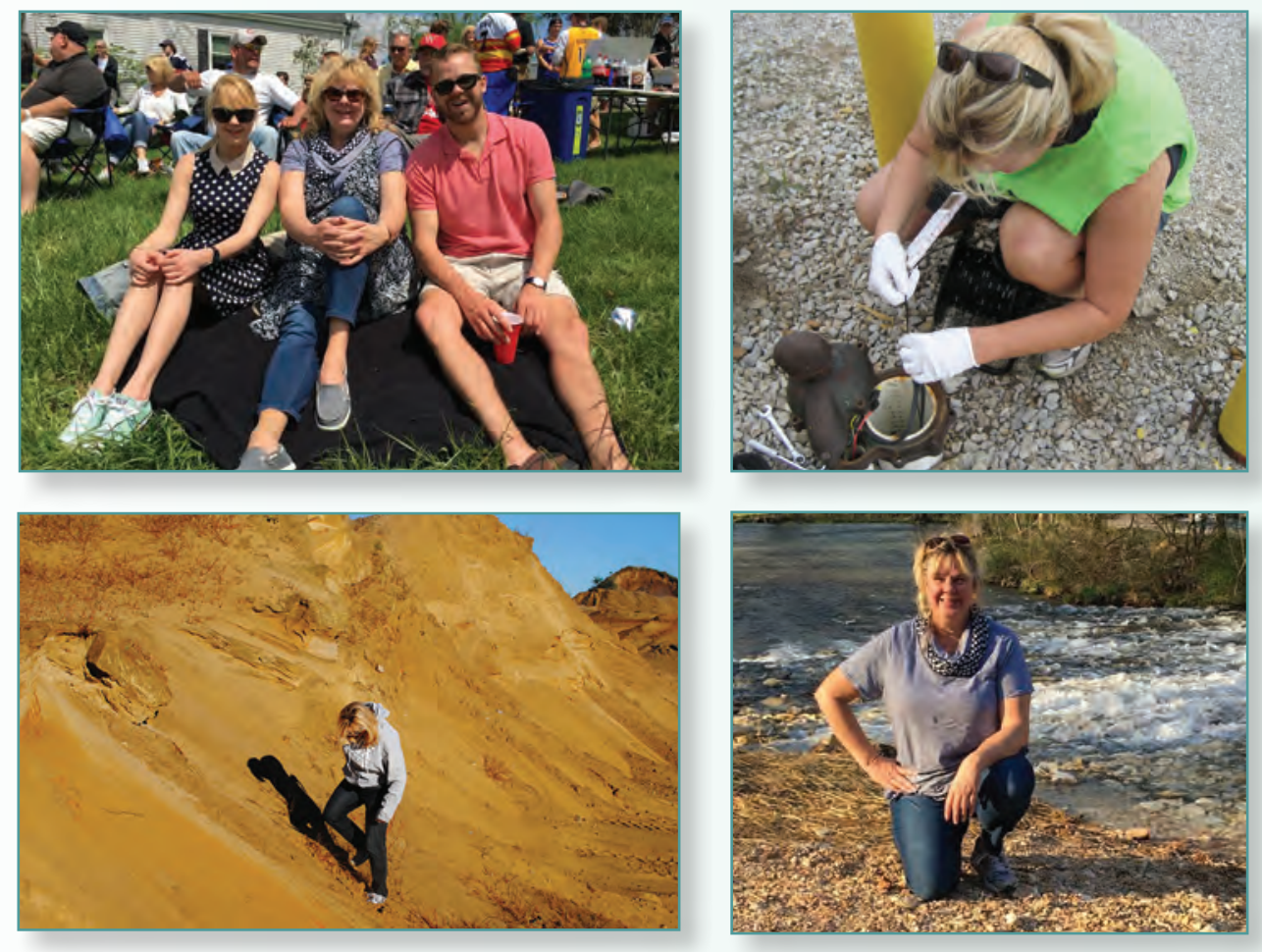

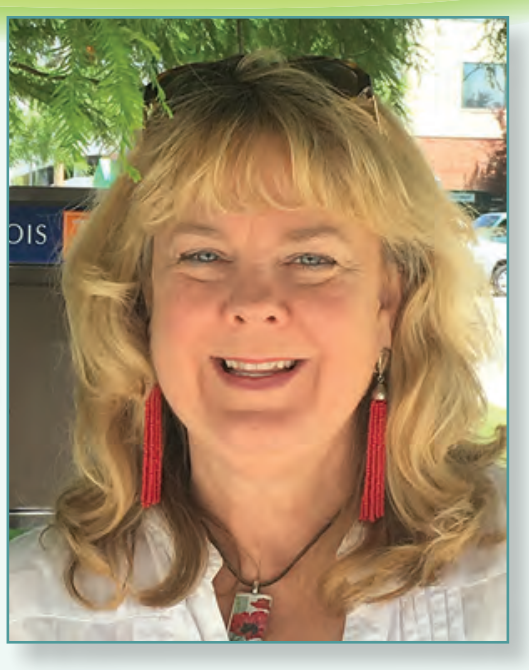

I love a great cup of coffee with a little cream and honey. It is funny that as a scientist, I look at everything with a wonder on how it works. When I add cream to my coffee it drops to the bottom of my cup and then circles back to the top in a pretty tan swirl. It reminds me of the convection currents in the magma that drive plate tectonics. When I get a latte with beautiful foam art, I think about what causes the coloration of the foam and how the sediment of cinnamon in my coffee parallels the sediment that collects at the edge of the river. Coffee and curiosity are two of my great loves.

Kelly Warner has a bachelor's degree in geology and mathematics from Knox College and a master's in stratigraphy and geomorphology from Northern Illinois University. She has worked on a doctorate in natural resource economics at the University of Illinois. https://www.usgs.gov/ staff-profiles/kelly-I-warner 


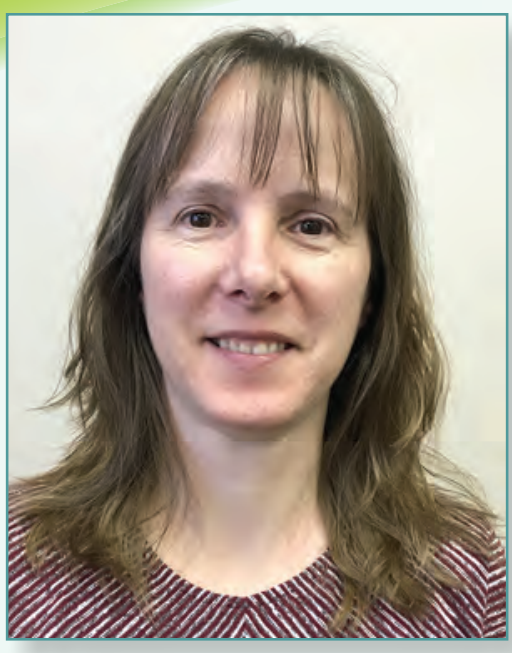

One of the best parts of a science career is always learning new things.

Science requires creativity and learning.

Linda Weir has a bachelor's degree in zoology from the State University of New York College at Oswego and a master's in sustainable development and conservation biology from the University of Maryland, College Park.

https://www.usgs.gov/staff-profiles/ linda-weir

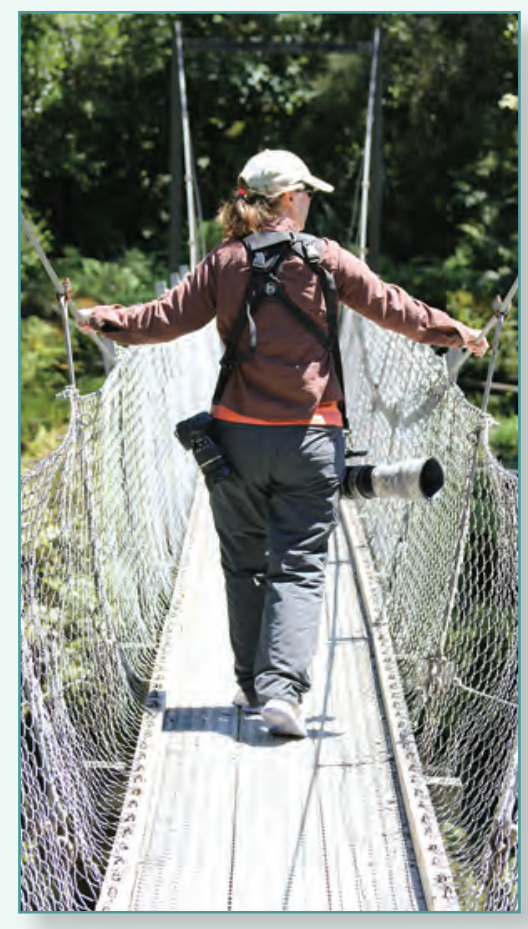

\section{Einda Weir}

\section{Research Manager at the Patuxent Wildlife Research Center in Laurel, Maryland}

"The best preparation for tomorrow is doing your best today."

-H. Jackson Brown, Jr.

Even as a young girl, I was always interested in wildlife conservation and science. When I was in fifth grade, I subscribed to a leading science magazine that was intended for adult readers... and read the articles! For me, one of the best parts of a science career is always learning new things.

As a wildlife biologist, I researched amphibians for more than 10 years. I coordinated a large-scale citizen science project that monitored calling frogs and toads in 24 States and focused a lot of my research on amphibian monitoring and citizen science, including understanding types of observer error and reporting population trend results. I coauthored a book that showcases the spectacular diversity of amphibians in North America, including many of which are endangered or threatened with extinction, and I manage the related National Amphibian Atlas database for the USGS.

As a research manager, I coordinate research programs specializing in migratory birds, coastal ecology, and ecotoxicology. I also coordinated a USGS program to research the effects of Hurricane Sandy on wetlands and bird populations.

In my spare time, I enjoy nature photography, including making my own calendar of nature photos.
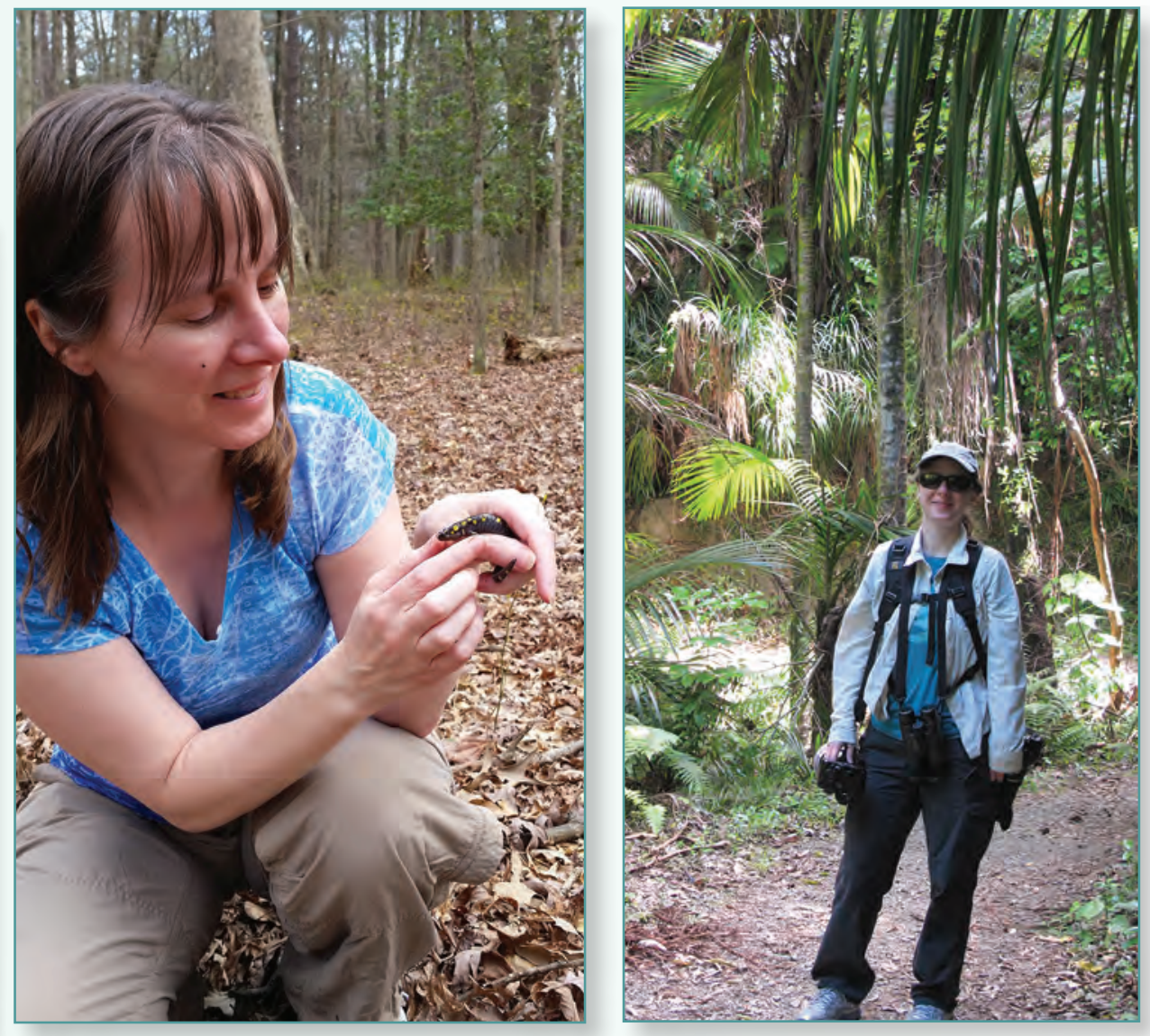


\section{Sylvia Wilson}

\section{Physical Scientist with the Eastern Geographic Science Center in Reston, Virginia}

Growing up in Peru, I decided to do a school project about spiders when I was a teenager, for which I started a collection of live spiders in my room. Realizing that the spiders kept my mother and sister away, I had to learn to care for the spiders by myself. It was very exciting, and I became convinced that I was going to become a biologist. That is, until I had to dissect a frog the following year. But those spiders planted a fascination with science in my head. Oddly enough, I'm now terrified of spiders!

When I went to college, I decided to study forest science, despite never having been in a forest before. It was fun, but very difficult for me the first 2 years, and I struggled with many courses. My professors inspired me to not give up, and after getting to spend two semesters doing fieldwork in remote areas of the Amazon River Basin, I knew that I had picked the right career.

I started working with the USGS after college but was encouraged to get a graduate degree by my first supervisor and mentor. Inspired by my husband's choice of field (and what appeared to be an easier course load!), I decided to study geography just as he did and got into a project that took me back to my native Peru to work on forest monitoring. I continue to work on forest science, providing information to decision makers on the effects of forest change on carbon emissions around the globe, though my work focuses on tropical forests. I am also part of an effort by many organizations to help developing countries with remote-sensing tools and applications so they can better monitor changes in land cover and estimate emissions from changes in land uses.

Sports have always been a passion; I was very competitive during my school and college years. I played soccer in college and participated in a few out-of-State and international soccer matches. I don't play sports now, but I enjoy hiking with my husband and watching my kids play sports. My favorite activity these days after work is enjoying summer in northern Virginia on my back porch, engaged in rich conversations with neighbors and friends.
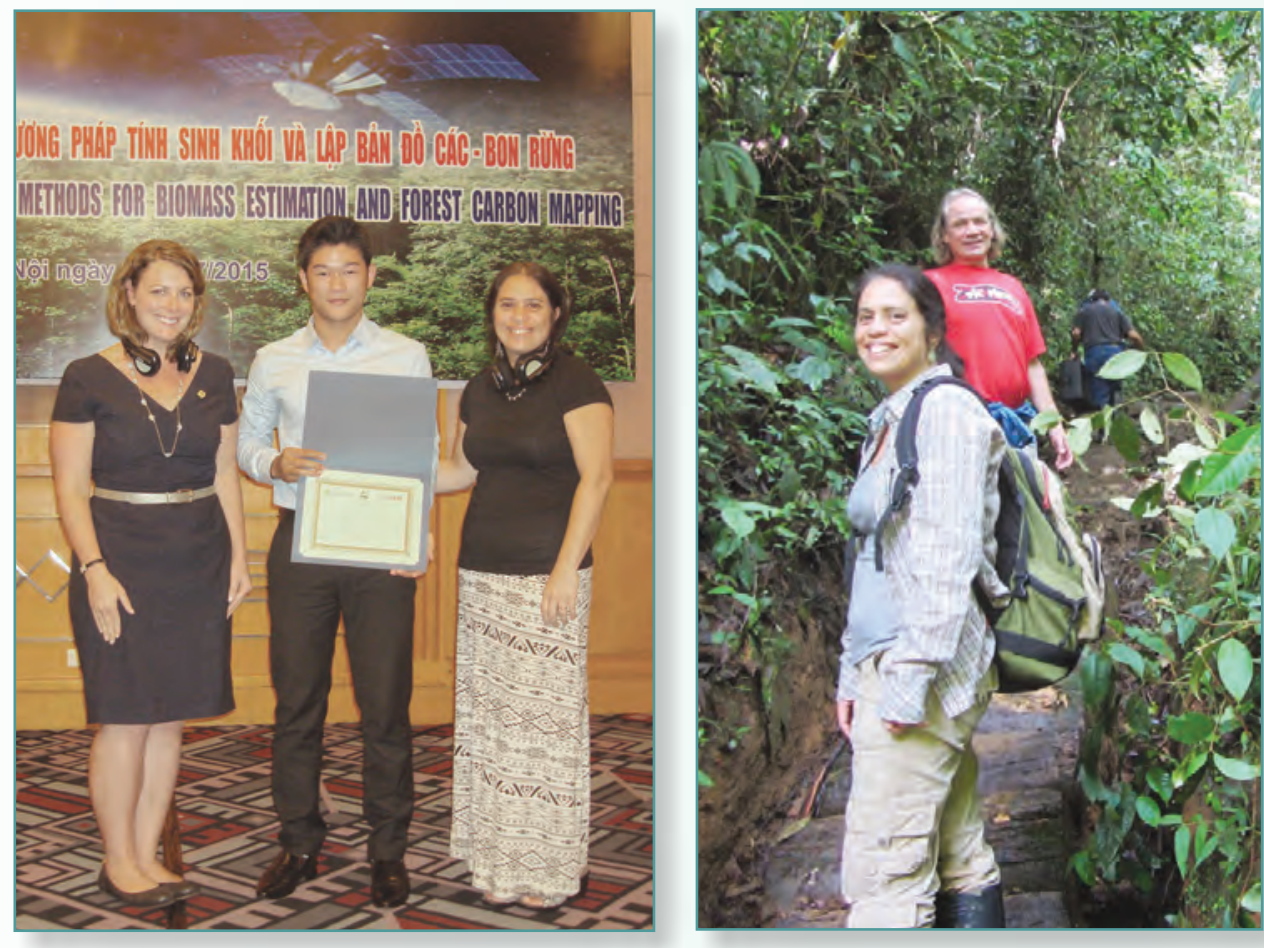

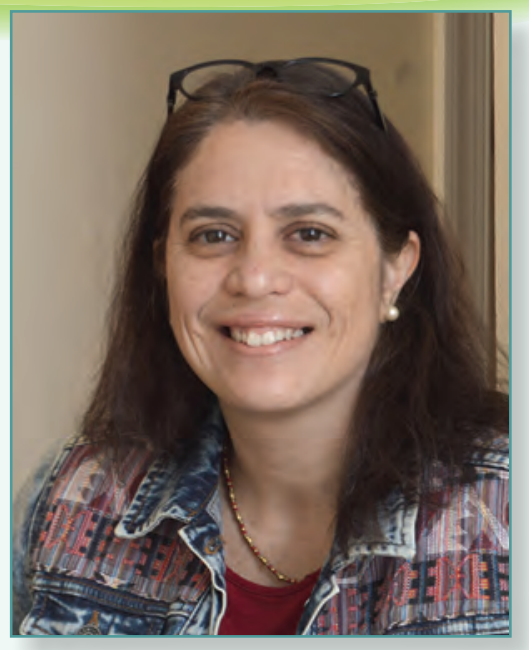

I love to get scientists and practitioners together to experience the power of capacity transfer. When you connect science with applications, science is no longer hard and unknown; it becomes a critical part of mitigation and policy and a common language for all that are aiming to conserve the forest.

Sylvia Wilson has a bachelor's degree in forestry from the National Agrarian University-La Molina (Lima, Peru) and a master's in geography from Texas State University, San Marcos.

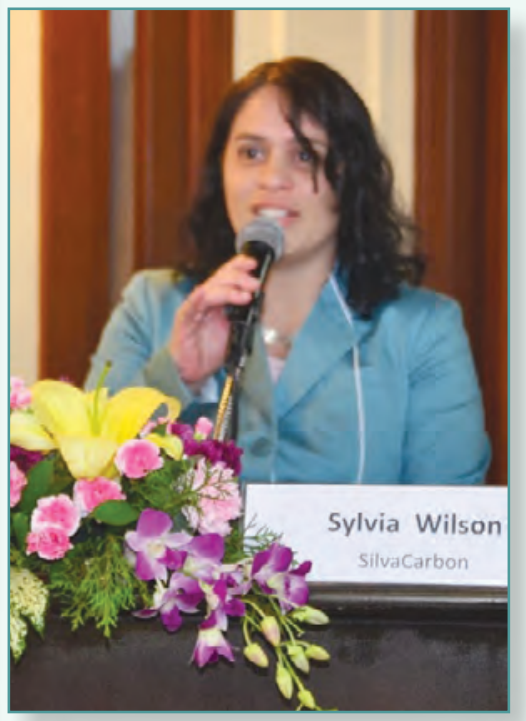




\section{Index of Women Featured in This Publication}

The women profiled in this publication are representative of a wide variety of career choices supported by the USGS. Their biographies provide an insight into their personal and professional challenges and achievements. As you will discover when you read about them, many started with just a basic love of nature and natural curiosity. From these fundamental ideals came incredible contributions to the USGS and our world.

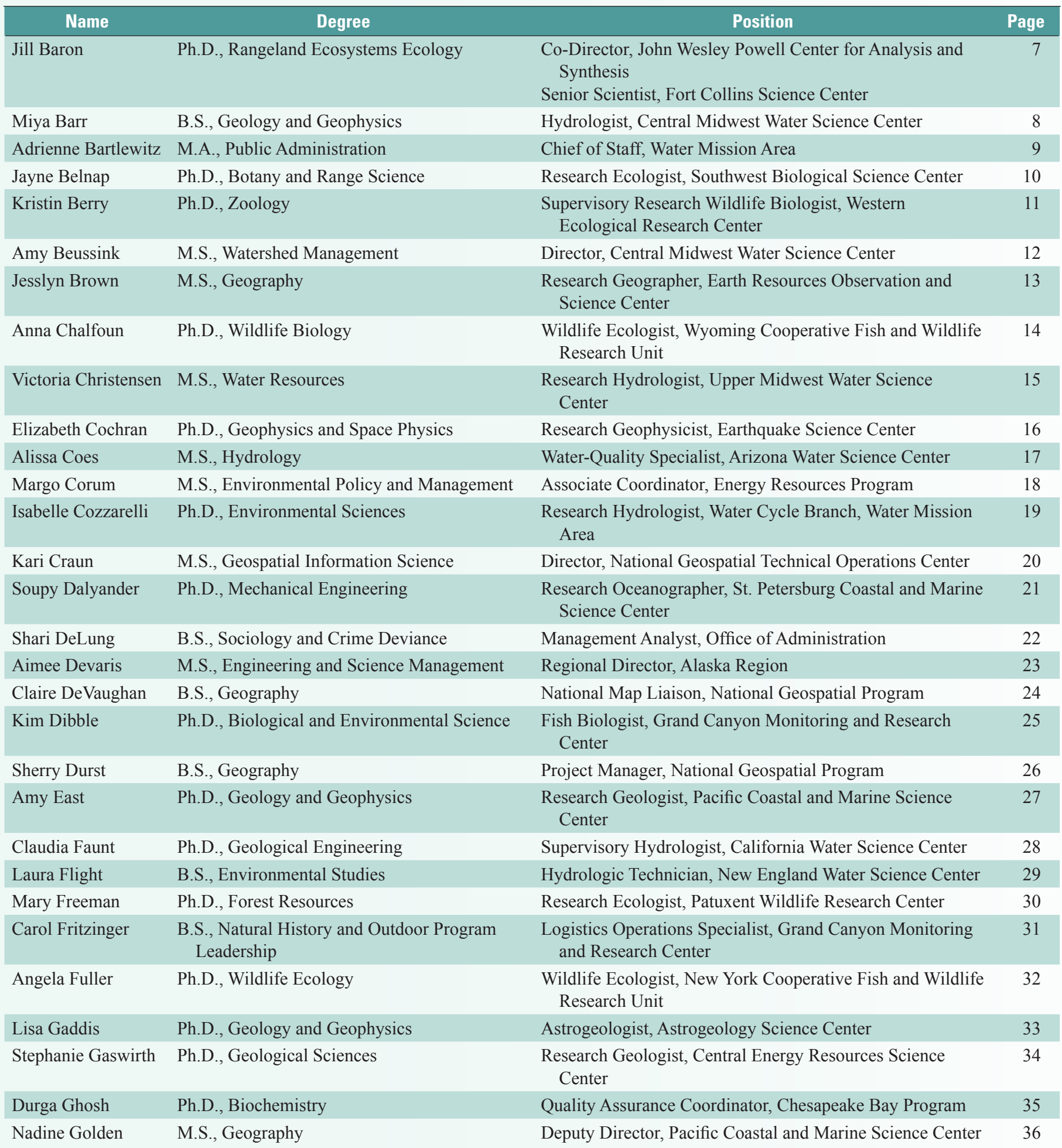




\section{Index of Women Featured in This Publication-Continued}

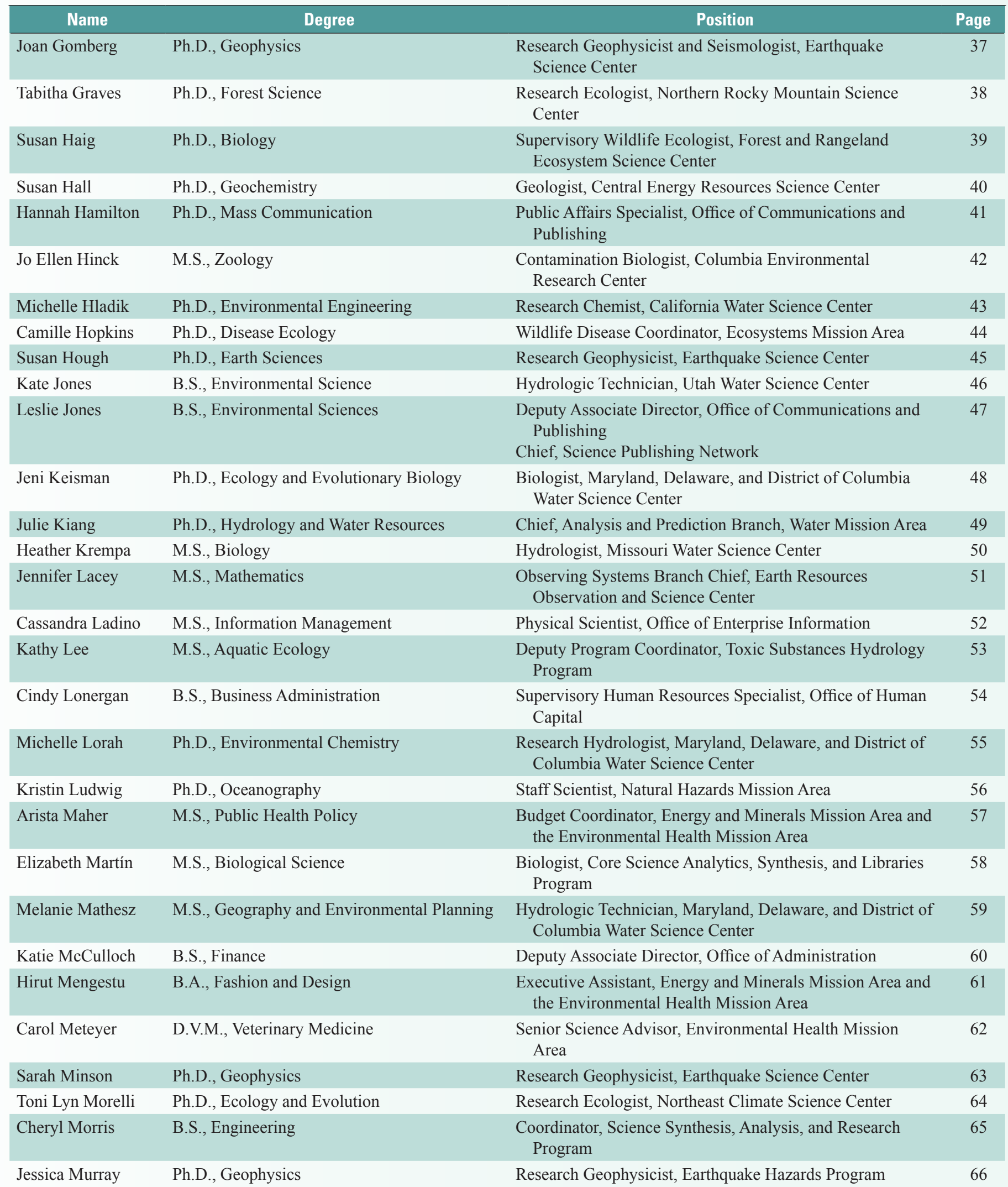




\section{Index of Women Featured in This Publication-Continued}

\begin{tabular}{|c|c|c|c|}
\hline Name & Degree & Position & Page \\
\hline Pamela Nagler & Ph.D., Soil, Water, and Environmental Science & $\begin{array}{l}\text { Research Physical Scientist, Southwest Biological Science } \\
\text { Center }\end{array}$ & 67 \\
\hline Diane Nicks & M.S., Environmental Biology & Biologist, Columbia Environmental Research Center & 69 \\
\hline Andrea Ostroff & M.S., Environmental Biology & Manager, Fisheries Program & 70 \\
\hline Jaime Painter & M.S., Geography & Geographer, South Atlantic Water Science Center & 71 \\
\hline Sandra Poppenga & M.S., Geography & $\begin{array}{l}\text { Geographer, Earth Resources Observation and Science } \\
\text { Center }\end{array}$ & 73 \\
\hline Diann Prosser & $\begin{array}{l}\text { Ph.D., Marine, Estuarine, and Environmental } \\
\text { Sciences }\end{array}$ & $\begin{array}{l}\text { Research Wildlife Biologist, Patuxent Wildlife Research } \\
\text { Center }\end{array}$ & 74 \\
\hline Karyn Rode & Ph.D., Zoology & Research Wildlife Biologist, Alaska Science Center & 78 \\
\hline Coral Roig-Silva & M.S., Geology & Physical Scientist, Eastern Geographic Science Center & 79 \\
\hline Karen Ryberg & $\begin{array}{l}\text { Ph.D., Environmental and Conservation } \\
\text { Sciences }\end{array}$ & Research Statistician, Dakota Water Science Center & 80 \\
\hline Kristi Sayler & M.S., Geography & $\begin{array}{l}\text { Physical Scientist, Earth Resources Observation and } \\
\text { Science Center }\end{array}$ & 81 \\
\hline Carol Schuler & M.S., Wildlife Science & Senior Science Advisor, Ecosystems Mission Area & 82 \\
\hline Kim Scott & M.B.A., Business Administration & Program Analyst, Office of Enterprise Information & 83 \\
\hline Jill Shaffer & M.S., Zoology & Ecologist, Northern Prairie Wildlife Research Center & 84 \\
\hline Mandy Stone & M.S., Zoology & Supervisory Hydrologist, Kansas Water Science Center & 89 \\
\hline Renee Takesue & Ph.D., Chemical Oceanography & $\begin{array}{l}\text { Marine Geochemist, Pacific Coastal and Marine Science } \\
\text { Center }\end{array}$ & 90 \\
\hline Susan Thiros & B.S., Geology & Hydrologist, Utah Water Science Center & 91 \\
\hline Amy Vandergast & $\begin{array}{l}\text { Ph.D., Environmental Science, Policy, and } \\
\text { Management }\end{array}$ & Research Geneticist, Western Ecological Research Center & 92 \\
\hline Alexa Van Eaton & Ph.D., Geology & Research Geologist, Cascades Volcano Observatory & 93 \\
\hline Cynthia Wallace & Ph.D., Geography & Research Geographer, Western Geographic Science Center & 94 \\
\hline Kelly Warner & M.S., Stratigraphy and Geomorphology & $\begin{array}{l}\text { Deputy Director of Investigations, Central Midwest Water } \\
\text { Science Center }\end{array}$ & 95 \\
\hline Linda Weir & $\begin{array}{l}\text { M.S., Sustainable Development and } \\
\text { Conservation Biology }\end{array}$ & Research Manager, Patuxent Wildlife Research Center & 96 \\
\hline Sylvia Wilson & M.S., Geography & Physical Scientist, Eastern Geographic Science Center & 97 \\
\hline
\end{tabular}




\section{Are you a woman working in Earth sciences? Do you have questions about Earth or natural sciences?}

Visit answers.usgs.gov

Tag USGS with \#WomenInScience and let us know!

\section{Connect with us}

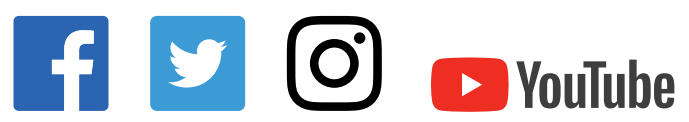

More social media at usgs.gov/socialmedia

The manuscript was synthesized by Anna Glover, Stephanie St. Amand, and Alan Jones, and was reviewed by Teresa Davies of the National Science Foundation and Rebekah Davis, Shawn Komlos, and Keith Kirk of the U.S. Geological Survey.

Production support provided by the Pembroke and Rolla Publishing Service Centers

Managing editor: Anna Glover

Editorial review: Kimberly Waltenbaugh and Alan Jones

Design and production: Suzanne Roberts 
floods drought

biology stratigraphygeomorphology

science environment invasive species entomology earthquake research plants endangered species, energy technology hydraulics geospatial analysis thami ecology hydrology geophysics sedimentology wildfire research data water quality minerals engineering land use hazards remote sensing artogral hazards phenology cartography geography volcanology biology mathematics spatial analysis hurricanes

watersheds resources

chemistry
physics 